\title{
Metabolic and pharmacokinetic aspects of tacrolimus in renal transplantaion
}

Citation for published version (APA):

van Duijnhoven, E. M. (2002). Metabolic and pharmacokinetic aspects of tacrolimus in renal transplantaion. [Doctoral Thesis, Maastricht University]. Universitaire Pers Maastricht. https://doi.org/10.26481/dis.20020705ed

Document status and date:

Published: 01/01/2002

DOI:

10.26481/dis.20020705ed

Document Version:

Publisher's PDF, also known as Version of record

\section{Please check the document version of this publication:}

- A submitted manuscript is the version of the article upon submission and before peer-review. There can be important differences between the submitted version and the official published version of record.

People interested in the research are advised to contact the author for the final version of the publication, or visit the DOI to the publisher's website.

- The final author version and the galley proof are versions of the publication after peer review.

- The final published version features the final layout of the paper including the volume, issue and page numbers.

Link to publication

\footnotetext{
General rights rights.

- You may freely distribute the URL identifying the publication in the public portal. please follow below link for the End User Agreement:

www.umlib.nl/taverne-license

Take down policy

If you believe that this document breaches copyright please contact us at:

repository@maastrichtuniversity.nl

providing details and we will investigate your claim.
}

Copyright and moral rights for the publications made accessible in the public portal are retained by the authors and/or other copyright owners and it is a condition of accessing publications that users recognise and abide by the legal requirements associated with these

- Users may download and print one copy of any publication from the public portal for the purpose of private study or research.

- You may not further distribute the material or use it for any profit-making activity or commercial gain

If the publication is distributed under the terms of Article $25 \mathrm{fa}$ of the Dutch Copyright Act, indicated by the "Taverne" license above, 


\section{Metabolic and pharmacokinetic aspects of tacrolimus in renal transplantation}


Elly van Duijnhoven, Sittard 2002

ISBN 905278348 9, Universitaire Pers Maastricht, Datawyse

Cover design: Tonek Jansen

Lay-out : Tiny Wouters

Financial support of Fujisawa, Pfizer, Merck Sharp \& Dohme, Abbott, Novo Nordisk, Astra, Roche and Wyeth 


\title{
Metabolic and pharmacokinetic aspects of tacrolimus in renal transplantation
}

\author{
PROEFSCHRIFT
}

ter verkrijging van de graad van doctor aan de Universiteit Maastricht, op gezag van de Rector Magnificus, Prof. Dr. A.C. Nieuwenhuijzen Kruseman, volgens het besluit van het College van Decanen, in het openbaar te verdedigen op vrijdag 5 juli 2002 om 16.00 uur

door

Elly M. van Duijnhoven

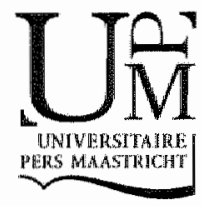




\section{Promotor}

Prof. dr. J.P. van Hooff

\section{Co-promotor}

Dr. M.H.L. Christiaans

\section{Beoordelingscommissie}

Prof. dr. R.A.M.G. Donckerwolcke (voorzitter)

Prof. dr. J.W. Cohen Tervaert

Prof. dr. J.P. Squifflet (Université Catholique de Louvain, Brussel, België)

Dr. N.A. Undre (Fujisawa GmbH, München, Duitsland)

Dr. B.H.R. Wolffenibuttel 
Aan: Esther 


\section{Contents}

$\begin{array}{lll}\text { Chapter } 1 \text { Introduction } & 9\end{array}$

Chapter 2 Influence of glucose metabolism before and after renal transplantation: a prospective study $J$ Am Soc Nephrol 2001; 12:538-588

Chapter 3 Glucose metabolism in renal transplant recipients on tacrolinus: the effect of steroid withdrawal and tacrolimus trough level reduction J Am Soc Nephrol 2002; 13: 221-227

Chapter $4 \quad$ Glucose metabolism in the first 3 years after renal transplantation in patients on tacrolimus versus cyclosporine-based immunosuppression $J$ Am Soc Nephrol 2002; 13: 213-220

Chapter 5 A late episode of posttransplant diabetes mellitus during active hepatitis $\mathrm{C}$ infection in a renal allograft recipient using tacrolimus

Am J Kidney Dis in press

Chapter 6a Tacrolimus dosing requirements in diabetic and nondiabetic patients calculated from pretransplantation data

Transplant Proc 1998: 30: 1266-1267

Chapter $6 b$ The effect of breakfast on the oral bioavailability of tacrolimus in diabetic and nondiabetic patients before transplantation

Transplant Proc 1998; 30: 1268-1270

Chapter $6 \mathrm{c} \quad$ Effects of breakfast on the oral bioavailability of tacrolimus and changes in pharmacokinetics at different times posttransplant in renal transplant recipients Transplant Proc 1998; 30: 1271-1273

Chapter $6 \mathrm{~d} \quad$ Evidence that fasting does not significantly affect trough levels of tacrolimus in stable renal transplant recipients Transplant Proc in press 
Chapter 7 Increase in tacrolimus trough levels after steroid withdrawal

Submitted

Chapter $8 \quad$ General discussion

Chapter 9 Samenvatting

Dankwoord

Curriculum vitae

List of publications 

Chapter 1

\section{Introduction}




\section{Introduction}

One of the most important developments in renal transplantation in recent years has been the number of new immunosuppressive agents for the prevention of acute rejection. Until the 1980s, the purine synthesis inhibitor azathioprine and corticosteroids were administered as maintenance immunosuppression. Sometimes this was combined with an induction course of anti-lymphocyte globulin (ALG) for the first week to reduce the number of acute rejections'. In the late $1970 \mathrm{~s}$, the calcineurin inhibitor cyclosporine A was introduced ${ }^{2}$. This reduced the number of acute rejections from more than $90 \%$ to $40-60 \%$. Moreover, it made it possible to reduce the amount of maintenance corticosteroids needed. This overall reduction in the use of corticosteroids made it possible for higher risk patients, such as those with substantial co-morbidity and older patients to undergo transplantation. Consequently, in combination with corticosteroids and azathioprine, cyclosporine became the standard immunosuppressive agent and it remained so through the mid1990s.

Due to the small therapeutic window and the large interpatient variability in the absorption of cyclosporine, pharmacokinetic drug monitoring was necessary. In the Netherlands, cyclosporine/Sandimmune was replaced in 1995 by cyclosporine/ Neoral, a microemulsion formula with a - virtually bile-independent - more rapid and consistent absorption, which led to lower intrapatient variability than Sandimmune ${ }^{3}$. After 1995, a number of new immunosuppressive agents were introduced. The long-term efficacy of these drugs is not yet known, but preliminary data on the occurrence of acute rejection show promising results. The macrolide tacrolimus (FK 506, Prograf(t) , Fujisawa, Japan) is also a calcineurin inhibitor. Figure 1.1 shows the molecular formula of tacrolimus. Tacrolimus reduced the number of acute rejections even further. Yet, both tacrolimus and cyclosporine have nephrotoxic properties. A number of other, non-nephrotoxic drugs have since been introduced. However, most of them are not potent enough, to be given as cornerstone immunosuppression. Therefore, most patients currently undergoing renal transplantation are started on either cyclosporine or tacrolimus. Among the newer, non-nephrotoxic drugs is mycophenolate mofetil (Cellcept, Roche, Switzerland), a purine synthesis inhibitor selective for lymphocytes. The macrolides sirolimus (Rapamune, Wyeth, USA) and everolimus (Novartis, Switserland) are mTOR (mammalian target of rapamycin) inhibitors of cytokine signal transduction.

Since the introduction of all these new agents, different combinations of the new and the older agents have been studied in several trials for their efficacy in 
preventing rejection. In Table 1.1, the frequency of acute rejection after renal transplantation of calcineurin inhibitor-based combinations is shown ${ }^{4.22}$.

This thesis focuses on several aspects of tacrolimus, a cornerstone immunosuppressive agent in renal transplantation.

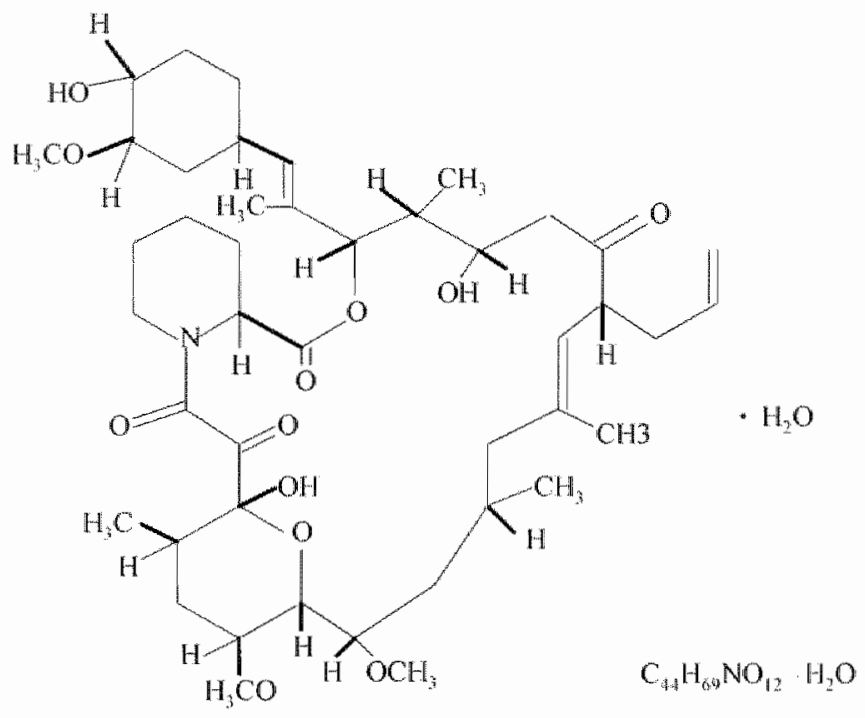

Figure 1.1 Molecular formula of tacrolimus.

Table 1.. The frequency of acute rejection in the first year after renal transplantation with different calcineurin inhibitor-based immunosuppressive regimens.

Cyclosporine + prednisolone + azathioprine ${ }^{5-6}$

$40-60$

Cyclosporine + prednisolone + 11 -2 receptor ab. ${ }^{7.9}$

$25-30$

Cyclosporine + prednisolone + azathioprine + IL-2 receptor ab. ${ }^{1 i}$

$20-25$

Cyclosporine + nycophenolate mofetil + I.L-2 receptor ab. $11-1.2$

$20-25$

Cyclosporine + mycophenolate mofetil + prednisolone

$15-25$

Cyclosporine t sirolimus twednisolone

$10-20$

Tacrolimus ${ }^{17}$

Tacrolimus + prednisolone $e^{\text {" }}$

$25 \cdot 30$

Tacrolimus + prednisolone + azathioprine ${ }^{19}$

$25-30$

Tacrolimus + mycophenolate mofetil + prednisolone ${ }^{15}$

Tacrolimus + mycophenolate mofetil + $1 \mathrm{~L}-2$ receptor ab. + prednisolone ${ }^{20}$

$15-20$

Tacrolimus + mycophenolate mofetil + $1 \mathrm{~L}-2$ receptor ab. ${ }^{21}$

Tacrolimus + sirolimus + prednisolone ${ }^{22}$ 


\section{Mode of action of corticosteroids and calcineurin inhibitors}

\section{Corticosteroids}

The immunosuppressive effects of corticosteroids are non-specific. Corticosteroids reduce the number of circulating lymphocytes (sequestration), i.e., the cells remain in the lymphoid tissue, and they reduce the number and potency of phagocytic cells. They also lead to decreased adhesion molecule expression, reduced capillary permeability and chemotaxis (preventing inflammatory cells from reaching the tissues), and decreased complement activity. Moreover, they reduce the level of inflammatory mediators (histamine and prostaglandins) by stabilizing lysosomal membranes. They interfere with the production of a number of T-cell and macrophage-derived cytokines including IL-1, IL-2, IL-3, IL-5, tumour necrosis factor-alpha (TNF- $\alpha$ ), and interferon-gamma (IFN- $\gamma)^{23}$.

Figure 1.2 shows the major modes of action in immunosuppression. By inhibiting a variety of cytokines, the corticosteroids disrupt T-cell activation and macrophagemediated tissue injury ${ }^{24}$. Although their precise mechanism of action is not fully understood, it is known that they bind to intracellular cytosolic receptors to form corticosteroid-receptor complexes, which translocate to the nucleus and bind to glucocorticoid response elements in the promoter regions of genes encoding cytokines and other factors involved in the immune response. In this way, they promote transcription of the $I \mathrm{kB}$, an inhibitory factor that binds to nuclear factor kappa-beta $(\mathrm{NF}-\mathrm{kB})$ in the cytosol and prevents it from translocating to the nucleus and activating various cytokine genes.

\section{Tacrolimus and cyclosporine}

As described by LC Paul" "despite structural differences, tacrolimus and cyclosporine share a similar cellular mechanism of action, though tacrolimus, at the molecular level, is 10 - 100 times more potent. After entry into the cell, both agents bind to their respective cytosolic immunophilins: cyclosporine to cyclophilin and tacrolimus to the FK506-binding proteins FKBP-12 and FKBP-52, a component of the glucocorticoid receptor complex. Immunophilins are a family of highly conserved proteins that likely participate in protein folding. The drugimmunophilin complex binds to and inhibits the activity of the enzyme calcineurin, a calcium/calmodulin-dependent protein phosphatase that is expressed in all mammalian tissues. As a result, the complex interrupts the calcium-dependent signal transduction pathway in T-cells. Inhibition of calcineurin by cyclosporine or tacrolimus leads to interference with translocation to the nucleus of various nuclear 
factors involved in the transcription of cytokine genes, such as the cytosolic subunit of the nuclear factor of activated T-cells (NF-ATc). It also antagonizes the interaction of the transcription factor, cyclic adenosine monophosphatase (CAMP)response element binding protein (CREB), with its putative DNA binding site, CRE, which in turn inhibits CAMP-directed transcriptional events. As a result of calcineurin inhibition, the transcription of early $T$-cell activation genes is suppressed, affecting the production of interleukin (IL)-2 and many other cytokines, such as IL-3, interferon-gamma, and TNF- $\alpha$ ". A simplified model illustrating the intracellular mode of action of tacrolimus and cyclosporine is shown in Figure 1.3.

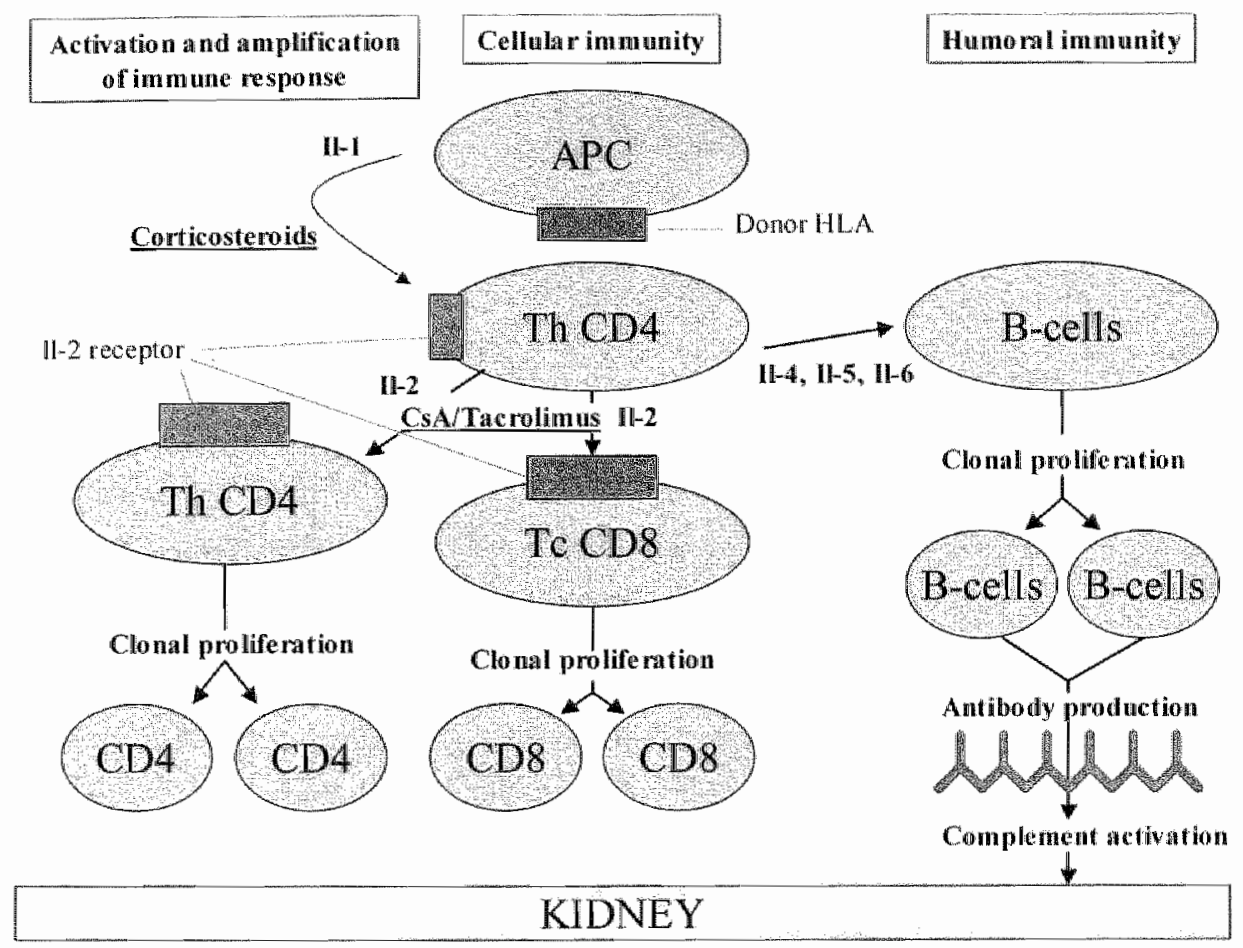

Figure 1.2 Modes of action of calcineurin inhibitors and corticosteroids.

\section{Differences between tacrolimus and cyclosporine in mode of action}

Although both tacrolimus and cyclosporine inhibit the enzyme calcineurin and, subsequently, IL-2 transcription, the greater immunosuppressive efficacy of tacrolimus, as discussed in this introduction, suggests that it has additional immunomodulating properties over cyclosporine that favor graft acceptance. 
Moreover, several molecular differences have been documented in experimental studies, animal studies, and studies in various organ transplantations that may provide an additional explanation for the differences in efficacy as well as in safety that have been observed in clinical practice (Table 1.2). This is clinically reflected in tacrolimus's ability to successfully reverse acute steroid-resistant rejection episodes in patients receiving cyclosporine ${ }^{26}$. The most important explanation may be tacrolimus"s ability to inhibit primed as well as naive T-cells, whereas cyclosporine inhibits only naive T-cells ${ }^{27}$.

There is increasing evidence that suggests that antibodies contribute to the pathogenesis of chronic immunological graft dysfunction ${ }^{28}$. Significantly lower levels of antibody production have been found in patients given tacrolimus than in those given cyclosporine $e^{29}$.

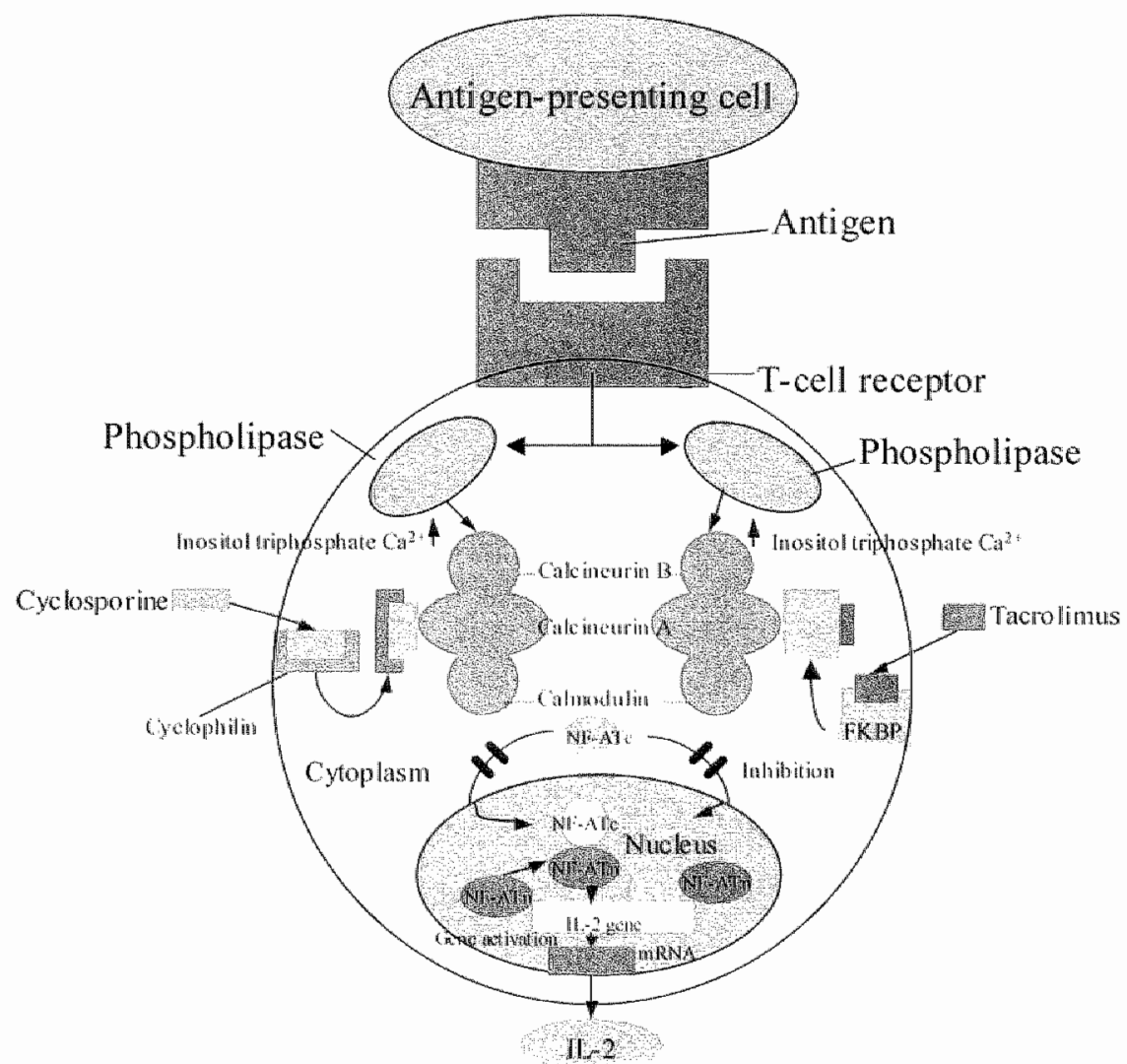

Figure 1.3 Intracellular mode of action of tracolimus and cyclosporme. Adapted from LC Paul. Mechanistic differences of connerstone immunosuppressants. ISBN $\mathbb{- 8 9 8 7 2 9}$ - 15-8. 
Table 1.2 Mechanistic differences between tracolimus and cyclosporin

\section{Tacrolimus}

- Inhibition of primed T-cells

- Lower levells of antibody production

Potentiation of apoptosis

- Suppression of IL- 10 and IL-10-mediated cytotoxic cell infiltration

- Association with the glucocorticoid receptor

- Inhibition of IL-2, IL-5, and IL-7

- Reduced platelet aggregability
Cyclosporine

- Greater aftinity for P-gp

- Overexpression of Pugp

- Elevation of TGF-B

- Increased platelet aggregability

After transplantation, donor antigen-specific T-cell expansion must be abrogated through apoptosis (programmed cell death). In vitro and preclinical studies have shown a significant downregulation of the apoptosis-related gene fatty acid synthase (Fas) on murine hepatocytes, an augmentation of anti-CD3-induced peripheral $\mathrm{T}$-cell apoptosis, potentiation of steroid-induced apoptosis, and augmentation of staphylococcal enterotoxin B (SEB)-stimulated genetic factor $\mathrm{V} \beta 8^{+} \mathrm{T}$-cell apoptosis by downregulation of the survival gene bcl-xL during tacrolimus administration, but not during cyclosporine administration ${ }^{30}$.

P-glycoprotein (P-gp) is a member of the ATP-binding cassette protein family, a group of proteins that transport substrates across biological membranes. Compared to tacrolimus, cyclosporine has a significantly greater affinity for $\mathrm{P}-\mathrm{gp}^{31-32}$. Unlike tacrolimus, cyclosporine induces overexpression of $\mathrm{P}-\mathrm{gp}^{3,3,34}$, which may lead to reduced intracellular drug concentrations of cyclosporine and steroids ${ }^{35}$.

IL- 1.0 mRNA upregulation correlates significantly with acute rejection ${ }^{36}$. In animal studies, tacrolimus, but not cyclosporine, induces intragraft suppression of IL-10 and inhibition of IL-10-mediated cytotoxic cell infiltration into the graft ${ }^{37}$.

In contrast to cyclosporine-binding protein, FK506-binding protein 52 (FKBP-52) is associated with the cytoplasmic glucocorticoid receptor (GCR) complex. When corticosteroids bind to the GCRs, the GCRs are relleased from the complex. Free GCRs transmigrate to the nucleus where they may bind to glucocorticoid response elements in the regulatory regions of genes or modulate the binding of other transcription factors, such as activator protein-1 (AP-1), and the signal transducers and activators of transcription (STAT) factors. At the same time, free GCRs may inhibit activation of other transcription factors, such as nuclear factor-кB. Each of these factors regulates genes that are important in immune activation and organ graft rejection. By binding to FKBP-52 in the GCR complex, tacrolimus may alter the affinity of interactions and either cause release of the GCRs at lower steroid concentrations, which would translate into a steroid-sparing effect, or possibly liberate the GCRs in the absence of steroids, a steroid-mimetic effect ${ }^{38}$. This may explain why steroid-free regimens can be more readily employed in patients treated with tacrolimus ${ }^{39}$. 
The effect on cytokine-stimulated T-cell activation is also different. Tacrolimus, in contrast to cyclosporine, inhibits both IL-2-induced $I \mathrm{~L}-5$ production by $\mathrm{CD} 4^{*}$ T-cells and T-cell proliferation stimulated by $1 \mathrm{~L}-2$ and $\mathrm{IL}-7^{40}$.

There are also differences with regard to the cytokine-transforming growth factorbeta (TGF- $\beta$ ). Cyclosporine, but not tacrolimus, elevates TGF- $\beta^{41}$ and, unlike cyclosporine, tacrolimus has the potential to inhibit signal transduction through the TGF- $\beta$ type 1 receptor ${ }^{42}$. Not only is TGF- $\beta$ associated with immunosuppressive effects ${ }^{43-44}$, but increased levels of active TGF- $\beta$ are also associated with fibrosis, arteriosclerosis, and chronic graft dysfunction, as well as with the cardiovascular risk factors hypertension and hyperlipidemia. In fact, recent studies have postulated that tacrolimus appears to have less fibrogenic potential than cyclosporine microemulsion ${ }^{45}$. Moreover, there may be a link between TGF- $\beta$ and the occurrence of gingival hyperplasia and hirsutism ${ }^{46-47}$.

Cyclosporine treatment leads to increased platelet aggregability, whereas tacrolimus treatment reduces platelet response ${ }^{48}$. Reduced platelet thrombogenicity may be of benefit for the prevention of both allograft vasculopathy and atherosclerosis in general. In cardiac transplant patients reduced incidences of graft thrombosis have been reported in patients treated with tacrolimus compared to patients treated with cyclosporine $e^{49}$.

The differences mentioned above with regard to impact on cellular and humoral immune responses, as well as potential drug interactions with concomitant immunosuppressant agents, may explain the differences observed in efficacy between tacrolimus and cyclosporine. Of course, it is also possible that differences in efficacy can be partly attributed to differences in dosing possibilities, due to different side effects of the two drugs.

\section{Tacrolimus pharmacokinetics}

\section{Absorption}

Tacrolimus is a hydrophobic compound. A solid, dispersible formulation in hydroxypropyl methylcellulose results in rapid oral resorption and excellent stability ${ }^{56}$. Time until maximum absorption ranges from 0.5 to 2.0 hours $^{51}$. The oral bioavailability in adult renal transplant recipients is $20-25 \%$, but has a wide range (approximately $5-45 \%)^{51-52}$. Several factors contributing to the variability in oral bioavailability of tacrolimus are depicted in Figure 1.4. Extensive gut metabolism of tacrolimus may be a major contributing factor ${ }^{53}$. 
Gut llumen

Enterocytes

Liver

Systemic circulation

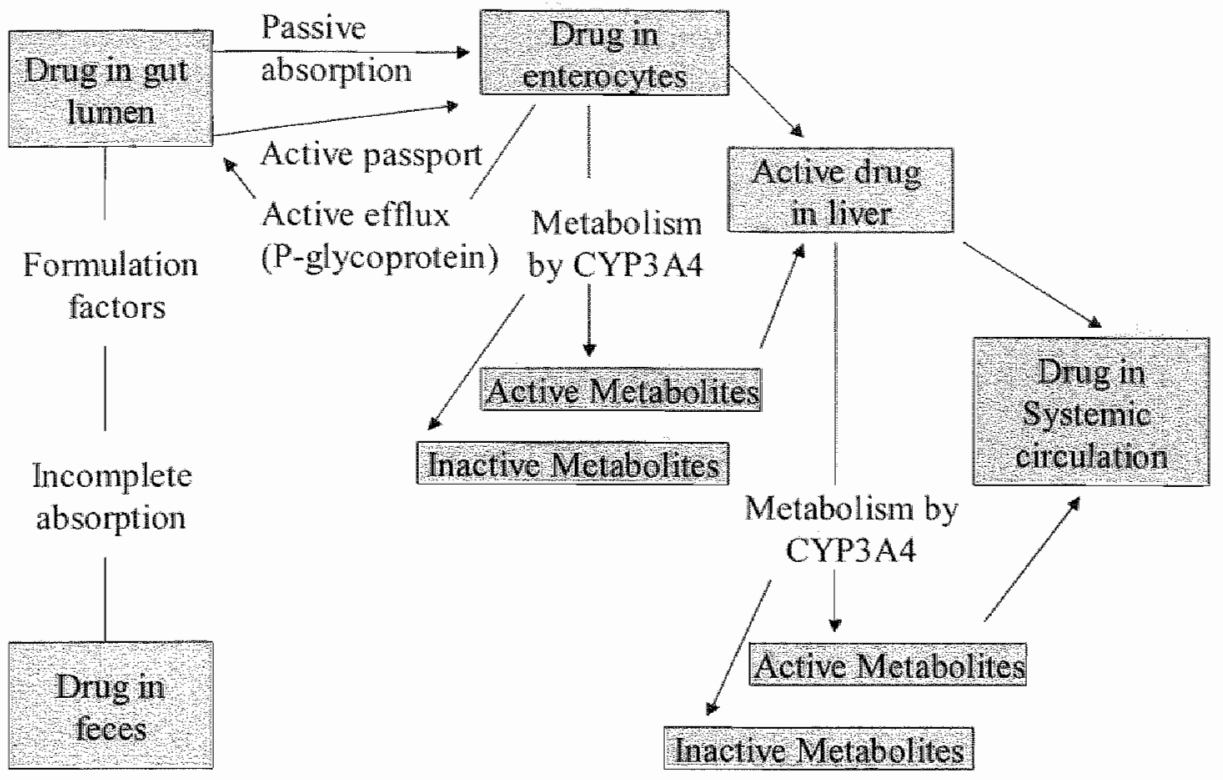

Figure 1.4 Factors contributing to the poor oral bioavalability of tacrolimus.

In healthy volunteers and liver transplant recipients, the presence of food containing a high fat or carbohydrate content was found to affect the oral bioavailibity of tacrolimus ${ }^{51,54}$. After ingestion of tacrolimus 0.25 to 1.5 hours after such a meal, $C_{\text {max }}$ decreased by $50-75 \%$ and $A U C$ decreased by $25-40 \%$ relative to the fasting condition. Therefore, to maximize absorption, all patients were advised not to eat or drink anything from 2 hours before until 1 hour after ingestion of tacrolimus. Since tacrolimus is usually taken orally, twice daily, every 12 hours, this meant that no food or beverage could be consumed for 6 hours of each day! Whether these inconvenient measurements also applied to the continental European breakfast (which generally contains less fat) and to kidney transplant patients was unclear.

\section{Distribution}

Animal studies indicate that the drug is distributed widely over most tissues, including the lungs, spleen, heart, kidney, pancreas, brain, muscle, and liver. This is indicated by a steady state volume of distribution of more than 1000 liter 55 . Whole blood concentrations of tacrolimus are about 15 - 35 times those measured in plasma, although the ratio can vary even more widely depending on such factors as hematocrit and drug concentration. Approximately $99 \%$ of the tacrolimus in 
plasma is bound to plasma proteins (mainly albumin and $\alpha_{1}$-acid glycoprotein). Hematocrit and plasma protein concentration influence active tacrolimus exposure because the pharmacologically active component of tacrolimus in blood is considered to be the unbound fraction in plasma water (Figure 1.5$)^{51}$.

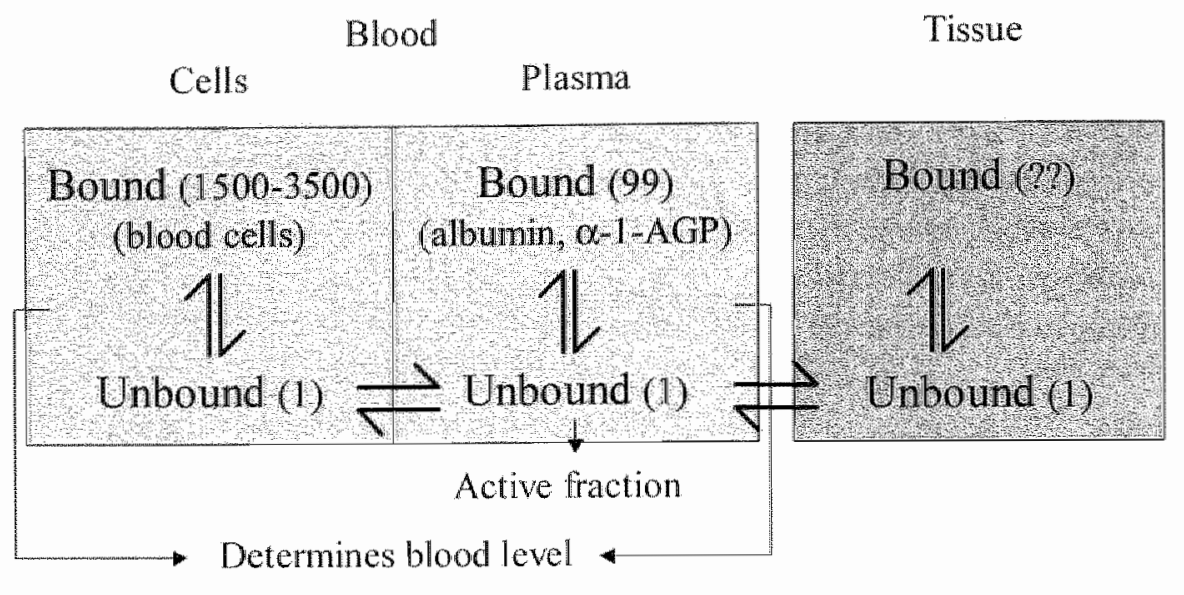

Tacrolimus $=$ Tacrolimus + Tacrolimus + Tacrolimus
$($ Blood $) \quad$ (Erythrocytes)

Figure 1.5 Relative concentrations of tacrolimus after distribution in the body.

\section{Metabolism and clearance}

Tacrolimus is almost completely metabolized via the cytochrome P450 $3 \mathrm{~A} 4$ isoenzyme ${ }^{56}$. Metabolism occurs mainly in the liver. Tacrolimus is a low-clearance drug (hepatic extraction ratio less than $5 \%$ ). Extrahepatic metabolism of tacrolimus by gastrointestinal cytochrome P450 $3 \mathrm{~A} 4$ in the small intestine has also been demonstrated ${ }^{56}$. This metabolism by gastrointestinal cytochrome $\mathrm{P} 4503 \mathrm{~A} 4$ reduces the bioavailibility of tacrolimus by disposal of tacrolimus in the absorption phase. The specific number of metabolites formed is unclear ${ }^{52}$ but appears to be at least 8 and possibly 15 . The main metabolic pathways are hydroxylation and demethylation, and the predominant metabolite is 31-O-demethyl-tacrolimus. Tacrolimus activity is primarily associated with the parent drug, although the 31-O-demethyl metabolite and possibly some of the other metabolites have immunosuppressive activity.

The elimination half-life of tacrolimus is up to approximately 40 hours and is highly variable. Therefore, dose adjustments may take several days to reach steady 
state. The elimination half-life of the active part of tacrolimus, the free fraction, depends on hematocrit and albumin levels and time after transplantation. Tacrolimus clearance decreases as hematocrit and albumin levels increase. Severe liver dysfunction decreases the clearance of tacrolimus even further ${ }^{5}$.

\section{Tacrolimus dosing}

Many side effects were initially encountered with intravenous administration of tacrolimus, among them severe neurotoxicity and nephrotoxicity. Intravenous doses were 10 - 100 times as high as those that are now advised. In some patients, anaphylaxis caused by the intravenous soluble was reported. As a result, the oral route of administration is generally preferred. Initial administration of tacrolimus should begin within 24 hours after kidney reperfusion ${ }^{52}$.

Oral tacrolimus is administered in two divided daily doses at 12-hour intervals. Initial doses for kidney transplantation are $0.20-0.30 \mathrm{mg} / \mathrm{kg}$ per day. During maintenance therapy, the dose of tacrolimus can often be reduced. At least 2 - 3 days are necessary after dose adjustments before a new steady state is reached. Because of the long half-time of tacrolimus, once daily dosing is currently under investigation. In addition, the manufacturer (Fujisawa) is working on a slowrelease formulation of tacrolimus ${ }^{52}$.

\section{Drug interactions}

Since tacrolimus is metabolized by the cytochrome P450 $3 \mathrm{~A} 4$ iso-enzyme system, co-administration of substances known to inhibit this iso-enzyme may decrease the metabolism and increase blood levels, and substances known to induce the isoenzyme may increase metabolism resulting in decreased blood levels. Few formal pharmacokinetic drug interaction studies have been conducted with tacrolimus. In spite of this, various lists have been compiled of drugs that may increase whole blood concentrations of tacrolimus (i.e., hepatic microsomal enzyme inhibitors) and of those that may decrease tacrollimus concentrations (i.e., hepatic microsomal enzyme inducers). Such lists have been compiled primarily on the basis of several case reports and data from animal studies or in vitro investigations. Close monitoring of whole blood tacrolimus trough levels with appropriate dosage adjustments is essential when such drugs are used concomitantly, not only at the start of drug administration, but also after they are discontinued. Table 1.3 shows inhibitors and inducers of cytochrome P450 3A4 that have been reported to interact with tacrolimus metabolism and substances that might theoretically interact with tacrolimus ${ }^{5}$. Theoretically, corticosteroids, commonly used in combination with tacrolimus, could also increase tacrolimus metabolism. 
On the other hand, tacrolimus has the potential to affect plasma concentrations of concomitantly administered drugs that are also CYP3A4 substrates.

Table 1.3 Potential inhibitors and inducers of cytochrome P450 3 A4 iso-enzyme or those reported to interfere with tacrolimus metabolism ${ }^{32}$.

\begin{tabular}{lll}
\hline Inhibitors of CXP3A4 & & Metabolism $\downarrow$ - Tacrolimus levels $\uparrow$ \\
\hline Bromocriptine & Diltiazem & Naringenin (grapefuit juice) \\
Cimetidine & Erythromycin & Nicardipine \\
Ciprofloxacin & Fluconazole & Nifedipine \\
Cisapride & Gestodene & Protease inhibitors \\
Clarithromycin & Itraconazole & Troleandromycin \\
Clotrimazole & Ketoconazole & Verapamil \\
Danazol & Metoclopramide & \\
\hline Inducers of CYP3A4 & & Metabolism $\uparrow$ - Tacrolimus levels $\downarrow$ \\
\hline Barbiturates & Phenytoin & Rifampicin \\
Carbamazepine & Rifabutin & St John's wort \\
Phenobarbital & & \\
\hline
\end{tabular}

\section{Tacrolimus drug monitoring}

The large interpatient variability in oral bioavailability of tacrolimus, the small therapeutic window, and drug interactions mean that the dosage needs to be individualized using tacrolimus whole blood trough concentration monitoring to guide dosing ${ }^{5 \%}$. The most exact way to monitor tacrolimus drug exposure is by making pharmacokinetical profiles: from immediately before one drug dose is ingested until immediately before the next drug dose is ingested, tacrolimus levels are measured at several time points (e.g. $10-12$ times). From the curve thus obtained, the total tacrolimus exposure (area under the curve $=A U C$ ), the trough level, the maximum concentration $\left(C_{\text {max }}\right)$, the time when the maximum concentration is reached $\left(t_{\text {max }}\right)$, and the half-time $\left(t_{6 / 2}\right)$ can be calculated. This is illustrated in Figure 1.6. Because obtaining complete pharmacokinetic profiles for every patient is not feasible in clinical practice, a parameter strongly correlating with $\mathrm{AUC}$ was sought. The strong correlation between $\mathrm{AUC}$ and the trough concentration of tacrolimus in whole blood $(r=0.93 ; \mathrm{P}<0.001)$ led to the use of trough levels as an indicator of systemic exposure and, therefore, of dose adjustments $^{5.9}$. Later, correlations of $0.80-0.90$ between trough level and AUC were found, and $C_{2 h r s}$ monitoring, effective for cyclosporine monitoring, was investigated for tacrolimus ${ }^{60}$. However, correlations between $\mathrm{C}_{2 \text { hrs }}$ monitoring and AUC were no better than correlations between monitoring of the trough level and AUC (Nas Undre, Fujisawa GmbH, personal communications). This may be explained by much smaller peak/trough ratios for tacrolimus than for cyclosporine. 
High-performance liquid chromatography (HPLC), especially HPLC linked to mass spectrometry (HPLC-MS), is the most accurate, sensitive, and specific assay for therapeutic drug monitoring of tacrolimus, with a detection limit of $0.2 \mathrm{ng} / \mathrm{ml}$. Moreover, it can separately quantify the parent compound and its metabolites. However, this assay requires specialized equipment and is, therefore, not routinely used in clinical laboratories ${ }^{58}$.

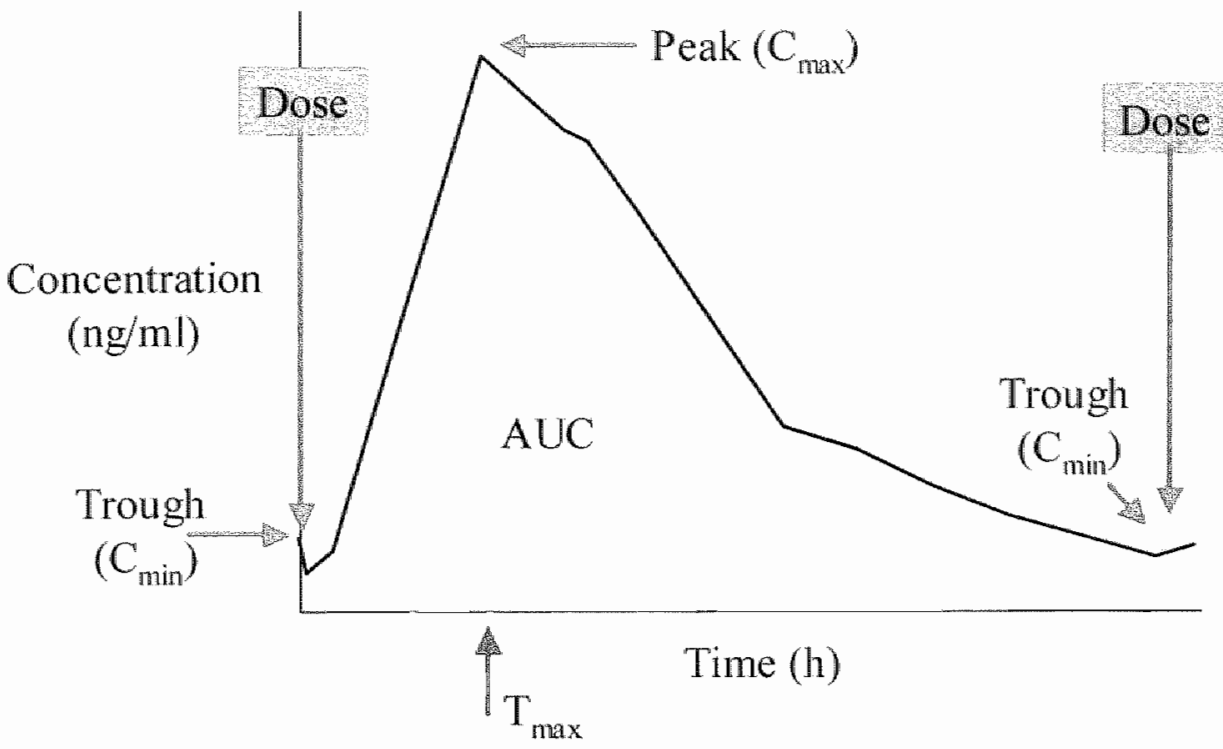

Figure 1.6 Pharmacokinetic profile of tacrolimus: area under the time-concentration curve (AUC) as paraneter for tolal drug exposure, and the main pharmacokinetic description parameters.

Enzyme immunoassay is a bioanalytical technique for therapeutic drug monitoring of tacrolimus. Enzyme-linked immunosorbent assay (ELISA), though reliable in routine use, is very time-consuming, and results are not available for at least 24 hours. Two other methods are more suitable for routine quantification of tacrolimus in whole blood. The first is the manual immunoassay Incstar Proc-Trac (Diasorin Inc, Italy), modified in 1996 (Incstar Proc-Trac II, Diasorin Inc), with an anallyser time of $3-4$ hours. The very high sensitivity $(0.5 \mathrm{ng} / \mathrm{ml})$ makes it useful in special cases ${ }^{58}$.

The second method is a semiautomatic, microparticulate enzyme immunoassay (MElA, Abbott, USA). The initial version had a detection limit of $5 \mathrm{ng} / \mathrm{ml}$, thus lacking the sensitivity required for monitoring patients maintained on low levels of tacrolimus. In 1997, the second-generation assay (TAC II, IMx analyser, Abbott), with a sensitivity of $1.5 \mathrm{ng} / \mathrm{ml}$, became available. With this method, results can be obtained in less than an hour ${ }^{58}$. This is the assay commonly used for testing large 
patient populations and used in most hospitals for clinical practice. This assay method for determining tacrolimus in blood (IMx II, Abbott) is reported to have a precision of up to $\pm 20 \%$ at $5 \mathrm{ng} / \mathrm{m}^{61-62}$.

In renal transplantation, advised trough levels are in the range of $15-20 \mathrm{ng} / \mathrm{ml}$ for the first 2 weeks after transplantation, $10-15 \mathrm{ng} / \mathrm{ml}$ for the next 2 weeks; thereafter, they are gradually tapered to $5-10 \mathrm{ng} / \mathrm{ml}$ for the first year, and $5-7$ ng/ml thereafter ${ }^{6.3}$.

\section{Long-term side effects after renal transplantation}

After transplantation, grafts may be lost due to (chronic) graft dysfunction as a result of immunological or non-immunological factors, or as a result of patient mortality (with a functioning graft). Other complications may also occur. Some may be due to immunosuppressive toxicity, e.g., malignancies and infections, and others to non-immunosuppressive toxicity, e.g., cardiovascular disease as a result of hypertension, posttransplant diabetes mellitus, and posttransplant hyperlipidemia ${ }^{64-68}$.

Corticosteroids are associated with hypertension, hypercholesterolemia, diabetes mellitus, obesity, osteoporosis, ocular complications, myopathy, mood changes, sleep disorders, and growth retardation. The major side effects of cyclosporine and tacrolimus are renal, cardiovascular, metabolic, neurological, and gastrointestinal, while other side effects such as hirsutism and gingival hyperplasia, have also been reported. Table 1.4 shows a comparison of the side effects in patients on cyclosporine (Sandimmune) and on tacrolimus-based immunosuppression in the first year after renal or liver transplantation. The data are derived from four major randomized, multicenter, non-blinded trials conducted in the USA and Europe between 1993 and $1996^{6,52,6 \%, 7 !}$. With regard to cardiovascular and metabolic side effects, several later studies have confïmed the increased incidence of hyperlipidemia in cyclosporine-treated patients compared to those treated with tacrolimus ${ }^{18.72-74}$, and they have detected an increased risk and severity of hypertension in cyclosporine-treated patients compared to those on tacrolimus ${ }^{67.75}$. Table 1.5 shows the main side effects of steroids, cyclosporine, and tacrolimus. 
Table 1.4 A comparison of the side effects in patients on cyclosporine or tacrolinus-based immunosuppression in the frst year after renal or liver transpiantation. Data derived from fout major randomized, multicenter, non-blinded trials conducted in the USA and Europe between 1993 and $1996^{52}$.

Incidence of adverse events in tacrolimus versus cyclosporine-based immunosuppression tor liver or renal transplantation (range across studies; percentage of patients).

\begin{tabular}{|c|c|c|c|}
\hline & Tacrolimus & Cyclosporine & Significance number of studies \\
\hline $\begin{array}{l}\text { Remal } \\
\text { Increased serum creatinine } \\
\text { Oliguria } \\
\text { Kidney failure }\end{array}$ & $\begin{array}{l}20-45 \\
8-21 \\
10-11\end{array}$ & $\begin{array}{l}14-41 \\
8-12.5 \\
6-6.5\end{array}$ & $\begin{array}{l}\text { Inconclusive }(1 \mathrm{~s}, 2 \mathrm{~ns}) \\
\text { Inconclusive }(1 \mathrm{~s}, 2 \mathrm{~ns}) \\
\text { Not significant }(2)\end{array}$ \\
\hline $\begin{array}{l}\text { Cardiovascular } \\
\text { Hypertension } \\
\text { Chest pain or angina } \\
\text { Arrhythmia }\end{array}$ & $\begin{array}{c}35-50 \\
11-19 \\
1.3\end{array}$ & $\begin{array}{c}39-56 \\
3-13 \\
6.2\end{array}$ & $\begin{array}{l}\text { Not significant (4) } \\
\text { Inconclusive (1s. Ins) } \\
\text { Significant (1) }\end{array}$ \\
\hline $\begin{array}{l}\text { Metabolic } \\
\text { Diabetes mellitus } \\
\text { Hyperglycenta } \\
\text { Hypercholesterolemua } \\
\text { Hyperkalemia }\end{array}$ & $\begin{array}{c}8-20 \\
16-47 \\
8 \\
21-45\end{array}$ & $\begin{array}{c}2-9 \\
7-38 \\
14.5 \\
16-26\end{array}$ & $\begin{array}{l}\text { Inconclusive }(2 \mathrm{~s}, 1 \mathrm{~ns}) \\
\text { Inconclusive }(2 \mathrm{~s}, \mathrm{lns}) \\
\text { Significant }(1) \\
\text { Inconclusive }(1 \mathrm{~s}, \mathrm{Ins})\end{array}$ \\
\hline $\begin{array}{l}\text { Neurological } \\
\text { Trenor } \\
\text { Headache } \\
\text { Insomnia } \\
\text { Paresthesia } \\
\text { Confusion } \\
\text { Generalized spasm }\end{array}$ & $\begin{array}{c}35-56 \\
20.5-64 \\
24-32 \\
13.5-40 \\
10 \\
8\end{array}$ & $\begin{array}{c}12-46 \\
14-60 \\
26-29.5 \\
15-30 \\
3 \\
2\end{array}$ & $\begin{array}{l}\text { Inconclusive }(3 \mathrm{~s}, \text { Ins) } \\
\text { Not signilicant }(3) \\
\text { Not significant }(2) \\
\text { Inconclusive }(2 \mathrm{~s}, 1 \mathrm{~ns}) \\
\text { Significant (1) } \\
\text { Significant (1) }\end{array}$ \\
\hline $\begin{array}{l}\text { Gastronntestinal } \\
\text { Diarthea } \\
\text { Nausea } \\
\text { Constipation } \\
\text { Anorexia }\end{array}$ & $\begin{array}{c}22-72 \\
17-46 \\
31-35 \\
34\end{array}$ & $\begin{array}{c}10-47 \\
16-37 \\
35-42.5 \\
24\end{array}$ & $\begin{array}{l}\text { Inconclusive }(2 \mathrm{~s}, 1 \mathrm{~ns}) \\
\text { Inconclusive }(1 \mathrm{~s}, 2 \mathrm{~ns}) \\
\text { Not significant }(2) \\
\text { Significant (1) }\end{array}$ \\
\hline $\begin{array}{l}\text { Other } \\
\text { Acne } \\
\text { Alopecia } \\
\text { Anemia } \\
\text { Gingivitis } \\
\text { Gum/gingival hyperplasia } \\
\text { Hirsutism } \\
\text { Pruritis }\end{array}$ & $\begin{array}{c}3 \\
11-20 \\
17.5-47 \\
1.5 \\
0.5-1 \\
0-7 \\
15-36\end{array}$ & $\begin{array}{c}10 \\
1-6 \\
17-38 \\
9 \\
5-6 \\
9-31 \\
7-20\end{array}$ & $\begin{array}{l}\text { Significant (1) } \\
\text { Significant (2) } \\
\text { Inconclusive (1s, Ins) } \\
\text { Significant (1) } \\
\text { Signilicant (2) } \\
\text { Significant (4) } \\
\text { Significant (2) }\end{array}$ \\
\hline
\end{tabular}

$\mathrm{S}=$ significant, $\mathrm{ns}=$ not significant

\section{Diabetes melitus}

\section{Criteria}

The first internationally accepted diagnostic criteria for diabetes were established in 1979 by the National Diabetes Data Groups and by the World Health 
Organization (WHO) in 1980. The latter were modified in 1985, but all of these diagnostic criteria were based on both fasting glucose levels and glucose measured 2 hours after a $75-\mathrm{g}$ glucose load (oral glucose tolerance test, OGTT). In 1997 , simplified diagnostic criteria, based on fasting plasma glucose levels only, were introduced by the American Diabetes Association (ADA). In 1998, the WHO criteria were again modified, combining the fasting levels of the ADA criteria with 2-hour OGTT levels. These criteria are summarized in Table $1.6^{76}$.

Table 1.5 Comparison of the major side effects of corticosteroids, eyclosporine, and tacrolimus.

\begin{tabular}{lccc}
\hline Side effect & Corticosteroids & Cyclosporine & Tacrolimus \\
\hline Nephrotoxicity & - & $\uparrow \uparrow$ & $\uparrow(\uparrow)$ \\
Hypertension & $\uparrow$ & $\uparrow \uparrow$ & - or $(\uparrow)$ \\
PTDM & $\uparrow \uparrow$ & $\uparrow \uparrow$ & $\uparrow \uparrow$ \\
Hyperlipidemia & $\uparrow \uparrow$ & $\uparrow$ & - \\
Obesity & $\uparrow \uparrow$ & $\uparrow$ & - \\
Neurotoxicity & $\uparrow$ & $\uparrow \uparrow$ & $\uparrow \uparrow$ \\
Hirsutism & - & $\uparrow \uparrow$ & - \\
Cingival hyperplasia & - & $\uparrow$ & - \\
\hline
\end{tabular}

$\uparrow \uparrow$ large increase, $\uparrow$ small increase, no increase

Table 1.6 Diagnostic cutooff points for glucose intolerance: ADA-97 and WHO-98 criteriat, and criteria for PTDM used in this thesis.

\begin{tabular}{lccc}
\hline & Plasma & Capillary & Whole \\
\hline ADA-97 and WHo-98 criteria & & & \\
Fasting blood glucose (mmol/) & & & \\
Normal & $<6.1$ & $<5.6$ & $<5.6$ \\
Impaired fasting glycemia & $6.1-6.9$ & $5.6-6.0$ & $5.6-6.0$ \\
Fasting diabetes & $\geq 7.0$ & $\geq 6.7$ & $\geq 6.7$ \\
2-hour blood glucose (mmol/l) & & $<7.8$ & $<6.7$ \\
Normal & $<7.8$ & $7.8-11.0$ & $6.7-9.9$ \\
Inpaired glicose tolerance & $7.8-11.0$ & $\geq 11.1$ & $\geq 10.0$ \\
Diabetes & $\geq 11.1$ & & \\
PTDM criteria used in this thesis & & $<5.6$ & $<5.6$ \\
Fasting blood glucose (mmol/) & $<6.1$ & $\geq 5.6$ & $\geq 5.6$ \\
Nondiabetes & $\geq 6.1$ & & $<6.7$ \\
PTDM & & $<7.8$ & $\geq 6.7$ \\
Nonfasting blood glucose (mmol/1) & $\geq 7.8$ & & \\
Nondiabetes & & & \\
PTDM & & & \\
\hline
\end{tabular}

Methods of glucose metabolism investigation

Diabetes mellitus can be diagnosed with either the ADA or WHO criteria. Not only glucose levels, but also HbAlc is often used in clinical practice. HbAlc is a glycosylated form of hemoglobin, that is used as a parameter of mean glucose 
concentration in the last $2-3$ months. This is a parameter commonly used in the follow-up of diabetes mellitus regulation, but increased levels have also been associated wih an increased mortality risk in a nondiabetic population ${ }^{77}$.

For the detection of subclinical impaiment of glucose metabolism and differentiation between insulin secretion and resistance, fasting glucose levels and routine 2-hour oral glucose tolerance tests are not sufficient. More detailed investigations of glucose metabolism are necessary.

Several tests for insulin resistance are possible.

Basal fasting tests, include not only fasting glucose but also fasting insulin and fasting C-peptide (connecting-peptide, a polypeptide chain linking the alpha and beta chains of active insulin). The half-time of C-peptide is considerably longer than that of insulin (30 versus 5 minutes) and C-peptide clearance is almost completely renal. In nondiabetics, fasting glucose, fasting insulin, fasting C-peptide, insulin/glucose ratio, and HOMA-R (homeostasis model assessment of resistance: fasting glucose (mmol/1) multiplied by fasting insulin ( $\mathrm{mU} / \mathrm{l})$ divided by 22.5) that are calculated from these data, are used as markers for insulin resistance ${ }^{78}$.

Other more sophisticated tests for the assessment of insulin resistance also exist. In the insulin suppression test, epinephrine and propranolol are infused to inhibit endogenous insulin release, interrupting the glucose feedback signal to the pancreas. Then, insulin and glucose are infused, and the resulting endogenous steady-state plasma glucose is assumed to reflect the degree of insulin resistance. Another technique is the euglycemic or hyperglycemic clamp. In this method, insulin is infused systematically, but plasma glucose is maintained at a fixed level by an exogenous glucose infusion calculated to maintain plasma glucose at a predetermined level, which is usually either the preclamp ambient level or a level above the ambient value. The target glucose level is attained by making frecuent measurements of the glucose level and calculating the glucose infusion needed to compensate for increases in glucose disappearance.

In addition to these tests, stress tests are used to calculate insulin secretion in response to a pancreatic stimulus.

In the arginine stimulation test, which stimulates insulin and glucagon release, arginine- $\mathrm{HCl}$ is infused for 30 minutes. Before and at several time-points during the 2 hours after the infusion, samples for glucose and insulin are taken.

In the classical. OGTT, plasma glucose is measured 2 hours after an oral glucose load of $75 \mathrm{~g}$ glucose is administered for 5 minutes in 250 water in a fasting patient. Levels below $7.0 \mathrm{mmol} / 1$ indicate normal glucose tolerance, levels between 7.0 and $11.1 \mathrm{mmol} / \mathrm{l}$ impaired glucose tolerance, and levels of $11.1 \mathrm{mmol} / \mathrm{l}$ or more 
diabetes mellitus. Modified OGTTs have been developed that consist of frequent sampling of glucose and insulin for up to 240 minutes. Such tests, however, still lack precision. Therefore, more sophisticated methods for investigating glucose metabolism have been developed ${ }^{79}$.

The minimal model method is a process of determining insulin sensitivity using a computer model. After i.v. glucose injection, very frequent sampling of glucose and insulin is necessary. The model is forced to simulate plasma glucose dynamics when plasma insulin dynamics are supplied. In this way, insulin sensitivity can be determined. Several such models exist.

A more classical and easier method is the intravenous glucose tolerance test (IVGTT) $^{80}$, in which insulin secretion under stress is studied. This method is used in all of the studies of glucose metabolism in renal transplant recipients described in this thesis. Before and after an intravenous glucose load, frequent sampling of blood for glucose, insulin and C-peptide takes place. Different sampling times are described. In our studies, $0.5 \mathrm{~g} / \mathrm{kg}$ glucose was administered for $2-3$ minutes. Samples for measurements of glucose, insulin, and C-peptide were taken at $t=-15,0,5,10,15,20,30(, 40,50$, and 60$)$ minutes. Parameters of insulin resistance (fasting glucose, insulin and $\mathrm{C}$-peptide, insulin/glucose ratio, and HOMA-R) and insulin secretion were determined and calculated. The increments of C-peptide and insulin secretion determined by the area under the curve, calculated using a linear, trapezoidal technique from the serum values at each time point after subtraction of the $t=0$ value, have been used to assess insulin secretion (Figure 1.7). The $\mathrm{k}_{\mathrm{G}}$ (insulin sensitivity index or glucose disappearance rate) is a parameter determined by insulin resistance as well as by insulin secretion. The $k_{0}$ is calculated by linear regression from the log-transformed glucose values of $t=10$ to 30 (or 60) minutes (Figure 1.8). During the first minutes after rapid glucose infusion, redistribution of glucose occurs and preformed insulin is released from the granulae. Therefore, $\mathrm{k}_{Q}$ was calculated from 10 to 30 minutes. After the initial IVGTTs, we thought it might be more precise to calculate the decline between 10 to 60 minutes. Therefore, the IVGTT's were lengthened to 60 minutes. However, $\mathrm{k}_{\mathrm{G}}$ values calculated from glucose levels between 10 and 30 minutes and those calculated from glucose levels between 10 and 60 minutes showed excellent agreement $(r=0.85, \mathrm{P}<0.05)$. A $\mathrm{k}_{\mathrm{G}}$ level below $0.8 \%$ per min was considered abnormal (indicating reduced insulin sensitivity), between 0.8 to $1.2 \%$ per min indeterminate, and above $1.2 \%$ per min normal ${ }^{70-80}$.

Most of these techniques for investigating glucose metabolism have mainly been used for research purposes, and several modifications of the protocols exist. For most of these tests, validation has been limited and has only been performed in research settings. In the limited number of studies available about the 
reproducibility of the IVGTT (with modifications in time and duration of blood sampling compared to our IVGTTs), reproducibility for a given group was generally good, but individual variability was fairly high (mean $20-25 \%)^{81-84}$.

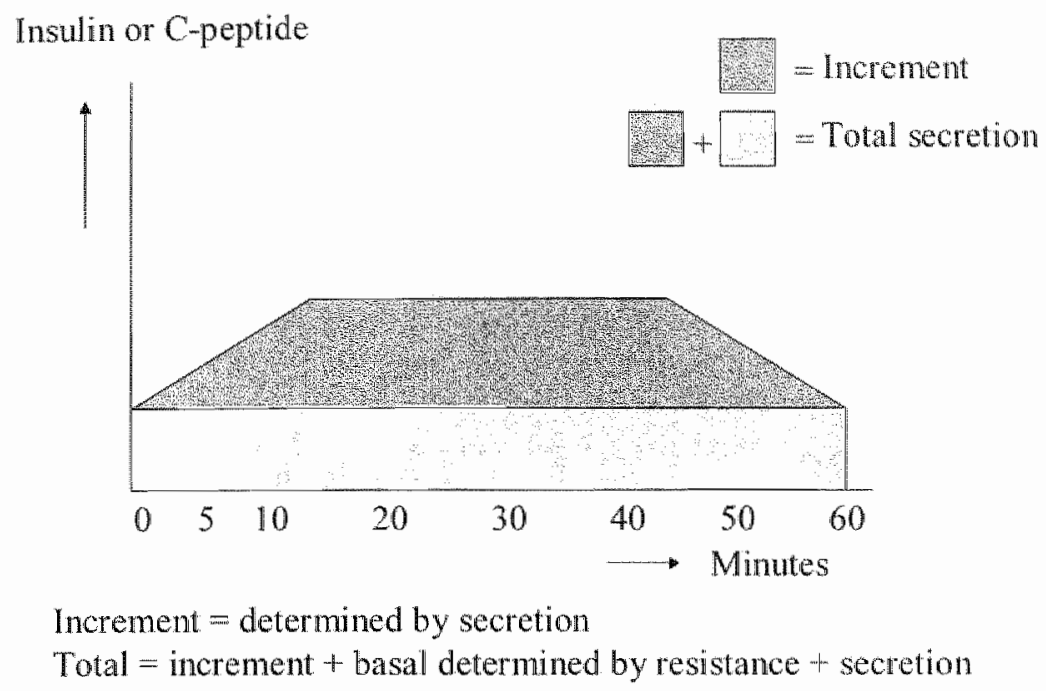

Figure 1.7 Calculation of insulin and C-peptide secretion (increment).

\section{Classification}

Traditionally, two main types of diabetes mellitus are distinguished: type 1 and, occurring approximately ten times as often, type 2 diabetes mellitus. Type 1 is mainly seen in young patients, while type 2 is associated with obesity and increasing age. Diabetes can also be related to the use of certain drugs, e.g., corticosteroid-induced diabetes mellitus or posttransplant diabetes mellitus.

\section{Pathophysiology}

Type 1 diabetes mellitus is an autoimmune disease associated with anti-islet autoantibodies. In combination with genetic factors and environmental triggers and regulators, the immune dysregulation results in a variable insulitis and $\beta$-cell sensitivity to injury, leading to a loss of $\beta$-cell mass ${ }^{85}$.

Type 2 diabetes mellitus is a heterogeneous disorder. The pathophysiology of type 2 diabetes is a kind of black box. A lot of facts are still unclear. The hypothesis is that a combination of genetic and environmental factors (life-style) leads to disturbed insulin secretion as well as disturbed insulin sensitivity in muscles, fat, and the liver (insulin resistance). Whether impaired secretion or increased insulin resistance is the primary defect in the majority of patients is not known, although it 
is generally agreed that defective insulin release is a requirement for the disease to develop. When overt type 2 diabetes has developed, glucotoxicity and lipotoxicity increase insulin resistance further and decrease pancreatic secretion function further, thus continually worsening glycemic control ${ }^{86}$.

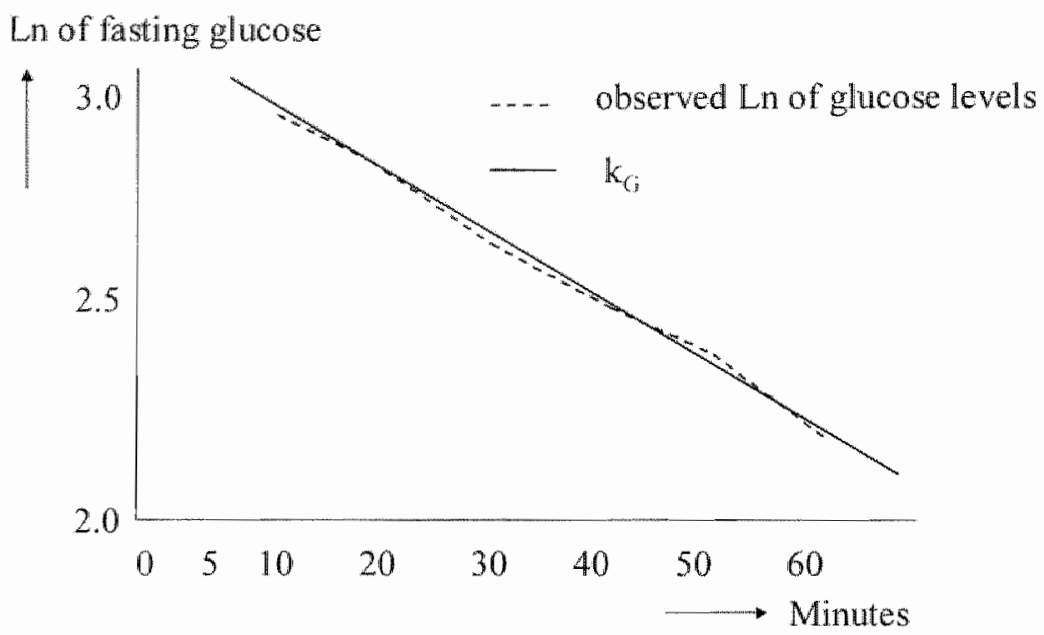

Figure 1.8 Calculation of insulin sensitivity index: linear regression of the natural logarithm (Ln) of glucose levels from 10 till 30 (60) minutes after glucose injection.

\section{Posttransplant diabetes mellitus}

\section{Definitions}

There are no clear definitions of posttransplant diabetes (PTDM); many different definitions have been used. Some investigators only include those patients using insulin treatment, while others also include patients taking oral glucose-lowering drugs; still others adhere to more stringent criteria. Because not all of our patients could be seen in the morning, nonfasting routine blood controls were necessary and, consequently, we could not strictly adhere to the ADA criteria for diabetes mellitus as mentioned above. Routine OGTTs, necessary for adhering to WHO criteria, were not feasible. Therefore, in our investigations, we have defined PTDM as abnormal plasma glucose values (fasting $>6.1 \mathrm{mmol} / 1$ and nonfasting $>7.8$ mmol/1) for two or more different samples without the presence of a known temporary cause for hyperglycemia, such as infection or high doses of corticosteroids (rejection treatment) (Table 1.6). In a number of patients without PTDM according to the above-mentioned definitions, a subclinical impairment of 
glucose metabolism might be detected with more sophisticated methods of investigation, such as IVGTTs or euglycemic clamping.

\section{Incidence}

Depending on the definition of PTDM used, incidences of approximately $5-40 \%$ have been reported in patients after renal transplantation ${ }^{87-8 \%}$. Despite the fact that we classify more patients as having PTDM because of our broad definition of PTDM mentioned above, the occurrence of PTDM in our center is only approximately $15 \%$ of all renal transplant recipients on tacrolimus or cyclosporinebased immunosuppression ${ }^{90}$.

\section{Risk factors}

Several risk factors for the occurrence of PTDM have been described: genetic factors, race, family history of diabetes, older age, high body weight, and high dosages of calcineurin inhibitors and of corticosteroids ${ }^{6,18,87,94-43}$. In some studies, the incidence of PTDM has been higher in patients using tacrolimus than in those using cyclosporine $e^{6,18,94}$, while others have not found any differences in incidence.

\section{Mechanism}

Corticosteroids can cause increased insulin resistance ${ }^{95}$; however, the mechanism by which calcineurin inhibitors such as cyclosporine and tacrolimus may cause impaired glucose metabolism is unknown. Theoretically, from the binding of tacrolimus to FKBP-52 in the GCR complex, an increased insulin resistance might be suspected due to liberation of GCRs, which could result in a steroid-mimetic effect ${ }^{38}$. The mechanism responsible for the development of PTDM has been examined both in animals and in clinical studies. An impaired insulin secretion during tacrolimus administration was found in the former. In rats, Tamura et al. ${ }^{96}$ found a defect in insulin synthesis as a result of an mRNA transcriptional defect dependent on duration of exposure to tacrolimus. They hypothesized that the defect in mRNA transcription induced by tacrolimus was mediated by binding to FK506-binding protein- 12 and that the subsequent inhibition of calcineurin in $\beta$-cells caused the diminished insulin secretion. Others have described a reduced insulin secretion in human pancreatic $\beta$-cells transplanted into animals ${ }^{97-98}$. Overexpression of $\mathrm{P}-\mathrm{gp}$ induced by cyclosporine compared to tacrolimus, resulting in lower intracellular calcineurin inhibitor levels, could result in fewer abnormalities in glucose metabolism in cyclosporine-treated patients $^{35}$. In clinical studies, an increase in insulin resistance was suggested as an additional mechanism underlying the development of $\mathrm{P}^{\mathrm{T}} \mathrm{DM}^{87.99}$. However, in those studies, all patients were on steroids, which can cause an increase in insulin resistance ${ }^{87.88}$. 
Of course, in addition to the effects of tacrolimus (and corticosteroids) on the pancreas, a decline in pancreatic function, comparable to changes in pancreatic function that occur with the increasing incidence of type 2 diabetes mellitus in time, can occur also in patients after renal transplantation and result in diabetes mellitus.

\section{Consequences}

The development of PTDM after renal transplantation has been associated with an increased risk of sepsis ${ }^{100}$, and/or cardiovascular disease ${ }^{101}$, resulting in a reduction in graft as well as patient survival ${ }^{102}$. Therefore, understanding the mechanism by which tacrolimus causes PTDM is important if one is to develop strategies to prevent and treat PTDM and perhaps also to improve graft and patient survival in patients with glucose metabolic disorders after renal transplantation.

\section{Aim of the thesis}

Immunosuppressive regimens have changed considerably in the last decade. With increasing efficacy of immunosuppressive regimens, pharmacokinetic aspects of the new drugs and the incidence and mechanisms of side effects become important issues in the choice of an immunosuppressive regimen.

The purpose of this thesis is to find answers to the following questions:

\section{Glucose metabolism}

1. What is the mechanism responsible for glucose metabolic disorders caused by tacrolimus? (Chapter 2)

2. Which patients are at risk for PTDM during tacrolimus maintenance therapy? (Chapter 2)

3. What is the role of concomitant use of corticosteroids in glucose metabolic disorders during tacrolimus use? (Chapter 3)

4. Do glucose metabolic disorders correlate with tacrolimus exposure? (Chapter 3)

5. Are there differences in glucose metabolism between renal transplant recipients treated with cyclosporine and those treated with tacrollimus? (Chapter 4)

6. Does chronic $\beta$-cell toxicity occur after long-term use of calcineurin inhibitors? (Chapter 4)

7. Which interactions may occur between hepatitis C, PTDM, and tacrolimus pharmacokinetics? (Chapter 5)

8. Which practical guidelines for the management of PTDM in tacrolimus-based immunosuppression can be made based on the results of our investigations? (Chapter 8) 


\section{Pharmacokinetics of tacrolimus}

1. Do large interindividual differences in pharmacokinetic profiles as described in liver transplant recipients also occur in renal transplant recipients, and are there differences in pharmacokinetic profiles between diabetics and nondiabetics? (Chapter 6a)

2. Does nonfasting ingestion of tacrolimus influence its oral bioavailability, and are there differences in pharmacokinetic profiles between diabetics and nondiabetics? (Chapter 6b)

3. Are there differences in oral bioavailability at different times after transplantation, and are they different between fasting and nonfasting ingestion of tacrolimus? (Chapter 6c)

4. Do trough levels remain in the therapeutic range after conversion to nonfasting ingestion of tacrolimus? (Chapter $6 \mathrm{~d}$ )

5. Does comedication with corticosteroids influence tacrolimus trough levels? (Chapter 7)

6. Which practical guidelines for conversion to nonfasting ingestion of tacrolinus can be made based on the results of our investigations? (Chapter 8 ) 


\section{References}

1. Starzl TE, Marchiori TL, Porter KA, Iwasaki Y, Cerelli CJ. The use of heterologous antilyphoid agents in canine renal and liver homotransplantation, and in luman renal homotransplantation. Surgery, Gynaecology, and Obstetrics 1967; 124:301-318.

2. Calne RY, Rolles K, White DJ, Thiru S, Evans DC, McMaster P, Dumn DC, Craddock GN, Henderson RG, Aziz S, Lewis P. Cyclosporine A initially as the only immunosuppressant in 34 recipients of cadaveric organs. Lancet 1979; ii: 1033-1036.

3. Friman S, Backman L. A new microemulsion formulation of cyclosporine; pharmacokinetic and clinical features. Clin Phamacokinetic 1996; 30: 181-193.

4. Hall BM, Tiller DJ, Hardie I, Mahony J, Mathew T, Thatcher G, Miach P, Thomson $\mathbb{N}$, Sheil $A G$. Comparison of three immunosuppressive regimens in cadaver renal transplantation: long-term cyclosporine, short term cyclosporine followed by azathioprine and prednisolone, and azathioprine and prednisolone without cyclosporine. N Engl J Med 1988; $318: 1499-1507$.

5. European Multicentre Trial Group. Cyclosporine in cadaveric renal transplantation: one year follow-up of a multicenter trial. Lancet 1983;2:986-989.

6. Mayer AD, Dmitrewski J, Squifflet JP, Bessen T, Grabensee B, Klein B, Eigler FW, Heemann $U$, Pichmayr $R$, behrend $M$, Vanrenterghem $Y$, Donck $J$, van $H_{\text {looff }} \mathrm{J}$, Christiaans M, Morales JM, Andres A, Johnson RWG, Short C, Buchholz B, Rehmert N, Land W, Schleibner S, Forsythe JLR, Talbot D, Neumayer HH, Hauser I, Ericzon $B G$, Brattström $\mathrm{C}$, Claesson $\mathrm{K}$, Mühlbacher F, Pohanka E. Multicenter randomized trial comparing tacrolimus (FK506) and cyclosporine in the prevention of renal allograft rejection. Transplantation 1997; 64: 436-443.

7. Nashan B, Light S, Hardie JR, Lin A, Johnson JR. Reduction of acute renal allograft rejection by daclizumab. Daclizumab Double Therapy Study Group. Transplantation 1999:67(1): 110-115.

8. Kahan BD, Rajagopalam PR, Hall M. Reduction of the occurrence of acute cellular rejection among renal allograft recipients treated with basiliximab, a chimeric antiinterleukin-2-receptor monoclonal antibody. United States Simulect Renal Study Group. Transplantation 1999; 67 (2): 276-284.

9. Nashan B, Moore R, Amlot P, Schimdt AG, Abeywickrama K, Soulillou JP. Randomised trial of basiliximab versus placebo for control of acute cellular rejection in renal allograft recipients. CHIB 201 International Study Group. Lancet 1997; 350 (9086): 1193-1198.

10. Vincenti E, Kirkman R, Light S, Bumgardner G, Pescovitz M, Halloran P, Neylan J, Wilkinson A, Ekberg H, Gaston R, Backman L, Burdick J. Interleukin-2-receptor blockade with daclizumab to prevent acute rejection in renal transplantation. Daclizumab Triple Therapy Study Group. N Engl I Med 1998; 338 (3); 161-165.

11. Vincenti F, Monaco A, Grinyo J, Kinkhabwala M, Neylan J, Roza A, Somberg K. Rapid steroid withdrawal versus standard steroid therapy in patients treated with basiliximab, cyclosporine, and mycophenolate mofetil for the prevention of acute rejection in renal transplantation. Transplant Proc 2001; 33: 1011-1012.

12. Cole E, Landsberg D, Russell D, Zaltzman J, Kiberd B, Caravaggio C, Vasquez AR, Halloran P. A pilot study of steroid-free immunosuppression in the prevention of acute rejection in renal allograft recipients. Transplantation 2001; 72 (5):845-850.

13. U.S. Renal Transplant Mycophenolate Mofetil Study Group. Mycophenolate mofetil for the prevention of acute rejection in primary cadaveric renal allograft recipients. Transplantation 1995; 60: 225-232. 
14. European Mycophenolate Mofetil Cooperative Study Group. Placebo-controlled study of mycophenolate mofetil combined with cyclosporine and corticosteroids for prevention of acute rejection. Lancet $1995 ; 345: 1321-1325$.

15. Johnson C, Ahsan N, Gonwa T, Halloran P, Stegall M, Hardy M. Metzger R. Shield C, Rocher L, Scandling $J$, Sorensen J, Mulloy L, Light $J$, Corwin $C$, Danovitch $G$, Wachs M, van Veldhuisen P, Salm K, Tolzman D, Fitzsimmons WE. Randomized trial of tacrolimus (Prograf) in combination with azathioprine or mycophenolate mofetil versus cyclosporine (Neoral) with mycophenolate moletil after cadaveric kidney transplantation. Transplantation 2000; 69 (5): 834-841.

16. Kahan BD. Efficacy of sirolimus compared with azathioprine for reduction of acute renal allograft rejection: a randomised multicentre study. The Rapamune US Study Group. Lancet 2000; 356 (9225): 194-202.

17. Coupes B, Speake M, Johnson R, Campbell B, Short C. Tacrolimus monotherapy in renal transplantation: four year data. ICI, San Diego, 6-8 Dec $200 \mathrm{l}$, abstract 209.

18. Pirsch JD, Miller J, Deierhoi MH, Vincenti F, Filo RS. A comparison of tacrolimus (FK506) and cyclosporine for immunosuppression after cadaveric renall transplantation. FK506 Kidney transplant group. Transplantation 1997; 63: 977-983.

19. Calconi $\mathrm{G}$, Vianello $\mathrm{A}$ for the Italian and Spanish Tacrolimus Study Group. One-year follow-up of a large European Trial comparing dual versus triple tacrolimus-based immunosuppressive regimens following renal transplantation. Transplant Proc 2001; 33: $1021-1024$.

20. Ciancio G, Miller A, Burke GW, Gharagozloo H, Rosen A, Roth D, Kupin W, Pinna A. Cespedes M, Esquenazi V, Miller J. Daclizumab induction for primary kidney transplant recipients using tacrolimus, mycophenolate mofetil, and steroids as maintenance immunosuppression. Transplant Proc 2001; 33 (1-2); 1013-1014.

21. Squifflet JP, Vanrenterghem $Y$, Abramowicz D, Mourad M, Kuypers D, Meurisse M, Daems J. The clinical outcome of a single-arm pilot trial in renal transplant patients investigating the safety of a low FK506/low-stop corticosteroid regimen in combination with mycophenolate mofetil and daclizumab induction therapy. ICI, San Diego, 6-8 Dec 2001, abstract 104.

22. Hooff van JP, Squifflet JP, Wlodarczyk Z, Vanrenterghem Y, Paczek L. Dose-finding study of tacrolimus in combination with rapamycin: the 3-month results. ICI, San Diego, 6-8 Dec 2001, abstract 206.

23. Henry ML. Cyclosporine and tacrolimus (FK 506): a comparison of efficacy and safety proliles. Clin Transplant 1999; 13:209-220.

24. Denton MD, Magee CC, Sayegh MH. Immunosuppressive strategies in transplantation. Lancet 1999; 353: 1083-1091.

25. Almawi WY, Melemedjian OK. Clinical and mechanistic differences between FK 506 (tacrolimus) and cyclosporine A. Nephrol Dial Transplant 2000; 15: 1916-11918.

26. Briggs JD. The European tacrolimus renal rejection study group. Conversion at first rejection: a prospective trial comparing cyclosporin-mictoemulsion with tacrolimus in renal transplantation. Transplantation 2000; 69 (Suppl.): S1 13, abstract 9.

27. Roelen DL, van Bree FPMJ, Schanz U, van Rood JJ, Claas FHJ "Differential inhibition of primed alloreactive CTLs in vitro by clinically used concentrations of cyclosporine and FK 506. Transplantation 1993; 56: 190-195.

28. Hornick PI, Mason PD, Yacoub MH, Rose ML, Batchelor R, Lechler RI. Assessment of the contribution that direct allorecognition makes to the progression of chronic cardiac transplant rejection in humans. Circulation 1998; 97: 1257-1263. 


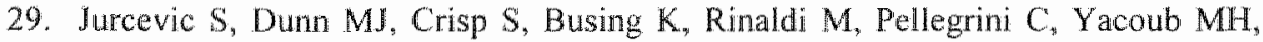
Vigano M, Banner NL, Rose ML. A new enzyme-linked immunosorbent assay to measure anti-endothelial antibodies after cardiac transplantation demonstrates greater inhibition of antibody formation by tacrolimus compared with cyclosporine. Transplantation 1998; 65: 1197-1202.

30. Migita K, Origuchi T, Kawabe Y, Tominaga M, Ida H, Kawakami A, Eguchi K. FK 506 markedly enhances apoptosis of antigen-stimulated peripheral $\mathrm{T}$ cells by down-regulation of Bcl-xL. Transplantation 1999; 68: 1018-1023.

31. Tanaka K, Hirai M, Tanigawara $Y$, Yasuharar M, Hori R, Ueda $\mathbb{K}$, Inui $K$. Effect of cyclosporin analogues and FK506 on transcellular transport of daunorubicin and vinblastine via p-glycoproten. Pharmacol Res 1996; 13: 1073-1077.

32. Gelder van T, Klupp J, Sawamoto T, Christians U, Morris RE. ATP-binding cassette transporters and calcineurin inhibitors: potential clinical implications. Transplant Proc: $2001 ; 33: 2420-2421$.

33. Jette L, Beaulieu E, Leclerc JM, Beliveau R. Cyclosporin A treatment induces overexpression of p-glycoprotein in the kidney and other tissues. Am I Physiol 1996; 270: F756-F765.

34. Hauser IA, Koziolek M, Hopfer U, Thevenod F. Therapeutic concentrations of cyclosporin A, but not FK506, increase p-glycoprotein expression in endothelial and renal tubule cells. Kidney Int 1998; 54:1139-1149.

35. Zanker B, Barth C, Stachowski J, Baldamus CA, Land W. Multidrug resistance gene MDR1 expression: a gene transfection in vitro model and clinical analysis in cyclosporine-treated patients rejecting their renal grafts. Transplant Proc 1997; 29: 1507-1508.

36. Platz KP, Mueller AR, Roissant R, Steinmuller T, Lemmens HP, Lobeck H, Neuhaus $P$. Cytokine pattern during rejection and infection after liver transplantation improvements in postoperative monitoring? Transplantation 1996; 62: 1441-1450.

37. Fujimura $T$, Yang XF, Sorinao R, Ogawa $T$, Kobayashi $M_{3}$ Jiang $H$. Cellular surface molecular and cytokine gene expression. in rat heart allografts under optimal doses of cyclosporine and FK 506. Transplant Proc 1998; 30: $1023-1026$.

38. Hutchinson IV, Bagnall W, Bryce P, Pufong B, Geraghty P, Brogan I. Differences in the mode of action of cyclosporine and FK 506. Transplant Proc 1998; 30: 959-960.

39. Boots JMM, Christialans MHL, van Duijnhoven EM, van Suylen R-J, van Hooff JP. Early steroid withdrawal in renal transplant recipients on tacrolimus dual therapy: a pilot study. Submitted.

40. Almawi WY, Melemedjian OK. Clinical and mechanistic differences between FK 506 (tacrolimus) and cyclosporin A. Nephrol Dial Transplant 2000; 15: 1916-1918.

41. Mohamed MAS, Robertson H, Booth TA, Balupuri S, Kirby JA, Talbot D. TGF$\beta$ expression in renal transplant biopsies. Transplantation 2000; 69: 1002-1005.

42. Wang T, Donahoe PK, Zervos AS. Specific interaction of type 1 receptors of the TGFp family with the immunophilin FKBP-12. Science 1994; 265: 674-676.

43. Wahl SM, Hunt DA, Wong HL, Dougherty S, McCarmey-Francis N, Wahl LM, Ellingsworth L, Schmidt JA, Hall G, Roberts AB. Transforming growth factor-beta is a potent immunosuppressive agent that inhibits IL-1-dependent lymphocyte proliferation. J Immunol 1988; 140 (9): 3026-3032.

44. Lawrence DA. Transforming growth factor-beta: a general review. Eur Cytokine Netw 1996; 7 (3): 363-374.

45. Jain S, Bicknell GR, Nicholson ML. Tacrolimus has less fibrogenic potential than cyclosporin $\mathrm{A}$ in a model of renal ischemia-reperfusion injury. $\mathrm{Br} J$ Surg $2000 ; 87$. $1563-1568$. 
46. Skaleric U, Kramar B, Petelin M, Pavlica Z, WahI SM. Changes in ToF beta I levels in gingiva, crevicular flud and serum associated with peridontal intammation in humans and dogs. Eur J Oral Sci 1997; $105(2): 136-142$

47. Paus R, Foitzik K, Welker P, Bulfone-Paus S, Eichmuller S. Transforming growth factor-beta receptor type $I$ and type II expression during murine hair follicle development and cycling. J Invest Dermatol 1997; $109(4): 518-526$

48. Muraki T, Sasaki Y, Gidding JC, Ishii H, Kaneko T, Yamamoto J. Antithrombotic effect of FK 506 versus prothrombotic effect of cyclosporine in vivo. Transplantation $1995 ; 60: 308-310$.

49. Freudenberger R, Alexis J, Gass A, Fuster V, Badimon J. Antithrombotic effect of FK506 vs cyclosporine in cardiac transplant recipients: potential implications in transplant arteriopathy. J Heart Lung Transplant 199; 18 (12): 1228-1231.

50. Undre NA, Schäfer A, and the European Tacrolimus Multicentre Renal Study Group. Factors affecting the pharmacokinetics of tacrolimus in the first year after renal transplantation. Transplant Proc 1998; 30: 1261-1263.

51. Venkataramanan R, Jain A, Warty VS, Abu-EImagd K, Alessiani M, Lever J, Krajak A, Flowers J, Mehta S, Zuckerman S, Fung J, Todo S, Starzl TE. Pharmacokinetics of FK506 in transplant patients. Transplant Proc 1991; 23 (6): 2736-2740.

52. Plosker Gl, Foster RH. Tacrolimus. A further update of its pharmacology and therapeutic use in the management of organ transplantation. Drugs 2000; 59 (2): 323389.

53. Tuteja S, Alloway RR, Johson JA, Gaber AO. The effect of gut metabolism on tacrolimus bioavailibilty in renal transplant recipients. Transplantation 2001; 71 (9): 1303-1307.

54. Mekki Q, Lee C, Carrier S, Klintmalm G, Shaefer M, Burke P, Schechter P. The effect of food on oral bioavalability of tacrolimus ( $\mathrm{K} 506) \mathrm{in}$ liver transplant patients. Clin Pharmacol Ther 1993; 53 (2): 229, abstract PIII-92.

55. Venkataramanan $R$, Jain A, Cadoff E, Warty V, Iwasaki K, Nagase K, Krajack A, Imventarza O, Todo S, Fung JJ, Starzl TE. Pharmacokinetics of FK 506: preclinical and clinical studies. Transplant Proc 1990; 22 (Suppl. 1): 52-56.

56. Vincent SH, Karanam BV, Painter SK, Chiu SH. In witro metabolism of FK-506 in rat, rabbit and human liver microsomes: identification of a major metabolite and of cytochrome P450 3 A4 as the major enzymes responsible for its metabolism. Arch Biochem Biophys 1992; 294 (2): 454-460.

57. Abu-Elmagd K, Fung JI, Alessiani M, Jain A, Venkataramanan R, Warty VS, Takaya S, Todo S, Shamon WD, Starz TE. The effect of graft function on FK 506 plasma levels, dosages, and renal function, with particular reference to the liver. Transplantation 1991; 52: 71-77.

58. Shaw LM, Holt DW, Keown P, Venkataramanan R, Yatscoff PW. Current opinions on therapeutic drug monitoring of immunosuppressive drugs. Clin Ther 1999; $21(10)$ : $1632-1652$.

59. Mekki Q, Lee C, Aweeka F, Laskow D, Neylan J, Mendez R, Steinmuller D, Schechter P. Pharmacokinetics of tacrolimus (FK506) in kidney transplant patients. Clin Pharmacol Ther 1993; 53 (2): 238, abstract PIII-130.

60. Armstrong VW, Oellerich M. New developments in the immunosuppressive drug monitoring of cyclosporine, tacrolimus, and azathioprine. Chin Biochem $2001 ; 34$ (1): 9-16.

61. Wallemacq PE, Leal T, Besse T, Squiffet J-P, Reding $\mathbb{R}$, Otte J-B, Lerut $J$, Hassoun A. Imx Tacrolimus II vs Imx tacrolimus microparticle enzyme immunoassay evaluated in renal and hepatic transplant patients. Clin Chem 1997; 43 (10): 1989. 1991. 
62. Tredger IM, Gilkes CD, Gonde CE. Performance of the Imx tacrolimus II assay and practical limits of detection. Clin Chem 1999; 45 (10): $188 \mathrm{l}-1882$.

63. Hooff van JP, Boots JMM, van Duijnhoven EM, Christiaans MHL. Dosing and management guidelines for tacrolimus in renal transplant patients. Transplant Proc $1999 ; 31$ (7A) Suppl. S: 54 S $-57 \mathrm{~S}$.

64. Silkensen JR. Long-term complications in renal transplantation. J Am Soc Nephrol $2000 ; 11(3): 582-588$.

65. Paul LC Overview of side effects of immunosuppressive therapy. Transplant Proc $2001 ; 33: 2089-2091$.

66. Kasiske B, Chakkera H, Roel J. Explained and unexplained ischemic heart disease risk after renal transplantation. J Am Soc Nephrol 2000; 11:1735-1743.

67. Ligtenberg $G$, Hene RJ, Blankestijn PJ, Koomans HA. Cardiovascular risk factors in renal transplant patients: cyclosporine A versus tacrolimus. J Am Soc Nephrol 2001; $12(2): 368-373$

68. Hjelmesxth J, Hartmann A, Midtvedt K, Aakhus S, Stenstrøm J, Mørkrid L, Egeland T, Tordarson H, Fauchald P. Metabolic cardiovascular syndrome after renal transplantation. Nephrol Dial Transpl 2001; 16: 1047-1052.

69. European FK506 Multicentre Liver Study Group. Randomised trial comparing tacrolimus (FK506) and cyclosporin in prevention of liver allograft rejection. Lancet $1994 ; 344: 423-428$.

70. The U.S. Multicenter FK 506 Liver Study Group. A comparison of tacrolimus (FK506) and cyclosporine for immunosuppression in liver transplantation. N Engl J Med 1994; $331: 1110-1115$.

71. Mayer AD, for the European Tacrolimus Multicentre Renal Study Group. Four-year follow-up of the European Tacrolimus Multicentre Renal Study. Transplant Proc 1999; 31 Suppl 7A: 27S-28S.

72. Friemann S, Feuring E, Padberg W, Enst W. Improvement of nephrotoxicity, hypertension, and lipid metabolism after conversion of kidney transplant recipients from cyclosporine to tacrolimus. Transplant Proc 1998; 30:1240-1242.

73. McCune TR, Thacker II LR, Peters TG, Mulloy L, Rohr MS, Adams PA, Yium J Light JA, Pruett T, Gaber AO, Selman SH, Jonsson J, Hayes JM, Wright FH, Armata T, Blanton J, Burdick JF. Effects of tacrolimns on hypenlipidemia after successful renal transplantation: a Southeastern Organ Procurement Foundation multicenter chinical study. Transplantation 1998; 65:87-92.

74. Claesson K, Mayer AD, Squiffet JP, Grabensee B, Eigler FW, Behrend M, Vanrenterghem $Y$, van Hooff J, Morales JM, Johnson RW, Buchholz B, Land W, Forsythe JL, Neumayer HH, Ericzon BG, Muhlbacher F. Lipoprotein patterns in renal transplant patients: a comparison between FK 506 and cyclosporine A patients. Transplant Proc 1998; 30: 1292-1294.

75. Artz MA, Boots JMM, Ligtenberg G, Roodnat J, Christiaans MHL, Hene RJ, Blom HJ, Demacker PN, Hilbrands LB. Randomized conversion from cyclosporin to tacrolimus in renal transplant patients. ICI, San Diego, 6-8 Dec 2001, abstract 210.

76. Vegt de F, Dekker JM, Stehouwer CD, Nijpels G, Bouter LM, Heine RJ. Similar 9year mortality risks and reproducibility for the World Health Organization and American Diabetes Asssociation glucose tolerance categories: the Hoorn Study. Diabetes Care $2000 ; 23(1): 40-44$.

77. Khaw K, Wareham N, Luben R, Bingham S, Oakes S, Welch A, Day N. Glycated haemoglobin, diabetes, and mortality in men in Norfolk cohort of European Prospective Investigation of Cancer and Nutrition (EPIC, Norfolk). BMJ 2001; 322: 15-18. 
78. Mathews DR, Hosker JP, Rudenski As, Naylor BA, Treacher DF, Tumer RC, Homeostasis model assessment: insulin resistance and beta-cell function from fasting plasma glucose and insulin concentrations in man. Diabetologia 1985: 28:412-419.

79. Bergman RN, Finegood DT, Ader M. Assessment of insulin sensitivity in vivo. Endocrine Reviews 1985; 6(1): 45-86.

80. Elmer DS, Hathaway DK, Gaber AO. Monitoring of pancreas allograft function with glucose disappearance rate $\left(\mathrm{k}_{\mathrm{O}}\right)$ : calculation and interptetation. J Transplant Coordination 1994; 4: 7-11.

81. Colman PG, Stewart V, Kean J, Koschmam M, Alford F, Ward G, Deam D, Harrison LC. Comparison of two commonly used standard ivgtts. Diabetes Care 1992;15 (8): 1053-1055.

82. Bardet S, Pasqual C, Maugendre D, Remy JP, Charbonnel B, Sai P. Inter and intra individual variability of acute insulin response during intravenous glucose tolerance tests. Diabetes Metab 1989; 15 (5): 224-232.

83. Ganda OP, Day JL, Soeldner JS, Connon JJ, Gleason RE. Reproducibility and comparative analysis of repeated intravenous and oral glucose tolerance tests. Diabetes 1978; 27 (7): 715-725.

84. Hedstrand H, Boberg J. Statistical analysis of the reproducibility of the intravenous glucose tolerance test and the serum insulin response to this test in the middle-aged men. Scand J Clin Invest 1975; 35 (4): $331-337$.

85. Atkinson MA, Eisenbach GS. Type 1 diabetes: new perspectives on disease pathogenesis and treatment. Lancet 2001; 358:221-229.

86. Otenson $\mathrm{CG}$. The pathophysiology of type 2 diabetes mellitus: an overview. Acta Physiol Scand 2001; 171. (3): $241-247$.

87. Weir MR, Fink JC. Risk for posttransplant diabetes mellitus with current immunosuppressive medications. Am J Kidney Dis 1999; 34: 1-13.

88. Krentz AJ, Dmitrewski J, Mayer D, Nattrass M. Effects of immunosuppressive agents on glucose metabolism. Clin Immunother 1995; 4: 103-123.

89. Jindal RM, Sidner RA, Milgrom ML. Post-transplant diabetes mellitus. The nole of immunosuppression. Drug Saf 1997; 16:242-257.

90. Boots JMM, van Duijnhoven EM, Christiaans MHL, Nieman FHM, van Suylen R-J, van Hooff JP. Single center experience with tacrolimus versus cyclosporin-Neoral in renal transplant recipients. Transplant Int $2001 ; 14: 370-383$.

91. Sumrani NB, Delaney V, Ding ZK, Davis R, Daskalakis P, Friedman EA, Butt KM, Hong JH. Diabetes mellitus after renal transplantation in the cyclosporine era - an analysis of risk factors. Transplantation 1991; 51 (2):343-347.

92. Hjelmesaeth J, Hartmann A, Kofstad J, Stenstrom J, Leivestad T, Egeland T, Fauchald P. Glucose intolerance after renal transplantation depends upon prednisolone dose and recipient age. Transplantation 1997; 64 (7): 979-983.

93. Cosio FG, Pesavento TE, Osei K, Henry ML, Ferguson RM. Post-transplant diabetes mellitus. Increasing incidence in renal allograft recipients transplanted in recent years. Kidney Int 2001; 59:732-737.

94. Scantlebury V, Shapiro R, Fung J, Tzakis A, McCauley J, Jordan M, Jensen C, Hakala T, Simmons R, Starzl TE. New onset of diabetes in FK 506 ws cyclosporine treated kidney transplant recipients. Transplant Proc 1991; 23 (6): 3169-3170.

95. Weir M. Impact of immunosuppressive regimes on posttransplant diabetes mellitus. Transplant Proc 2001; 33 (Suppl 5A): 23S-26S.

96. Tamura K, Fujimura T, Tsutsumi T, Nakamura K, Ogawa T, Atumaru C, Hirano Y, Ohara K, Ohtsuka K, Shimomura K, Kobayashi M. Transcriptional inhibition of insulin by $F K 506$ and possible involvement of $F K 506$ binding protein 12 in pancreatic beta-cell. Transplantation 1995; 59: 1606-1613. 
97. Ricordi $C_{\text {, Zeng }} \mathrm{Y}$, Alejandro $\mathrm{R}$, Tzakis $\mathrm{A}$, Venkataramanan $\mathrm{R}$, Fung J, Bereiter $\mathrm{D}$, Mintz D, Starzl T. In vivo effect of FK 506 on human pancreatic islets. Transplantation $1991 ; 52: 519-522$.

98. Rilo $H$, Zeng $Y$, Alejandro $R$, Carroll $P$, Bereiter $D$, Venkataramanan $R$, Tzakis A, Starzl T, Ricordi C. Effect of FK506 on function of human islets of Langerhans. Transplant Proc 1991; 23:3164-3165.

99. Golling $M$, Lehmann $T$, Senninger $N$, Herfarth $C$, Otto $G$. Tacrolimus reduction improves glucose metabolism and insulin secretion after liver transplantation. Transpl Proc 1996;28:3180-3182.

100. Miles AMV, Sumrani N, Horwitz R, Homel P, Maursky V, Markell MS, Distant DA, Hong $\mathrm{JH}$, Sommer BG, Friedman EA. Diabetes mellitus after renal transplantation as deleterious as non-transplant-associated diabetes? Transplantation 1998; 65:380-384.

101. Kasiske BL. Cardiovascular disease after renal transplantation. Semin Nephrol 2000; $20(2): 176=187$.

102. Revanur VK, Jardine $A G$, Kingsmore DB, Jaques $B C$, Hamilton DH, Jindal RM. Influence of diabetes mellitus on patient and graft survival in recipients of kidney transplantation. Clin Transplant 2001;15(2): 89-94. 
Chapter 2

\section{Influence of tacrolimus on glucose metabolism before and after renal transplantation: a prospective study}

EM van Duijnhoven, JMM Boots, MHL Christiaans, BHR Wolffenbuttel, JP van Hooff

IAm Soc Nephrol 2001; 12: 583-588 


\section{Abstract}

Most studies concerning the influence of tacrolimus on glucose metabolism have been performed either in animals or after organ transplantation. These clinical studies have largely been transversal with patients who were using steroids. Therefore, this prospective longitudinal study investigated the influence of tacrolimus on glucose metabolism before and after transplantation.

\section{Materials and methods}

Eighteen Caucasian dialysis patients underwent an intravenous glucose tolerance test before and 5 days after the start of tacrolimus. Insullin sensitivity index $\left(\mathrm{k}_{\mathrm{G}}\right)$, insulin resistance (insulin/glucose ratio and homeostasis model assessment (HOMA-R)), and C-peptide and insulin secretion were calculated. Trough levels of tacrolimus were measured. After transplantation, the occurrence of posttransplant diabetes mellitus (PTDM) was prospectively monitored. Statistical analysis was performed using the Wilcoxon signed ranks test and Spearman's rho for correlation.

\section{Results:}

Before tacrolimus, $\mathrm{k}_{\mathrm{G}}$ was indeterminate in three patients. During tacrolimus, $\mathrm{k}_{\mathrm{G}}$ decreased in 16 of 18 patients, from a median of $1.74 \%$ per min to $1.08 \%$ per min ( $P<0.0001)$. The correlation between $\mathrm{C}$-peptide and insulin data was excellent. Insulin secretion decreased from $851.0 \mathrm{mU} / \mathrm{min} / 1$ to $558.0 \mathrm{mU} / \mathrm{min} / 1(\mathrm{P}=0.014)$, whereas insulin resistance did not change. Insulin sensitivity correlated negatively with tacrolimus trough level. After transplantation, three patients developed PTDM; before tacrolimus, two had an indeterminate and one a low normal $\mathrm{k}_{\mathrm{G}}$.

\section{Conclusion}

During tacrolimus administration, $\mathrm{k}_{\mathrm{G}}$ decreased in almost all patients as a result of a diminished insulin secretion response to a glucose load, whereas insulin resistance did not change. Patients with an abnormal or low normal $k_{0}$ seem to be at risk of developing PTDM while on tacrolimus. 


\section{Introduction}

Tacrolimus is a macrolide with potent immunosuppressive effects. It has been used successfully as a prophylactic immunosuppressant for solid organ transplantation. After transplantation, a high incidence of posttransplantation diabetes mellitus (PTDM) has been reported. However, systematic, prospective data regarding the incidence of PTDM in renal allograft recipients treated with tacrolimus are scarce. Studies report an incidence of $8-36 \%{ }^{1-11}$. This variation may be explained partly by different definitions of PTDM that are used. Moreover, it has been reported that the incidence is higher in older patients, that it is influenced by both steroid and tacrolimus dosage, and that it differs according to race. Thus, the incidence of PTDM depends in part on the demographics of the patient group studied. The development of PTDM has important sequelae. Miles et al. ${ }^{12}$ studied the long-term outcome of 40 PTDM patients who were using cyclosporine. Although they failed to show a significant difference in mortality rate after 12 years, they did find an increased frequency of sepsis as a cause of death and a greater risk of developing graft failure (relative risk $=3.72 ; \mathrm{P}=0.04$ ).

The mechanism responsible for the development of PTDM has been examined both in animals and in clinical studies. An impaired insulin secretion during tacrolimus administration was found in the former. In clinical studies, an increase in insulin resistance was suggested as an additional mechanism underlying the development of PTDM ${ }^{1,13}$. However, in the latter studies, all patients were on steroids, which can cause an increase in insulin resistance.

In rats, Tamura et al. ${ }^{14}$ found a defect in insulin synthesis as a result of an mRNA transeriptional defect dependent on duration of exposure to tacrolimus. They hypothesized that the defect in mRNA transcription induced by tacrolimus was mediated by binding to FK506-binding protein-12 and that the subsequent inhibition of calcineurin in $\beta$-cells caused the diminished insulin secretion. Others have described a reduced insulin secretion in human pancreatic $\beta$-cells transplanted into animals ${ }^{15-16}$. In a transversal study in 14 liver transplant recipients, Fernandez et al. ${ }^{17}$ found a reduced insulin secretion in patients who were using tacrolimus and cyclosporine compared with a healthy control group. This study was performed in liver transplant recipients who were being treated with steroids (as well as other medication) and who were examined after transplantation.

In the present study, insulin secretion and insulin resistance were assessed before and during the use of tacrolimus in patients who were awaiting renal transplantation. The patients did not receive steroids. The patients were also evaluated after transplantation for the development of PTDM. To our knowledge, 
this is the first prospective study performed before transplantation, with follow-up after transplantation, concerning the influence of tacrolimus on glucose metabolism. In an interim analysis of nine patients from this study ${ }^{18}$, it was shown that both insulin sensitivity index $\left(\mathrm{k}_{\mathrm{G}}\right)$ and insulin secretion decreased after tacrolimus. In this definitive report of 18 patients, these findings are confirmed and extended.

\section{Material and methods}

\section{Patients}

Patients were eligible to participate in the study if they met the following criteria: age 18 years or older, on our waiting list for renal transplantation, no known history of clinical diabetes, and no use of steroids or other immunosuppressive agents. All patients had to give informed consent to participate in the study. Eighteen Caucasian, nondiabetic patients ( $10 \mathrm{men}, 8$ women) were included in the study. Their primary renal diseases were hypertension $(n=5)$, hemolytic uremic syndrome $(n=4), \lg$ A glomerulonephritis $(n=3)$, focal intracapillary glomerulonephritis $(n=1)$, chronic pyelonephritis $(n=1)$, membranous glonerulonephritis $(n=1)$, reflux nephropathy $(n=1)$, and unknown $(n=2)$. Ten patients were on hemodialysis and eight were on peritoneal dialysis (PD). The median duration of dialysis was 19 months (range 8 to 48 months). Their median age was 49 years (23 to 58 years) and median body mass index $23.3 \mathrm{~kg} / \mathrm{m}^{2}\left(17.8\right.$ to $\left.34.5 \mathrm{~kg} / \mathrm{m}^{2}\right)$. Seventeen patients received a renal transplant. Three patients had no long-term follow-up (one died as a result of acute bleeding, one lost her graft as a result of shock, and one had primary nonfunction).

\section{Glucose metabolism}

Glucose metabolism was studied using intravenous glucose tolerance tests (IVGTTs). The tests were performed in the morning after an overnight fast both before and 5 days after starting tacrolimus. In PD patients, the peritoneal cavity was empty from 23.00 hours until after the test. Glucose $(0.5 \mathrm{~g} / \mathrm{kg}$ body weight) was administered intravenously for 2 to 3 minutes. Blood samples for measurement of whole blood glucose, $\mathrm{C}$-peptide, and insulin were taken from the opposite arm at $\mathrm{t}=-15,0,5,10,15,20,30,40,50$, and 60 minutes. The $\mathrm{k}_{\mathrm{G}}$ (glucose disappearance rate) was calculated by linear regression from the log-transformed glucose values of $\mathrm{t}=10$ to 30 minutes. A $\mathrm{k}_{\mathrm{G}}$ value below $0.8 \%$ per min was considered as abnormal, between 0.8 and $1.2 \%$ per min as indeterminate, and above $1.2 \%$ per min as normal ${ }^{19-20}$. 
C-peptide and insulin secretion, i.e., the secretion response to a glucose load, were calculated as area under the curve using a linear trapezoidal technique from the serum value at each time point after subtraction of the $t=0$ value (increment). Insulin resistance was calculated using the insulin/glucose ratio and the homeastasis model assessment (HOMA-R: fasting glucose (mmol/) multiplied by fasting insulin ( $\mathrm{mU} / 1$ ) divided by 22.5$)^{21-23}$.

During hospitalization after transplantation, urine was examined daily for glucosuria; afterwards, it was checked during every visit to the outpatient clinic. When glucosuria was detected, whole-blood glucose was examined. If no glucosuria was detected, glucose was measured initially at least once every week and later at least every 3 months. When glucose values were abnomal $>6.1$ $\mathrm{mmol} / \mathrm{l}$ in the fasting state or $>7.8 \mathrm{mmol} / 1$ in the nonfasting state), glycosylated hemoglobin (HbAlc) was measured.

A dipstick method was used for the detection of glucosuria. For the measurement of glucose in whole blood, the CX 7 (Beckman Instruments, Palo Alto, CA) was used, for C-peptide and insulin, the Autodelfia (Wallac, Turku, Finland), and for HbAlc, an HPLC method, Variant 2 (Biorad, Hercules, CA), was used.

\section{Immunosuppression}

Before transplantation, patients were examined by IVGTT before and 5 days after oral exposure to tacrolimus (twice daily $0.15 \mathrm{mg} / \mathrm{kg}$ body weight). Before the second IVGTT, the tacrolimus whole-blood 12-hour trough level was determined (IMx, Abbott, Hoofddorp, The Netherlands).

After transplantation, immunosuppression consisted of tacrolimus and steroids in all patients. Because of the prevailing immunosuppressive protocol at the time of transplantation, six patients also recelved azathioprine and three patients mycophenolate mofetil beginning on day 3 after transplantation. Target tacrolimus trough levels for all patients were 15 to $20 \mathrm{ng} / \mathrm{m}$ from day 1 until day 14 and then 10 to $15 \mathrm{ng} / \mathrm{ml}$ from day $15 \mathrm{until}$ day 28 ; thereafter, they were adjusted gradually to 5 to $10 \mathrm{ng} / \mathrm{ml}$. Steroid dosage consisted of $125 \mathrm{mg}$ methyllprednisolone on day 0 or $50 \mathrm{mg}$ prednisolone on day 0 and $25 \mathrm{mg}$ on day 1 . Thereafter, all patients received $10 \mathrm{mg} /$ day for the first 4 weeks after transplantation. The dosage was tapered to 5 $\mathrm{mg} /$ day at 3 months after transplantation and then to $0 \mathrm{mg}$ in first transplant recipients without an episode of acute rejection. In five patients, tubulointerstitial rejection was treated with steroid pulse therapy. Because of very severe acute tubulointerstitial rejection with a possible vascular component and the development of HLA class 1 antibodies 3 weeks after transplantation, one patient was treated with one bolus steroids, antithymocyte globulin, and plasmapheresis; mycophenolate mofetil was also added to the immunosuppressive regimen. 
At a median of 34 months (range $21-48$ months) after transplantation, eight patients were receiving tacrolimus monotherapy, two were receiving tacrolimus and azathioprine, two were receiving tacrolimus and mycophenolate mofetil, one was receiving tacrolimus and prednisolone, and one patient was receiving tacrolimus, azathioprine, and prednisolone.

\section{Statistical analyses}

For statistical anallysis, the SPSS version 9.0 for Windows (SPSS INC, Cary, NC) was used. To compare glucose metabolism before and during the use of tacrolimus, the Wilcoxon matched-pairs signed rank sum test was performed. For correlation between the different parameters, Spearman's rho was used. A P value below 0.05 was considered to be statistically significant.

\section{Results}

\section{Glucose and insulin sensitivity}

In Table 2.1, the results of glucose metabolism before transplantation (median and ranges) are shown. Before tacrolimus, fasting glucose was normal in all patients. The $k_{\mathrm{G}}$ was normal in 15 patients and indeterminate in 3 (Figure 2.1). There was no correlation between $\mathrm{k}_{\mathrm{i}}$ and age or gender. There was a trend towards a lower $\mathrm{k}_{\mathrm{G}}$ with an increase in BMI ( $r=0.423, \mathrm{P}=0.08)$.

Table 2.1 Glucose metabolism before and during tacrolimus.

\begin{tabular}{|c|c|c|c|c|c|}
\hline & Before & & During & & $\mathrm{P}$ \\
\hline Fasting glucose (mmol/) & 5.1 & $(3.9-6.9)$ & 5.2 & $(4.1-7.9)$ & 0.013 \\
\hline Insulin level at $t=0^{7 /}(\mathrm{mu} / \mathrm{l})$ & 12.0 & $(4.6-34.0)$ & 12.0 & $(3.0-17.8)$ & 0.15 \\
\hline Insulin sensitivity index (\% per min) & 1.74 & $(0.85-3.70)$ & $\llbracket .08$ & $(0.39-2.56)$ & $<0.0001$ \\
\hline \multicolumn{6}{|l|}{ Insulin resistance } \\
\hline HOMA-R ${ }^{H}\left(\mathrm{mmol} / /^{*} \mathrm{nu}\right.$ Un) & 2.74 & $(0.84-8.16)$ & 2.82 & $(0.59-6.25)$ & 0.33 \\
\hline Insulinglucose ratio (mU/mmol) & 2.25 & $(1.12-6.30)$ & 2.24 & $(0.68-3.33)$ & 0.039 \\
\hline Insulin secretion $\left(\mathrm{mU}^{*} \mathrm{~min} / \mathrm{l}\right)$ & 864.5 & $(274.0-40425)$ & 600.0 & $(0.0-2376.5)$ & $<0.0001$ \\
\hline
\end{tabular}

Median and range of glucose metabolism values before and during tacrolimus measured or calculated from measurements of IVGTT. 17 patients, see text. 


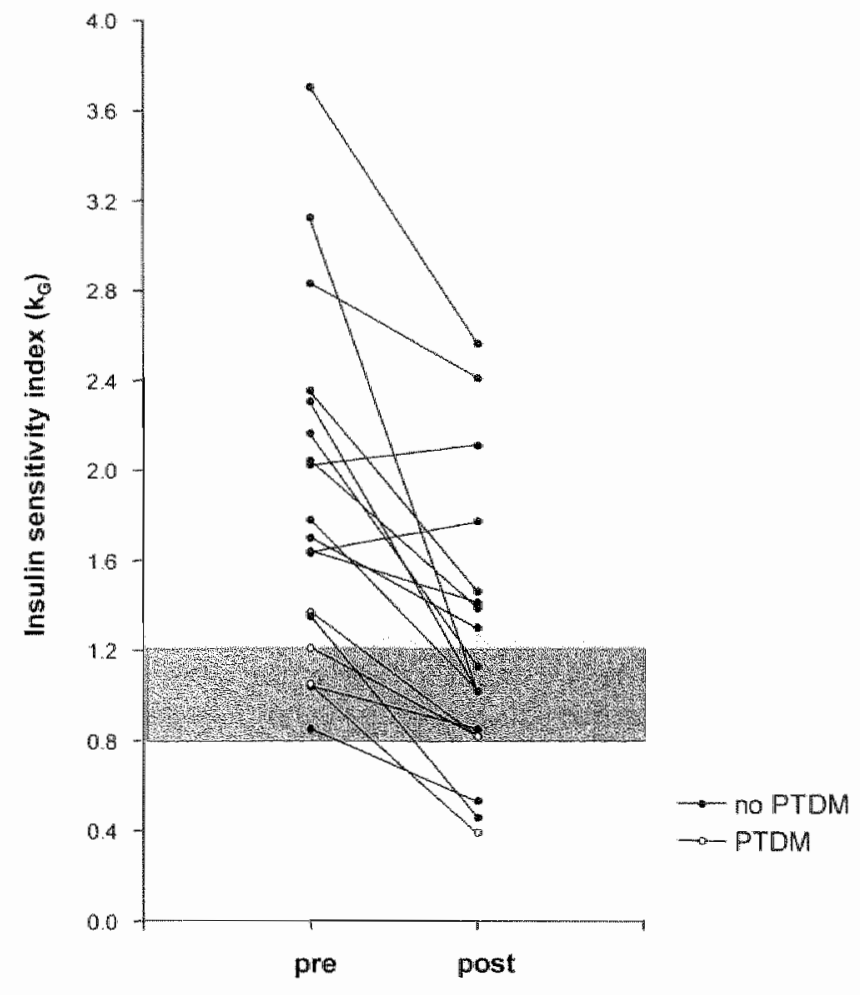

Figure 2.1 Pretransplant insulim sensitivity index: before (pre) and during (post) tacrolimus.

Patients who developed diabetes mellitus after transplantation (PTDM) are indicated with the open symbol. The light grey shade indicates an indeterminate value of $k_{0}$, a higher value indicates a normal $k_{0}$, and a lower value indicates an abnormal $k$ a.

Five days after the start of tacrolimus, at a median trough level of $17.1 \mathrm{ng} / \mathrm{ml}$ (range 7.6 to $38.0 \mathrm{ng} / \mathrm{ml}$ ), there was a small but statistically significant increase in median fasting glucose level, from $5.1 \mathrm{mmol} / 1$ to $5.2 \mathrm{mmol} / \mathrm{l}(\mathrm{P}=0.013$; Table 2.1 ). The fasting glucose level decreased in 2 patients ( 7 to $12 \%)$, did not change in 5 patients $( \pm 5 \%)$, and increased in 11 patients $\left(7\right.$ to $23 \%$ ). The median $\mathrm{k}_{\mathrm{G}}$ decreased $39 \%$, from $1.74 \%$ per min to $1.08 \%$ per $\min (\mathrm{P}<0.0001$; Table 2.1$)$. In 16 of our 18 patients, $\mathrm{k}_{\mathrm{G}}$ decreased during tacrolimus administration (Figure 2.1), whereas in 2 patients, there was a small increase in $\mathrm{k}_{\mathrm{G}}$ of less than $10 \%$ (from $\mathrm{J} .63$ to $1.77 \%$ per min and from 2.02 to $2.11 \%$ per min). Tacrolimus trough level correlated negatively $(\mathrm{r}=-0.478, \mathrm{P}=0.045)$ with $\mathrm{k}_{\mathrm{G}}$ during tacrolimus administration (Figure 2.2). There was no correlation between tacrolimus trough level and the relative reduction in $k_{G}$. 


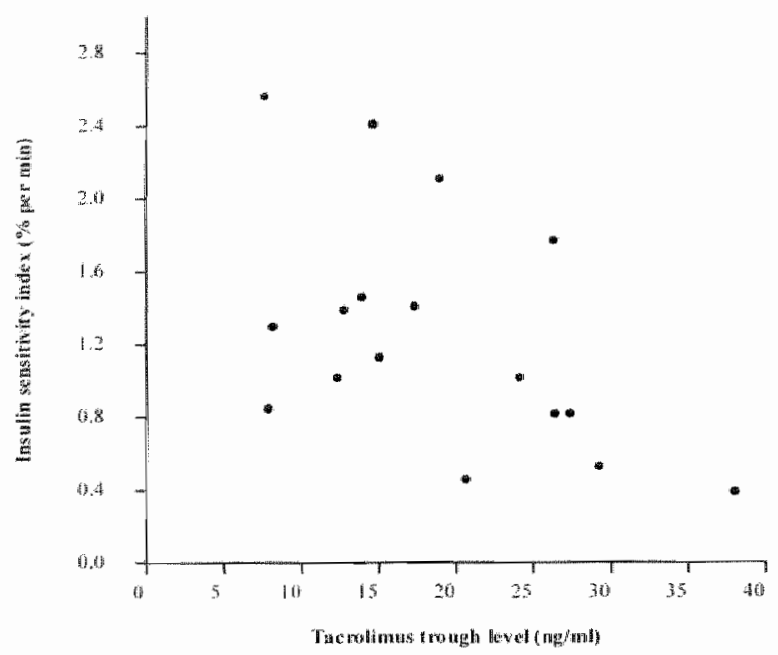

Figure 2.2 Relationship between insulin sensitivity index $\left(\mathrm{k}_{\mathrm{G}}\right)$ and tacrolimus trough level before transplantation.

Linear regression analysis showed a significant negative correlation $(r=-0.478, P=0.045)$.

Insulin secretion and insulin resistance

Insulin and $\mathrm{C}$-peptide values correlated significantly ( $\mathrm{r}=0.673, \mathrm{P}=0.002)$, and results for $\mathrm{C}$-peptide and insulin showed exactly the same trends. Therefore, only insulin data are shown. In Table 2.1, median values (and ranges) of insulin secretion are shown.

After the introduction of tacrolimus, basal insulin levels (at $t=0$ ) did not change significantly. Insulin resistance did not change when HOMA-R was used. There was a small but significant decrease in insulin resistance when the insulin/glucose ratio was used (Table 2.1); the ratio decreased in 11 patients, increased in 5 patients, and remained the same in 1 patient. In response to a glucose load, insulin secretion decreased significantly (median 20\%). Insulin secretion changed less than $5 \%$ in 4 patients and decreased 10 to $100 \%$ in 13 patients; in 1 patient, insulin values were not determined.

\section{Correlations between parameters of glucose metabolism}

In Table 2.2, correlations between the different parameters of glucose metabolism are shown. Before and during tacrolimus administration, fasting glucose and fasting insulin correlated significantly ( $\mathrm{P}=0.007$ and $\mathrm{P}=0.044$, respectively). Fasting glucose and insulin secretion did not correlate significantly. The $\mathrm{k}_{\mathrm{G}}$ and insulin secretion and their relative changes were highly correlated $(\mathrm{P}<0.001$ to 
$\mathrm{P}=0.01$ ) at all times. Insulin resistance (HOMA-R and insulin/glucose ratio) did not correlate with either $\mathrm{k}_{\mathrm{G}}$ or insulin secretion at any time (data not shown).

Table 2.2: Correlations between different glucose metabolism measurements".

\begin{tabular}{lcccc}
\hline Measurement & \multicolumn{1}{c}{ Insulin at $=0$} & \multicolumn{2}{c}{ Insulin secretion } \\
\hline Glucose & $\mathrm{r}$ & $\mathrm{P}$ & $\mathrm{r}$ & $\mathrm{P}$ \\
pre & 0.627 & 0.007 & 0.103 & $\mathrm{n} . \mathrm{s.}$ \\
post & 0.494 & 0.044 & -0.444 & n.s. \\
delta & 0.139 & n.s & -0.374 & n.s. \\
$k_{\mathrm{G}}$ & & & & \\
pre & 0.065 & n.s. & 0.603 & 0.010 \\
posi & -0.017 & n.s. & 0.793 & 0.001 \\
delta & 0.096 & n.s. & 0.627 & 0.007 \\
\hline
\end{tabular}

Correlations between glucose and insulin sensitivity index $\left(k_{0, j}\right)$ with corresponding insulin values $($ pre $=$ pre, post $=$ post, delta $=$ delta $)$.

\#: 17 patients, see text, $r$ : Spearman's rho, $P:$ n.s. = not statistically significant, delta $=$ relative change in (before and during tacrolimus compared), pre = before tacrolimus, post = after/during tacrolimus, $t=0=$ unstimulated, before i.v. glucose.

\section{Posttransplantation}

Seventeen out of the 18 patients underwent transplantation. Fourteen patients were followed up for a median of 34 months (range 21 to 48 months). Immediately after transplantation, all patients had hyperglycemia up to 1 day while receiving high doses of steroids (median glucose $13.8 \mathrm{mmol} / \mathrm{l}$; range 9.7 to $30.2 \mathrm{mmol} / \mathrm{l}$ ). Fourteen patients were normoglycenic thereafter. In three patients, hyperglycemia persisted (Table 2.3). Two of these patients used azathioprine and the other patient mycophenolate mofetil in addition to tacrolimus and steroids for approximately 6 months. One patient was treated with steroid pulse therapy on day 8 after transplantation because of tubulointerstitial rejection. Today, all three of them are receiving tacrolimus monotherapy with trough levels of $5.0,7.2$, and $7.3 \mathrm{ng} / \mathrm{ml}$, respectively. Two of these patients are being treated with a sulfonureum derivate and low-dose, long-acting insulin at bedtime. Their $\mathrm{HbAlc}$ is $6.8 \%$ and $7.7 \%$. Before transplantation, their $\mathrm{k}_{\mathrm{i}}$ was $1.21 \%$ per min and $1.05 \%$ per min before tacrolimus, and $0.82 \%$ per min and $0.39 \%$ per min during their use of tacrolimus (Figure 2.1). The third patient's nonfasting glucose levels are mainly below 8 $\mathrm{mmol} / \mathrm{l}$, with peaks up to $11.6 \mathrm{mmol} / \mathrm{l}$ and $\mathrm{HbAlc}$ of $6.5 \%$. He is being treated only with diet and uses no medication for his hyperglycemia. Before transplantation, his $\mathrm{k}_{\mathrm{g}}$ was $1.37 \%$ per min before and $0.82 \%$ per min during tacrolimus administration (Figure 2.1). All of the other patients have been normoglycemic without oral medication or insulin since transplantation. 
Table 2.3 Characteristics of the three patients with typerglycemia postransplantation during use of tacrolimus.

\begin{tabular}{|c|c|c|c|}
\hline Patient & $1^{H}$ & 2 & 3 \\
\hline $\begin{array}{l}\text { Basic characteristics } \\
\text { Age (years) } \\
\text { Gender" } \\
\text { BMI }^{+*}\left(\mathrm{~kg}_{\mathrm{g}} \mathrm{m}^{3}\right)\end{array}$ & $\begin{array}{l}58 \\
\mathrm{~m} \\
29.7\end{array}$ & $\begin{array}{l}54 \\
m \\
33.1\end{array}$ & $\begin{array}{l}49 \\
\mathrm{~m} \\
27.8\end{array}$ \\
\hline 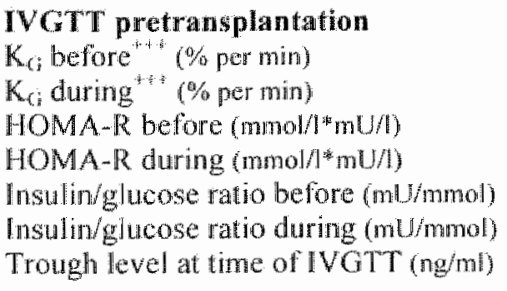 & $\begin{array}{l}1.21 \\
0.82 \\
- \\
- \\
- \\
26.4\end{array}$ & $\begin{array}{l}1.05 \\
0.39 \\
7.60 \\
6.25 \\
4.17 \\
2.25 \\
38.0\end{array}$ & $\begin{array}{l}1.37 \\
0.82 \\
4.16 \\
4.51 \\
3.09 \\
2.50 \\
16.8\end{array}$ \\
\hline $\begin{array}{l}\text { Posttransplantation } \\
\text { Additional intial immunosuppression } \\
\text { Azathioprine } \\
\text { Mycophenolate mofetil } \\
\text { Rejection therapy } \\
\text { Long-term trough level (ng/m) } \\
\text { Oral antidiabetics } \\
\text { Insulin therapy } \\
\text { Steroids } \\
\text { HbAlc(\%) }\end{array}$ & $\begin{array}{l}+ \\
- \\
+ \\
5.0 \\
+ \\
+ \\
- \\
6.8\end{array}$ & $\begin{array}{l}+ \\
- \\
- \\
7.3 \\
+7 \\
+ \\
-7.7\end{array}$ & $\begin{array}{l}- \\
+ \\
- \\
7.2 \\
- \\
- \\
- \\
6.5\end{array}$ \\
\hline
\end{tabular}

$\mathrm{m}=$ male, $\mathrm{f}=$ female; ${ }^{\text {tr }}$ body mass index; before and during tacrolimus" insulin not determined, see text.

\section{Discussion}

In this first prospective study to evaluate glucose metabolism by IVGTT before transplantation in nondiabetic dialysis patients before and after tacrolimus administration, we investigated the mechanism that is responsible for PTDM. Furthermore, during follow-up of these patients after transplantation, we investigated factors that may be associated with the development of PTDM.

Before tacrolimus, all patients were normoglycemic, but 3 out of $18(17 \%)$ had an indeterminate $\mathrm{k}_{\mathrm{f}}$. It is widely known that end-stage renal disease and dialysis are associated with impaired glycemic control caused, in part, by increased insulin resistance and, in part, by impaired insulin secretion ${ }^{24}$.

Several investigations have shown that the incidence of PTDM depends on the population studied, e.g., age, BMI, genetic factors ${ }^{\mid-11}$. In our Caucasian patients, no significant correlation between $\mathrm{k}_{\mathrm{G}}$ and age or gender was detected, and only a trend toward a negative correlation between $\mathrm{k}_{\mathrm{G}}$ and $\mathrm{BMI}$ was found.

Insulin is excreted by both the kidney and the liver. Notwithstanding the renal impaiment, the median fasting insulin level $(13.0 \mathrm{mU} / \mathrm{l})$ was within the normal 
reference values from our laboratory ( 1 to $25 \mathrm{mU} / \mathrm{l}$ ). Only one patient had a fasting insulin level above $25 \mathrm{mU} / \mathrm{(}(26.7 \mathrm{mU} / \mathrm{)})$ and, therefore, a high insulin/glucose ratio before tacrolimus, indicating increased insulin resistance. Although an increased incidence of insulin resistance was reported in end-stage renal failure and dialysis by $\mathrm{Mak}^{24}$, only 1 of our 18 patients $(5.5 \%)$ had an increased basal insulin level before tacrolimus. A high BMI of $33.1 \mathrm{~kg} / \mathrm{m}^{2}$ most likely accounted for the increased resistance in this patient. Four other patients with a BMl above $25 \mathrm{~kg} / \mathrm{m}^{2}$ $\left(25.5\right.$ to $\left.29.6 \mathrm{~kg} / \mathrm{m}^{2}\right)$ had normal fasting insulin levels.

The results of median $C$-peptide levels were above the nomal reference values from our laboratory. This is because $\mathrm{C}$-peptide is almost completely cleared by the kidney. Because $C$-peptide data correlated well with insulin data and results showed exactly the same trends, only insulin data are shown.

During tacrolimus administration, glucose metabolism was significantly altered in most patients. The $\mathrm{k}_{\mathrm{G}}$, in particular, was markedly reduced $(-39 \%)$. A reverse linear correlation between $\mathrm{k}_{\mathrm{G}}$ and tacrolimus trough level was found. An abnormal $k_{G}$ during the use of tacrolimus was not seen in patients who had tacrolimus trough levels below $15 \mathrm{ng} / \mathrm{ml}$ and a normal $\mathrm{k}_{\mathrm{o}}$ before the use of tacrolimus. These findings are in accordance with several clinical reports in which an impaired glucose metabolism was observed, especially when tacrolimus trough levels are high, whereas after a reduction in the tacrolimus dose, the disorder disappeared in most patients $13,25-28$.

A decrease in the $k_{G}$ indicates an impaired removal of a glucose load from the plasma. This can be caused either by reduced insulin secretion or by increased insulin resistance. We assessed secretion by calculating the increment from the values of the IVGTT and insulin resistance by calculating the insulin/glucose ratio and HOMA-R. Insulin secretion decreased significantly (-20\%). Insulin resistance did not change when HOMA-R was used. Because HOMA-R has not been validated explicitly for patients with renal insufficiency, the insulin/glucose ratio was also used as a parameter for insulin resistance. Thus, if anything, a signilicant small reduction in insulin resistance was found. These data prove that the decrease in the $k_{G}$ in our population was caused by a decrease in insulin secretion and not by an increase in insulin resistance. These findings are a confirmation and extension of data from animal studies ${ }^{14}$ and from a cross-sectional study in liver transplant recipients by Fernandezet al." ${ }^{17}$ Moreover, we were able to refute suggestions of an increase in insulin resistance in humans during tacrolimus administration ${ }^{1,13}$. In all other clinical reports, patients were using steroids, and it is widely known that the use of steroids can cause an increase in insulin resistance".

On days 0 and 1 after transplantation, hyperglycemia was observed in all patients. This illustrates the possible bias that can occur when the influence of tacrolimus on 
glucose metabolism is evaluated during the concomitant use of steroids, especially at high doses.

Three patients (17\%) developed PTDM. This incidence is within the range of 8 to $36 \%$ reported in the literature ${ }^{-11}$. Their trough levels were in accordance with target levels and did not differ from levels of patients without PTDM. In addition to tacrolimus and steroids, two of these patients were treated with azathioprine and one was treated with mycophenolate mofetill. One patient was treated with steroid pulse therapy because of rejection at day 8 after transplantation. In these patients, hyperglycemia was noticed immediately after transplantation and, contrary to those without PTDM, it did not disappear after dlay 1. Because azathioprine or mycophenolate mofetil was added at day 3 and the steroid pulse therapy in the patient with rejection was administered at day 8 , it is unlikely that the additional immunosuppression and rejection therapy played an important role in the development of PTDM.

Two of the three patients who developed PTDM already had an indeterminate $k_{0}$ before the start of tacrolimus, whereas the third patient who developed PTDM had a tow normal $\mathrm{k}_{\mathrm{G}}$ before starting tacrolimus $(1.21 \%$ per min). In contrast, none of the patients with an initial $k_{0}$ above $1.21 \%$ per min developed PTDM. Thus, it seens that by performing an IVGTT before transplantation, you can define a group of patients who are at risk of developing PTDM during tacrolimus use. Of course, other risk factors for PTDM may contribute to the actual development of PTDM, such as age and race ${ }^{1-11}$, the use of steroids, and high tacrolimus trough levels ${ }^{23,25.28}$. It is worth noting that all three patients who developed PTDM had a $\mathrm{BMI}$ above $25 \mathrm{~kg} / \mathrm{m}^{2}$. One patient with an indeterminate $\mathrm{k}_{\mathrm{G}}(0.85 \%$ per min) and a normal BMI $\left(23.2 \mathrm{~kg} / \mathrm{m}^{2}\right)$ did not develop diabetes after transplantation. Three patients with a nomal $\mathrm{k}_{\mathrm{i}}$ and a BMI above $25 \mathrm{~kg} / \mathrm{m}^{2}\left(25.5,27.7\right.$, and $\left.29.6 \mathrm{~kg} / \mathrm{m}^{2}\right)$ also did not develop PTDM. Thus, in addition to a low $\mathrm{k}_{\mathrm{G}}$, BMI could be an important factor determining the actual development of PTDM.

In summary, this prospective study of 18 Caucasian dialysis patients shows that before transplantation, the $\mathrm{k}_{\mathrm{i}}$ decreases significantly after the introduction of tacrolimus in almost all patients. This decrease is caused by a reduction in insulin secretion, whereas insulin resistance does not increase. A high tacrolimus trough level correlates with a low $\mathrm{k}_{\mathrm{G}}$.

Afler transplantation, 14 patients could be followed up long-term. Three patients developed PTDM, two with an indeterminate and one with a low normal $k_{G}$ before tacrolimus; none of the patients with a normal $k_{6}$ developed PTDM. This indicates that the $\mathrm{k}_{\mathrm{g}}$, calculated from data before the use of tacrolimus, can define a population at risk for PTDM during the use of tacrolimus. 


\section{References}

1. Weir MR, Fink JC. Risk for postmansplant diabetes mellirus with current immunosuppressive medications. Am J Kidney Dis 1999; 34:1-13.

2. Krentz AJ, Dimitrewski J, Mayer D, Nattrass M. Effects of immunosuppressive agents on glucose metabolism. Clin Immunother 1995; 4: 103-123.

3. Jindal RM, Sidner RA, Milgrom ML. Post-ransplant diabetes mellitus. The role of immunosuppression. Drug Saf 1997; 16:242-25\%.

4. Pirsch JD, Miller J, Deierhoi MH, Vincenti F, Filo RS. A comparison of tacrolimus and cyclosporine for immunosuppression after cadaveric renal transplantation. FK 506 Kidney Transplant Study Group. Transplantation 1997; 63: 977-983.

5. Neylan JF for the FK506 Kidney transplant Study Group. Racial differences in renal transplantation after immunosuppression with tacrolimus vs cyclosporine. Transplantation 1998; 65:515-523.

6. Mayer AD, Dmitrewski J, Squifflet JP, et al. Multicenter randomized trial comparing tacrolimus (FK506) and cyclosporine in the prevention of renal allograft rejection: a report of the European Tacrolimus Multicenter Renal Study Group. Transplantation 1997; 64: $436-443$.

7. Vincenti F, Laskow DA, Neylan JF, Mendez R, Matas AJ. One-year follow-up of an open-label trial of FK506 for primary kidney transplantation: a report of the US Multicenter FK506 Kidney Transplant Group. Transplantation 1996; 61: 1576-1581.

8. Scantlebury V, Shapiro R, Fung J, Tzakis A, McCauley J, Jordan M, Jensen C, Hakal T, Simmons R, Starzl TE. New onset of diabetes in FK 506 vs cyclosporine-treated kidney transplant recipients. Transpl Proc 1991; 23: 3169-3170.

9. Henry ML. Cyclosporine and tacrolimus (FK506): A comparison of efficacy and safety profiles. Clin Transplant 1999; 13: 209-220.

10. Knoll GA, Bell RC. Tacrolimus versus cyclosporin for immunosuppression in renal transplantation: meta-analysis of rancomised trials. Br Med J 1999; 318; 1104-1107.

11. Jain AB, Kashyap R, Rakela J, Starzl TE, Fung JJ. Primary adult liver transplantation wnder tacrolimus: more than 90 months actual follow-up, survival and adverse events. Liver Transpl Surg 1999; 5: 1144-1 150.

12. Milles AMV, Sumrani N, Horwitz R. Homel P, Maursky V, Markell MS, Distant DA. Hong $\mathrm{JH}$, Sommer BG, Friedman EA. Diabetes mellitus after renal transplantation as deleterious as non-transplant-associated diabetes? Transplantation 1998; 65:380-384.

13. Golling $M$, Lehmann $T$, Senninger $N$, Herfarth $C$, Otto $G$. Tacrolimus reduction improves glucose metabolism and insulin secretion after liver transplantation. Transpl Proc 1996;28: 3180-3182.

14. Tamma K, Fujimura T, Tsutsumi T, Nakamura K, Ogawa T, Atumaru C, Hirano $Y$, Ohata K, Ohtsuka K, Shimomura K, Kobayashi M. Transcriptional inhibition of insulin by FK 506 and possible involvement of FK 506 binding protein- 12 in pancreatic beta-cell. Transplantation 1995; 59: 1606-1613.

15. Ricordi $C$, Zeng $Y$, Alezandro $R$, Tzakis A, Venkataramanan $R$, Fung $J$, Bereiter $D$, Mintz D, Stard T. In vivo effect of FK506 on human pancreatic islets. Transplantation $1991 ; 52: 519-522$.

16. Rilo H, Zeng Y, Alejandro R, Carroll PB, Bereiter D, Venkataramanan R, Tzakis A, Starzl T, Ricordi C. Effect of FKS06 on function of human islets of Langerhans. Transplant Proc 1991; 23: 3164-3165. 
17. Fernandez L, Lehmann R, Luzi L, Battezzati A, Angelico M, Ricordi C, Tzakis A, Alejandro $\mathrm{R}$. The effects of maintenance doses of $\mathrm{FK} 506$ versus $\mathrm{Cyclosporin} A$ on glucose and lipid metabolism after orthotopic iner transplantation. Transplantation $1999 ; 68: 1532-1541$.

18. Hooff van JP, van Duijhhoven EM, Christiaans MHL. Tacrolimus and glucose metabolism. Transpl. Proc 1999; 7A: 49S-50S.

19. Elmer DS, Hathaway DK, Gaber AO. Monitoring of pancreas allograft function with glucose disappearance rate (Kg): calculation and interpretation. I Transpl Coord 1994; 4: $7-11$.

20. Bergman RM, Finegood DT, Ader M. Assessment of insulin sensitivity in wivo. Endocr Rev 1985; 6: 45-86.

21. Matthews DR, Hosker JP, Rudenski. AS, Naylor BA, Treacher DF, Turner RC. Homeostasis model assessiment: insulin resistance and beta-cell function from fasting plasma glucose and insulin concentrations in man. Diabetologia 1985;28: 412-419.

22. Avignon A, Boegner C, Mariano-Goulart D, Colette C, Monnier L. Assessment of insulin sensitivity from plasma insulin and glucose in the fasting or post oral glucoseload state. Int J Obes Relat Metab Disord 1999; 23: 512-517.

23. Yoshinaga $H$, Kosaka $K$. Heterogeneous relationship of early insulin response and fasting insulin level with development of non-insulin-dependent diabetes mellitus in non-diabetic Japanese subjects with or without obesity. Diabetes Res Clin Pract 1999; 44: 129-136.

24. Mak RHK. Impact of end-stage renal disease and dialysis on glycemic control. Senin Dial 2000; 13:4-8.

25. Uchida $K$, Tominaga $Y$, Haba $T$, Katayama A, Ichimori $T$, Yamada $K$, Hibi $Y$, Uemura $\mathrm{O}$, Morozumi $\mathrm{K}$, Takagi $\mathrm{H}$. Decreasing pancreatic toxicity of tacrolimus by dosage reduction. Transpl Proc 1998; 30: 1276-1278.

26. Shapiro R, Scantlebury VP, Jordan ML, Vivas C, Gritsch HA, McCauley J, Fung JJ, Hakala TR, Simmons RL, Starzl TE. Reversibility of tacrolimus induced posttransplant diabetes: an illustrative case and review of the literature. Transplant Proc 1997; 29: 2737 2738 .

27. Lagget M, Marzano A, Actis GC, Leone N, Ciancio A, Salizzoni M, Rizzetto M. Disappearance of diabetes mellitus after conversion from FK 506 to Neoral in two diver transplanted patients. Transplant Proc 1998; 30: 1863-1864.

28. Filler G, Neuschulz I, Vollmer I, Amendt P, Hocher B. Tacrolimus reversibly reduces insulin secretion in pediatric renal transplant recipients. Nephrol Dial Transplant 2000; $15: 867-871$. 


\section{Chapter 3}

\section{Glucose metabolism in renal transplant recipients on tacrolimus: the effect of steroid withdrawal and tacrolimus trough level reduction}

JMM Boots, EM van Duijnhoven, MHL Christians, BHR Wolfenbuttel, JP van Hooff

JAm Soc Nephrol 2002; 13:221-227 


\section{Abstract}

The relative role of steroids and tacrolimus in the development of glucose metabolic disorders and hyperlipidemia after renal transplantation has not yet been clearly established. Therefore, glucose metabolism was prospectively evaluated by intravenous glucose tolerance test, as was lipid profile, in fifteen white nondiabetic renal transplant recipients three times: before and after steroid withdrawal, and after tacrolimus trough level reduction. After withdrawal of $10 \mathrm{mg}$ of prednisolone, insulin resistance decreased (fasting $\mathrm{C}$-peptide, 0.99 to $0.77 \mathrm{nmol} / 1(\mathrm{P}=0.0009)$; fasting insulin, 9.5 to $8.1 \mathrm{mU} / \mathrm{l}(\mathrm{P}=0.09)$; insulin $/ \mathrm{glucose}$ ratio, 1.85 to $1.45 \mathrm{mU} / \mathrm{mmol}(\mathrm{P}=0.10)$ and lipid levels decreased (total cholesterol, 5.1 to $4.2 \mathrm{mmol} / \mathrm{l}(\mathrm{P}=0.006)$; HDL cholesterol, 1.4 to $1.1 \mathrm{mmol} / \mathrm{l}(\mathrm{P}=0.01)$; LDL cholesterol, 3.0 to $2.5 \mathrm{mmol} / \mathrm{l}(\mathrm{P}=0.15)$; triglycerides, 1.52 to $0.91 \mathrm{mmol} / \mathrm{l}(\mathrm{P}=0.02)$. After tacrolimus trough level reduction from 9.5 to $6.4 \mathrm{ng} / \mathrm{ml}$, pancreatic $\beta$-cell secretion capacity improved (C-peptide secretion increased from 49.0 to $66.6 \mathrm{nmol}^{*} \mathrm{~min} / \mathrm{l}(\mathrm{P}=0.04)$ and insulin secretion increased from 1134 to $\left.1403 \mathrm{mU}^{*} \mathrm{~min} / \mathrm{I}(\mathrm{P}=0.06)\right)$. HbAl $\mathrm{c}$ improved also, from 5.9 to $5.3 \%$ $(\mathrm{P}=0.002)$. Lipids did not change. In conclusion, steroid withdrawal resulted in a decrease in insulin resistance and a reduction in lipids, and tacrolimus trough level reduction resulted in an improved pancreatic B-cell secretion capacity. Therefore, these therapeutic measurements may contribute to the reduction of the cardiovascular morbidity and mortality in renal transplant recipients. 


\section{Introduction}

Both posttransplant diabetes mellitus (PTDM) and hyperlipidemia contribute to cardiovascular mortality and graft failure after transplantation ${ }^{\text {i.4 }}$.

PTDM occurs in up to $36 \%$ of transplant patients ${ }^{4-9}$. PTDM develops because of impairment of insulin secretion and/or increase of insulin resistance. Patients with an impaired $\beta$-cell function before transplantation are mainly at risk for developing PTDM during use of calcineurin inhibitors ${ }^{10-11}$. In dialysis patients, we were able to demonstrate that tacrolimus caused impaired insulin secretion, but had no influence on insulin resistance. However, insulin resistance has been suggested as an additional mechanism responsible for the development of PTDM during maintenance therapy with tacrolimus in renal transplant recipients. The coadministration of steroids might well have been the cause of this increased insulin resistance ${ }^{10,12}$,

Hyperlipidemia occurs in many patients after solid organ transplantation ${ }^{13}$. The type of calcineurin inhibitor plays a role in the hyperlipidemia: lipid profiles in renal transplant recipients treated with tacrolimus were better than those in patients treated with cyclosporine ${ }^{1+15}$.

Aside from causing other side effects ${ }^{16}$, steroids play a role in the development of both PTDM and posttransplant hyperlipidemia ${ }^{17-18}$. Several investigators have shown that steroid withdrawal is safe in a large proportion of transplant recipients ${ }^{15,19}$. Since then, improvement in lipid profile after steroid withdrawal on both cyclosporine and tacrolimus-based immunosuppression has been described in liver transplant recipients ${ }^{20}$. In renal transplant recipients, lipid profile improvement after steroid withdrawal has been reported only in patients on cycllosporine ${ }^{21-22}$, but not in patients on tacrolimus. In renal transplant recipients on tacrolimus, it is unknown what the effects are of steroid withdrawal on glucose metabolism. Not only the use of steroids, but also tacrolimus exposure are important factors that influence glucose metabolism, because it is a well known observation that PTDM disappears in a high proportion of the patients after tacrolimus dose reduction ${ }^{23}$. The relative role of steroids and tacrolimus levels in the development of glucose metabolic disorders and hyperlipidemia is unknown. Therefore, we prospectively evaluated glucose metabolism and lipid profile in renal transplant recipients on tacrolimus-based immunosuppression three times: before and after steroid withdrawal, and subsequently, after tacrolimus trough level reduction. 


\section{Material and methods}

\section{Patients}

Renal transplant recipients on tacrolimus and prednisolone were eligible to participate in the study if they were $>16$ years of age and scheduled for steroid withdrawal between 3 and 12 months posttransplantation after obtaining a normal ACTH stimulation test. Additional use of mycophenolate mofetil (MMF) was allowed. Exclusion criteria were as follows: contraindications for steroid withdrawal (defined as severe acute rejection (grade 2 or more in the Banff classification) or steroid-resistant rejection), use of steroids for comorbidity, preexisting diabetes mellitus or development of PTDM prior to the first test (defined as a need for oral blood glucose-lowering medication or insulin), and underlying disease known to interfere with the hypothalamus-pituitary-adrenal axis or glucose metabolism. Written informed consent was obtained from all patients. The medical ethical committee of our hospital approved the protocol of steroid withdrawal. Fifteen white patients ( 13 men, 2 women) participated in the study. Their median age was 58 years (range 16 to 75 years) and their median body mass index (BMI) was $23.8 \mathrm{~kg} / \mathrm{m}^{2}\left(20.4\right.$ to $\left.27.5 \mathrm{~kg} / \mathrm{m}^{2}\right)$. There were 13 first transplantations and 2 retransplantations; 12 patients had a cadaveric donor, 2 a living unrelated donor, and 1 a living related donor.

\section{Immunosuppression}

All patients started tacrolimus $(0.1 \mathrm{mg} / \mathrm{kg}$ orally twice daily) within 12 hours before transplantation. Further dosage adjustments were made according to whole blood 12-hours trough levels (IMx, Abbott, Hoofddorp, The Netherlands). The target range was 15 to $20 \mathrm{ng} / \mathrm{ml}$ in weeks $I$ and 2 positransplantation, and 10 to 15 $\mathrm{ng} / \mathrm{ml}$ in weeks 3 and 4 . Thereafter, the dose was gradually tapered to target levels below $10 \mathrm{ng} / \mathrm{ml}$. Immediately after transplantation, 14 patients were also treated with MMF (1000 mg/day). At the time of the first and second intravenous glucose tolerance test (IVGTT), nine patients were still using MMF. At the time of the third tests, four patients were still using MMF. The prednisolone dose was $20 \mathrm{mg}$ in weeks 1 and 2 , and $15 \mathrm{mg}$ in weeks 3 and 4 after transplantation. Thereafter, the dose was $10 \mathrm{mg}$ until withdrawal. Withdrawal was started at a median of 185 days ( 81 to 358 days) after transplantation. The prednisolone dosage was reduced to $5 \mathrm{mg} /$ day for 1 week and $2.5 \mathrm{mg} /$ day for a second week; thereafter it was stopped. For each patient, we aimed for the same individual tacrolimus trough level before 
and after steroid withdrawal. After the second test, tacrolimus dosages were adjusted gradually to reach target trough levels of 5 to $7 \mathrm{ng} / \mathrm{ml}$.

\section{Glucose metabolism}

The tests were performed in the morning, after a 12-hour overnight last. Tacrolimus was ingested after completion of the tests. The other medication was ingested at the usual time of day. In case of a stressful event (e.g., surgery or infection), the test was postponed for at least 3 weeks.

Glucose $50 \%(0.5 \mathrm{~g} / \mathrm{kg}$ body weight) was administered intravenously for 2 to 3 minutes. Blood samples for measurement of whole blood glucose, C-peptide, and insulin were taken from the opposite arm at $t=-15,0,5,10,15,20,30,40,50$, and 60 minutes. Insulin sensitivity index (glucose disappearance rate $=k_{\mathrm{G}}$ ) was calculated by linear regression from the log-transformed glucose values of $\mathrm{t}=10$ to 30 minutes. $\mathrm{A}_{\mathrm{G}}$ value above $1.2 \%$ per min was considered normal ${ }^{24-25}$. C-peptide and insulin secretion (increment), i.e., the secretion response to a glucose load, were calculated as area under the curve using a linear trapezoidal technique from the serum value at each time point after subtraction of the $t=0$ value. Insulin resistance was calculated by using the fasting insulin/glucose ratio and the homeostasis model assessment (HOMA-R: fasting glucose ( $\mathrm{mmol} / \mathrm{l})$ multiplied by fasting insulin ( $\mathrm{mU} / \mathrm{l}$ ) divided by 22.5$)^{26-27}$. Mean blood pressure, renal function (Cockcroft-Gault formula), hemoglobin, and HbAlc were measured at the time of the IVGTTs. The use of drugs that might interfere with glucose metabolism (antihypertensive drugs (especially beta-blockers and diuretics), oral contraceptives, phenytoin, and pentamidine) and lipids were monitored.

During each visit to the outpatient clinic, urine was examined for glucosuria (by dipstick). When glucosuria was detected, whole blood glucose was examined. When no glucosuria was detected, whole blood glucose was evaluated at least every 3 months. PTDM was diagnosed when glucose values were abnormal $(>6.1$ $\mathrm{mmol} / \mathrm{l}$ in the fasting state or $>7.8 \mathrm{mmol} / \mathrm{l}$ in the nonfasting state), for two or more different samples and without any other explanation, such as additional high-dose steroids, infection, or operative stress.

For the measurement of glucose in whole blood, the CX7 (Beckman, Mijdrecht, The Netherlands) was used. For C-peptide and insulin, IRMA (Autodelfia, Wallac, Turku, Finland) was used. For HbAlc, HPLC (Variant 2, Biorad, Hercules, CA). Normal reference values from our laboratory were 3.1 to $6.1 \mathrm{mmol} / \mathrm{l}$ for fasting glucose, 1.0 to $25.0 \mathrm{mU} / 1$ for fasting insulin, 0.12 to $1.20 \mathrm{mmol} / 1$ for fasting C-peptide levels, and 4.4 to $6.2 \%$ for HbAlc. 


\section{Lipid profiles}

Fasting blood samples for lipid measurements were taken at the time of the IVGTTs. The LX (Beckman) was used to determine lipid levels: total cholesterol (Roche Diagnostics, Almere, The Netherlands), HDL cholesterol (Roche Diagnostics), LDL cholesterol (LDL precipitating reagent, Merck, Amsterdam, The Netherlands), and triglycerides (Synchron, Beckman). Normal reference values from our laboratory were 4.1 to $6.4 \mathrm{mmol} / \mathrm{l}$ for total cholesterol, 0.6 to 1.9 $\mathrm{mmol} / /$ for HDL cholesterol, 3.0 to $4.5 \mathrm{mmol} / \mathrm{l}$ for LDL cholesterol, and 0.80 to $1.94 \mathrm{mmol} / 1$ for triglycerides.

Throughout the study, no changes in lipid-lowering drugs were allowed.

\section{Statistics}

For statistical analysis, SPSS version 10.0 for Windows (SPSS Inc., Chicago, IL) was used. To compare glucose metabolism before and after steroid withdrawal, as well as before and after tacrolimus trough level reduction, the Wilcoxon matchedpairs signed rank sum test was performed. For correlations between the different parameters, the Spearman rho rank correlation coefficient was used. Statistical significance was defined as $\mathrm{P}<0.05$. Unless indicated otherwise, data are described as median (range).

\section{Results}

Table 3.1 shows median levels of BMI, mean blood pressure, renal function, hemoglobin levels, tacrolimus trough levells, parameters of glucose metabolism, and lipid proliles before and after steroid withdrawal, and after tacrolimus trough level reduction.

\section{Patients and immunosuppression}

All patients completed the study. No person was treated for rejection. BMI and mean blood pressure did not change significantly. Many patients were treated with antihypertensive drugs: beta-blockers $(n=11)$, diuretics $(n=2)$, calcium-antagonists $(n=9-12$, at various time points), angiotensin-converting enzyme-inhibitors $(n=3-5)$, and vasodilators $(n=3-4)$. There were no significant changes in the use of the various antihypertensive drugs. Nobody used other drugs that might have interfered with glucose metabolism. Hemoglobin decreased by $5 \%(\mathrm{P}=0.04)$ after steroid withdrawal, and did not change after tacrolimus trough level reduction. 


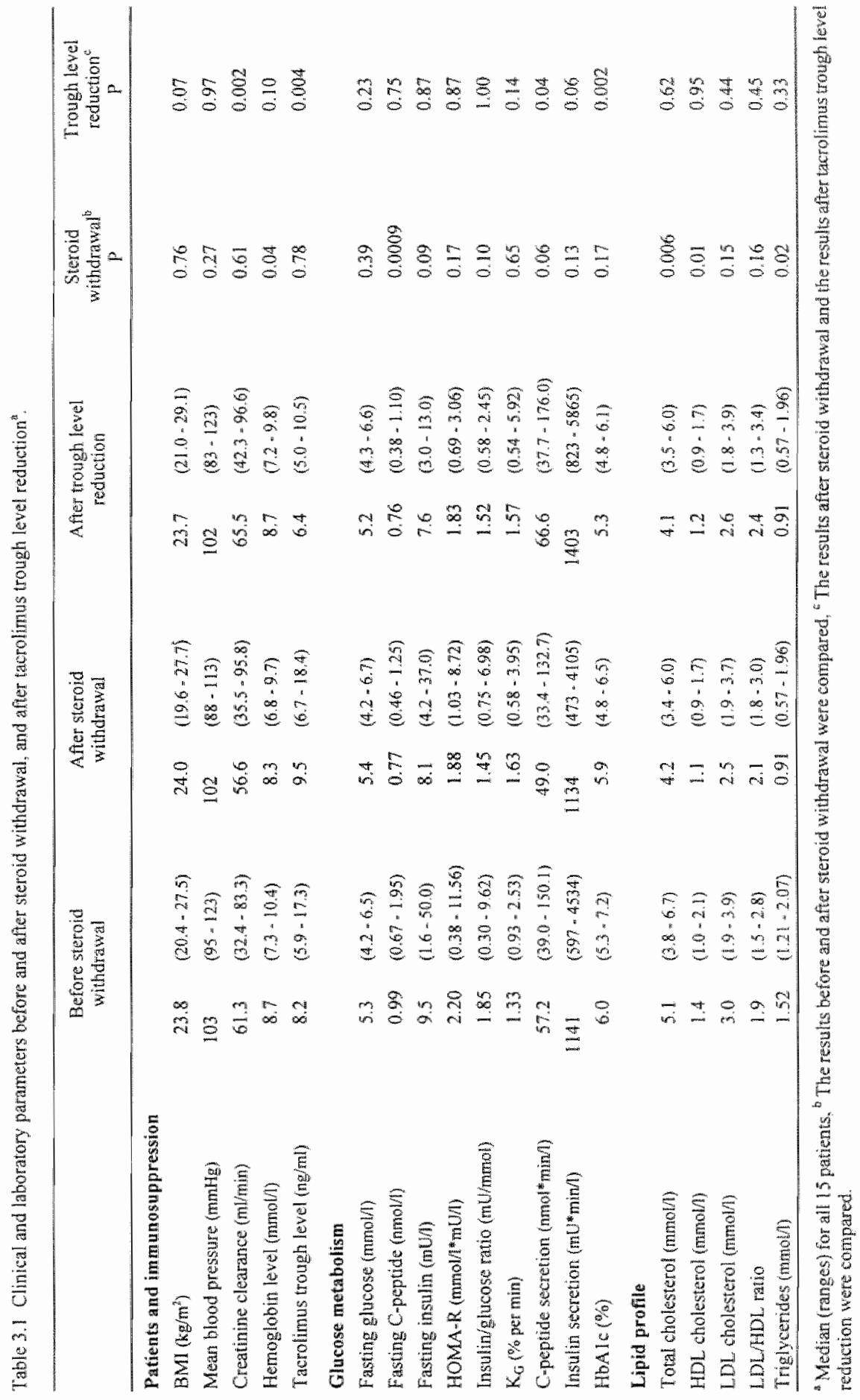


Creatinine clearance did not change significantly after steroid withdrawal, but increased by $16 \%(\mathrm{P}=0.002)$ after tacrolimus trough level reduction. After steroid withdrawal, tacrolimus dose was reduced in 11 patients and remained unchanged in the other four patients. Despite the dose reduction, there was a (statistically) nonsignificant rise in tacrolimus trough level (Figure 3.1). Between the second and third tests, trough level decreased by $33 \%(\mathrm{P}=0.004)$, as intended (Figure 3.1$)$.

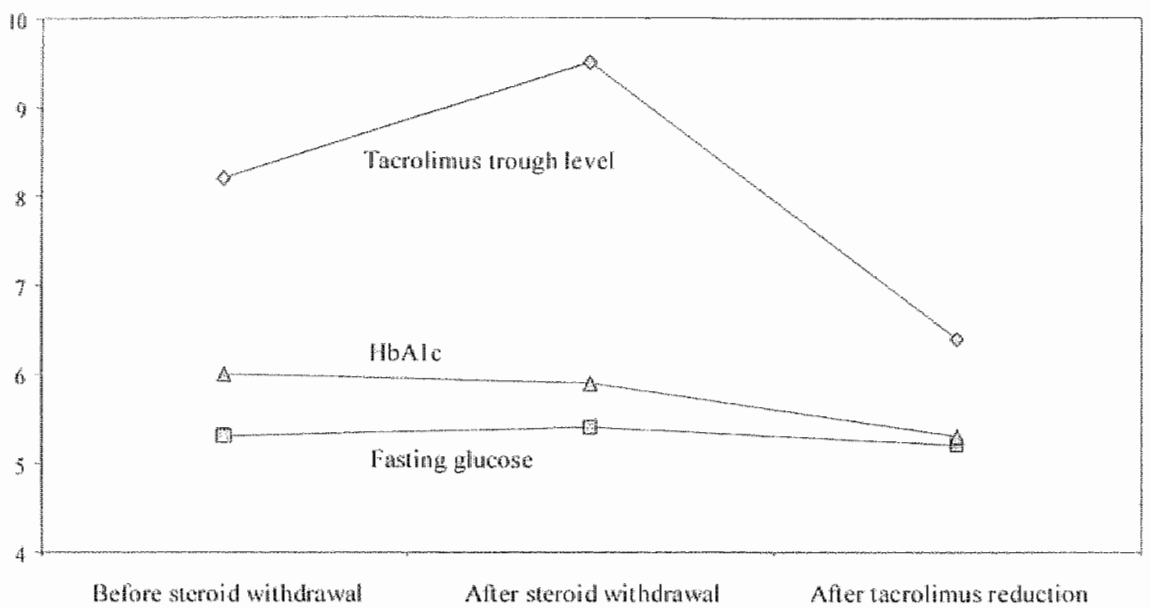

Figure 3.1 Median tacrolimus trough lewel, fasting glucose, and $\mathrm{HbA} \| \mathrm{c}$ lewels before and after steroid withdrawal, and after tacrolimus trough level reduction. Tacrolimus trough level (ng/ml), HbAlc (\%), fasting glucose (mmol/1).

\section{Glucose metabolism}

Glucose metabolism was assessed by IVGTT at a median of 20 days (range 13 to 35 days) before steroid withdrawal, 68 days ( 39 to 96 days) after complete cessation of steroids, and 307 days ( 163 to 345 days) thereafter (after tacrolimus trough level reduction). None of the patients developed hyperglycemia.

Figure $3.1,3.2$, and 3.3 show the median levels of the various parameters of glucose metabolism before and after steroid withdrawal, and after tacrolimus trough level reduction. Figure 3.1 shows fasting glucose and HbAlc, Figure 3.2 shows fasting parameters associated with insulin resistance, and Figure 3.3 shows $\mathrm{k}_{\mathrm{i}_{\mathrm{i}}}$ and stimulated parameters associated with pancreatic $\beta$-cell secretion capacity. After steroid withdrawal, fasting C-peptide levels decreased significantly by $22 \%$ ( $P=0.0009)$, fasting insulin levels and insulin/glucose ratio decreased as well $(\mathrm{P}=0.09$ and 0.10 , respectively). $\mathrm{C}$-peptide secretion decreased by $14 \%(\mathrm{P}=0.06)$. There was no significant change in any other parameter of glucose metabolism after steroid withdrawal. 
After tacrolimus trough level reduction, C-peptide secretion increased significantly by $36 \%(\mathrm{P}=0.04)$. A similar increase was observed for insulin secretion $(\mathrm{P}=0.06)$. HbAlc decreased significantly by $10 \%(\mathrm{P}=0.002)$. Insulin resistance parameters did not change.

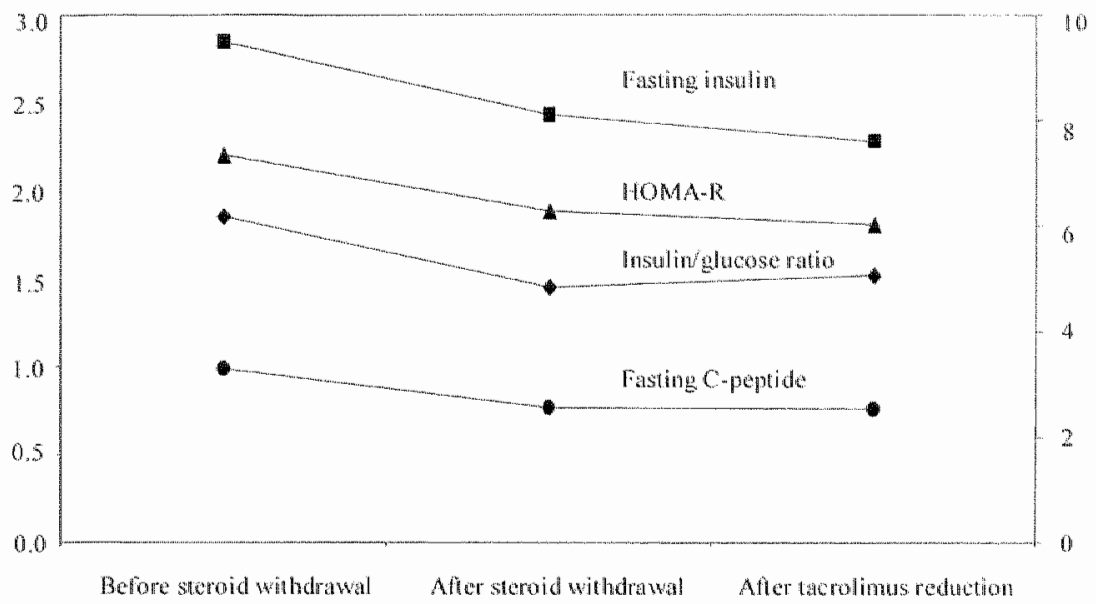

Figure 3.2 Median fasting parameters of glucose metabolism associated with insulin resistance before and after steroid withdrawal, and after tacrolimus trough level reduction.

Right $\mathrm{y}$-axis: fasting insulin (mU/l). Left $\mathrm{y}$-axis: fasting C-peptide (nmol/), HOMA-R (mmol/l* $\mathrm{mU} / \mathrm{l})$, and insulin glucose ratio ( $\mathrm{mU} / \mathrm{mmol})$.

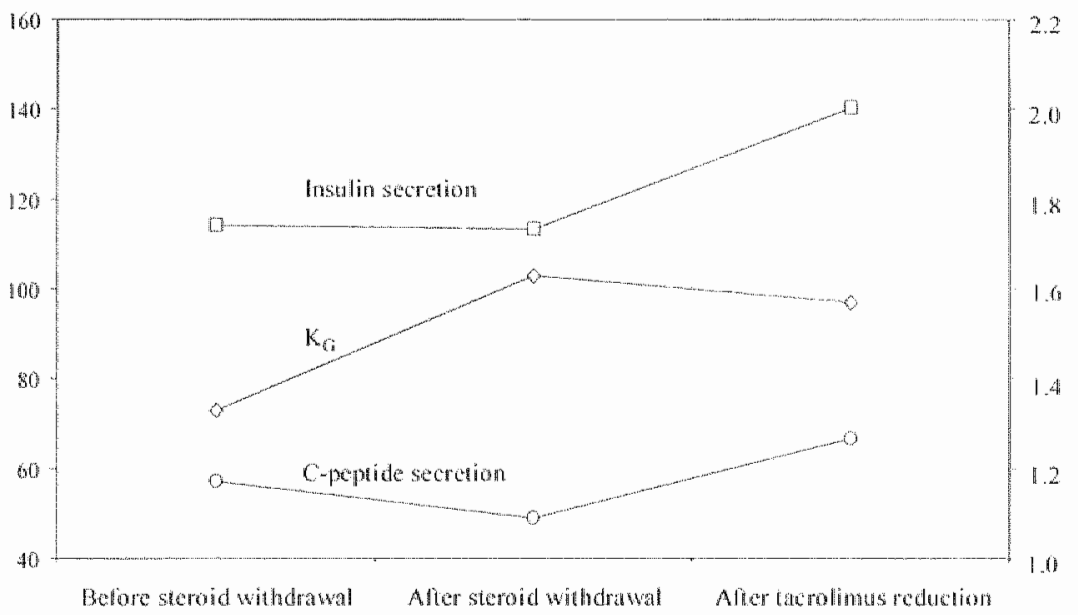

Figure 3.3 Median fasting $k_{0}$ and parameters of glucose metabolism associated with pancreatic $\beta$-cell secretion capacity before and after steroid withdrawal, and after tacrolimus trough level reduction.

Right $y$-axis: $\mathrm{K}_{G i}(\%$ per min). Left $y$-axis: C-peptide secretion (nmol" $\mathrm{min} / \mathrm{l}$ ) and insulin secretion $\left(\mathrm{mU}^{*} \mathrm{~min} / \mathrm{I}\right.$ divided by 10$)$. 


\section{Lipid profile}

Before and after steroid withdrawal, two patients were treated with $10 \mathrm{mg}$ simvastatin. After tacrolimus trough level reduction, the dosage of simvastatin in one of these patients was increased. Moreover, three additional patients were treated with lipid-lowering drugs. These four patients were therefore excluded from analysis.

After steroid withdrawal, there was a decrease in total cholesterol by $11 \%$ $(\mathrm{P}=0.006)$, HDL cholesterol by $21 \%(\mathrm{P}=0.01)$ and triglycerides by $25 \%(\mathrm{P}=0.02)$, a decrease of LDL cholesterol by $9 \%(\mathrm{P}=0.15)$, and an increase of LDL/HDL ratio by $12 \%(P=0.16)$.

After tacrolimus dose reduction, there were no significant changes in lipids.

Correlations between tacrolimus trough level and parameters of glucose metabolism

Tacrolimus trough level correlated significantly with $\mathrm{k}_{\mathrm{Q}}(\mathrm{r}=-0.362, \mathrm{P}=0.015)$, and with C-peptide secretion $(r=-0.311, P=0.037)$, but not with any of the other parameters of glucose metabolism

\section{Discussion}

In this prospective study in white renal transplant recipients the relative roles of steroids and tacrolimus on glucose metabolism and lipid profiles were evaluated. After steroid withdrawal, fasting C-peptide decreased significantly. C-peptide is almost completely cleared by the kidney ${ }^{28}$. Renal function did not change significantly. Therefore, improvement in renal function could not have been responsible for the decrease in C-peptide. From this observation, one can conclude that use of steroids causes an increase in insulin resistance in patients on tacrolimus, confirming the data in cyclosporine patients ${ }^{2}$.

After steroid withdrawal, $C$-peptide secretion also decreased $(P=0.06)$. It is very unlikely that this decrease is due to a direct effect of steroid withdrawal on $\beta$-cell production. In our opinion, this is due to an indirect effect of increased tacrolimus trough levels. We have observed that tacrolimus trough levels (with unchanged dose) increase after steroid withdrawal (submitted). This increase of trough levels does not occur in all patients, but in 40 to $60 \%$ of the patients. Due to the reduction in tacrolimus dose in $73 \%$ of the patients, the increase of tacrolimus trough level in this study was not statistically significant. But despite dose reductions, tacrolimus trough levels increased by more then $20 \%$ in 4 patients (range 43 to $65 \%$ ). In 3 of the latter patients, $C$-peptide secretion decreased by 25 to $46 \%$. 
In the second part of the study, tacrolimus trough level was reduced, resulting in a significant increase in stimulated $\mathrm{C}$-peptide secretion. Insulin resistance did not change. Thus, pancreatic $\beta$-cell secretion capacity increases when tacrolimus trough levels are lowered, confirming the reversibility of $\beta$-cell dysfunction caused by tacrolimus ${ }^{10,23,29}$. This occurs even within the normal range for maintenance therapy with tacrolimus: a $33 \%$ reduction in the tacrolimus trough level resulted in a $36 \%$ increase in median $\beta$-cell secretion capacity. The period between the IVGTT before and after trough level reduction was approximately 10 months because patients were generally seen only once every 2 to 3 months and a gradual decrease in tacrolimus trough levels to $5 \mathrm{ng} / \mathrm{ml}$ was desired. BMI, blood pressure and the use of antihypertensive drugs did not change in this period. We cannot completely rule out a spontaneous improvement of pancreatic $\beta$-cell secretion capacity in this period. However, given the correlation found between tacrolimus trough level and pancreatic $\beta$-cell function in both this study and our previous studies ${ }^{10,29}$ and observations of improved glucose metabolism after tacrolimus dose reduction ${ }^{29}$, it is more likely that the reduced tacrolimus trough levels explain at least part of the improvement.

Before and after steroid withdrawal, concomitant use of MMF was the same, but before and after tacrolimus trough level reduction, five patients discontinued MMF. Although there are no descriptions of alterations in glucose metabolism or lipid profile due to the use of MMF, we compared changes in parameters of glucose metabolism after steroid withdrawal and after trough level reduction separately for patients using MMF and those not using MMF. The changes in both groups were similar to changes for all patients.

After tacrolimus trough level reduction, $\mathrm{HbAl} \mathrm{c}$ decreased significantly. This is an important finding because an association between $\mathrm{HbAlc}$ levels and risk of cardiovascular morbidity and mortality has been described in nondiabetic patients ${ }^{30}$. In our study, hemoglobin levels did not change significantly after trough level reduction. Therefore, it seems unlikely that the decrease in HbAlc in our study can be explained by an increase in hemoglobin levels ${ }^{31}$. HbAlc levels in patients with renal insufficiency and patients after kidney transplantation correlate well with mean capillary blood glucose levels; therefore, the improvement in renal function in our patients does not seem to explain the decrease in $\mathrm{HbAl}$ c either ${ }^{32}$. Furthermore, fasting glucose levels did not change in our study; therefore, reduced postprandial glucose levels must have caused the decrease in HbAlc. In the DECODE study ${ }^{3,}$, abnormal blood glucose 2 hours after an oral glucose tolerance test was associated with an increased mortality risk by a factor 2.0 for men and 2.8 for women. An increased risk of cardiovascular disease has also been shown in studies comparing normal and increased postprandial blood glucose levels ${ }^{34}$. Consequently, tacrolimus trough level reduction, which results in lower post- 
prandial glucose and $\mathrm{HbA} / \mathrm{c}$ levels might reduce cardiovascular morbidity and mortality, not only in patients with PTDM but also in nondiabetic patients.

Due to a violation of protocol, lipid-lowering drugs were changed in four patients. However, between the first and second test, where relevant changes in lipids occurred, lipid-lowering drugs were unchanged. To exclude bias due to the exclusion of patients we also compared lipid profiles before and after steroid withdrawal for all 15 patients. The results of this analysis were the same. The changes in lipids after steroid withdrawal, i.e., a decrease in all lipids, are very similar to the changes described after steroid withdrawal in nondiabetic renal transplant recipients on cyclosporine-based immunosuppression ${ }^{22}$. The reductions in total cholesterol, LDL cholesterol, and triglycerides are obviously beneficial. The extent to which these beneficial changes are counterbalanced by the concomitant decrease in HDL is unclear. We found no indications that decreasing tacrolimus trough levels influenced lipid profiles, indicating that tacrolimus does not influence lipids. However, a decrease in tacrolimus trough level by $33 \%$ did result in a significant improvement in renal function of approximately $16 \%$. This could be of importance because studies in cyclosporine patients have shown that renal function in the first year after transplantation has a large impact on long-term graft survival $^{35}$.

Our findings support our current policy for patients who develop PTDM on tacrolimus-based immunosuppression: at first, steroid withdrawal, while maintaining therapeutical tacrolimus trough levels of approximately 10 to $15 \mathrm{ng} / \mathrm{mL}$ for 4 to 6 weeks after transplantation to avoid acute rejection. After this period, tacrolimus trough levels are reduced to 5 to $7 \mathrm{ng} / \mathrm{ml}$. This often results in a reduction in, or the cessation of, insulin therapy, or even in the disappearance of PTDM ${ }^{15}$.

In summary, steroid withdrawal in white renal transplant recipients on tacrolimusbased immunosuppression leads to a general improvement in glucose metabolism, due to a decrease in insulin resistance, as well as to a reduction in lipids, and tacrolimus trough level reduction improves glucose metabolism by increasing pancreatic $\beta$-cell secretion capacity. 


\section{References}

1. Massy ZA, Kasiske BL. Post-transplant hyperlipidemia: mechanisms and management. J Am Soc Nephrol 1996; 7 (7): $971-977$.

2. Aakhus $\mathrm{S}$, Dahl $\mathrm{K}$, Wideroe TE Cardiovascular morbidity and risk factors in renal transplant patients. Nephrol Dial Transplant 1999; 14 (3): 648-654.

3. Kasiske BL. Cardiovascular disease after renal transplantation. Semin Nephrol 2000; $20(2): 176-187$.

4. Jindal RM, Sidner RA, Milgrom ML. Post-transplant diabetes mellitus. The role of immunosuppression. Drug Saf 1997; 16: 242-257.

5. Weir MR, Fink JC. Risk for posttransplant diabetes mellitus with current immunosuppressive medications. Am I Kidney Dis 1999; 34:1-13.

6. Krentz AJ, Dmitrewski I, Mayer D, Nattrass M. Effects of immunosuppressive agents on glucose metabolism. Clin Immunother 1995; 4: 103-123.

7. Pirseh JD, Miller J, Deierhoi MH, Vincenti F, Filo RS. A comparison of tacrolimus and cyclosporine for immuno-suppression after cadaveric renal transplantation. FK 506 Kidney Transplant Study Group. Transplantation 1997; 63: 977-983.

8. Mayer AD, Dmitrewski J, Squifflet JP, Bessen T, Vanrenthergem Y, Donck J, van Hooff J, Christiaans M, Morales JM, Andres A, Johnson RWG, Short C, Buchholz B, Rehmert N, Land W, Schleibner S, Forsythe ILR, Talbot D, Neumayer HH, Hausen I., Ericzon BG, Brattstrom $\mathrm{C}$, Claesson $\mathrm{K}$, Mülnlbacher F, Pohanka E. Multicenter randomized trial comparing tacrolimus (FK506) and cyclosporine in the prevention of renal allograft rejection: a report of the European Tacrolimus Multicenter Renal Study Group. Transplantation 1997; 64: 436-443.

9. Knoll GA, Bell RC. Tacrolimus versus cyclosporin for immunosuppression in renal transplantation: meta-analysis of randomised trials. Br Med J 1999; 318 : 1104-1107.

10. Duijhhoven van EM, Boots JMM, Christiaans MHL, Wolffenbuttel BHR, van Hooff JP. Influence of tacrolimus on glucose metabolism before and after renal transplantation: a prospective study. IJ Am Soc Nephrol 2001; 12:583-588.

11. Nam JH, Mun J, Kim SI, Kang SW, Choi KH, Park K, Ahn CW, Cha BS, Song YD, Lim SK, Kim KR, Lee HC, Huh KB. B-cell dysfunction rather than insulin resistance is the main contributing factor for development of postrenal transplantation diabetes mellitus. Transplantation 2001; 71 (10): 1417-1423.

12. Ekstrand A, Ahonen J, Gronhagen-Riska C, Groop L. Mechanisms of insulin resistance after kidney transplantation. Transplantation 1989; 48 (4): 563-568.

13. Jindal RM. Post-transplant hyperlipidaemia. Postgrad Med ل 1997; 73 (866): 785-793.

14. McCune TR, Thacker LR, Peters TG, Mulloy L, Rohr MS, Adams PA, Yium J, Light JA, Pruett T, Gaber AO, Selman SH, Jonsson J, Hayes JM, Wright FH, Armata T, Blanton J, Burdick IF. Effects of tacrolimus on hyperlipidemia after succesful renal transplantation: a Southeastern Organ Procurement Foundation Multicenter clinical study. Transplantation 1998; 65 (1):87-92.

15. Boots JMM, van Duijhhoveu EM, Christiaans MHL, Nieman FHM, van Suylen R-J, van Hooff JP. Single center experience with tacrolimus versus cyclosporin-Neoral in renal transplant recipients. Transplant Int 2001; 14:370-383.

16. Veenstra DL, Best JH, Homberger J, Sullivan SD, Hricik DE. Incidence and longterm cost of steroicl-related side effects after renal transplantation. Am J Kidney Dis $1999 ; 33(5): 829-839$. 
17. Fernandez-Miranda C, Guijarro C, de la Calle A, Loinaz C, Gonzalez-Pinto I, Gomez-

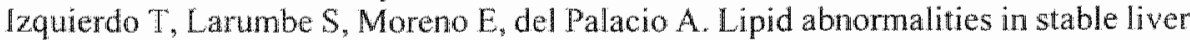
transplant recipients - effects of cyclosporin, tacrolimus, and steroids. Transpl Int $1998 ; 11(2): 137-142$.

18. Pirsch JD, d'Alessandro AM, Sollinger HW, Knechtle SJ, Reed A, Kalayoglu M, Belzer FO. Hyperlipidemia and transplantation: etiologic factors and therapy. J Am Soc Nephrol 1992; 2 (12 Suppl): \$238-\$242.

19. Shapiro $\mathbb{R}$, Jordan ML, Scantlebury VP, Vivas C, Gritsch HA, Corry RJ, Egidi $F$, McCauley J, Ellis D, Gilboa $\mathrm{N}$, et al. The superiority of tacrolimus in renal transplant recipients - - the Pittsburgh experience. Clin Transpl 1995; 199-205.

20. McDiarmid SW, Famer DA, Goldstein LI, Martin P, Vargas J, Tipton JR, Simmons F, Busurtil RW. A randomized prospective trial of steroid withdrawal after liver transplantation. Transplantation 1995; 60 (12): ]443-1450.

21. Hricik DE, Bartucci MR, Moir EJ, Mayes JT, Schulak JA. Effects of steroid withdrawal on posttransplant diabetes mellitus in cyclosporine-treated renal transplant recipients. Transplantation 1991; 5 1. (2): 374-377.

22. Schulak $\mathbb{A}, \mathbb{H}$ ricik DE. Steroid withdrawal after renal transplantation. Clin Transplant $1994: 8(2 \mathrm{Pt} 2): 211-216$.

23. Shapiro R, Jordan M, Scantlebury V, Fung J, Jensen C, Tzakis A, McCauley J, Carroll P, Ricondi C, Demetris AI, Mitchell S, Jain A, Iwaki Y, Kobayashi M, Reyes J, Todo S, Hakala "TR, Simmons RL, Strazl TE. FK 506 in clinical kidney transplantation. Transpl Proc 1991; $23(6): 3065-3067$

24. Elmer DS, Hathaway DK, Gaber AO. Monitoring of pancreas allograft function with glucose disappearance rate $(\mathrm{Kg})$ : calculation and interpretation. J Transpl Coord 1994; 4: 7-11.

25. Bergman RN, Finegood DT, Ader M. Assessment of insulin sensitivity in vivo. Endocr Rev 1985; 6:45-86.

26. Matthews DR, Hosker JP, Rudenski AS, Naylor BA, Treacher DF, Turner RC. Homeostasis model assessment: insulin resistance and beta-cell function from fasting plasma glucose and insulin concentrations in man. Diabetologia 1985;28:412-419.

27. Avignon A, Boegner C, Mariano-Goulart D, Colette C, Monnier L. Assessment of insulin sensitivity from plasma insulin and glucose in the fasting or post oral glucoseload state. Int J Obes Relat Metab Disord 1999:23:512-517.

28. Greenspan FS, Baxter JD. Basic \& clinical endocrinology. $4^{\text {th }}$ ed: $1994 ; 573$.

29. Duijnhoven wan EM., Christiaans MHL, Boots JMM, Nieman FHM, Wolffenbuttel BHR, van Hooff JP. Glucose metabolism in the first 3 years after renal transplantation in patients on tacrolimus versus cyclosporine-based immunosuppression. I Am Soc Nephrol 2002; 13:213-220.

30. Khaw K, Wareham N, Luben R, Bingham S, Oakes S, Welch A, Day N. Glycated haemoglobin, diabetes, and mortality in men in Norfolk cohort of European Prospective Investigation of Cancer and Nutrition (EPIC, Norfolk). BMJ 2001; 322: $15-18$.

31. Nakao T, Matsumoto H, Okada T, Han M, Hidaka H, Yoshino M, Shino T, Yamada C. Nagaoka $Y$. Influence of erythropoetit treatment on hemoglobin A le levels in patients with chronic renal failure on hemodialysis. Intern Med 1998;37(10); 826830.

32. Morgan L, Marenah CB, Jeffcoate WJ, Morgen AG. Glycated proteins as indices of glycemic control in diabetic patients with chronic renal failure. Diabet Med 1996; $13(6): 514-519$ 
33. The DECODE study group. European diabetes epidemiology group. Glucose tolerance and mortality: comparison of WHO and American Diabetes Association diagnostic criteria. Diabetes Epidemiology: Collaborative analysis of diagnostic criteria in Europe. Lancet 1999; 354 (9179): 617-621.

34. Balkau B, Pyorala M, Shipley MI, Forthan A, Jarret RJ, Eschwege E. Higl blood glucose concentration is a risk factor for mortality in middle-aged nondiabetic men 20-year follow-up in the Whitehall Study, the Paris Prospective Study, and the Helsinki Policemen study. Diabetes Care 1998;21:360-367.

35. Kuo PC, Johnson LB, Schweitzer EJ, Alfrey EJ, Waskerwitz J, Bartlet ST. Utilization of the older donor for renal transplantation. Am J Surg 1996; 172:551-557. 

Chapter 4

\section{Glucose metabolism in the first 3 years after renal transplantation in patients receiving tacrolimus versus cyclosporine-based immunosuppression}

EM van Duijhhoven, MHL Christiaans, JMM Boots, FHM Niemani, BHR Wolffenbuttel, JP van Hooff

I Am Soc Nephrol 2002; 13:213-220 


\begin{abstract}
The long-term effects of tacrolimus and cyclosporine on pancreatic islet cell function in renal transplant recipients are unclear. Therefore, a prospective, randomized, longitudinal study was performed that compared glucose metabolism in adult kidney allograft recipients on tacrolimus versus cyclosporine-based immunosuppression. Twenty-three white renal allograft recipients, randomized for either therapy with cyclosporine or tacrolimus, underwent intravenous glucose tolerance tests 6 times during the first 3 years after transplantation. Concomitant therapy (low-dose steroids and azathioprine) was the same in both groups. Insulin sensitivity index $\left(\mathrm{k}_{\mathrm{O}}\right)$, insulin resistance (insulin/glucose ratio and homeostasis model assessment), and C-peptide and insulin secretion were calculated. Trough levels of tacrolimus and cyclosporine were measured. The occurrence of posttransplantation diabetes mellitus was prospectively monitored. Statistical analysis was performed by ANOVA for repeated measures, and parametric and nonparametric tests were also performed. Although only one patient treated with cyclosporine developed posttransplantation diabetes mellitus, $\mathrm{k}_{\mathrm{G}}$ levels were below normal in up to one-third of both patients who received tacrolimus and cyclosporine. The only significant difference between patients who received tacrolimus and those who received cyclosporine was in pancreatic secretion capacity at week 3 after transplantation, when the increment of C-peptide secretion was $57 \%$ lower and the increment of insulin secretion was $48 \%$ lower for patients receiving tacrolimus. In both groups, from week 3 to month 6 , there was a tendency towards an increase in $\mathrm{k}_{\mathrm{G}}$, despite a significant increase in fasting glucose and insulin resistance calculated by homeostasis model assessment. After month 6 there were no significant changes in any of the parameters of glucose metabolism, indicating that longterm use of either tacrolimus or cyclosporine does not cause chronic, cumulative pancreatic toxicity.
\end{abstract}




\section{Introduction}

The calcineurin inhibitors tacrolimus and cyclosporine are both associated with an impaired glucose metabolism and with posttransplantation diabetes mellitus (PTDM) in 5 to $35 \%$ of all renal transplant recipients ${ }^{1-9}$. The variation in incidence may be explained in part by different definitions of PTDM and in part by the population studied ${ }^{9}$. Several risk factors for PTDM have been established and others proposed. They include increasing age, family history of diabetes, prediabetic state, African or Hispanic descent, high body weight, high prednisolone dose, high calcineurin inhibitor dose, cadaveric transplant, and several HLA antigens $^{9-13}$. Increasing time after transplantation has also been postulated as a risk factor ${ }^{14}$.

The development of PTDM can have important sequelae. Miles et al. ${ }^{15}$ found a significantly increased frequency of sepsis as a cause of death and a significantly greater risk of developing graft failure in 40 patients with PTDM treated with cyclosporine.

There have been suggestions that the diabetic potential of tacrolimus may be higher than that of cyclosporine ${ }^{12-13,16}$. Detailed comparisons of glucose metabolism, by use of such techniques as the oral glucose tolerance test or more precise tests, such as the intravenous glucose tolerance test (IVGTT), minimal modelling, euglycemic clamping, and arginine infusion, have mainly been conducted in liver transplant recipients. The only detailed study of glucose metabolism in renal allograft recipients showed more abnormal IVGTTs in patients treated with tacrolimus than in patients who received cyclosporine ${ }^{17}$. That study was performed in children and was nonrandomized and cross-sectional. Besides, improvement in glucose metabolism after dose reduction ${ }^{12-13}$ indicates that the outcome of a study comparing tacrolimus with cyclosporine may depend on target trough levels.

Herein, we present what is to our knowledge the first prospective, randomized, longitudinal study comparing glucose metabolism by IVGTT in adult renal transplant recipients on tacrolimus versus cyclosporine-based immunosuppression with identical concomitant immunosuppression in the first 3 years after kidney transplantation. We also describe prospective monitoring for hyperglycemia and PTDM. 


\section{Material and methods}

\section{Patients}

Patients were eligible to participate in the study if they met the following criteria: age 18 years or older, recipient of a cadaveric renal allograft, and no known history of clinical diabetes mellitus. All patients gave written, informed consent to participate in the study.

Twenty-three white patients were included in the study. Before surgery they were randomized to a study group by opening a sealled envelope assigning them to the tacrolimus $(n=11)$ or cyclosporine $(n=12)$ groups. At the time of transplantation, both groups were comparable in gender, age, transplantation number, body mass index (BMI), and primary renal disease (Table 4.1). During the study, their BMI, renal function (Cockcroft-Gault formula), and the use of drugs that might interfere with glucose metabolism (e.g., antihypertensive drugs, oral contraceptives, phenytoin, pentamidine) were monitored.

Table 4.1 Patient characteristics at the time of renal transplantation.

\begin{tabular}{lcc}
\hline & Tacrolimus & Cyclosporine \\
\hline Gender (M/F) & $8 / 3$ & $9 / 3$ \\
First transplant/retransplant & $9 / 2$ & $9 / 3$ \\
Primary renal disease: & $3 / 8$ & $3 / 9$ \\
immunological/ non- immunological & $45.4(25.0-70.1)$ & $46.8(23.0-61.1)$ \\
Age, yr (range) & $26.0(19.2-36.0)$ & $24.6(18.1-28.5)$ \\
Median body mass index, $\mathrm{kg} / \mathrm{m}^{2}$ (range) &
\end{tabular}

\section{Immunosuppression}

The tacrolimus dosage was $0.3 \mathrm{mg} / \mathrm{kg}$ per day orally in two doses starting on day 0 . The target trough level was initially 10 to $15 \mathrm{ng} / \mathrm{ml}$, and after month 3 , the trough level was lowered to 7 to $10 \mathrm{ng} / \mathrm{ml}$. The cyclosporine dosage was $8 \mathrm{mg} / \mathrm{kg}$ per day orally in two doses starting on day 0 . Initially, the target trough level was 100 to $200 \mathrm{ng} / \mathrm{ml}$; after month 3 it was changed to 100 to $150 \mathrm{ng} / \mathrm{ml}$. Both groups received I $102 \mathrm{mg} / \mathrm{kg}$ per day azathioprine until month 3, together with $500 \mathrm{mg}$ methylprednisolone on day 0 and $125 \mathrm{mg}$ methylprednisolone on day 1 after transplantation. Thereatter, they were given $20 \mathrm{mg}$ prednisolone, which was tapered to $15 \mathrm{mg}$ at week 2, to $10 \mathrm{mg}$ at week 4 , and to $5 \mathrm{mg}$ from week 6 onward. Cyclosporine (Enzyme Multiplied Immune Technique, Dade Behring, Leusden, the Netherlands) and tacrolimus (IMx, Abbott, Hoofddorp, the Netherlands) whole- 
blood 12-hour trough levels were determined Cumulative doses of tacrolimus of cyclosporine, and of steroids were calculated at every IVGTT.

Rejection was treated with intravenous steroid pulse therapy $(0.5 \mathrm{~g}$ to $1.0 \mathrm{~g}$ methylprednisolone on 3 alternate days) and, in the case of steroid resistance, with antithymocyte globulin for 10 days. During antithymocyte globulin administration, daily orally administered prednisolone was continued. At the time of the first dose of antithymocyte globulin, an additional bolus of $25 \mathrm{mg}$ prednisolone was prescribed.

\section{Glucose metabolism}

Glucose metabolism was studied via IVGTT. The tests were performed in the morning after an overnight fast, at week 3 , at months 3 and 6 , and at years 1, 2, and 3 after renal transplantation. None of the tests was performed during or within 3 weeks after rejection treatment. Glucose $(0.5 \mathrm{~g} / \mathrm{kg})$ was administered intravenously for 2 to 3 minutes. Blood samples for measurement of whole-blood glucose, $C$-peptide, and insulin were taken from the opposite arm at $t=-15,0,5,10,15,20$, $30,40,50$, and 60 minutes. Insulin sensitivity index (glucose disappearance rate $=$ $\mathrm{k}_{\mathrm{o}}$ ) was calculated by linear regression from the log-transformed glucose values of $t=10$ to 30 minutes. A $k_{G}$ value less than $0.8 \%$ per minute was considered to be abnormal, between 0.8 and $1.2 \%$ per minute to be indeterminate, and greater than $1.2 \%$ per minute to be normal ${ }^{18-1 \%}$. C-peptide and insulin secretion - both the increment (the secretion response to a glucose load) and the total secretion (basal + increment) - were calculated as area under the curve by use of a linear trapezoidal technique from the serum value at each time point. With the increment this was done after subtracting the $t=0$ value. Insulin resistance was calculated by use of the insulin/glucose ratio and the homeostasis model assessment (HOMA-R: fasting glucose (mmol/1) multiplied by fasting insulin $(\mathrm{mL} / 1)$ divided by 22.5$)^{20-2 !}$.

During hospitalization, urine was examined daily for glucosuria, and at the outpatient clinic it was examined during every visit. When glucosuria was detected, whole-blood glucose was examined. When no glucosuria was detected, wholeblood glucose was measured initially at least once every week and later at least every 3 months. When glucose values were abnomal (more than $6.1 \mathrm{mmol} / \mathrm{in}$ the fasting state or more than $7.8 \mathrm{mmol} / 1$ in the nonfasting state) for 2 or more different samples and there was no known explanation, such as additional high-dose steroids or infection, PTDM was diagnosed.

A dipstick method was used for the detection of gllucosuria. For the measurement of glucose in whole blood, the CX 7 (Beckman Instruments, Pallo Alto, CA) was used, and for C-peptide and insulin, the Autodelfia (Wallac, Turku, Finland) was used. In patients who developed PTDM, fasting glucose levels and fructosamine levels were monitored (Unimate 5 FRUC, ABX, Eindhoven, the Netherlands). 
Normal reference values from our laboratory were 3.1 to $6.1 \mathrm{mmol} / \mathrm{f}$ for fasting glucose, 1.0 to $25.0 \mathrm{mU} / \mathrm{l}$ for fasting insulin, 0.12 to $1.20 \mathrm{nmol} / 1$ for fasting C-peptide fevels, and 0.62 to $1.22 \mathrm{mmol} / 1$ for fructosamine.

\section{Statistical analyses}

For statistical analysis, SPSS version 9.0 for Windows (SPSS, Inc., Chicago, IL) was used. For analysis of basic characteristics, the appropriate parametric and nonparametric tests were used. Changes in time and differences between patients who received tacrolimus and cyclosporine were evaluated by ANOVA for repeated measures in 2 separate periods: an early period, from week 3 to month 6 (when patients were still recovering from the operation, when catabolism and immobility gradually improved, and when steroid dose and trough levels gradually decreased) and in a more stable later period, from month 6 to year 3. When Mauchly"s sphericity test was statistically significant, results for univariate tests were given after applying the Greenhouse-Geisser epsilon correction. For correlations between parameters, the Spearman rho rank correlation coefficient was used. Correlations between trough level and parameters of glucose metabolism were evaluated for month 6 to year 3 because only in this period would tacrolimus trough levels correlate adequately with the free levels that are responsible for its actions. $P<0.05$ was considered statistically significant.

\section{Results}

\section{Patients}

At week 28, 1 patient in the cyclosporine group was diagnosed as having PTDM. He was therefore excluded from further investigations. In the tacrolimus group, 2 patients with marginal renal function since transplantation because of preexisting abnormalities in their kidney grafts returned to dialysis at month 10 and month 27 , respectively; they were therefore unable to complete the study. Two other patients in the tacrolimus group were treated for acute rejection with courses of solumedrol at day 6 and month 3 , respectively. Two patients in the cyclosporine group were treated twice for rejection: one patient with two courses of solumedrol at day 2 and day 12 , and the other with a course of solumedrol at day 18 and of antithymocyte globulin at day 25 .

Table 4.2 shows BMI and renal function up to the third year after transplantation. There were no significant differences in BMI and renal function between patients who received tacrolimus and patients who received cyclosporine at any time. From week 3 to month 6, BMI increased gradually in patients who received cyclo- 
sporine, whereas there was an intial decrease of $\mathrm{BML}$ in patients who received tacrolimus, with a gradual increase thereafer. In both groups creatinine clearance improved gradually during the first 6 to 12 months. Table 4.3 shows the antihypertensive drugs (from which at least $\beta$-blockers and diuretics might interfere with glucose metabolism) used at the time of the IVGTTS. No one Was treated with other drugs known to interfere with glucose metabolism.

\section{Immunosuppression}

Table 4.2 shows trough levels and cumulative doses of steroids and of the calcineurin inhibitor up to the third year after transplantation. Cyclosporine levels gradually decreased from approximately 180 to $120 \mathrm{ng} / \mathrm{ml}$ and tacrolimus trough levels from approximately 13 to $8 \mathrm{ng} / \mathrm{ml}$. Median steroid dose was not significantly different for patients who received tacrolimus compared with patients who received cyclosporine at any time. One patient who received cyclosporine needed a very large amount of additional steroids because of rejection, and by mistake, another patient who received cyclosporine received a much smaller dose of steroids than intended at the time of the transplantation.

\section{Hyperglycemia or PTDM}

In the first 24 hours after transplantation, all patients had hyperglycemia while receiving high doses of steroids (median glucose, $17.8 \mathrm{mmol} / \mathrm{l}$; range, 7.5 to 28.8 $\mathrm{mmol} / \mathrm{l})$.

After this period, 2 patients who received tacrolimus and 1 who received cyclosporine had hyperglycemia for 7 to 14 days during steroid pulse therapy for acute rejection (maximum glucose $9.7,21.6$, and $22.5 \mathrm{mmol} / \mathrm{l}$, respectively). One of the 2 patients who received tacrolimus also had an abnomal glucose level of $12.9 \mathrm{mmol} / \mathrm{l}$ during additional steroid administration because of surgical intervention. Two patients who received cyclosporine also had an abnormal glucose level of 10.1 and $9.0 \mathrm{mmol} / \mathrm{l}$, respectively, during additional steroid administration because of surgical intervention.

One patient who received cyclosporine had 2 abnormal fasting glucose levels of maximum $7.8 \mathrm{mmol} / \mathrm{l} 28$ weeks after transplantation. Because there was no obvious cause for his hyperglycemia, PTDM was diagnosed. His treatment consisted only of changes in diet. Thereafter, fasting glucoses ranged from 7.1 to $9.5 \mathrm{mmol} / 1$, with normal fructosamine levels of 1.04 and $1.11 \mathrm{mmol} / \mathrm{l}$ up to graft failure at month 18 .

All other patients had fasting glucose levels less than $6.1 \mathrm{mmol} / \mathrm{l}$ and nonfasting glucose levels less than $7.8 \mathrm{mmol} / 1$. 


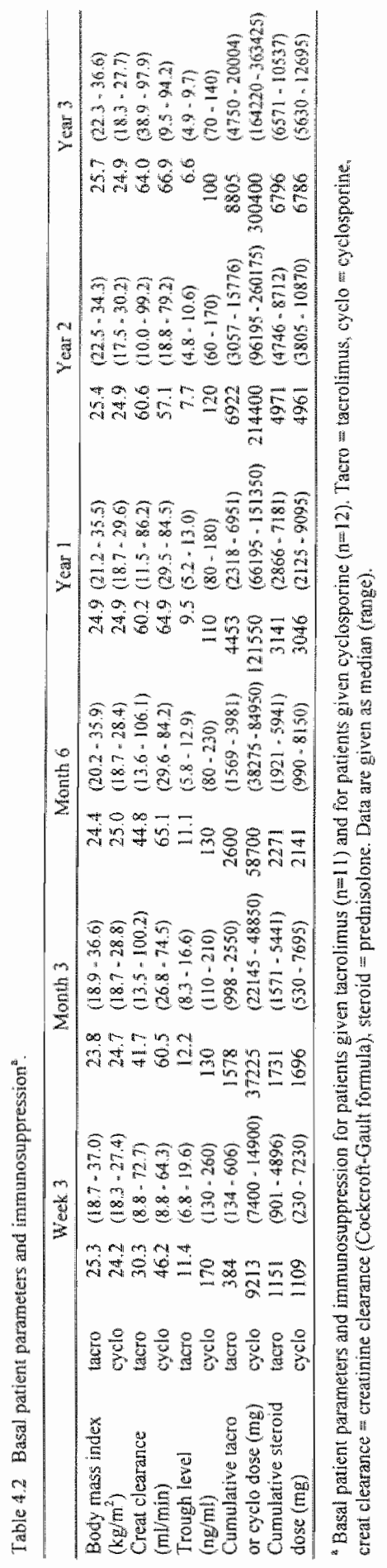


Table 4.3 Anti-liypertensive medication.

\begin{tabular}{|c|c|c|c|c|c|c|c|}
\hline & & $\begin{array}{c}\text { Week } 3 \\
(\%)\end{array}$ & $\begin{array}{c}\text { Month } 3 \\
(\%)\end{array}$ & $\begin{array}{c}\text { Month } 6 \\
(\%)\end{array}$ & $\begin{array}{c}\text { Year } 1 \\
(\%)\end{array}$ & $\begin{array}{c}\text { Year } 2 \\
(\%)\end{array}$ & $\begin{array}{c}\text { Year } \\
(\%)\end{array}$ \\
\hline \multirow[t]{2}{*}{ Beta-blockers } & tacro & 36 & 55 & 64 & 70 & 90 & 78 \\
\hline & cyclo & 25 & 50 & 55 & 55 & 55 & 65 \\
\hline \multirow[t]{2}{*}{ Diuretics } & Iacro & 0 & 18 & 27 & 30 & 30 & 30 \\
\hline & cyclo & 8 & 0 & 9 & 9 & 18 & 9 \\
\hline \multirow[t]{2}{*}{ ACE-inhibitors } & tacro & 0 & 0 & 0 & 0 & 20 & 11 \\
\hline & cyclo & 0 & 0 & 9 & 9 & 18 & 45 \\
\hline \multirow[t]{2}{*}{ Calcium-antagonists } & tacro & 55 & 73 & 64 & 80 & 80 & 78 \\
\hline & cyclo & 50 & 75 & 64 & 73 & 64 & 64 \\
\hline \multirow[t]{2}{*}{ Vasodilators } & tacro & 0 & 0 & 0 & 20 & 20 & 11 \\
\hline & cyclo & 0 & 9 & 18 & 18 & 27 & 45 \\
\hline
\end{tabular}

"Use of antihypertensive drugs in patients given tacrolimus $(\mathrm{n}=11$ ) and in patients given cyclosporine $(n=12)$ at the times of the IVGTr's.

Tacro $=$ tacrolimus, cyclo $=$ cyclosporine, $\mathrm{ACE}=$ angiotensine converting enzyme.

\section{Glucose metabolism}

Tables 4.4 and 4.5 show the median levels and range of basal and stimulated parameters of glucose metabolism. Table 4.6 shows changes in time, as well as differences between patients who received tacrolimus and patients who received cyclosporine.

\section{Basal}

In the early period (week 3 to month 6), there was a significant increase in glucose and HOMA-R and a tendency towards a rise in insulin, whereas C-peptide decreased significantly. There was no significant change in the insulin/glucose ratio.

In the later period (month 6 to year 3), there were no significant changes in any of the basal parameters.

Differences between patients who received cyclosporine and those who received tacrolimus were not statistically significant for any basal parameter in either period.

\section{Srimulated parameters}

In the early period, there was a tendency towards an increase in $\mathrm{k}_{\mathrm{g}}$. In both groups there were several patients with a $\mathrm{k}_{\mathrm{G}}$ below normal (less than $1.2 \%$ per min). At week $3, \mathrm{k}_{\mathrm{G}}$ was below normal in $45 \%$ of the patients who received tacrolimus and in $17 \%$ of the patients who received cyclosporine, and at year 3 , in $33 \%$ of the patients who received tacrolimus and $36 \%$ of the patients who received cyclosporine. 

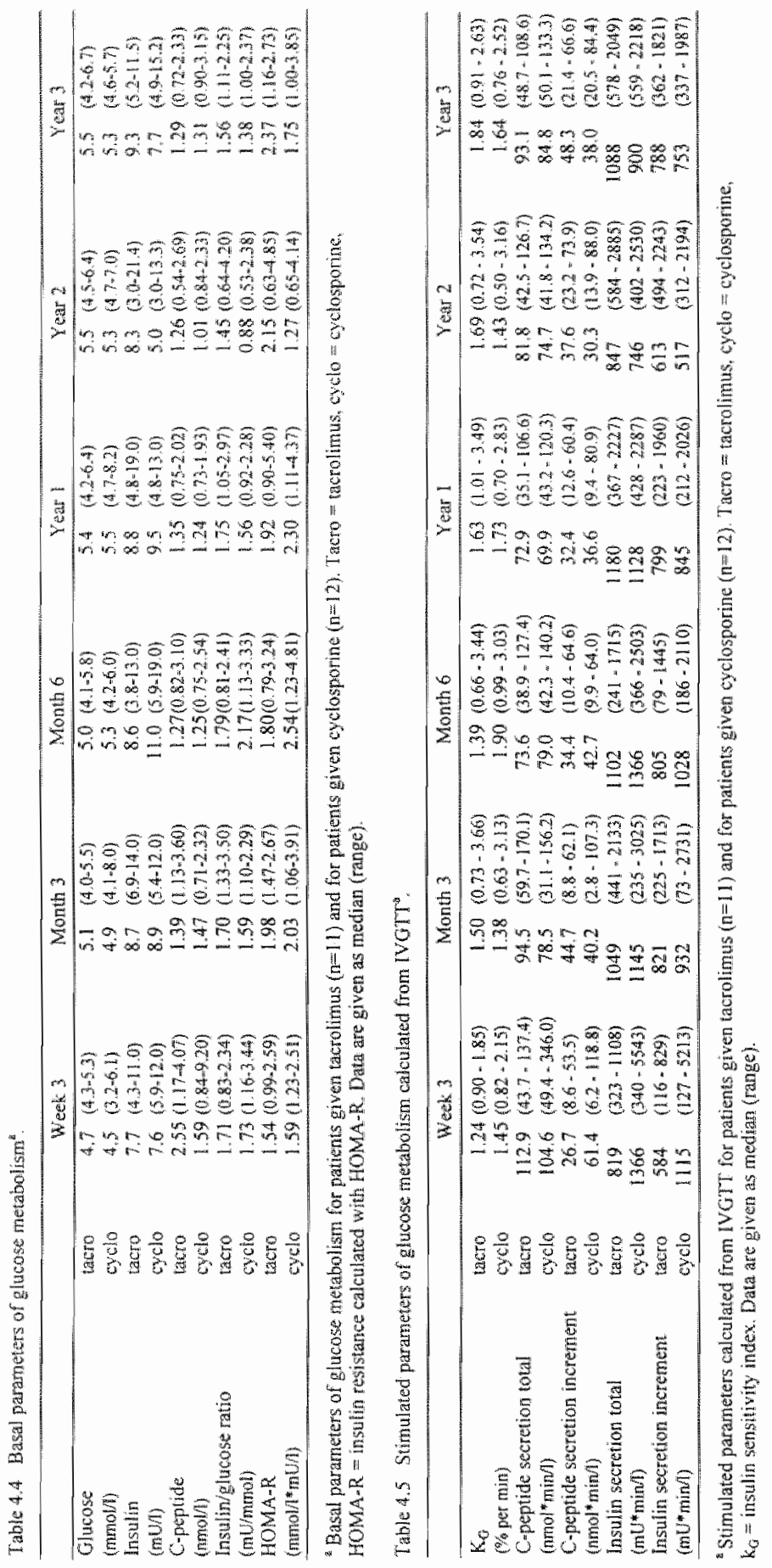
Total C-peptide secretion decreased significantly, whereas the increment of C-peptide secretion and insulin secretion (both total and increment) did not change significantly over time.

In the later part of the study, there were no significant changes in any of the stimulated parameters.

The increment of C-peptide secretion and the increment of insulin secretion were significantly different for patients who received tacrolimus versus cyclosporine. At week 3 , the increment of C-peptide secreton was $57 \%$ lower, and the increment of insulin secretion was $48 \%$ lower for patients who received tacrolimus than for those who received cyclosporine $(26.68$ versus $61.44 \mathrm{nmol} * \mathrm{~min} / 1$ and 584.0 versus $1114.6 \mathrm{mU} U^{*}$ min/1, respectively). After 3 months, the differences were no longer significant between the 2 groups (44.65 versus $40.23 \mathrm{nmol}$ min/l and 821.3 versus $931.9 \mathrm{mU}$ *min/l at month 3 , respectively).

Table 4.6 Results of repeated-measures ANOVA for the early period (week 3 to month 6 ).

\begin{tabular}{|c|c|c|c|c|}
\hline & $\begin{array}{c}\text { Changes in lime } \\
\text { for all patients } \\
\text { P }\end{array}$ & $\begin{array}{c}\text { Perentual change } \\
\text { Tacrolimus } \\
\% / 6\end{array}$ & $\begin{array}{c}\text { Pelcentual elange } \\
\text { Cyclosporine } \\
y / 0\end{array}$ & $\begin{array}{c}\text { Dillerence for } \\
\text { lacto ve Cycto } \\
\text { P }\end{array}$ \\
\hline Glucose & 0.026 & +6 & +18 & 0.33 \\
\hline Insulin & 0.059 & +12 & +58 & 0.075 \\
\hline C-peptide & 0.026 & -50 & -21 & 0.83 \\
\hline Insulin/glucose ratio & 0.43 & +5 & +25 & 0.35 \\
\hline $\operatorname{HOMA}-\mathrm{R}$ & 0.027 & +17 & +60 & 0.057 \\
\hline$K_{;}$ & 0.055 & +12 & +24 & 0.25 \\
\hline Insulin secretion total & 0.25 & +34 & 0 & 0.058 \\
\hline Insulin secretion increment & 0.23 & +38 & -8 & $0.04 !$ \\
\hline C-peptide secretion total & 0.020 & -35 & -25 & 0.32 \\
\hline C-peptide secretion increment & 0.48 & +29 & -30 & 0.041 \\
\hline
\end{tabular}

"Given ate changes in time for all palients, changes in time per calcincurim inhibiton, and diforences in ehanges beween tacrolinus (tacro) and cyclosporine (cych).

Correlations between trough level and parameters of glucose metabolism

A weak, but statistically significant, correlation was found between cyclosporine trough level and both total insulin secretion and increment of insulin secretion $(r=0.312, \mathrm{P}=0.039)$. Otherwise, tacrolimus and cyclosporine trough levels did not correlate significantly with any of the parameters of glucose metabolism investigated. 


\section{Discussion}

To our knowledge, this is the first randomized, prospective study in which fasting and stimulated parameters of glucose metabolism, and the development of hyperglycemia and PTDM have been evaluated longitudinally in renall transplant recipients treated with tacrolimus or cyclosporine. All patients received the same concomitant immunosuppression, including low-dose steroids and azathioprine. Only 1 patient (4\%) who received cyclosporine developed PTDM, compared with 5 to $35 \%$ in other reports ${ }^{1-9}$. In our center, the observed incidence of PTDM, defined as the need for antidiabetic drugs or insulin, in 128 consecutive renal transplant recipients treated with either tacrolimus or cyclosporine was $18.5 \%$ and $10.8 \%$, respectively, $(\mathrm{P}=\mathrm{n}$.s., data not shown) over a follow-up period of 18 to 46 months. Thus, in the group of 23 patients in this study, we would only have expected 2 to 3 patients to develop PTDM. Plausible explanations for the relatively low incidence of PTDM in this study, and in our center in general, are fairly low tacrolimus trough levels and steroid dose, and the fact that most of the patient we studied were white.

In 1 patient, PTDM was diagnosed 28 weeks after transplantation. At week 3 and month 3 , he already had low insulin sensitivity indexes and extremely low insulin increment secretion levels; his insulin/glucose ratio was below median levels. No other patient had two such low consecutive secretion levels.

Although the incidence of PTDM, with frequent regular check-ups, was low, approximately $33 \%$ of the patients had an insulin sensitivity index below nomal (less than $1.2 \%$ per min), indicating impaired glucose tolerance. This is a significantly higher incidence than the $17 \%$ we found in dialysis patients before treatment with tacrolimus, but a lower incidence than the $56 \%$ observed in dialysis patients during treatment with tacrolimus in our previous study ${ }^{2 ?}$. A high median tacrolimus trough level of $17.1 \mathrm{ng} / \mathrm{ml}$ at the time of the IVGTTs in the previous study, compared with median trough levels of 6.6 to $12.2 \mathrm{ng} / \mathrm{ml}$ in this study, could possibly account for this difference. In contrast to our previous study, in the study presented here, we could not find a correlation between tacrolimus trough levels and $k_{i}$, possibly because in this study, tacrolimus trough levels were in a much lower range.

The median $k_{i_{i}}$ and the incidence of $k_{\mathrm{G}}$ levels below normal did not change significantly after the first 6 months. Therefore, there are no indications for chronic cumulative pancreatic toxicity with either calcineurin inhibitor up to 3 years after renal transplantation. This contradicts the increasing incidence of PTDM reported by Cosio et al. ${ }^{1+}$ in a retrospective study in renal allograft recipients treated with 
cyclosporine-based immunosuppression up to 15 years after transplantation. They did not include patients who developed PTDM during the first month after transplantation. Because this was the period, at least in our center, in which most cases of PTDM on tacrolimus-based immunosuppression developed ${ }^{22}$, it is possible that the increased incidence described reflects the natural history of development of diabetes mellitus with increasing age, as would be expected in the general popullation.

Significant changes over time were found for fasting glucose, HOMA-R, fasting $C$-peptide, and total C-peptide secretion. All changes occurred in the first 6 months after transplantation, especially early in the unstable period, between week 3 and month 3. The increase in fasting glucose and HOMA-R indicates an increase in insulin resistance, most likely related to the increase in BMI which, after renal transplantation, is predominantly due to augmentation of body fat mass ${ }^{23}$. It is unlikely that this increase in insulin resistance was caused by the immunosuppression because both steroid dose and calcineurin inhibitor trough levels decreased in this period. In patients who received tacrolimus, BMI decreased initially, probably because at week 3 , many patients who received tacrolimus had access fluid as a result of late onset of graft function.

Although there was a tendency for basal insulin levels to increase, basal C-peptide and total C-peptide secretion levels decreased significantly in the first 6 months after transplantation. Because C-peptide is almost completely cleared by the kidney ${ }^{24}$, this decrease was due to the improvement in graft function over this period: from week 3 to month 6 , median creatinine clearance increased considerably from 36 to $52 \mathrm{ml} / \mathrm{min}$ (Wilcoxon signed-rank test, $\mathrm{P}<0.0001$ ). The subnormal creatinine clearance also explains the fact that fasting $\mathrm{C}$-peptide levels were above levels found in healthy subjects. It seems unlikely that the acute response of the pancreas, responsible for the increment of $\mathrm{C}$-peptide secretion, is influenced by renal function.

At the different IVGTTs, there was quite a large variability in the median parameters of glucose metabolism, especially of insul in-related parameters. The most noticable variation occurred for insulin/glucose ratio and insulin secretion increment from year 1 to year 2 . At that time, there were no significant changes in BMI, renal function, calcineurin inhibitor level, steroid dose, or antihypertensive drugs. We verified that there was no technical failure in the measurement of insulin; the low insulin levels had not been determined in the same run, and qualitity control had been adequate for all insulin levels at year 2 . We compared the insulin glucose levels and insulin secretion increment levels at year I with the levels at year 2 (paired $t$ test). Both were not significantly different ( $P=0.23$ and $P=0.31$, respectively). Therefore, normal individual changes must have been responsible for the variability in the results. 
The tendency towards improvement in the insulin sensitivity index in the first 6 months after transplantation suggests a general improvement in glucose metabolism. Explanations for the lower $k_{\mathrm{G}}$ at week 3 include higher calcineurin inhibitor levels, a higher dosage of steroids, catabolic state, immobility, and operative stress early after transplantation. Moreover, the free levels of tacrolimus are higher because of hypalbuminemia and anemia. The initially lower $\mathrm{k}_{\mathrm{G}}$ correlates with the period in which PTDM is usually diagnosed, observed both during our clinical practice and in our earlier study ${ }^{22}$ : all patients who developed PTDM while on tacrolimus did so in the first 6 months after renal transplantation. The $k_{G}$ is determined by the balance between pancreatic secretion capacity (the increment of $C$-peptide and insulin secretion) and insulin resistance (insulin/ glucose ratio and HOMA-R).

Despite a rise in insulin resistance, $k_{\mathrm{G}}$ improved in the first 6 months after transplantation as a result of a rise in pancreatic secretion capacity. Therefore, we conclude that abnormalities in glucose metabolic control caused by calcineurin inhibitors are due to a decreased pancreatic secretion capacity and not to increased resistance. In the case of tacrolimus, this may be caused by an inhibition of calcineurin in $\beta$-cells as a result of an mRNA transcriptional defect ${ }^{25}$. Thus, the results of this study, as well as those of our previous study ${ }^{22}$, refute suggestions of an increase in insulin resistance due to calcineurin inhibitors ${ }^{3,4,9}$ as a cause of PTDM.

The only significant difference in glucose metabolism found between the tacrolimus and cyclosporine groups, was a lower increment of C-peptide and insulin secretion at week 3 for patients who received tacrolimus compared with those who received cyclosporine, indicating a lower pancreatic secretion capacity. Although not statistically significant, $\mathrm{k}_{\mathrm{G}}$ was also lower at week 3 for the patients who received tacrolimus. After 3 months, the increment of C-peptide and insulin secretion in patients who received tacrolimus had risen to the same levels as in patients who received cyclosporine. Elmer et al. ${ }^{26}$ showed that differences detected between pancreatic allograft recipients treated with tacrolimus and cyclosporine were influenced by steroid dose. At $15 \mathrm{mg}$ prednisolone per day, they found an increased risk of diabetogenicity for patients who received tacrolimus, whereas they did not detect any significant differences at doses of 20 to $30 \mathrm{mg} /$ day. Perhaps the influence of high steroid doses on glucose metabolism was so large that differences due to calcineurin inhibitors could not be detected. In our study, we only detected differences at week 3 and not thereafter. At low steroid doses, the (free) levels of the calcineurin inhibitors at the time of comparison may be the most important factor determining the outcome. At the relatively low target trough levels for both calcineurin inhibitors in this study, this did not result in important longterm differences in glucose metabolism. 
In summary, although only one patient treated with cyclosporine developed PTDM during the 3-year prospective follow-up of glucose metabolism, inpaired glucose metabolism $\left(\mathrm{k}_{\mathrm{G}}<1.2 \%\right.$ per min) was seen in approximately 1 of 3 patients treated with either tacrolimus or cyclosporine. In the early period after transplantation, $\mathrm{k}_{\mathrm{G}}$ improved because of a rise in secretion capacity, despite a concomitant increase in insulin resistance. After 6 months, there were no changes in glucose metabolism, as revealed by IVGTTs. Thus, there were no indications of chronic, cumulative, pancreatic islet cell toxicity as a result of long-term use of either tacrolimus or cyclosporine. At week 3, pancreatic secretion capacity, as measured by the increment of $\mathrm{C}$-peptide and insulin secretion, was significantly lower in patients who received tacrolimus than in those who received cyclosporine, probably because of high free tacrolimus levels. After week 3, there were no significant differences between patients who received tacrolimus and patients who received cyclosporine in any of the parameters of glucose metabolism. 


\section{References}

1. Boudreaux IP. McHugh $\amalg$, Canatax DM, Ascher N, Sutherland DE, Payne W, Simmons RL, Najarian JS, Fryd DS. The impact of cyclosporine and combination immunosuppression on the incidence of posttransplant diabetes in renal allograft recipients. Transplantation 1987; 44 (3): 376-381.

2. Roth D, Milgrom M, Esquenazi V, Fuller L, Burke G, Miller I. Posttransplant hyperglycemia. Increased incidence in cyclosporine-treated renal allograft recipients. Transplantation 1989; 47 (2): 278-281.

3. Krentz AJ, Dmitrewski J, Mayer D, Nattrass M. Effects of immunosuppressive agents on glucose metabolism. Clin Immunother 1995; 4 (2): 103-123.

4. Jindal RM, Sidner RA, Milgrom ML. Post-transplant diabetes mellitus. The nole of immunosuppression. Drug Saf 1997; $16(4): 242-257$.

5. Mihatsch MU, Kyo M, Morozumi K, Yanaguchi $Y$, Nickeleit V, Ryffel B. The side effects of ciclosporine-A and tacrolimus. Clin Nephrol 1998; 49 (6): 356-363.

6. Drachenberg CB, Klassen DK, Weir MR, Wiland A, Fink JC, Bartlett ST, Cangro CB, Blahut S, Papadimitriou JC. Islet cell damage associated with tacrolimus and cyclosporine: morfological features in pancreas allograft biopsies and clinical correlation. Transplantation 1999; 68 (3): 396-402.

7. Knoll GA, Bell RC. Tacrolimus versus cyclosporin for immunosuppression in renal transplantation: meta-analysis of randomised trials. BMJ 1999; $318(7191)$ : 11.041107.

8. Plosker GL. Tacrolimus: a further update of its pharmacology and therapeutic use in the management of organ transplantation. Drugs $2000 ; 59(2): 323-389$.

9. Weir MR, Fink JC. Risk for postransplant diabetes mellitus with current immunosuppressive medications. Am J Kidney Dis 1999; 34 (1):1-13.

10. Sumrani NB, Delaney V, Ding ZK, Davis R, Daskalakis P. Friedmna EA, Butt KM, Hong $\mathrm{JH}$. Diabetes mellitus after renal transplantation in the cyclosporine era - an analysis of risk factors. Transplantation 1991; 51 (2): 343-347.

11. Hjelmesaeth J, Hartmann A, Kofstad J, Stenstrom J, Leivestad T, Egeland T, Fauchald $P$. Glucose intolerance after renal transplantation depends upon prednisolone dose and recipient age. Transplantation 1997; 64 (7): 979-983.

12. Pirsch ID, Miller J, Deierhoi MH, Vincenti F, Filo RS. A comparison of tacrolimus (FK506) and cyclosporine for immunosuppression after cadaveric renal transplantation. FK506 Kidney Transplant Study Group. Transplantation 1997; 63 (7): 977.983.

13. Mayer AD, Dmitrewski I, Squifflet JP, et al. Multicenter randomized trial comparing tacrolimus (FK506) and cyclosporine in the prevention of renal allograft rejection: a report of the European Tacrolinnus Multicenter Renal Study Group. Transplantation 1997: $64(3): 436-443$

14. Cosio FG, Pesavento TE, Osei K, Henry ML, Ferguson RM. Post-transplant diabetes meilifus: Increasing incidence in renal allograft recipients transplanted in recent years. Kidney Int 2001: $59: 732-737$.

15. Miles AMV, Sumrani N, Horwitz R, Homel P, Maursky V, Markell MS, Distant DA, Hong JH, Sommer BG, Friedman EA. Diabetes mellitus after renal transplantation as deleterious as non-transplant-associated diabetes? Transplantation 1998; 65 (3): 380 384. 
16. Scantlebury V, Shapiro R, Fung J, Tzakis A, McCauley J, Jordan M. Jensen C. Hakala T, Simmons R, Starzl TE. New onset of diabetes in FK 506 vs cyclosporine treated kidney transplant recipients. Transplant Proc $1991 ; 23(6): 3169-3170$.

17. Filler G, Neuschulz I, Vollmer I, Amendt P, Hocher B. Tacrolimus reversibly reduces insulin secretion in paediatric renal transplant recipients. Nephrol Dial Transplant $2000 ; 15: 867-871$.

18. Elmer DS, Hathaway DK, Gaber AO. Monitoring of pancreas allograft function with glucose dissapearance rate $\left(\mathbb{k}_{G}\right)$ : Calculation and interpretation. J Transpl Coord 1993; 4: $7-11$.

19. Bergman RN, Finegood DT, Ader M. Assessment of insulin sensitivity in vivo. Endocr Rev $1985 ; 6: 45-86$.

20. Mathews DR, Hosker JP, Rudenski AS, Naylor BA, Treacher DF, Turner RC. Homeostasis model assessment: insulin resistance and beta-cell function from fasting plasma glucose and insulin concentrations in man. Diabetologia 1985;28:412-419.

21. Avignon A, Boegner C, Mariano-Goulart D, Colette C, Monnier L. Assessment of insulin sensitivity from plasma insulin and glucose in the fasting or post-oral glucoseload state. Int J Obes Relat Metab Disord 1999;23:512-517.

22. Duijnhoven van EM, Boots JMM, Christiaans MHL, Wolffenbuttel BHR, van Hooff JP. Influence of tacrolimus on glucose metabolism before and after renal transplantation: a prospective study. J Am Soc Nephrol 2001; 12:583-588.

23. Ham van de EC, Kooman JP, Christiaans MH, Leunissen KM, van Hooff JP. Posttransplantation weight gain is predomimantly due to an increase in body fat mass. Transplantation 2000; 70: 241-242.

24. Greenspan FS, Baxter JD. Basic \& Clinical endocrinology 4th ed., 1994, Appleton \& Lange, East Norwalk, Connecticut, USA. ISBN 0-8385-0646-1

25. Tamura K, Fujimura T, Tsutsumi T, Nakamura $K$, Ogawa $\mathbb{T}$, Atumaru $C$, Hirano $Y$, Ohara K, Ohtsuka K, Shimomura K, Kobayashi M. Transcriptional inhibition of insul in by $\mathrm{FK} 506$ and possible involvement of FK 506 binding protein- 12 in pancreatic beta-cell. Transplantation 1995; 59: 1606-1.613.

26. Elmer DS, Abdulkarim AB, Fraga D, Shokouh-Amiri H, Stratta RJ, Hathaway DK, Reddy K, Gaber AO. Metabolic effects of FK 506 (tacrolimus) versus cyclosporine in portally drained pancreas allografts. Transplant Proc 1998; 30 (2): 523-524. 

Chapter 5

\section{A late episode of posttransplant diabetes mellitus during active hepatitis $C$ infection in a renal allograft recipient using tacrolimus}

EM van Duijnhoven, MHL Christiaans, JMM Boots, VJ Goossens, NA Undre, JP van Hooff Am J Kidney Dis in press 


\section{Abstract}

\section{Background}

An association between hepatitis $\mathrm{C}$ and (postransplant) diabetes mellitus has recently been reported.

\section{Methods}

We report a patient on tacrolimus-based immunosuppression who developed an episode of posttransplant diabetes mellitus (PTDM) 2 years after renal transplantation, after contracting a hepatitis $C$ infection. Her glucose metabolism was regularly evaluated by IVGTT, before as well as after the PTDM episode.

\section{Resulss}

Before contracting hepatitis $\mathrm{C}$, the patient"s insulin resistance and insulin secretion were nomal. After contracting hepatitis $C$, tacrolimus exposure increased, insulin resistance increased, and insulin secretion decreased markedly. Despite low tacrolimus exposure in the last 4 years, glucose metabolism did not recover completely. Although PTDM resolved and insulin resistance normalized, pancreatic $\beta$-cell secretion remained impaired by approximately $50 \%$ compared to the period before the hepatitis $\mathrm{C}$ infection.

\section{Conchusion}

After an initial increase in insulin resistance, insulin secretion decreased markedly in a patient who contracted hepatitis $\mathrm{C} 12$ to 22 months after renal transplantation. This resulted in an episode of PTDM. Increased tacrolimus exposure due to reduced cytochrome P450 metabolism as a result of impaired thepatocellular function at the time of the development of PTDM seems a likely explanation for the marked decrease in insulin secretion. Viral toxicity to the $\beta$-cell might be an additional explanation. The latter might be suspected from several recent reports about an association between diabetes mellitus and hepatitis $\mathrm{C}$ in patients who do not use drugs that interfere with glucose metabolism. 


\section{Introduction}

Several risk factors have been indicated for the development of posttransplant diabetes mellitus (PTDM): calcineurin inhibitor and steroid dosage, advanced age, black or Hispanic race, high body mass index, use of beta-blockers, CMV infection, and a low or intermediate insulin sensitivity index before transplantation ${ }^{1-11}$. Recently, there have also been reports of an association between (posttransplant) diabetes mellitus and hepatitis $\mathrm{C}$ virus (HCV) infection ${ }^{12-19}$. An incidence of PTDM as high as $40-60 \%$ has been described in immunecompromised allograft recipients with hepatitis $\mathrm{C}$ infection ${ }^{13,17}$. The mechanism by which hepatitis $\mathrm{C}$ infection contributes to the development of PTDM has not yet been elucidated.

In this case report, we describe a Caucasian woman who developed reversible PTDM at the age of 26 , two years after her third kidney transplantation, during a hepatitis $\mathrm{C}$ infection while using tacrolimus and steroids as immunosuppression. In the period during which she underwent transplantation, glucose metabolism was regularly evaluated in all our patients by intravenous glucose tolerance tests (IVGTTs). This detailed investigation revealed that glucose metabolism was completely normal in the period before the hepatitis $\mathrm{C}$ infection: both insulin resistance and insulin production were normal. In this report, we describe the marked changes that occurred after our patient contracted hepatitis $C$. This may add to our current knowledge about the mechanism responsible for the development of PTDM during hepatitis $\mathrm{C}$ infection.

\section{Methods}

\section{Glucose metabolism}

According to our protocol, IVGTTs were scheduled for month 1,6,12, 18,24, and 36. Actual IVGTTs were performed at months 1, 5, 12, 20,30, 38, and 77 posttransplantation. Glucose, $0.5 \mathrm{~g} / \mathrm{kg}$ body weight, was administered intravenously over $2-3$ minutes. Blood samples for the measurement of whole blood glucose, C-peptide, and insulin were taken from the opposite arm at $t=-15,0,5$, $10,15,20$, and 30 minutes. Insulin resistance was calculated using the insulin/glucose ratio and the homeostasis model assessment (HOMA-R: fasting glucose multiplied by fasting insulin divided by 22.5$)^{20}$. C-peptide and insulin secretion, i.e., the secretion response to a glucose load, were calculated as area 
under the curve using a linear trapezoidal technique from the serum value at each time point after subtraction of the $\mathrm{t}=0$ value (increment). Insulin sensitivity index $\left(k_{i}\right)$ was calculated by linear regression from the log-transformed glucose values of $t=10-30$ minutes. $K_{G i}$ is determined by insulin secretion as well as by insulin resistance. $\mathrm{A} \mathrm{k}_{\mathrm{i}}$ value below $0.8 \%$ per min was considered to be abnormal, a value between 0.8 and $1.2 \%$ per min to be indeterminate, and a value above $1.2 \%$ per min to be normal ${ }^{21-22}$.

At the time of the IVGTTS, tacrolimus trough level (Imx II, Abbot, Hoofddorp, the Netherlands), fructosamine (Unimate 5 FRUC, ABX, Eindhoven, the Netherlands), and $\mathrm{HbA}_{1} \mathrm{C}$ (HPLC, Variant 2, Biorad, Hercules, CA, USA) were measured. The normal reference values of our laboratory were $0.62-1.22 \mathrm{mmol} D M F /$ for fructosamine, and $4.4-6.2 \%$ for $\mathrm{HbAlc}$.

\section{Hepatitis investigation}

The presence of anti-hepatitis $C$ virus antibodies was detected by the AxSYM $\mathrm{HCV}$ assay, version 3.0 (Abbott GmbH Diagnostika, Wiesbaden-Delkenheim, Germany), while the confirmation of specific anti-HCV antibodies was done using the Chiron RIBA HCV 3.0 Strip Immunoblot Assay (Chiron Corporation, Emeryville, CA, USA).

Hepatitis $\mathrm{C}$ virus RNA was detected qualitatively using the Amplicor HCV test (Roche Diagnostic Systems Inc., Branchburg, New Jersey, USA). Hepatitis C virus RNA levels were quantified by branched DNA signal amplification using the Versant HCV RNA 3.0 Quantitative Assay (Bayer Diagnostics, Puteaux, Puteaux Cedex, France). Both qualitative and quantitative HCV-RNA determinations were done in serum samples.

\section{Case report}

Before contracting hepatitis $\mathrm{C}$ infection

A 24-year-old woman was admitted to our hospital for a third cadaveric kidney transplantation because of reflux nephropathy and ectopia vesicae. Two previous grafts failed due to rejection and acute venous thrombosis. The patient had no history of hyperglycemia or (posttransplant) diabetes mellitus. Family history was also negative for diabetes mellitus. The donor was CMV IgG-negative. At the time of the transplantation, the patient's body mass index was $20.2 \mathrm{~kg} / \mathrm{m}^{2}$, her serum glucose and liver tests were normal, recipient $\lg M$ against CMV was negative, $\operatorname{IgG}$ 
against $\mathrm{CMV}$ positive, and $\mathrm{Hb}_{3} \mathrm{Ag}$, antiHb and $\mathrm{gG}$ against $\mathrm{HCV}$ (Elisa) were negative.

Initial immunosuppressive medication consisted of azathioprine ( $50 \mathrm{mg}$ daily), cyclosporine (initial target trough levels $0.15 \mathrm{mg} / 1$ to $0.20 \mathrm{mg} / 1$ ), and steroids. Steroid dose consisted of prednisolone $50 \mathrm{mg}$ i.v. on day $1,10 \mathrm{mg}$ p.o. from day 2. There was immediate renal function with a gradual decrease in serum creatinina. On day 8 after transplantation, serum creatinine increased from $3.66 \mathrm{mg} / \mathrm{dl}(324$ umol/1) to $5.46 \mathrm{mg} / \mathrm{dl}$ (483 umol/l). There were no signs of urinary obstruction or leakage. Rejection was suspected. Due to intra-abdominal localization of the graft because of her Bricker urostoma and the presence of earlier grafts, no biopsy was performed. The patient was treated with $1000 \mathrm{mg}$ methylprednisolone on days 8 , 10 , and 12, and from day 13, prednisolone was increased to $20 \mathrm{mg}$. On day 10 , cyclosporine was replaced by tacrollimus. Transplant function improved: serum creatinine was $2.36 \mathrm{mg} / \mathrm{dl}(209 \mathrm{umol} / \mathrm{l})$ at discharge on day 31 and decreased gradually to approximately $1.13 \mathrm{mg} / \mathrm{dl}$ (100 umol/1). From day 22 , prednisolone was gradually tapered from $20 \mathrm{mg}$ to $5 \mathrm{mg}$ at month 4 . During the first year, all fasting and nonfasting serum glucose and liver tests were nomal. Hepatitis C RNA in stored blood samples was negative at month 12 .

During this period, three IVGTTs were performed (Table 5.1) at months 1, 5, and 12. $\mathrm{K}_{\mathrm{G}}$ was within the normal range at all times and improved gradually during the first year, accompanied by a parallel improvement in insulin resistance and insulin secretion (Figure 5.1).

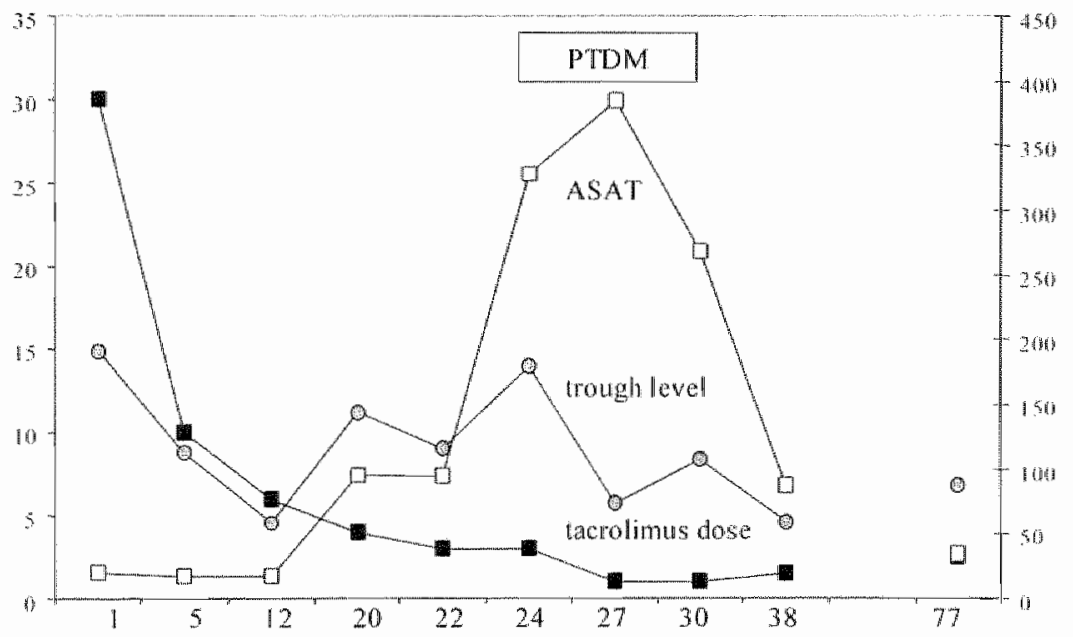

Figure 5.1 Immunosuppression and liver function in time (months). Left y-axis: tacrolimus trough level ( $\mathrm{ng} / \mathrm{ml})$ and tacrolimus dose $(\mathrm{mg})$. Right y-axis: ASAT (U/1). 


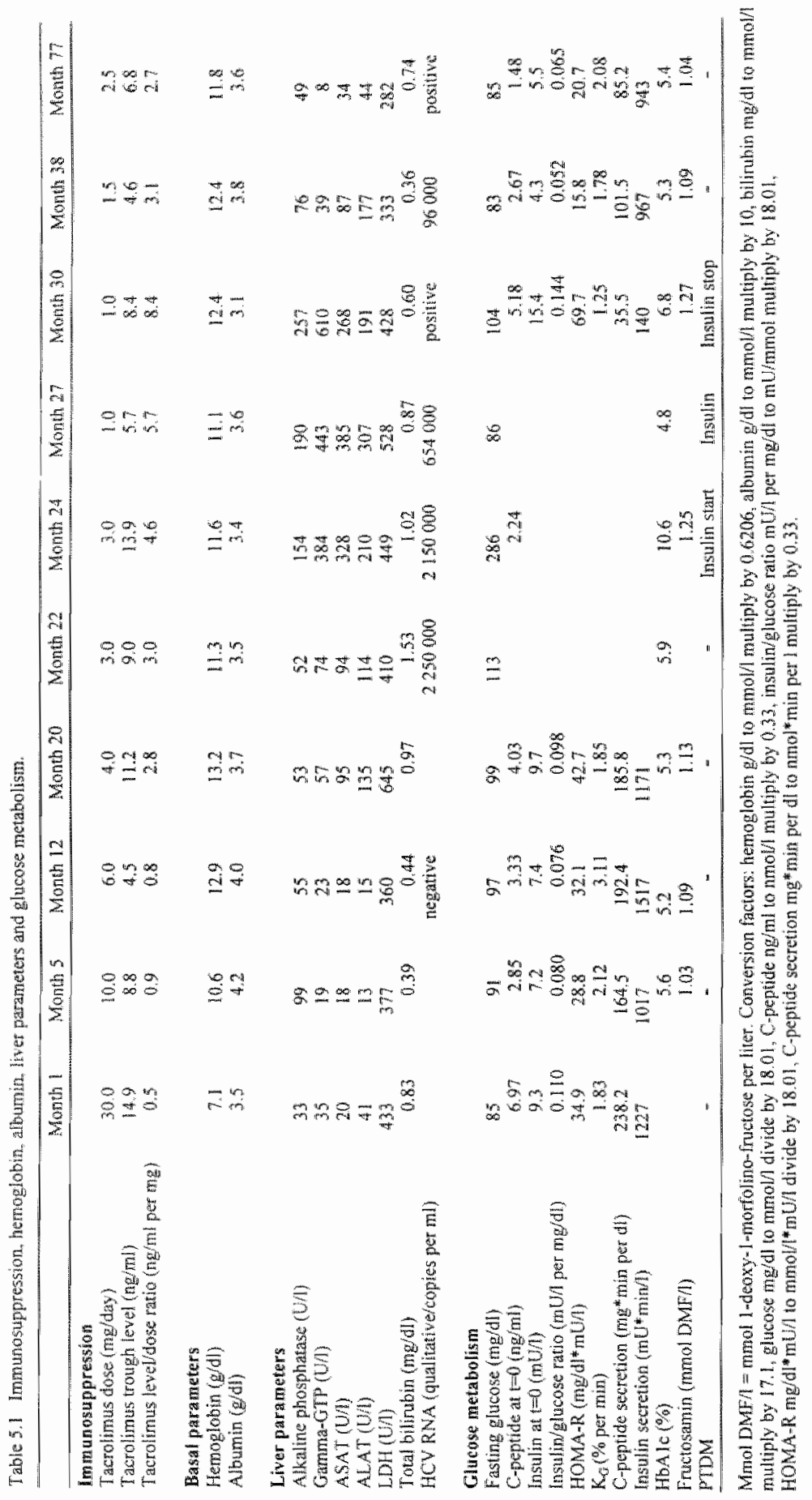




\section{Hepatitis C and PTDM}

Twenty months after transplantation both cholestatic and parenchymatous liver tests became progressively abnormal (Table 5.1). Liver synthesis was slightly impaired: hemostasis was normal, but albumin, although still within the normal range, had decreased. Despite a decrease in the dosage, an increase in the tacrolimus trough level was noticed. The ratio tacrolimus level/dose increased from 0.75 to $2.8 \mathrm{ng} / \mathrm{ml}$ per $\mathrm{mg}$. Tests for viral infection with CMV (antigen detection and $\operatorname{IgM}$ detection), for hepatitis $\mathrm{A} \operatorname{IgM}$ and $\operatorname{IgG}$ antibodies, for hepatitis B surface antigen, the AxSym screening assay for anti-HCV antibodies, and for autoimmune liver disease (ANF, anti-dsDNA, ab against smooth muscle, mitochondria) were all negative at that time. Ceruloplasmin, alpha-1-antitrypsin, and alpha-fetoprotein were within the normal range. Ultrasound and MRI of the liver were normal. A liver biopsy showed focal, aspecific chronic infiltration around the portal triangles. To rule out a role for azathioprine in the liver disease, this medication was discontinued.

At month 20, an IVGTT (originally scheduled for month 18) was performed (Table 5.1, Figure 5.2). Compared to the IVGTT at month $12, \mathrm{k}_{\mathrm{G}}$, although still in the normal range, had dropped from 3.11 to $1.85 \%$ per min, while insulin secretion had decreased from 1517 to $1171 \mathrm{mU} U^{*} \mathrm{~min} / 1$, and insulin resistance had increased (insulin/glucose ratio increased from $0.076 \mathrm{mU} / \mathrm{l}$ divided by $\mathrm{mg} / \mathrm{dl}(1.37$ $\mathrm{mU} / \mathrm{mmol})$ to $0.097 \mathrm{mU} / \mathrm{l}$ divided by $\mathrm{mg} / \mathrm{dl}(1.76 \mathrm{mU} / \mathrm{mmol}))$.

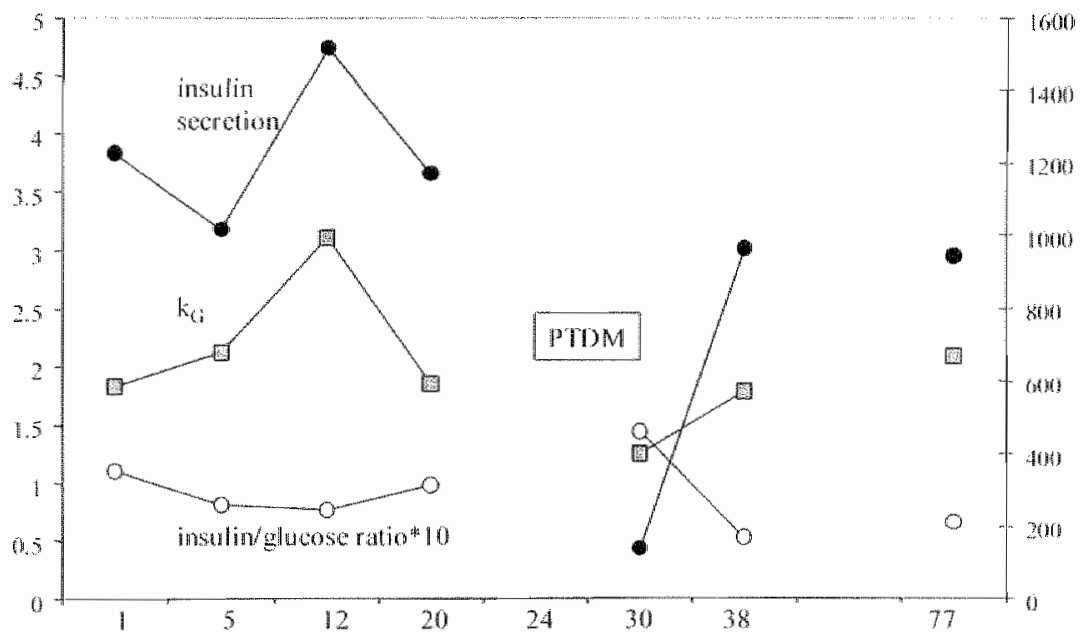

Figure 5.2 Parameters of glucose metabolism (months)

Left $y$-axis: $k_{0}(\%$ per $m$ in) and insul hin/glucose ratio multiplied by 10 ( $\mathrm{mU} / \mathrm{l}$ per $\mathrm{mg} / \mathrm{d})$ (multiply with 18.01 for $\mathrm{mU} / \mathrm{mmol}$ ). Right $y$-axis: insulin secretion ( $\mathrm{mU}^{*} \mathrm{~min} /$ ). 
According to our protocol, more than one year after transplantation routine fasting glucose levels were performed approximately every 3 months. Retrospectively, although still in the normal range, compared to earlier measurements the glucose level had already increased from $99 \mathrm{mg} / \mathrm{dl}$ to $113 \mathrm{mg} / \mathrm{dl}$ at month 22 (Table 5.1). After that check-up she was seen twice before PTDM developed. Regretfully, no blood glucose levels were checked at those times. Routine urine dipstick testings for glucosuria, however, were performed, and were negative at each of these visits, the last one month before the acute admittance abroad because of de novo PTDM.

Four months after the last ivgtt, the patient was admitted to a hospital abroad because of hyperosmolar, non-ketotic PTDM. Her serum glucose level was 1080 $\mathrm{mg} / \mathrm{dl}(60.0 \mathrm{mmol} / \mathrm{l})$. Rehydration and insulin therapy were started. After two days she was referred to our hospital in reasonably good condition. Vital functions were normal. Body mass index was $20.3 \mathrm{~kg} / \mathrm{m}^{2}$, stable compared to pretransplant body mass index. Physical examination revealed no abnormalities. Serum creatinine was $1.41 \mathrm{mg} / \mathrm{dl}(125 \mathrm{umol} / \mathrm{l})$ and glucose $270-360 \mathrm{mg} / \mathrm{dl}(15-20 \mathrm{mmol} / 1)$ with a total of 60 units of insulin ( 3 times short acting and once NPH) daily. Her tacrolimus trough level was $13.9 \mathrm{ng} / \mathrm{ml}$, despite further reductions in tacrolimus dose. The ratio tacrolimus level/dose was again higher than it had been $2-4$ months before. The prednisolone dose was still $5 \mathrm{mg} / \mathrm{day}$. Because of the unexpected late development of PTDM and further deterioration of liver laboratory parameters (ASAT $328 \mathrm{U} / 1$ ), evaluation for liver disease was repeated and pancreatic function was evaluated. Again, liver evaluations did not initially yield a diagnosis. C-pepticle was $2.24 \mathrm{ng} / \mathrm{ml}(0.74 \mathrm{nmol} / \mathrm{l})$ (normal $0.52-3.00 \mathrm{ng} / \mathrm{ml}$ or $0.17-0.99$ nmol/l) and there were no antibodies against the islets of Langerhans. Fatty acid and fat excretion in the feces were normal, and an MRI of the pancreas was also normal. Published data suggested that tacrolimus metabolites account for less than $20 \%$ of the drug related material in circulation ${ }^{23}$. In order to evaluate that there was no accumulation of tacrolimus metabolites owing to resorption via a Bricker intestinal loop, blood samples were assayed by HPLC-MS/MS method (Covance Lab Ltd, England). The blood concentrations of tacrolimus and metabolites were similar to those of patients without a Bricker intestinal loop.

After one month in the hospital, the patient was discharged, still using approximately 60 units of insulin daily. One month after discharge, hepatitis C PCR for RNA at month 24 was found to be positive, but the AxSym anti-HCV screening was still negative. Retrospectively, the HCV-RIBA was already reactive for $\mathrm{c} 33 \mathrm{c}$ but not for $\mathrm{c} 100, \mathrm{c} 22$, and NS5 at month 22 , while the PCR was negative at month 12 . This indicates that the infection must have occurred between month 12 and month 22. Although the hepatitis $\mathrm{C}$ infection must have occurred after the first year, the other recipients of organs from the same donor were tested for 
hepatitis $\mathrm{C}$, and were found negative. She did not receive blood transfusions at any time since this transplantation. The most likely explanation for the hepatitis $\mathrm{C}$ infection would be a sexual partner she met approximately one and a half year after transplantation. At the time the diagnosis became apparent, she did not have contact with him any longer. Therefore he could not be tested for hepatitis $C$. After the diagnosis of PTDM, the tacrolimus dose was again reduced to obtain trough levels of $5-8 \mathrm{ng} / \mathrm{ml}$.

At the time of the IVGTT scheduled for month 24 , she had already been admitted for PTDM. Therefore IVGTT was contraindicated and could not be performed.

\section{Recovery phase}

Because of hypoglycemia, the insulin dose had to be reduced gradually and could be stopped completely at month 30,6 months after the development of PTDM. Thereafter, all fasting glucose levels and $\mathrm{HbAl} \mathrm{c}$ levels remained normal (fasting glucose $80-110 \mathrm{mg} / \mathrm{dl}(4.4-6.1 \mathrm{mmol} / \mathrm{l})$ and HbAlc 5.0 - 5.4\%). Hepatitis C PCR for RNA remained positive (at months $24,26,30,34,46$, and 77), but virall load decreased and liver tests improved gradually from month 24 onwards (Table 5. I). At month 77, the AxSym test for anti-HCV antibodies was positive and the HCVRIBA was positive for $\mathrm{c} 100 \mathrm{c}, \mathrm{c} 33 \mathrm{c}, \mathrm{c} 22$, and NS5.

Her body mass index did not change much during the last 4 years. At the time the insulin was stopped, it was still $20.3 \mathrm{~kg} / \mathrm{m}^{2}$. In between, it ranged from $20.1 \mathrm{~kg} / \mathrm{m}^{2}$ to $20.5 \mathrm{~kg} / \mathrm{m}^{2}$.

The tacrolimus dose had to be gradually increased from $1 \mathrm{mg} /$ day to $2.5 \mathrm{mg} /$ day to maintain target levels $(5-7 \mathrm{ng} / \mathrm{ml})$. The ratio level/dose decreased from 8.4 (at month 30) to $2.7 \mathrm{ng} / \mathrm{ml}$ per mg (at month 77 ). From month 42 onwards, the prednisolone dose was decreased to $5 \mathrm{mg}$ and $2.5 \mathrm{mg}$ on alternate days. Renal function remained excellent (creatinine at month $77,0.97 \mathrm{mg} / \mathrm{dl}(86 \mathrm{umol} / \mathrm{l})$ ) and there were no signs of chronic rejection.

Immediately after the cessation of insulin therapy at month 30, an IVGTT was performed. This IVGTT showed a low normal $k_{\mathrm{G}}$, while insulin secretion was markedly decreased and insulin resistance was increased compared to month 20 . Further IVGTTs were performed at months 38 and 77 , revealing a gradual improvement in $\mathrm{k}_{\mathrm{G}}$, with partial recovery of insulin secretion capacity and normalisation of insulin resistance (Table 5.1, Figure 5.2). 


\section{Discussion}

In this case report we describe a renal allograft recipient on tacrolimus and steroids with a well-documented episode of late PTDM during active hepatitis $C$ viral infection 2 years after transplantation. An association between $\mathrm{HCV}$ and diabetes mellitus was already described for chronic infection with $\mathrm{HCV}$, with or without cirrhosis ${ }^{12-19}$. However, this is, as far as we know, the first description of a welldocumented episode of late PTDM during a recently acquired and active hepatitis $C$ virus infection.

\section{Before contracting hepatitis $\mathrm{C}$ infection}

The gradual improvement in $\mathrm{k}_{\mathrm{g}}$, insulin secretion, and insulin resistance in the first year after transplantation is in accordance with what can be expected: decreasing steroid doses can account for a decrease in insulin resistance, while decreasing tacrolimus trough levels can account for an increase in insulin secretion ${ }^{24-25}$.

\section{Hepatitis $\mathrm{C}$ viral infection and PTDM}

Apart from using tacrolimus and low-dose steroids as immunosuppression ${ }^{1-3}$, our patient had no other known additional risk factors for PTDM: she was Caucasian, young, had no history of previous PTDM, a negative family history for diabetes mellitus, and a normal body mass index at the time of the PTDM episode. She had a normal glucose metabolism in the first year after transplantation. In our experience, patients using tacrolimus and steroids usually develop PTDM immediately after renal transplantation, when exposure to both tacrolimus and steroids is at the highest level ${ }^{11}$. However, 20 months after transplantation, at which time elevated liver test abnormalities were first noted, the insulin sensitivity index decreased considerably, while insulin resistance increased and insulin (and C-peptide) secretion decreased. An increase in insulin resislance has been observed during several kinds of infections ${ }^{26}$. The considerable increase in the tacrolimus level/dose ratio suggests that reduced cytochrome P450 tacrolimus metabolism ${ }^{27}$, due to liver dysfunction (caused by hepatitis $\mathrm{C}$ infection), may have been responsible for an increase in the systemic tacrolimus exposure. The decrease in insulin (and C-pepticle) secretion most likely was a result of this higher tacrolimus exposure $^{11.25}$. Additionally, the slight decreases in hemoglobin and albumin taken together with the liver dysfunction may also have resulted in a small contribution to the increased exposure to free (unbound) tacrolimus concentrations. There are several reports about an association between hepatitis $\mathrm{C}$ and diabetes mellitus, in patients using drugs which can interfere with glucose metabolism, such as for 
instance immunosuppressive agents, as well as in patients who do not use those kind of drugs ${ }^{12-19}$. Therefore direct toxic viral effects on $\beta$-cell function, although not yet shown, might also be suspected and play an additional role in the development of PTDM in this patient ${ }^{16}$. Of course, also a combination of these mechanisms may have been responsible for the reduced pancreatic $\beta$-cell secretion.

For obvious reasons, no stimulation tests could be performed during PTDM. Unfortunately, insulin/glucose ratio and HOMA-R could also not be determined, because samples for fasting insulin levels had not been taken at admittance for PTDM abroad. Basal C-peptide secretion was still normal and islet cell antibodies were negative, excluding type 1 diabetes mellitus. Insulin resistance must still have been high because the patient needed 60 units (approximately $1 \mathrm{U} / \mathrm{kg}$ ) of insulin therapy. The very low insulin secretion at month 30 suggests an additional marked reduction in insulin secretion during the period of PTDM.

\section{Recovery phase}

After tacrolimus dose reduction and after the decrease in HCV viral load and some improvement in parenchymal liver functions had occurred, insulin treatment could be stopped and an IVGTT was performed (month 30). Insulin resistance was still considerably increased, probably caused by active infection, while insulin secretion was very low. Thereafter, insulin resistance normalized, but insulin secretion and $\mathrm{k}_{\mathrm{G}}$ recovered only partially from month 30 to month 38 , and they remained unaltered from month 38 until the last IVGTT at month 77.

Whereas in the occurrence of PTDM, increased tacrolimus exposure must most likely have played an important role in the markedly decreased insulin secretion, this mechanism is in our opinion less certain for the persistant decrease in insulin secretion during more than 3 years of follow-up after the episode of PTDM. Generally, there is a good correlation between total tacrolimus exposure and tacrolimus trough levels ${ }^{28}$. For more than 3 years, from month 38 to month 77 , tacrolimus trough levels were kept between 5 and $7 \mathrm{ng} / \mathrm{ml}$, while albumin and hemoglobin levels were normal. Therefore, low tacrolimus exposure was likely during this period. Despite this low tacrolimus exposure, insulin secretion remained below the levels of months 1 and 5 posttransplantation, times when tacrolimus trough levels were much higher. Although we cannot completely rule out persistent pancreatic $\beta$-cell dysfunction due to longtime increased tacrolimus exposure in the past, the increase in insulin secretion after tacrolimus trough level reduction observed in an earlier study ${ }^{2.5}$ and the fact that we found no indications for chronic pancreatic $\beta$-cell toxicity during 3 years of tacrolimus use after renal transplantation in another study ${ }^{24}$ do not support such a hypothesis. This, combined with increasing evidence for an association between hepatitis $\mathrm{C}$ and diabetes 
mellitus, which was also observed in patients who do not use drugs that interfere with glucose metabolism ${ }^{12.18}$, suggests that toxic hepatitis $C$ viral effects on the $\beta$-cell might be considered as an explanation for the persistent decrease in insulin secretion. Further studies are necessary to elucidate this issue.

\section{Conclusion}

In this report we have described a renal allograft recipient, regularly evaluated by IVGTT, on tacrolimus and steroids. She had normal insulin resistance and insulin secretion in the first year posttransplantation, but developed an episode of PTDM 2 years posttransplantation, during hepatitis $C$ infection. She had to be treated with insulin for a period of 6 months. In the period of most active viral replication, reflected by the highest HCV viral loads and the severest parenchymal liver dysfunction, tacrolimus exposure increased, insulin resistance increased, and insulin secretion decreased markedly. During 4 years of follow-up, there was a gradual reduction in viral replication and a partial improvement in parenchymal liver test abnormalities, while insulin resistance normalized. Although PTDM resolved, pancreatic $\beta$-cell secretion remained approximately at a $50 \%$ level compared to the period before the hepatitis $\mathrm{C}$ infection. 


\section{References}

1. Weir MR, Fink JC, Risk for posttransplant diabetes mellitus with current immunosuppressive medications. Am J Kidney Dis 1999; 34: 1 13.

2. Krentz AJ, Dmitrewski J, Mayer D, Nattrass M. Effects of immunosuppressive agents. on glucose metabolism. Clin Immunother 1995; 4: 103-123.

3. Jindal RM, Sidner RA, Milgrom ML. Post-transplant diabetes mellitus. The role of immunosuppression. Drug Saf 1997; 16: 242-257.

4. Pirsch JD, Miller J, Deierhoi MH, Vincenti $F$, Filo RS. A comparison of tacrolimus (FK506) and cyclosporine for immunosuppression after cadaveric renal transplantation. FK506 Kidney Transplant Study Group. Transplantation 1997; 63: $977-983$.

5. Neylan JF for the FK506 Kidney Transplant Study Group. Racial differences in renal transplantation after immunosuppression with tacrolimus versus cyclosporine. FK 506 Kidney Transplant Study Group. Transplantation 1998; 65: 515-523.

6. Mayer AD, Dmitrewski J, Squifflet JP, et al. Multicenter randomized trial comparing tacrolimus (FK 506) and cyclosporine in the prevention of renal allograft rejection: a report of the European. Tacrolimus Multicenter Renal Study Group. Transplantation $1997 ; 64: 436-443$.

7. Vincenti F, Laskow DA, Neylan JF, Mendez R, Matas AJ. One-year follow-up of an open-label trial of FK506 for primary kidney transplantation: a report of the US Multicenter FK506 Kidney Transplant Group. Transplantation 1996; 61: 1576-1581.

8. Scantlebury V, Shapiro R, Fung J, et al. New onset of diabetes in FK506 vs cyclosporine-treated kidney transplant recipients. Transpl Proc 1991; 23: 3169-3170.

9. Golling $M$, Lehmann $T$, Senninger $N$, Herfarth $C$, Otto G. Tacrolimus reduction improves glucose metabolism and insulin secretion after liver transplantation. Transpl Proc 1996;28:3180-3182.

10. Hjelmesaeth $\mathrm{J}$, Hartmann A, Kofstad J, et al. Glucose intolerance after renal. transplantation depends upon prednisolone dose and recipient age. Transplantation 1997; 64: 979-983.

11. Duijhhoven van EM, Boots JMM, Christiaans MHL, Wolffenbuttel BHR, van Hooff JP. Influence of tacrolimus on glucose metabolism before and after renal transplantation; a prospective study. J Am Soc Nephrol 2001; 12:583-588.

12. Allison ME, Wreghitt T, Palmer CR, Alexander GJ. Evidence for a link between hepatitis $\mathrm{C}$ virus infection and diabetes mellitus in a cirrhotic population. I Hepatol. $1994 ; 21: 1135-1139$.

13. Knobler H, Stagnaro-Green A, Wallenstein S, Schwartz M, Roman SH. Higher incidence of diabetes in liver transplant recipients with hepatitis $C$. $\mathbb{C}$ Clin Gastroenterol 1998; 26:30-33.

14. Younossi ZM, Bratun WE, Protiva DA, Gifford RW, Straffon RA. Clironic viral hepatitis in renal transplant recipients with allografts functioning for more than 20 years. Ttansplantation 1999;67:272-275.

15. Mason AL, Lau Jy, Hoang $N$, et al. Association of diabetes mellitus and chronic hepatitis C virus infection. Hepatology 1999; 29:328-333.

16. Caronia $S$, Taylor $\mathrm{K}$, Pagliaro L, et al. Further evidence for an association between non-insulin dependent diabetes mellitus and chronic hepatitis $\mathrm{C}$ virus infection. Hepatology 1999; 30:1059-1063. 
17. Bigam DL, Penington JJ, Carpentier A, et al. Hepatitis C-related cirrhosis: a predictor of diabetes after liver transplantation. Hepatology $2000 ; 32 ; 87-90$.

18. Zein NN, Abdulkarim AS, Wiesner RH, Egan KS, Persing DH. Prevalence of diabetes. mellitus in patients with end-stage liver cirhosis due to hepatitis $C$, alcohol, or cholestatic disease. J Hepatol $2000: 32: 209-217$.

19. Gursoy $\mathbb{M}$, Guvener $\mathbb{N}_{\text {, Koksal }}$, et al. Impact of HCV infection on development of posttransplantation diabetes mellitus in renal allograft recipients. Transplant Proc 2000; $32: 561-562$.

20. Elmer DS, Hathaway DK, Gaber AO. Monitoring of pancreas allograft function with glucose disappearance rate (Kg): calculation and interpretation. I Transpl Coord 1994; 4: $7-11$.

21. Bergman RN, Fnegood DT, Ader M. Assessment of insulin sensitivity in viwo. Endocr Rev 1985; 6:45-86.

22. Matthews DR, Hosker JP, Rudenski AS, Naylor BA, Treacher DF, Tumer RC. Homeostasis model assessment: insulin resistance and beta-cell function from fasting. plasma glucose and insulin concentrations in man. Diabetologia $1985 ; 28: 412-419$.

23. Undre NA, Stevenson P, Schafer A. Pharmacokinetics of tacrolimus: clinically relevant aspects. Transplant Proc 1999; $31: 21 \mathrm{~S}-24 \mathrm{~S}$.

24. Dujinhoven van EM, Christiaans MHL, Boots JMM, Nieman FHM, Wolffenbuttel BHR., wan Hooff JP. Gllucose metabolism in the first 3 years after renal transplantation in patients on tacrolimus versus cyclosporine-based immunosuppression. J Am Soc Nephro1 2002; 13:213-220.

25. Boots JMM, van Duijnhoven EM, Christiaans MHL, Wolffenbuttel BHR, van Hooff IP. Glucose metabolism in renal transplant recipients on tacrolimus: the effect of steroid withdrawal and tacrolimus trough level reduction. J Am Soc Nephrol 2002; 13: $221-227$

26. Sammalkorpi K. Glucose intolerance in acute infections. J Intern Med 1989; 225: $15-19$.

27. Abu-Elmagd K, Fung JJ, Alessiani M, et al. The effect of graft function on FK506 plasma levels, dosages, and renal function, with particular reference to the liver. Transplantation 1991; $52: 71-77$.

28. Mekki Q, Lee C, Aweeka F, Laskow D, Neylan J, Mendez R, Steinmuller D, Schechter P. Phamacokinetics of tacrolinus (FK506) in kidney transplant patients. Clin Phamacol Ther 1993; 53 (2): 238, abstract PIII-130. 
Chapter 6a

\section{Tacrolimus dosing requirements in diabetic and nondiabetic patients calculated from pretransplantation data}

E van Duijnhoven, M Christiaans, A Schäfer, N Undre, J. van Hooff Transplant Proc: 1998: 30:1266-1267 


\section{Introduction}

Tacrolimus (FK506) is a macrolide with potent immunosuppressive effects ${ }^{1-2}$. It is highly lipophilic and binds strongly to plasma proteins $(>98.8 \%$ in rat, dog, monkey and man) and to erythrocytes ${ }^{3}$. The pharmacokinetics have previously been elucidated in healthy volunteers and liver and kidney transplant patients. Following oral administration, the drug is generally absorbed, with mean time to peak concentrations of 1.5 to 2 hours. In some patients, however, the drug may be absorbed over a prolonged absorption period, resulting in a more flat absorption profile ${ }^{4-6}$. The mean oral bioavailability is approximately $21 \%$ although there is large interindividual variability.

Patients with end-stage renal failure due to type 1 diabetes also have a high proportion of other diabetic complications. One of the complications of diabetes is disturbed gastrointestinal (Gl) motility due to autonomous neuropathy, eg, delayed emptying of the stomach, which can lead to impaired GI absorption of drugs? Therefore, in our centre the absorption characteristics of cyclosporine (CyA) were routinely assessed in diabetics before transplantation.

The objective of this study was to compare the absorption characteristics of tacrolimus in diabetic type 1 patients and in nondiabetic patients. To avoid complicating factors in the postoperative period such as differences in doses of steroids and concomitant immunosuppressives, we studied patients awaiting combined kidney-pancreas or kidney-alone transplantation.

\section{Patients and methods}

\section{Patients}

Patients were eligible for the pharmacokinetic study if they were

- awaiting kidney or combined kidney-pancreas transplantation

- aged 18 years or older

- capable of understanding the purposes and risks of the study, and had been fully informed.

Eighteen patients took part in this study, of which 7 were diabetic and 11 nondiabetic. The median age in the diabetic group was 45.3 (range $27.3-48.1$ ) years and in the nondiabetic group $51.9(37.0-61.8)$ years. Median weights for the two groups were $61.0(56.8-65.0)$ and $66.0(48.0-104.2) \mathrm{kg}$, respectively. 
Dosage and blood concentration monitoring of tacrolimus

Tacrolimus was admimistered orally after an overnight fast, followed by a standard continental breakfast 1 hour later. Median dose 0.15 (range 0.09 to 0.16 ) $\mathrm{mg} / \mathrm{kg}$. Blood concentration-time profiles ( 10 samples) were taken over a 12-hour period following the administration of tacrolimus. Tacrolimus concentrations in whole blood were determined by the IMx analyser (Abbott).

Pharmacokinetic data evaluation

Pharmacokinetic parameters were determined, using the computer program TOPFIT V2.0, and summary statistics were calculated using Excel v5.0. Comparisons between both groups were performed by the Wilcoxon unpaired signed rank test (SAS).

\section{Results}

Mean concentration-time profiles for both diabetic and nondiabetic patients can be seen in Figure 6a.1.

The calculated pharmacokinetic parameters, together with summary statistics, can be found in Table 6a.1. Median (range) maximum concentration $\left(\mathrm{C}_{\max }\right)$ for the diabetic and nondiabetic groups, respectively, were 40.3 (24.1 to 155.0$)$ and 55.2 $(38.5$ to 117.0$) \mathrm{ng} / \mathrm{ml}(\mathrm{P}=0.28)$. The median time to maximum concentration $\left(\mathrm{t}_{\text {max }}\right)$ was 1.0 hour for both groups $(\mathrm{P}=0.92)$. Area under the concentration-time curve (AUC) was calculated for the 12-hour period, and the median values were 145.4 (65.9 to 457.0$) \mathrm{ng} . \mathrm{h} / \mathrm{ml}$ (diabetic group) and $236.0(58.1$ to 255.0$) \mathrm{ng} . \mathrm{h} / \mathrm{ml}$ (nondiabetic group) $(P=0.42)$.

Table $6 \mathrm{a} . \mathrm{I}$. Pharmacokinetic parameters of tacrolimus for diabetics and nondiabetics.

\begin{tabular}{|c|c|c|c|c|c|c|}
\hline & \multicolumn{3}{|c|}{ Diabetic patients $(n=7)$} & \multicolumn{3}{|c|}{ Nondiabetic Patients ( $n=11$ ) } \\
\hline & $\begin{array}{c}\mathrm{C}_{\mathrm{nins}} \\
(\mathrm{ng} / \mathrm{ml})\end{array}$ & $\begin{array}{l}t_{\max } \\
(\mathrm{h})\end{array}$ & $\begin{array}{c}\mathrm{AUC}_{1} \\
(\mathrm{ng} / \mathrm{h} / \mathrm{ml})\end{array}$ & $\begin{array}{c}C_{\max } \\
(\mathrm{ng} / \mathrm{ml})\end{array}$ & $\begin{array}{l}t_{\text {mins }} \\
(\mathrm{h}) \\
\end{array}$ & $\begin{array}{c}A \cup C_{i} \\
\text { (ng.h/mI) }\end{array}$ \\
\hline Median & 40.3 & 1 & 145.4 & 55.2 & 1 & 236.0 \\
\hline Minimum & 24.1 & 0.75 & 65,93 & 38.5 & 0.5 & 58.1 \\
\hline Maximum & $\| 5.5 .0$ & 2 & 457.0 & 117.0 & 2 & 646.6 \\
\hline
\end{tabular}




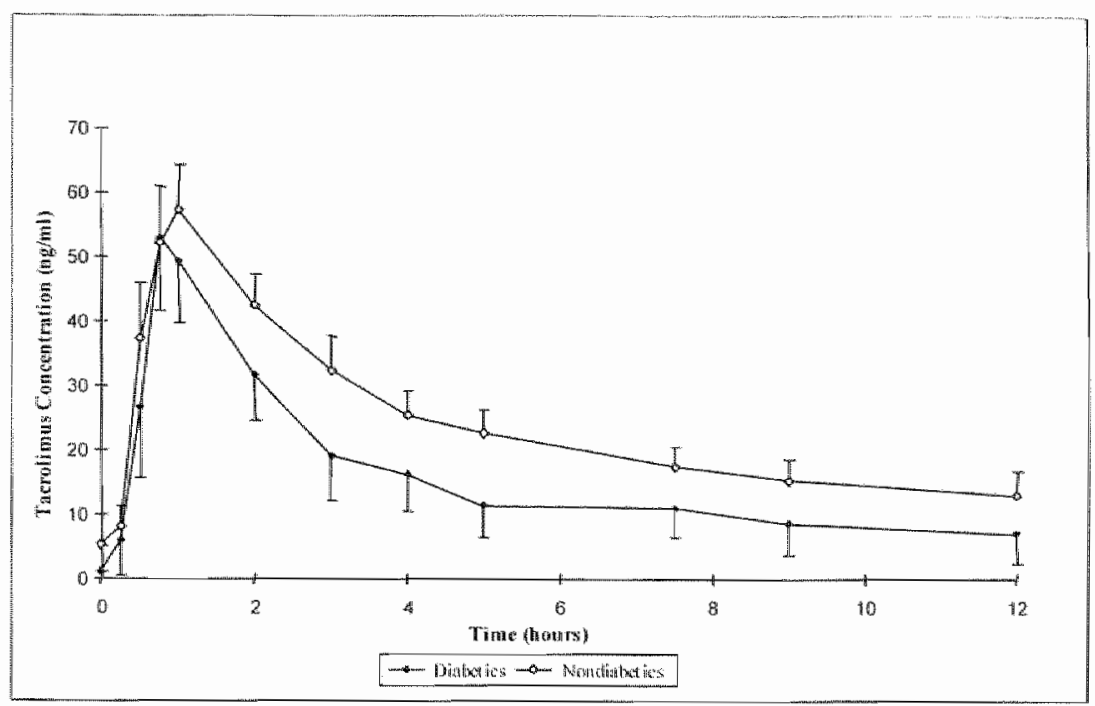

Figure 6a.1 Blood concentration-time profiles ( $\mathrm{SEM}$ ) for diabetics and nondiabetics.

\section{Discussion and conclusion}

Whereas the median $\mathrm{C}_{\max }$ and median $\mathrm{t}_{\max }$ are comparable, median AUC is $38 \%$ lower in the diabetic group. Although this difference is statistically not significant, these data suggest that diabetic kidney or kidney-pancreas recipients may require a higher initial dose to achieve target blood levels. However, in view of the large interindividual variability in oral bioavailability, a more logical approach is to perform routine pretransplant pharmacokinetic profiles to detect patients with low systemic exposure, as has been suggested for cyclosporine. 


\section{References}

1. European FK 506 Multicentre Liver Study Group. Lancet 1994; 344: 423.

2. European Tacrolimus Multicentre Renal Study Group. Transplantation 1997; 64:436.

3. Jay JE, Sampare, $K$ wateng $E$, et al. Transplant Proc 1991;23:2760.

4. Aweeka FT, Benet LZ, Gambertoglio JG et al. Clinical Pharmacol Ther 1993; $53: 151$.

5. Lee C, Jusko W, Sheafer M et al. Clinical Pharmacol Ther 1993; $33: 181$.

6. Christiaans M, Beysens T, wan Duijnhoven E, et al. Transplant Proc 1998; 30: 17711773.

7. Horowitz M., Fraser RJ. Scand. J Gastroenterol Suppl 1995; $213: 7$.

8. Kahan BD, Ried M, Newburger. I Transplant Proc 1983; 15: 446. 


\section{Chapter 6 b}

\section{The effect of breakfast on the oral bioavailability of tacrolimus in diabetic and nondiabetic patients before transplantation}

E van Duijnhoven, M Christiaans, N Undre, P Stevenson, J. van Hooff Transplant Proc 1998; 30: 1268-1270 


\section{Introduction}

Absorption of tacrolimus has been shown to be highly variable between individuals. After oral administration, the drug is generally absorbed with mean time to peak concentrations of 1.5 to 2 hours. However, in some patients the drug may be absorbed over a prolonged absorption period, resulting in a more flat absorption profile $\mathrm{e}^{1-3}$. The mean bioavailability is approximately $21 \%$ although there is large inter-individual variability.

After transplantation, we observed that in a type 1 diabetic renal transplant recipient, it was necessary to increase the dose of tacrolimus with $100 \%$ to attain the same trough level when tacrolimus was administered during the nonfasting as compared to the fasting state. This could be explained by disturbed gastrointestinal (Gi) motility due to autonomous neuropathy, eg, delayed emptying of the stomach, which can lead to impaired GI absorption of drugs, especially if taken with food". Because postoperative factors, such as steroid use, may also influence the pharmacokinetic profile of tacrolimus, patients with end-stage renal disease awaiting transplantation were evaluated. In the fasting state before transplantation, pharmacokinetic profiles were largely comparable between diabetic and nondiabetic patients, however, a $38 \%$ decrease in the absorption of tacrolimus was found in diabetics."

The objective of this study was to evaluate the effect of food on the oral bioavailability of tacrolimus in diabetic type I patients awaiting combined kidneypancreas transplantation and nondiabetic patients awaiting kidney transplantation.

\section{Patients and methods}

\section{Subjects}

Patients entering the study fulfilled the following criteria: age 18 years or older, capable of understanding the purposes and risks of the study and fully informed, had end-stage renal failure awaiting either combined kidney-pancreas transplantation (type 1 diabetic patients) or kidney transplantation (nondiabetic patients).

Seventeen patients took part in the study, of which 7 were diabetic and 10 nondiabetic. The median age in the diabetic group was 45.3 (range $27.3-48.1$ ) years and in the nondiabetic group $51.5(37.0-61.8)$ years. The median weights of the two groups were $61.2(56.8-65.0) \mathrm{kg}$ and $64.8(48.0-92.0) \mathrm{kg}$, repectively. 
Dosage and blood concentration monitoring of tacrolimus

In the fasted phase of the study, tacrolimus was administered orally after an overnight fast, with a standard breakfast given 1 hour later. In the nonfasted phase, patients received tacrolimus orally together with a standard breakfast. The median dose was $0.15(0.11-0.16) \mathrm{mg} / \mathrm{kg}$. The breakfast delivered $460 \mathrm{kCalories}$, of which $43 \%$ were derived from fat.

Blood concentration-time profiles (10 samples) were taken during a 12-hour period after the administration of tacrolimus. Tacrolimus concentrations in whole blood were determined by the IMx analyser (Abbott).

Pharmacokinetic data evaluation

Pharmacokinetic parameters were determined, using the computer program TOPFIT $\sqrt{ } 2.0$, and summary statistics were calculated using Excel v5.0. Comparisons between both groups were performed by the Wilcoxon unpaired signed rank test (SAS).

\section{Results}

Pharmacokinetic parameters and descriptive statistics are shown in Tables 6b.1(nondiabetic patients) and 6b.2 (type 1 diabetic patients).

In nondiabetic patients, the median maximum concentration $\left(\mathrm{C}_{\max }\right)$ decreased from 53.3 to $41.7 \mathrm{ng} / \mathrm{ml}$ when tacrolimus was taken after food $(\mathrm{P}=0.23)$. The median time to achieve maximum concentration $\left(t_{\text {max }}\right)$ increased from 1 hour in the fasted state to 1.5 hours after ingestion of food $(\mathrm{P}=0.09)$ (Figure 6b.1).

There was no significant difference in median area under the concentration-time curve ( $A U C_{1}$ ) during the dosing period between the two profiles; 232.1 (58.1 to 646.6) ng.h/ml fasted and 166.8 (46.9 to 664.0) ng.h/ml nonfasted $(P=0.92)$.

In diabetic patients, the median $\mathrm{C}_{\max }$ decreased from 40.3 to $22.7 \mathrm{ng} / \mathrm{ml}$ when tacrolimus was taken after food $(\mathrm{P}=0.02)$. An increase in median time to achieve maximum concentration ( $\mathrm{t}_{\text {max: }}$ ) was also apparent, from 1 hour in the fasted state to 2 hours after ingestion of food ( $\mathrm{P}=0.02$ ) (Figure 6b.2).

There was a small difference in median $\mathrm{AUC}_{1}$ during the dosing period between the two profiles; $145.4(65.9$ to 475.0$) \mathrm{ng} . \mathrm{h} / \mathrm{ml}$ fasted and $105.6(60.8$ to 450.9$) \mathrm{ng} . \mathrm{h} / \mathrm{ml}$ nonfasted $(\mathrm{P}=0.30)$. 
Table $6 \mathrm{~b} .1$ Pharmacokinetic parameters of tacrolimus in nondiabetic patients.

\begin{tabular}{|c|c|c|c|c|c|c|}
\hline \multirow[b]{2}{*}{ Patient No. } & \multicolumn{3}{|c|}{ Fasted } & \multicolumn{3}{|c|}{ Notfasted } \\
\hline & $\begin{array}{c}\mathrm{C}_{\mathrm{max}} \\
(\mathrm{ng} / \mathrm{ml})\end{array}$ & $\begin{array}{l}t_{\text {max }} \\
\text { (h) }\end{array}$ & $\begin{array}{c}\mathrm{AUC} \\
\text { (ng.h/ml) }\end{array}$ & $\begin{array}{l}\mathrm{C}_{\mathrm{m} \text { an }} \\
\mathrm{g} / \mathrm{mll})\end{array}$ & $\begin{array}{l}t_{\text {maxix }} \\
\text { (h) }\end{array}$ & 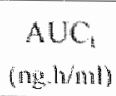 \\
\hline 1 & 74.6 & 0.75 & 58.1 & 41.1 & 0.75 & 184.9 \\
\hline 2 & 38.9 & 2 & 209.1 & 32.3 & 3 & 173.7 \\
\hline 3 & 81.5 & 1 & 646.6 & 85.8 & 2 & 6640 \\
\hline 4 & 38.5 & 1 & 133.9 & 42.3 & 0.75 & 159.8 \\
\hline 5 & 66.2 & 0.75 & 263.0 & 103.0 & 0.75 & 430.1 \\
\hline 6 & 51.4 & 2 & 274.2 & 57.5 & 2 & 429.9 \\
\hline 7 & 117.0 & 0.75 & 369.5 & 86.9 & 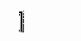 & 154.2 \\
\hline 8 & 44.6 & 0.5 & 62.4 & 17.6 & 2 & 81.3 \\
\hline 9 & 55.2 & 1 & 255.0 & 17.4 & 5 & 152.8 \\
\hline 10 & 47.6 & 1 & 200.1 & 19.4 & 1 & 46.9 \\
\hline Median & 53.3 & 1 & 232. & 41.7 & 1.5 & 166.8 \\
\hline Minimum & 38.5 & 0.5 & 58.1 & 17.4 & 0.75 & 46.9 \\
\hline Maximum & 117.0 & 2 & 646.6 & 103.0 & 5 & 664.0 \\
\hline
\end{tabular}

$\mathrm{C}_{\text {max }}=$ maximum concentration; $\mathrm{t}_{\text {mux }}=$ time to achieve maximum concentration; $A U C_{i}=$ area under the concentration-time curve.

Table 6b.2 Pharmacokinetic parameters of tacrolimus in diabetic patients.

\begin{tabular}{|c|c|c|c|c|c|c|}
\hline \multirow[b]{2}{*}{ Patient No. } & \multicolumn{3}{|c|}{ Fasted } & \multicolumn{3}{|c|}{ Nonlasted } \\
\hline & $\underset{(\mathrm{ng} / \mathrm{ml})}{\mathbb{C}_{\mathrm{nax}}}$ & $\begin{array}{l}\mathrm{t}_{\max } \\
(\mathrm{h})\end{array}$ & $\begin{array}{c}\text { AUC }_{8} \\
(\mathrm{ng} h / \mathrm{ml})\end{array}$ & $\begin{array}{c}\mathrm{C}_{\max } \\
(\mathrm{ng} / \mathrm{mil})\end{array}$ & $\begin{array}{l}\text { tmax } \\
\text { (b) }\end{array}$ & $\begin{array}{c}\mathrm{AUC}_{1} \\
(\mathrm{agg} h / \mathrm{m} /)\end{array}$ \\
\hline 1 & 24.1 & 1 & 65.9 & 12.8 & 2 & 105.6 \\
\hline 2 & 40.3 & 2 & 170.7 & 30.3 & 3 & 93.1 \\
\hline 3 & 57.9 & 0.75 & 145.4 & 22.7 & 1 & 1349 \\
\hline 4 & 31.6 & 1 & 107.7 & 7.5 & 4 & 60.8 \\
\hline 5 & 67.5 & 0.75 & 248.7 & 51.3 & 2 & 291.7 \\
\hline 6 & 155.0 & 1 & 457.0 & 67.7 & 2 & 450.9 \\
\hline 7 & 29.0 & 0.75 & 144.3 & 21.7 & 1 & 63.9 \\
\hline Median & 40.3 & 1 & $\| 45.4$ & 22.7 & 2 & 105.6 \\
\hline Minimum & 24.1 & 0.75 & 65.9 & 7.5 & $\pi$ & 60.8 \\
\hline Maximum & 155.0 & 2 & 457.0 & 67.7 & 4 & 450.9 \\
\hline
\end{tabular}

$\mathrm{C}_{\mathrm{m}: \mathrm{x}}=$ maximum concentration; $\mathrm{t}_{\text {max }}=$ time to achieve maximum concentration; $A U \mathrm{C}_{1}=$ area under the concentration-time curve. 


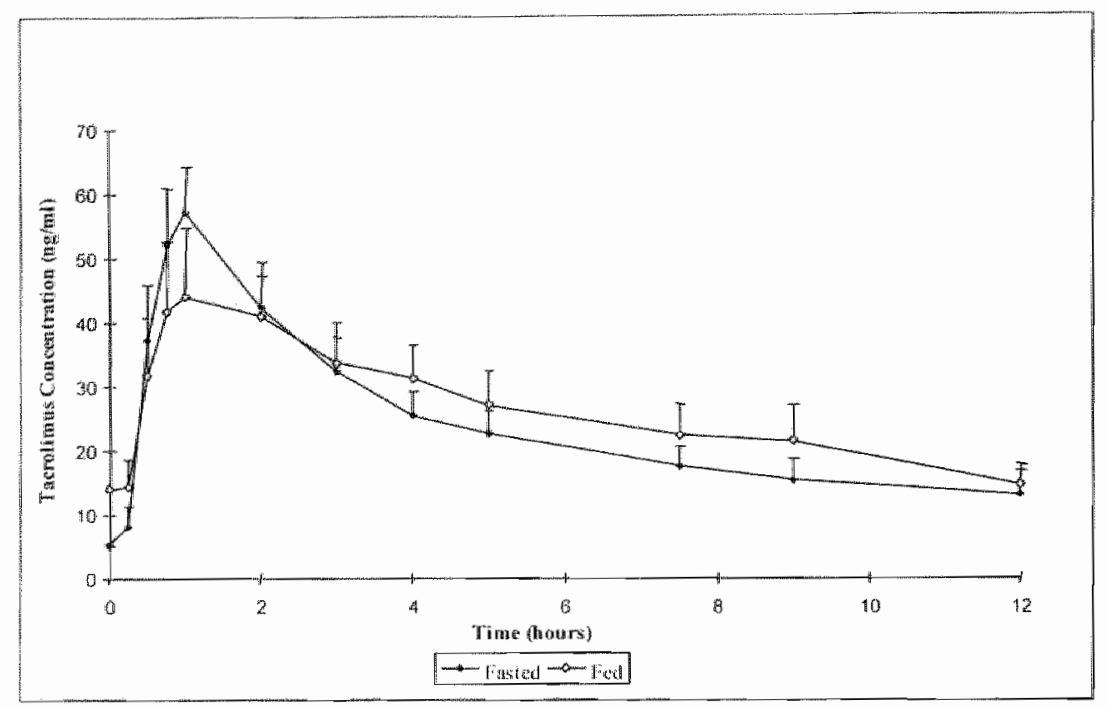

Figure 6b.1 Mean ( \pm SEM) concentration-time profiles for both fasted and nonfasted states (nondiabetics).

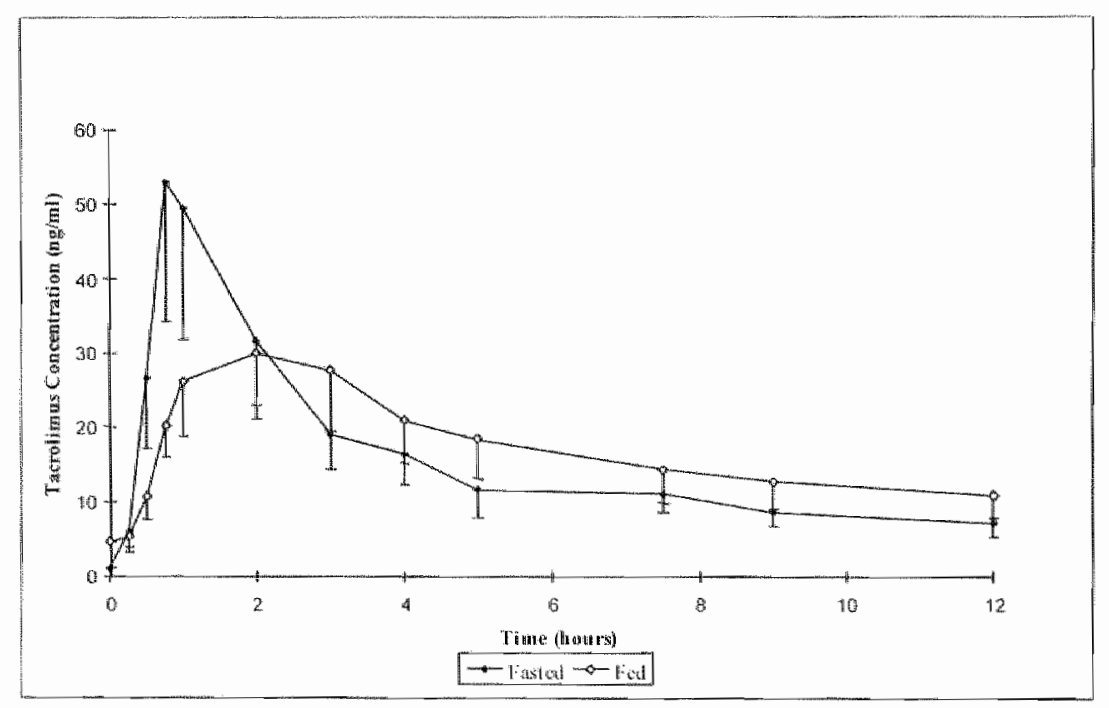

Figure 6b.2 Mean ( 1 SEM) concentration-time profiles for both fasted and nonfasted states (diabetics). 


\section{Discussion and conclusion}

In a previous fasting study between diabetics and nondiabetics before renal transplantation, a $38 \%$ decrease in absorption of tacrolimus was observed in diabetics compared to nondiabetics. In the current study, pharmacokinetic profiles in fasted and nonfasted state in nondiabetic and diabetic patients were compared. When tacrolimus was taken together with a continental breakfast in nondiabetic patients, there was a $22 \%$ decrease in median $\mathrm{C}_{\max }$ and $50 \%$ increase in $t_{\max }$, while $\mathrm{AUC}_{\mathrm{f}}$ did not change. This suggests that in nondiabetic patients tacrolimus can be taken together with food. These findings are a confirmation and extension of our observations obtained in the early postoperative period ${ }^{3}$.

In diabctic patients, the median $\mathrm{C}_{\max }$ decreased by $44 \%$, the median $\mathrm{t}_{\max }$ doubled, while the median $\mathrm{AUC}_{1}$ remained unchanged. This indicates that in both the diabetic and nondiabetic patients, although the rate of absorption is slowed, the extent of absorption is not affected.

Although the observed changes in $\mathrm{C}_{\max }$ and $\mathrm{t}_{\max }$ are more pronounced in diabetic than nondiabetic patients, the delayed absorption in the latter group does not effect adversely overall systemic availability of tacrolimus when taken with food.

However, individually there may be important exceptions, eg, diabetic patient 4 (Table 6b.2) showed a decrease in $\mathrm{C}_{\max }$ of $75 \%$ and an increase of $\mathrm{t}_{\max }$ from 1 to 4 hours, and a decrease in $\mathrm{AUC}_{\mathrm{i}}$ of more than $40 \%$. These changes are clinically relevant.

In both nondiabetic as well as type 1 diabetic patients with end-stage renal failure, the overall effect on the absorption of tacrolimus $\left(A \cup C_{1}\right)$ when administered after a standard continental breakfast is small and statistically insignificant. However, in diabetic patients, the $\mathrm{C}_{\max }$ is decreased and $\mathrm{t}_{\max }$ is prolonged $(\mathrm{P}=0.02)$. Moreover, some individuals show a considerable, clinically important decrease in the absorption of tacrolimus when taken together with food and in such patients (eg, patient 4), careful dose adjustment may be necessary if tacrolimus is taken with food. 


\section{References}

I. Aweeka FJ, Benet LZ, Gambertoglio $\mathbb{I} G$, et al. Clinical Pharmacol Ther 1993; 53 : 151.

2. Lee $C$, Jusko $W$, Sheafer $M$, el al. Clinical Phamacol Ther 1993; 53: 181.

3. Christians $M$, Beysens T, van Duijnhoven E, et al. Transplant Proc 1998; 30: 1271. 1273.

4. Horowitz M. Fraser RJ. Scand. J. Gastroenterol. Suppl $1995 ; 213.7$.

5. Duijnhoven van E, Christiaans $M$, Schäfer A, et al. Transplant Proc 1998; 30: 12661267. 


\section{Chapter 6 c}

\section{Effect of breakfast on the oral} biovailability of tacrolimus and changes in pharmacokinetics at different times posttransplant in renal transplant recipients

\footnotetext{
M Christiaans, E van Duijnhoven, T Beysens, N Undre, A Schäfer,

J. van Hooff

Transpiant Proc 1998; 30: $1271-1273$
} 
Changer to 


\section{Introduction}

Tacrolimus is a macrolide with potent immunosuppressive effects. It has been successfully used as a prophylactic immunosuppressant for solid organ transplantation ${ }^{1-4}$. Tacrolimus is highly lipophilic and binds strongly to plasma proteins ( $>98.8 \%$ in rat, dog, monkey, and man) and to erythrocytes ${ }^{5}$. A study conducted in stable liver tramsplant patients has shown that the oral bioavailability of tacrolimus is decreased if tacrolimus is taken after food containing a moderate fat content $(34 \% \text { of the calories were derived from fat })^{6}$. This observation has led to the recommendation that tacrolimus be administered on an empty stomach: 1 hour before or 2 hours after meals. The objectives of this study were to estimate oral clearance of tacrolimus in stable kidney transplant patients and to evaluate the effect of food on relative oral bioavailability at various times after transplantation.

\section{Materials and methods}

\section{Subjects}

Patients were eligible for the pharmacokinetic study if they fulfilled the following criteria: stable kidney transplant function; receiving tacrolimus from day 0 onwards, age 18 years or older, capable of understanding the purposes and risks of the study, fully informed, and given informed consent to participate in the study.

\section{Dosage and blood concentration monitoring of tacrolimus}

The effect of food on the oral bioavailabilty of tacrolimus was evaluated at 3 weeks, 6 months, and 1 year after transplantation. On each occasion, on two consecutive days, patients received an oral dose of tacrolimus. In the fasted phases of the study, tacrolimus was administered after an overnight fast, with a standard breakfast given 1 hour later. In the nonfasted phase, patients received tacrolimus immediately after a standard breakfast. The content of the breakfast was calculated from the Dutch Standardized Nutrients List (NEVO, version 1996). It contained $1928 \mathrm{~kJ}(460 \mathrm{kCal})$ of energy of which $43 \%$ was derived by fat.

Blood concentration-time profiles were taken over a 12-hour period ( 10 samples) after the administration of an oral dose of tacrolimus. Tacrolimus concentrations in whole blood were determined by the IMx analyser (Abbott). 
Intake of tacrolimus together with food

At 1 year after transplantation 14 of these patients and one rescue patient were offered the possibility to transfer to taking tacrolimus with food. The increase in dose of tacrolimus needed to maintain therapeutic levels was calculated from the relative bioavailability in individual patients based on the results of the fasted and nonfasted data at I year posttransplantation. To be safe, the actual administered dose of tacrolimus was 10 to $15 \%$ above the calculated dose. Thereafter, the oral dose of tacrolimus was adjusted to maintain a trough level between 7 and $9 \mathrm{ng} / \mathrm{ml}$.

Pharmacokinetic data evaluation

Pharmacokinetic parameters were determined, using the computer program TOPFIT v2.0 and summary statistics were calculated using Excel v5.0. Analysis of variance for repeated measurements was used for comparing the fasting profiles of the patients between different occasions. Wilcoxon matched pairs signed rank sum test was performed for comparing fasted and nonfasted data at each occasion. Both of these tests were formed using SAS.

\section{Results}

Sixteen patients participated in the first study, although complete profiles for all three periods were only collected from 10 patients. The mean ages, weights and doses of FK 506 of the patients during all phases of the study can be found in Table $6 \mathrm{c} .1$.

Table 6c. I Demographics and dosing data.

\begin{tabular}{lcccccc}
\hline & \multicolumn{2}{c}{ Week 3} & \multicolumn{2}{c}{ Month 6} & \multicolumn{2}{c}{ Month 12 } \\
& $\begin{array}{c}\text { Weight } \\
(\mathrm{kg})\end{array}$ & $\begin{array}{c}\text { Dose } \\
(\mathrm{mg} / \mathrm{kg})\end{array}$ & $\begin{array}{c}\text { Weight } \\
(\mathrm{kg})\end{array}$ & $\begin{array}{c}\text { Dose } \\
(\mathrm{mg} / \mathrm{kg})\end{array}$ & $\begin{array}{c}\text { Weight } \\
(\mathrm{kg})\end{array}$ & $\begin{array}{c}\text { Dose } \\
(\mathrm{mg} / \mathrm{kg})\end{array}$ \\
\hline Mean & 68.1 & 0.157 & 67.3 & 0.078 & 67.1 & 0.056 \\
SD & 11.7 & 0.068 & 9.2 & 0.045 & 8.1 & 0.033 \\
n & 14 & 14 & 13 & 13 & 14 & 14 \\
Range & $53-98$ & $0.080-0.280$ & $56-91$ & $0.025-0.190$ & $52-82$ & $0.020 \times 0.125$ \\
\hline
\end{tabular}

Selected mean pharmacokinetic parameters, together with descriptive statistics are shown in Table $6 c .2$, together with percentage changes in area under concentrationtime curve $\left(A \cup C_{1}\right)$ and maximum concentration $\left(C_{\max }\right)$ between fasted and nonfasted states for all three periods. Blood concentration-time profiles for fasted and nonfasted states are shown for all three phases in Figure 6c.]. 
Table 6c.2 Selected pharmacokinetic parameters of tacrolimus.

\begin{tabular}{|c|c|c|c|c|}
\hline Time posttransplant & Parameter & $\mathrm{C}_{\mathrm{naxax}}(\mathrm{ng} / \mathrm{ml})$ & $t_{\operatorname{man}}(\mathrm{h})$ & AUC $(n g h / m)$ \\
\hline Week 3 & $\begin{array}{l}\text { Fasted } \\
\text { Nonfasted } \\
\% \text { Difference }\end{array}$ & $\begin{array}{c}49.8 \pm 15.7 \\
40.5 \pm 21.0 \\
-15\end{array}$ & $\begin{aligned} 1.0 \pm 0.6 \\
1.8 \pm 1.3 \\
+80\end{aligned}$ & $\begin{array}{c}264 \pm 60 \\
261+80 \\
-2\end{array}$ \\
\hline Month 6 & $\begin{array}{l}\text { Fasted } \\
\text { Nonfasted } \\
\% \text { Difference }\end{array}$ & $\begin{array}{c}38.9 \pm 14.6 \\
23.0 \pm 11.0 \\
-38\end{array}$ & $\begin{array}{r}1.2 \pm 0.3 \\
1.7 \pm 0.9 \\
+42\end{array}$ & $\begin{array}{r}203 \pm 58 \\
170 \pm 57 \\
-12\end{array}$ \\
\hline Month 12 & $\begin{array}{l}\text { Fasted } \\
\text { Nonfasted } \\
\% \text { Difference }\end{array}$ & $\begin{array}{c}32.3 \pm 18.7 \\
21.5 \pm 10.1 \\
-21\end{array}$ & $\begin{aligned} 1.1 & \neq 0.5 \\
1.5 & +0.8 \\
& +36\end{aligned}$ & $\begin{array}{c}170 \pm 60 \\
153 \pm 56 \\
-9\end{array}$ \\
\hline
\end{tabular}

$\mathrm{C}_{\text {nax }}=$ maximum concentration; $\mathrm{t}_{\mathrm{max}}=$ time to achieve maximum concentration; $\mathrm{AUC}_{\mathrm{f}}=$ area under concentration-time curve.

The oral clearances were calculated for the 10 patients who participated in all three phases of the study and are shown in Figure 6c.2. There was a trend towards a decrease in the oral clearance of tacrolimus with time posttransplant (mean value of $38.7 \mathrm{l} / \mathrm{h}$ at week 3 to 33.7 at month 6 and $25.4 \mathrm{l} / \mathrm{h}$ at month 12 ).

The effect of food on the oral bioavailability was assessed by comparing the $\mathrm{C}_{\max }$ and $\mathrm{AUC}_{(0-12)}$ on consecutive days (fasting and nonfasting) at week $3 \quad(n=14)$, month $6(n=13)$ and month $12(n=14)$. Relative to the fasted state, the mean $C_{\text {max }}$ was decreased by $15 \%$ at week $3,38 \%$ at month 6 , and $21 \%$ at month 12 . Corresponding decreases in $\mathrm{AUC}_{(0-12)}$ were $2 \%, 12 \%$, and $9 \%$, respectively. Both $A U C$ and $C_{\max }$ showed higher interpatient variability in the nonfasting state than in the fasted state.

Fifteen patients participated in the second part of the study. The mean trough level at entry was $9.7 \mathrm{ng} / \mathrm{ml}$ (range 5.3 to $16.2 \mathrm{ng} / \mathrm{ml}$ ) with a mean daily oral dose of 7.6 $\mathrm{mg}$ ( 3 to $16 \mathrm{mg}$ ). When tacrolimus was administered with food, the mean dose was increased by $33 \%$, resulting in a mean increase in trough concentrations of $24 \%$. The dose of tacrolimus was subsequently adjusted in 2 to 3 months to achieve the target trough level of $7-9 \mathrm{ng} / \mathrm{ml}$. The actual mean decrease in dose of tacrolimus was $4 \%$, while the mean trough level decreased by $18 \%$ (Figure $6 \mathrm{c} .3$ ). There were no adverse events on kidney function. Although changes in individual trough levels ranged from +18 to $-64 \%$, stressing the need for stringent monitoring, all levels were within the therapeutic range. 

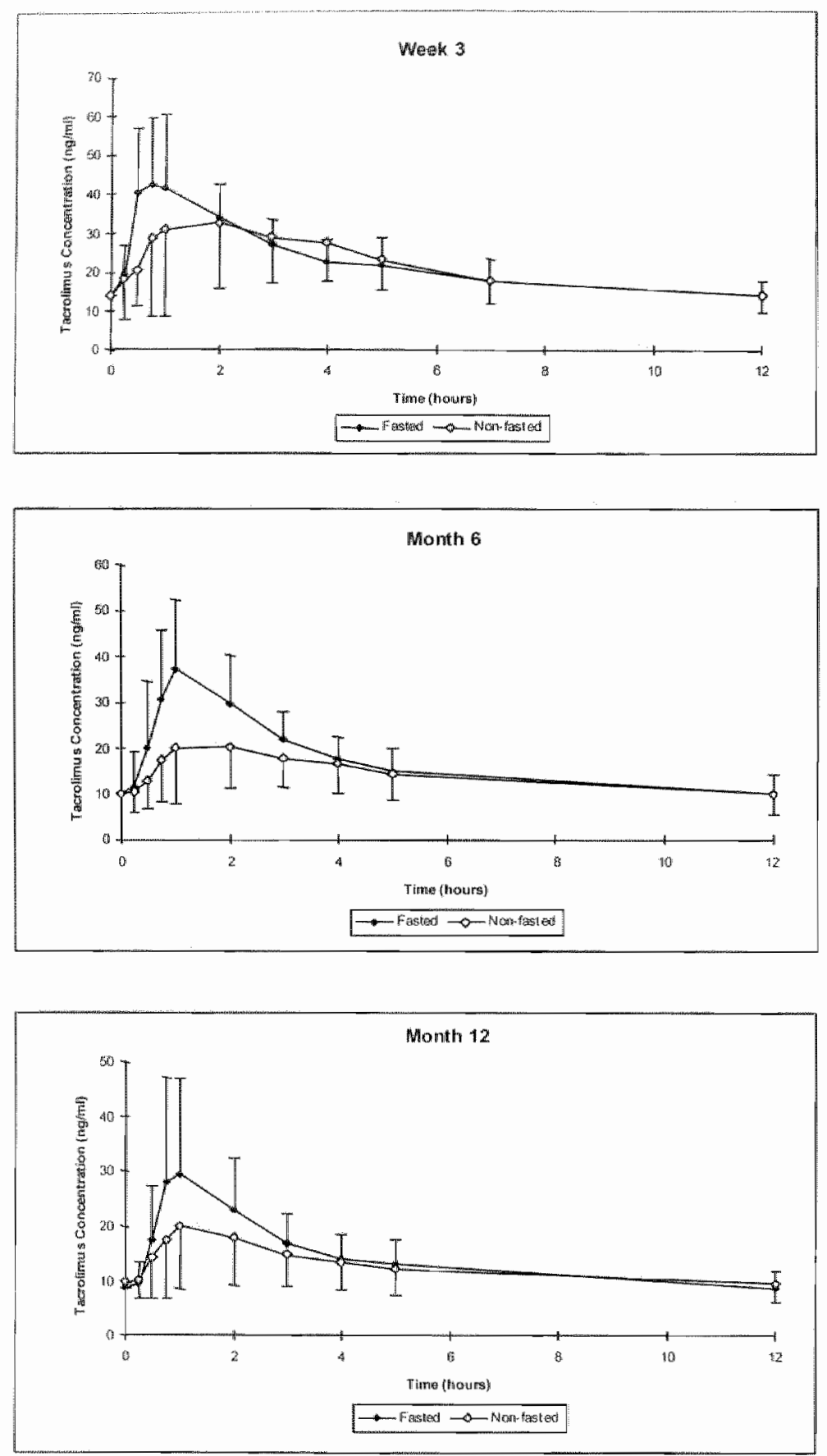

Figure 6c.l Blood concentration-time profiles ( \pm SD) for all three phases of the study. 


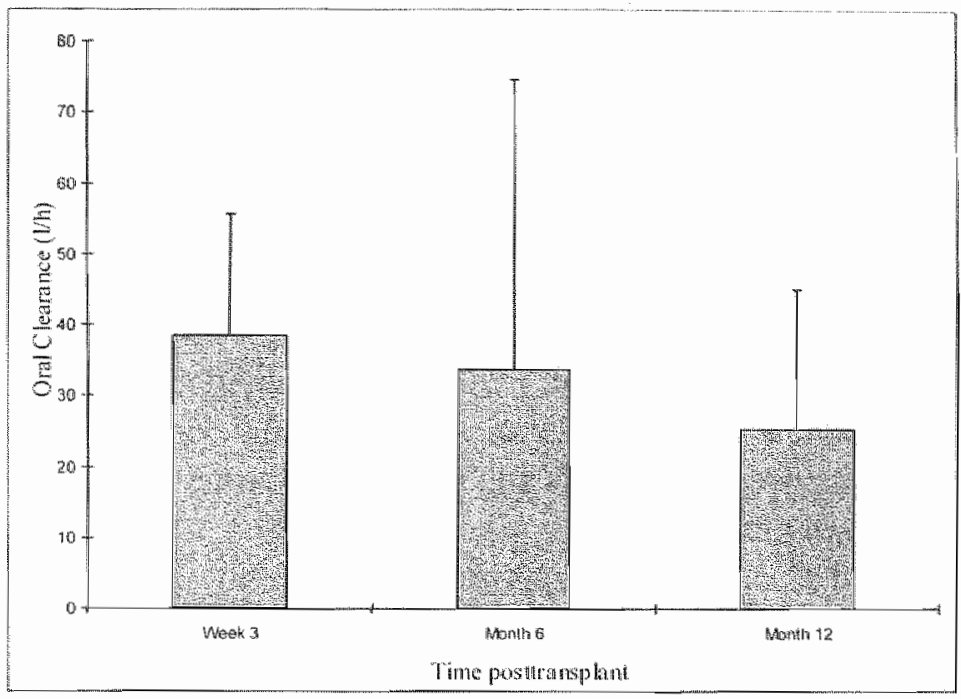

Figure 6c.2 Oral clearance values $(/ / / h)$ with SDs for patients who participated in all three phases of the study $(n=10)$.

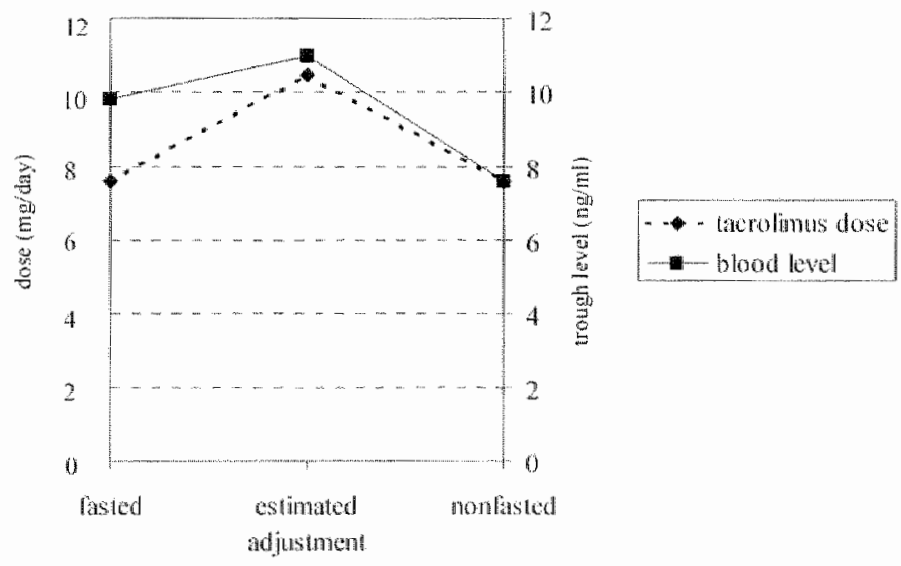

Figure 6c.3 Changes in mean dosing and trough level of tacrolimus when taken rogether with food instead of fasting I year after transplantation.

\section{Discussion and conclusion}

The apparent decreases in oral clearance suggest that dosage requirements decline over time. The exact reason for this is not yet known. It may possibly be related to the lower haematocrit and serum albumin levels immediately posttransplant which 
result in a higher free fruction of tacrolimus available for metabolism. As the patient recovers from transplantation, the haematocrit and serum albumin levels return to normal and free tacrolimus levels are decreased. Alternatively, the lower doses of steroids at the later time points after transplantation $(15 \mathrm{mg} / \mathrm{d}$ at week 3 and $5 \mathrm{mg} / \mathrm{d}$ from week 6 onwards) are known to result in lower metabolism of tacrolimus.

The decrease in mean $\mathrm{C}_{\text {max }}$ and increase in the median $t_{\text {max }}$ when tacrolimus was taken in a nonfasted state, is indicative of a decrease in the rate of absorption in the first 2 hours of the profile. However, these differences did not achieve statistical significance. Of interest was the lack of any significant differences in the AUC values between the two profiles. This might indicate absorption of the drug later at a more distal part of the gut.

The unchanged AUC values between fasted and nonfasted states are in contrast to an earlier study in stable liver transplant patients in which statistically significant reductions in both the rate and extent of absorption of tacrolimus were observed following administration after food containing a moderate fat content ${ }^{6}$. The fat content of the breakfast used in the current study was comparable ( $43 \%$ versus $34 \%$ ). Thus, the smaller "food" effect observed in this study cannot be explained by the different composition of the food.

Patients find it inconvenient to take tacrolimus on an empty stomach and to fast for another hour afterwards. From our data we suggest that the patients wishing to switch to taking tacrolimus with food 1 year after transplantation should be on a stable dose that produces trough level of 8 to $10 \mathrm{ng} / \mathrm{ml}$ and that this dose should be increased by $25 \%$, when taking tacrolimus with food.

At an earlier time after transplantation this might be performed easier. Our data show that the mean difference in AUC between the fasted and nonfasted profile is only $2 \%$ at 3 weeks after transplantation. This probably is the best period to start taking tacrolimus together with food. High trough levels shortly after transplantation may add to the safety of the procedure. Stringent monitoring of trough level is necessary because of the higher interpatient variability in oral bioavailability in the nonfasting state. 


\section{References}

1. European FK506 Multicentre Liver Study Group. Lancet 1994; $344: 423$.

2. The US Multicenter FK506 Liver Study Group. N Engl J Med 1994: 331: 11 10.

3. Pirsch JD, Miller J, Deierhoi MH, et al. Transplantation 1997; 63: 977.

4. European Tacrolimus Multicentre Renal Study Group. Transplantation 1997; 64: 436.

5. Jay JE, Sampare-Kwateng E, Gereaghty F, et al. Transplant Proc 1991;23:2760.

6. Mekki Q, Lee C,Carrier S, et al. Clinical Pharmacol Ther 1993; 53:229. 
Cliapter 6d

\section{Evidence that fasting does not significantly affect trough levels of tacrolimus in stable renal transplant recipients}

EM van Duijnhoven, MHL Christiaans, JMM Boots, JP van Hooff Transplawt Proc in press 


\section{Introduction}

In stable liver transplant recipients, oral bioavailability of tacrolimus was found to decrease when tacrolimus was taken after food containing a moderate fat content ${ }^{\text {. }}$ This observation led to the recommendation that tacrolimus should be administered on an empty stomach, 1 hour before or 2 hours after a meal. However, this is not always convenient for patients.

In previous studies ${ }^{2-4}$, our group investigated pharmacokinetic parameters of tacrolimus after fasting versus nonfasting ingestion of the drug. Plharmacokinetic profiles of tacrolimus were studied in 10 renal transplant recipients at three different times after renal transplantation. When comparing ingestion without fasting to that with fasting, mean $\mathrm{C}_{\max }$ decreased by 15 to $38 \%$, and AUC by 2 to $12 \% . T_{\text {max }}$ increased by 18 to $42 \%$. Decreases in trough level were generally more pronounced in diabetics than in nondiabetics. None of the observed differences were statistically significant. Furthermore, trough levels of 15 patients were investigated with and without fasting after individual dose adjustments were made according to changes observed in the pharmacokinetic profiles. The mean dose increased by $33 \%$, resulting in an increase in trough level of $24 \%$. Individual trough levels changed by +18 to $-64 \%$. All trough levels remained within the therapeutic range.

Since dose adjustments according to changes in pharmacokinetic profile are not applicable in daily clinical practice, we performed this prospective study comparing trough levels after fasting ingestion and after simultaneous ingestion of food at unchanged tacrolimus doses.

\section{Material and methods}

\section{Patients}

Patients were eligible for this study if they fulfilled the following criteria: 1) they were 18 years or older, 2) more than 3 months had passed since undergoing renal transplantation, 3) they were on tacrolimus monotherapy or tacrolimus combined with steroids, 4) tacrolimus trough levels after fasting were above $5 \mathrm{ng} / \mathrm{ml}$, and 5) they had a stable hemoglobin level and renal function, and proteinuria below $1.0 \mathrm{~g} / \mathrm{l}$. 


\section{Methods}

During a routine check-up at the outpatient clinic, the tacrolimus 12-hour trough level was determined while patients ingested the drug on an empty stomach. They started ingestion of tacrolimus simultaneously with a European continental breakfast, and at the same time they disregarded the empty stomach recommendation in the evening, 7 days before their next visit to the outpatient clinic. The tacrolimus dose remained unchanged. From 7 days before the first trough level evaluation until after the second evaluation, no changes in any drug prescription (including tacrolimus and steroid dose) were allowed. Tacrolimus trough level was determined by TAC II analyzer (IMx, Abbott, Hoofddorp, the Netherlands).

\section{Statistics}

For statistical analysis, SPSS version 10.0 for Windows (Cary Inc, Chicago, 1I) was used. To compare fasting and nonfasting data, the Wilcoxon matched-pairs signed. rank sum test was performed. A P value below 0.05 was considered statistically significant.

\section{Results}

Table 6d.1 shows patient characteristics at the time of inclusion.

Tacrolimus trough levels of 27 patients were evaluated at a median of 206 (range 90 - 309) days after transplantation, fasting, and $35(8-133)$ days later, nonfasting. After simultaneous ingestion of tacrolimus with food, there were no significant changes in the median tacrolimus level: $9.0(5.4-15.5) \mathrm{ng} / \mathrm{ml}$ fasting and 8.7 $(5.3-20.2) \mathrm{ng} / \mathrm{ml}$ nonfasting. All nonfasting tacrolimus levels remained within the therapeutic range.

Figure $6 \mathrm{~d}$. I shows the relative change (in \%) in the tacrolimus trough level without fasting compared to fasting. The level decreased by more than $20 \%$ (maximum $28 \%$ ) in three patients, while an increase of more than $20 \%$ also occurred in three patients (maximum $44 \%$ ). In the majority of patients $(78 \%$ ), the tacrolimus trough level changed by less than $20 \%$ and was thus considered to be unchanged. 
Table 6d.1 Patient characteristics.

\begin{tabular}{ll}
\hline Gender: male/female & $17 / 10$ \\
Tx number: firstretransplant & $20 / 7$ \\
Tx type: postmontal/LRD/LUD & $20 / 4 / 3$ \\
Diabetes mellitus/PTDM & $1 / 1$ \\
Prednisolone dose: $0 / 2.5 / 5 / 10(\mathrm{mg} /$ day') & $20 / 1 / 4 / 2$ \\
Tacrolimus dose (mg/day) & $5.0(2.0-14.0)$ \\
Age (yrs) & $54.9(32.7-72.6)$ \\
Creatinine clearance (ml/min) & $54.9(32.2-90.4)$ \\
Time after transplantation (days) & $206(90-309)$ \\
Body mass index $\left(\mathrm{kg} / \mathrm{m}^{2}\right)$ & $23.9(19.1-32.0)$ \\
Hemoglobin (mol/) & $8.6(6.3-9.3)$ \\
\hline
\end{tabular}

Patient characteristics at inclusion in the study. Data shown are numbers or median (and range). $T \mathrm{x}=$ transplantation, $\mathrm{LRD}=$ living related donor, $\mathrm{LUD}=$ living unrelated donor, PTDM = postransplant diabetes mellitus.

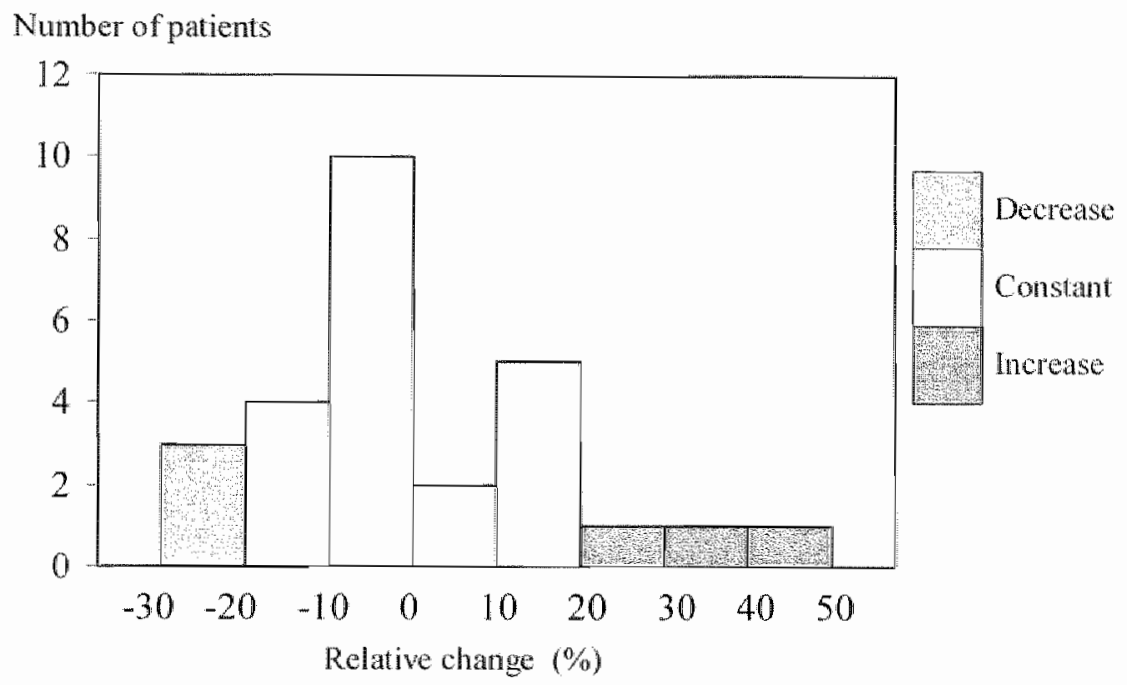

Figure 6d.1 Relative change (\%) in tacrolimus trough level after nonfasting ingestion of tacrolimus.

\section{Discussion}

In our earlier pharmacokinetic studies, we described a reduced bioavailability and slower absorption of tacrolimus when ingested without fasting. The same was described in healthy volunteers. However, in our opinion, the changes observed after nonfasting ingestion in our earlier study were not great enough to imply a need for life-long fasting ingestion of tacrolimus. Therefore, tacrolimus trough levels were evaluated prospectively in this study during fasting ingestion of tacrolimus and one week after nonfasting ingestion. 
Tacrolimus trough levels with and without fasting were statistically and clinically not significantly different. Because at tacrolimus trough levels of $5 \mathrm{ng} / \mathrm{ml}$, coefficients of variation of 10 to $20 \%$ are described ${ }^{6.7}$, we evaluated the number of patients with a decrease and the number with an increase of more than $20 \%$ in their tacrolimus trough level. There was a decrease in $11 \%$ and also an increase in $11 \%$ of the patients. Individual decreases up to $28 \%$ and increases up to $44 \%$ occurred after ingestion of tacrolimus without fasting, but all nonfasting trough levels remained within the therapeutic range. We analyzed stable renal allograft recipients in order to avoid bias by other well-known factors that influence tacrolimus trough level, such as medication, albumin, and hemoglobin levels. We found that in transplant recipients with tacrolimus trough levels above $5 \mathrm{ng} / \mathrm{ml}$, ingestion of tacrolimus without fasting at unchanged tacrolimus doses did not change tacrolimus trough levels significantly. In our previous studies tacrolimus trough levels correlated good with tacrolimus exposure (area under the curve), and did not change significantly after nonfasting ingestion of tacrolimus. This study confirmed these findings for a larger more heterogenous group.

Because there were no changes in tacrolimus dosages, there were no financial disadvantages.

Based on our earlier study ${ }^{2}$ that showed that the smallest difference in AUC between ingestion with and without fasting occurred at 3 weeks after transplantation and was only $2 \%$, we recommend conversion to ingestion of tacrolimus without fasting at 3 weeks after transplantation, provided tacrolimus trough levels are within the therapeutic range. Based on the current study, for all stable outclinic patients, we recommend conversion to ingestion without fasting at therapeutic trough levels 1 week before a new check-up.

In conclusion: in general, conversion to nonfasting ingestion of tacrolimus, without dose adjustments, did not significantly change tacrolimus trough levels in stable renal transplant recipients. 


\section{References}

1. Mekki Q, Lee C, Carrier S, et al. Clin Pharmacol Ther 1993; 53:229.

2. Christiaans $M$, van Duijnhoven $E$, Beysens $T$, Undre $N$, Schäfer $A$, van Hooff J. Transplant Proc 1998; 30: 1271-1273.

3. Duinhoven van E, Christiaans $M$, Undre N, Stevenson P, van Hooff J. Transplant Proc 1998; 30: 1268-1270.

4. Duijnhoven van E, Christiaans M, Schafer A, Undre N, van Hooff J. Transplant Proc 1998; 30:1266-1267.

5. Bekersky I, Dressler D, Mekki QA. J Clin Pharmacol 2001; 41: 176-182.

6. Wallemacq PE, Leal T, Besse T, et al. Clin Chem 1997; 43 (10): 1989-91.

7. Tredger JM, Gilkes CD, Gonde CE. Clin Chen 1999; 45 (10): 1881-2. 
Chaprer 7

\section{Increase in tacrolimus trough levels after steroid withdrawal}

EM van Duijnhoven, JMM Boots, MHL Christiaans, LML Stolk. NA Undre, JP van Hooff

Subnritied 


\section{Abstract}

\section{Background}

In several renal allograft recipients we noticed an increase of tacrolimus trough levels after steroid withdrawal. Although there are experimental reports of cytochrome P450 3A4 isoenzyme (CYP3A4) induction by glucocorticoids, there are no clinical reports about an interaction between tacrolimus and steroids. Therefore, we evaluated the effect of steroid withdrawal on the systemic exposure to tacrolimus in this elinical and pharmacokinetic study.

\section{Methods}

Tacrolimus trough level and dose were compared before and after withdrawal of $5 \mathrm{mg}$ prednisolone in 54 patients retrospectively, and in 8 patients prospectively, and after withdrawal of $10 \mathrm{mg}$ prednisolone in 30 patients retrospectively, and in 14 patients prospectively. Additionally, in 8 patients phamacokinetic parameters were prospectively compared before and after withdrawal of $5 \mathrm{mg}$ of prednisolone. All pharmacokinetic parameters were compared after dose-normalization.

\section{Results}

After withdrawal of $5 \mathrm{mg}$ prednisolone, median tacrolimus dose-nomalized level increased $14 \%$ in the retrospective, and $11 \%$ in the prospective part of the study. After withdrawal of $10 \mathrm{mg}$, this was $33 \%$ and $36 \%$, respectively. Tncreases of more than $20 \%$ occurred in $43 \%$ and $61 \%$ of the patients after withdrawal of $5 \mathrm{mg}$ and $10 \mathrm{mg}$ prednisolone, respectively. The pharmacokinetic part of the study revealed an unchanged $C_{\max }$ and $t_{\max }$, suggesting unchanged absorption, and an $18 \%$ increase in $\mathrm{AUC}(\mathrm{P}=0.05)$ and a $10 \%$ decrease of oral clearance $(P=0.05)$, compatible with a reduced metabolism after steroid withdrawal, possibly by reversal of CYP3A4 induction caused by corticosteroids.

\section{Conclusion}

The significant increase in tacrolimus exposure after steroid withdrawal may on the one hand counteract the reduction in immunosuppression intended by steroid withdrawal, and on the other hand may result in an increase of serum creatinine which could be misinterpreted as rejection! 


\section{Introduction}

Tacrolimus is an effective drug for the prevention of acute rejection after renal transplantation ${ }^{1-4}$. Generally, it is combined with steroids, both initially and during maintenance therapy. The Pittsburgh group and other investigators ${ }^{5-9}$ have shown that steroids can safely be withdrawn after renal transplantation in a large proportion of patients. In our center as well, steroids were safely withdrawn, without rejection, in a majority of patients, who had been treated with tacrolimus and steroids for more than three to six months, had stable graft function and no proteinuria $^{10}$. In several of these patients, we observed an increase in tacrolimus trough levels following steroid withdrawal, although the tacrolimus dose was unchanged.

An interaction between steroids and tacrolimus has been described in in vitro studies and in in vivo animal studies ${ }^{11-15}$. Tacrolimus is metabolized by the cytochrome P450 3A4 (CYP3A4) iso-enzyme. Glucocorticoids are inducers of CYP3A4 and consequently would be expected to increase the metabolism of tacrolimus ${ }^{16}$. It is sofar unclear whether interaction on the P-glycoprotein (P-gp) level could also play a role ${ }^{17}$.

Since increase in systemic exposure to tacrolimus after steroid withdrawal has not yet been described, we studied the effect of withdrawal of two different steroid dosages on the systemic exposure to tacrolimus. The evaluations were made both by retrospective and prospective examination of tacrolimus trough level and corresponding dosing data as well as by a pharmacokinetic study.

\section{Material and methods}

\section{Patients}

Renal allograft recipients on tacrolimus-based immunosuppression, at least 3 months posttransplantation were included. Patients with a history of acute rejection (BANFF 2 or higher), steroid resistant rejection, hyperimmunized state, unstable renal function or proteinuria, had been excluded from steroid withdrawal.

In the retrospective part of the study all patients with steroid withdrawal who met these criteria were evaluated. In 54 Causcasian patients $5 \mathrm{mg}$ prednisolone per day had been stopped, and in 30 Caucasian patients $10 \mathrm{mg}$ prednisolone per day. In the prospective part of the study, 8 Caucasian patients were evaluated before and after withdrawal of $5 \mathrm{mg}$ prednisolone, and 14 Caucasian before and after withdrawal of 
$10 \mathrm{mg}$ prednisolone. Additionaly, in 8 patients pharmacokinetic parameters were prospectively compared before and after withdrawal of $5 \mathrm{mg}$ of prednisolone, while tacrolimus dose did not change. All patients had given informed constent. Patient characteristics are shown in Table 7.1.

Table 7.I Basic patient characteristics.

\begin{tabular}{|c|c|c|c|c|}
\hline \multirow[b]{2}{*}{ Steroid dose } & \multicolumn{2}{|c|}{ Retrospective part } & \multicolumn{2}{|l|}{ Prospective part } \\
\hline & $5 \mathrm{mg}$ & 10 mgs & $5 \mathrm{mg}$ & $10 \mathrm{mg}$ \\
\hline Number of patients & 54 & 30 & 8 & 14 \\
\hline Gender: maleifemale & $34 / 20$ & $23 / 7$ & $\pi 1$ & $10 / 4$ \\
\hline $\begin{array}{l}\text { Tw rimber: } \\
\text { firstretransplant }\end{array}$ & $44 / 12$ & $25 / 5$ & $6 / 2$ & $13 / 1$ \\
\hline $\begin{array}{l}\text { Tx type: } \\
\text { LRD/LUD/cadaveric }\end{array}$ & $0 / 6 / 48$ & $1 / 2 / 27$ & $0 / 17$ & $1 / 1 / 12$ \\
\hline $\begin{array}{l}\text { Immunosupp: } \\
\text { AZA/MMF/none }\end{array}$ & $8 / 4 / 44$ & $0 / 13 / 17$ & $0 / 17$ & $0 / 14 / 0$ \\
\hline Diabetes mellitus & 4 & 5 & 0 & 1 \\
\hline Age (years) & $51.5(15.9-67.5)$ & $57.0(22.0-72.0)$ & $50.9(32.7-67.8)$ & $60.5(32.0-75.0)$ \\
\hline Body mass index $\left(\mathrm{kg} / \mathrm{m}^{2}\right)$ & $24.7(16.6-36.5)$ & $24.5(15.6-31.3)$ & $25.8(18.8-34.7)$ & $25.2(17.1-31.7)$ \\
\hline Time after $x$ (days) & $262(88-1626)$ & $242(127-393)$ & $209(151-864)$ & $90 \quad(85-92)$ \\
\hline
\end{tabular}

$L R D=$ living related donor, $L U D=$ living unrelated donor. Immunosupp = other immunosuppressive agents. Data are given as numbers or median (range).

\section{Methods}

\section{Retrospective evaluations}

Steady-state tacrolimus whole blood 12-hour trough levels and the corresponding chaly doses were recorded before tapering of steroids and after complete cessation of steroids. Steady-state was assumed when the daily dose of tacrolimus was stable (unchanged) for three or more days prior to the measurement of trough level. Blood levels taken shorty before the start of steroid reduction, and those taken shortly alter complete cessation of steroids that met the steady-state definition were used for this study. To account for changes in tacrolimus dose, comparisons were made between the dose-normalized concentrations (tacrolimus trough level divided by the conresponding daily dose).

\section{Prospective evalluations}

In the patients using $5 \mathrm{mg}$ prednisolone, 209 (151-864) days after transplantation prednisolone was tapered to $2.5 \mathrm{mg} /$ day for one week and thereafter completely stopped. 
In the patients using $10 \mathrm{mg}$ prednisolone, after obtaining nomal ACTH stimulation tests, prednisolone daily dose was reduced from $10 \mathrm{mg}$ to $5 \mathrm{mg}$ for one week and $2.5 \mathrm{mg}$ for the next week and thereafter competely stopped.

Immediately before, and one week after complete cessation of steroids, tacrolimus blood concentration-time profiles were taken over a 12-hour dosing period. Blood samples were taken at pre-dose $(0)$ and then at $0.25,0.5,0.75,1.0,2.0,3.0,4.0$, $5.0,7.5,9.0$, and 12.0 hours post-dose. For a period of 1 week prior to the first pharmacokinetic profile until after the second profile, the daily dose of tacrolimus had to be unchanged. Tacrolimus was administered after an overnight fast, and a standard break fast containing $1928 \mathrm{~kJ}$ of energy, $43 \%$ fat content, was given after the withdrawal of 1 -hour blood.

Concentrations of tacrolimus in whole blood were determined by IMX (Abbott, Hoofddorp, the Netherlands). Blood concentration-time data were used to calculate standard pharmacokinetic parameters, $C_{\text {max }}, t_{\text {max }}$, oral clearance, and $A U C_{012}$, using the computer program MWPHARM 3.30 (Mediware, Groningen, the Netherlands).

\section{Statistics}

For statistical analysis, SPSS version 10.0 for Windows (Cary Inc, Chicago, 11) was used. To compare dose-normalized level and pharmacokinetic parameters before and after steroid withdrawal, Wilcoxon matched-pairs signed rank sum test was performed. Unless indicated otherwise data are given as median and range. A $P$ value below 0.05 was considered to be statistically significant.

\section{Results}

In Table 7.2 are presented tacrolimus dose, trough level and dose-nomalized level before and after steroid withdrawal.

In the retrospective part of the study steroid tapering started at a median of 262 (range 88 - 1626) days after transplantation, and was completed in $100(0-208$ ) days in patients using $5 \mathrm{mg}$ prednisolone per day. In patients using $10 \mathrm{mg}$ prednisolone per day steroid tapering started 242 (127-393) days after transplantation, and was completed in 68 (6-311) days. Dose-normalized level increased by $14 \%$ after withdrawal of $5 \mathrm{mg}$ prednisolone, from 1.4 to $1.6 \mathrm{ng} / \mathrm{ml} \mathrm{per}$ $\mathrm{ng}(\mathrm{P}=0.003)$, and by $33 \%$ after withdrawal of $10 \mathrm{mg}$ prednisolone, from 1.5 to $2.0 \mathrm{ng} / \mathrm{ml}$ per $\mathrm{mg}(\mathrm{P}=0.011)$.

In the prospective part of the study, 8 patients were evaluated 7 days after withdrawal of $5 \mathrm{mg}$ prednisolone, $209(151$ - 864) days after transplantation, and 14 patients were evaluated before and $17(13-31)$ days after withdrawal of $10 \mathrm{mg}$ 
prednisolone, $90(85-92)$ days after transplantation. Dose-normalized level increased by $12 \%$ after withdrawal of $5 \mathrm{mg}$ presnisolone, from 1.6 to $1.8 \mathrm{ng} . \mathrm{ml}$ per $\mathrm{mg}(\mathrm{P}=0.058)$, and by $36 \%$ after withdrawal of $10 \mathrm{mg}$ prednisolone, from 1.4 to 1.9 $\mathrm{ng} / \mathrm{ml}$ per $\mathrm{mg}(\mathrm{P}=0.002)$. After withdrawal of $10 \mathrm{mg}$ prednisolone, serum creatinine increased from $143(67-246)$ umol//1 to $151(67-259)$ umol/l $(\mathrm{P}=0.034)$.

Table 7.2 Tacrolimus dose and trough level before and after steroid whthdrawal.

\begin{tabular}{|c|c|c|c|c|c|c|}
\hline \multirow{2}{*}{ Retrospective } & & \multicolumn{2}{|c|}{$\begin{array}{c}\text { Before steroid } \\
\text { withdrawal }\end{array}$} & \multicolumn{2}{|c|}{$\begin{array}{l}\text { After steroid } \\
\text { withdrawal }\end{array}$} & \multirow[t]{2}{*}{$\mathrm{P}$} \\
\hline & & & & & & \\
\hline $\begin{array}{l}5 \mathrm{mg} \text { prednisolone } \\
(\mathrm{n}=54)\end{array}$ & $\begin{array}{l}\text { Trough level (ng/ml) } \\
\text { Dose (mg/d) } \\
\text { Dose- } \mathrm{n}(\mathrm{ng} / \mathrm{mm} \text { per mg/d) }\end{array}$ & $\begin{array}{l}8.5 \\
6.0 \\
1.4\end{array}$ & $\begin{array}{l}(4.3-17.2) \\
(2.0-20.0) \\
(0.5-4.3)\end{array}$ & $\begin{array}{l}8.3 \\
5.0 \\
1.6\end{array}$ & $\begin{array}{l}(3.6-25.9) \\
(2.0-19.0) \\
(0.6-7.8)\end{array}$ & 0.003 \\
\hline $\begin{array}{l}10 \text { mg prednisolone } \\
(\mathrm{n}=30)\end{array}$ & $\begin{array}{l}\text { Trough level (ng/mi) } \\
\text { Dose }(\mathrm{mg} / \mathrm{d}) \\
\text { Dose-n }(\mathrm{ng} / \mathrm{ml} \text { per } \mathrm{mg} / \mathrm{d})\end{array}$ & $\begin{array}{l}7.8 \\
5.0 \\
1.5\end{array}$ & $\begin{array}{l}(4.2-25.6) \\
(2.0-14.0) \\
(0.5-6.4)\end{array}$ & $\begin{array}{l}9.4 \\
4.5 \\
2.0\end{array}$ & $\begin{array}{l}(5.3-16.8) \\
(2.0-14.0) \\
(0.6-4.9)\end{array}$ & 0.011 \\
\hline \multicolumn{7}{|l|}{ Prospective } \\
\hline $\begin{array}{l}5 \mathrm{mg} \text { prednisolone } \\
(\mathrm{n}=8)\end{array}$ & $\begin{array}{l}\text { Trough level (ng/mi) } \\
\text { Dose (mg/d) } \\
\text { Dose-n (ng/ml per mg/d) }\end{array}$ & $\begin{array}{l}7.3 \\
5.0 \\
1.6\end{array}$ & $\begin{array}{l}(3.8-9.9) \\
(2.5-13.0) \\
(0.4-4.0)\end{array}$ & $\begin{array}{l}8.1 \\
5.0 \\
1.8\end{array}$ & $\begin{array}{l}(5.0-14.1) \\
(2.5-13.0) \\
(0.6-5.6)\end{array}$ & 0.058 \\
\hline $\begin{array}{l}10 \mathrm{mg} \text { prednisolone } \\
(\mathrm{n}=14)\end{array}$ & $\begin{array}{l}\text { Trough level }(\mathrm{ng} / \mathrm{ml}) \\
\text { Dose }(\mathrm{mg} / \mathrm{d}) \\
\text { Dose-n }(\mathrm{ng} / \mathrm{ml} \mathrm{per} \mathrm{mg} / \mathrm{d})\end{array}$ & $\begin{array}{l}8.3 \\
5.5 \\
1.4\end{array}$ & $\begin{array}{l}(4.9-14.5) \\
(3.0-15.0) \\
(0.2-2.9)\end{array}$ & $\begin{array}{r}11.9 \\
5.5 \\
1.9\end{array}$ & $\begin{array}{l}(7.6-15.0) \\
(4.0-16.0) \\
(0.8-3.5)\end{array}$ & 0.002 \\
\hline
\end{tabular}

Median and ranges of tacrolimus trough levels, tacrolimus dose and dose-nomalized level (Dose-n) before and after steroid withdrawal.

Figures 7.1 and 7.2 show relative changes in tacrolimus dose-normalized levels after withdrawal of 5 and $10 \mathrm{mg}$ prednisolone in all patients. Increases of more than $20 \%$ occurred in $43 \%$ of the patients after withdrawal of $5 \mathrm{mg}$, and in $61 \%$ after withdrawal of $10 \mathrm{mg}$ prednisolone.

Table 7.3 shows the pharmacokinetic parameters before and after steroid withdrawal.

The median AUC increased from $132.3 \mathrm{ng} . \mathrm{h} / \mathrm{ml}$ before steroid withdrawal to 156.6 $\mathrm{ng} . \mathrm{h} / \mathrm{ml}$ after steroid withdrawal $(\mathrm{P}=0.05)$. The corresponding values for oral clearance were 0.280 and $0.253 \mathrm{l} / \mathrm{h} / \mathrm{kg}(\mathrm{P}=0.05)$, trough levels were 7.3 and 8.1 $\mathrm{ng} / \mathrm{ml}(\mathrm{P}=0.08)$ and $\mathrm{C}_{\max }$ were 24.9 and $27.1 \mathrm{ng} / \mathrm{ml}(\mathrm{P}=0.12)$. 
Table 7.3 Phamacokinetic parameters before and after steroid withdrawal for each patient.

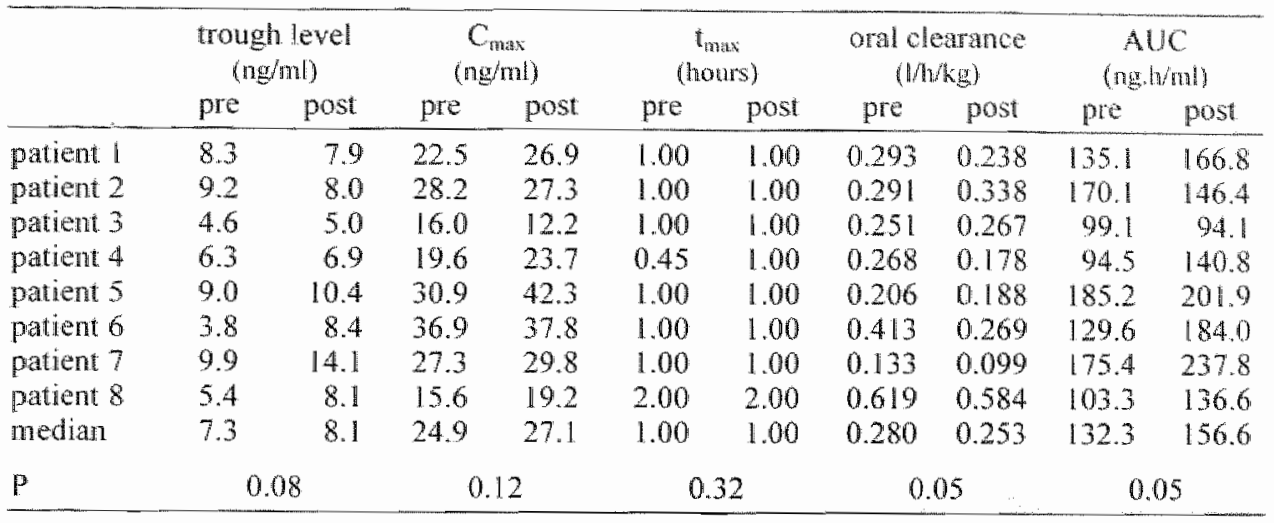

Tacrolinus trough level, $C_{\text {nax }}$ (the maximum trough level after tacrolimus ingestion), thax (the time after transplantation when the maximum trough level was reached), oral clearance and area under the curve (total tacrolimus exposure).

\section{Discussion}

Based on our clinical observations, and supported by reports about a possible interaction between tacrolimus and steroids ${ }^{11-17}$, we evaluated the effect of steroid withdrawal on the systemic exposure to tacrolimus.

The results of our evaluations have confirmed that the withdrawal of steroids results in an increased systemic exposure to tacrolimus. The increase in systemic exposure to tacrolimus following the withdrawal of $10 \mathrm{mg}$ prednisolone was higher $(33-36 \%)$ when compared with the increase after withdrawal of $5 \mathrm{mg}$ prednisolone $(12-14 \%)$. The increase in AUC that is observed is not associated with an increase in either $C_{\max }$ or $\mathrm{t}_{\max }$, suggesting that the processes of absorption remain unaffected. The most likely cause for the increased exposure following steroid withdrawal may be associated with decrease in the metabolic clearance as a consequence of the reversal of CYP3A4 induction by steroids. In this study it is not possible to discern any influence of p-glycoprotein on the observed interaction. In an earlier study we described that oral clearance decreases over time ${ }^{18}$. From the current study, we can conclude that, besides increasing hemoglobin and albumin levels, also the marked steroid reduction in this period explains the decrease in oral clearance over time. Furthermore, the current study suggests that the effect of steroid withdrawal is steroid dose dependent. After withdrawal of only $10 \mathrm{mg}$ prednisolone, an increase in tacrolimus dose-normalized ratio of $\pm 35 \%$ was found. Generally, much higher steroid dosages are used in renal transplantation. After withdrawal of such higher steroid dosages, an even larger increase in tacrolimus trough levels might be expected. 
Number of patients

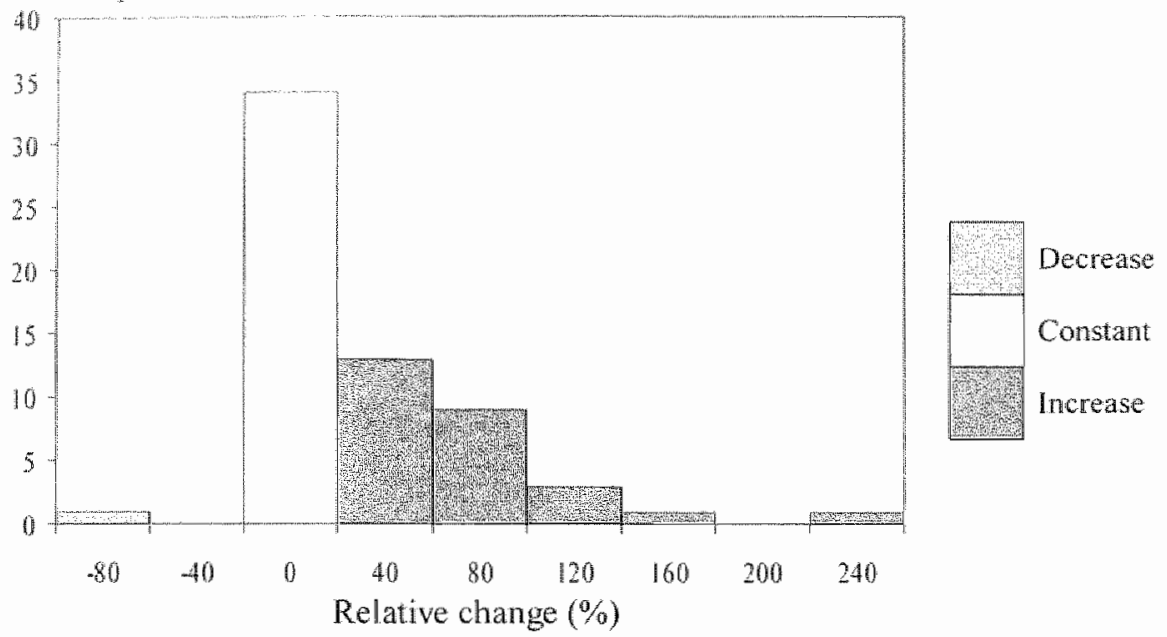

Figure 7.1 Relative changes (\%) in tacrolimus dose-normalized ratio after withdrawal of $5 \mathrm{mg}$ prednisolone.

A decrease was defined as a reduction of tacrolimus dose-normalized ratio of $20 \%$ or more, and an increase as an addition of $20 \%$ or more. When tacrolimus dose-normalized ratio had changed less than $20 \%$, this was regarded as no change.

Number of patients

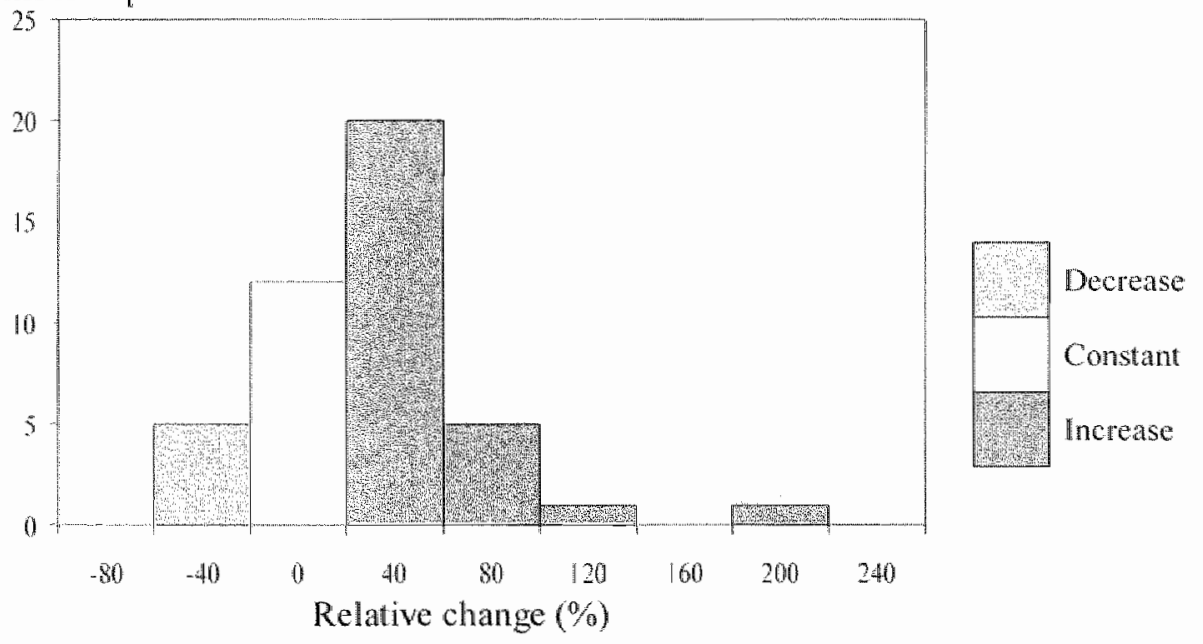

Figure 7.2 Relative changes $(\%)$ in tacrolimus dose-normalized ratio after withdrawal of $10 \mathrm{mg}$ prednisolone.

A decrease was defined as a reduction of tacrolimus dose-normalized ratio of $20 \%$ or more, and an increase as an addition of $20 \%$ or more. When tacrolimus dose-normalized ratio had changed less than $20 \%$, this was regarded as no change. 
The assay method used to determine tacrolimus blood levels (IMx, Abbott) is reported to have a precision of up to $\pm 20 \%$ at $5 \mathrm{ng} / \mathrm{ml}^{19-20}$. Therefore, an increase in blood level of $>20 \%$ was considered to be relevant. Such an increase occurred in $43 \%$ of the patients after withdrawal of $5 \mathrm{mg}$ prednisolone, and $61 \%$ after withdrawal of $10 \mathrm{mg}$ prednisolone. In individual patients the increase amounted to as much as $200 \%$. This indicates that the increase in tacrolimus trough level after steroid withdrawal is a clinically important issue.

The increase in systemic exposure to tacrolimus after steroid withdrawal may on one hand counteract the reduction in immunosuppression intended by steroid withdrawal, and on the other hand will in some patients result in an increase of serum creatinine, as observed in an earlier study ${ }^{21}$ and confirmed in this study, which could be misinterpreted as rejection! Therefore, evaluation of tacrolimus trough level within one to two weeks after steroid withdrawal is advisable for all patients. Tacrolimus dose should be reduced in all patients with a significant increase in trough level after steroid withdrawal. This is obviously also financially beneficial. 


\section{References}

1. Pirsch JD, Miller J, Deierhoi MH, Vincenti F, Filo RS. A comparison of tacrolimus (FK506) and cyclosporine for immunosuppression after cadaveric renal transplantation. FK506 Kidney Transplant Study Group. Transplantation 1997: 63 (7): $977-983$.

2. Mayer AD, Dmitrewskj J, Squifllet JP, et al. Multicenter randomized trial comparing tacrolimus ( $F K_{506}$ ) and cyclosporine in the prevention of renal allograft rejection: a report of the European Tacrolimus Multicenter Renal Study Group. Transplantation $1997 ; 64(3): 436-443$.

3. Johnson $\mathrm{C}$, Ahsan $\mathrm{N}$, Gonwa $\mathrm{T}$, et al. Randomized trial of tacrolimus (Prograf) in combination with azathioprine or mycophenolate mofetil versus cyclosporine (Neoral) with mycophenolate mofetil after cadaveric kidney transplantation. Transplantation 2000; 69 (5): 834-841.

4. Plosker GL. Tacrolimus: a further update of its pharmacology and therapeutic use in the management of organ transplantation. Dnugs 2000; 59 (2):323-389.

5. Shapiro R, Jordan ML, Scantlebury VP, et al. The superiority of tacrolimus in renal transplant recipients - the Pittsburgh experience. Clin Transpl 1995: 199-205.

6. Oppenheimer $\mathbb{F}$. Steroid withdrawal in renal transplant recipients. Transplant Proc $2000 ; 32: 14 \mathrm{~S}-15 \mathrm{~S}$.

7. Chakrabarti P, Wong HY, Scantlebury VP, et al. Outcome after steroid withdrawal in pediatric renal transplant patients receiving tacrolimus based immunosuppression. Transplantation 2000; 70: 760-764.

8. Hricik. DE, Kupin WL, First MR. Steroid-free immunosuppression after renal transplantation. J Am Soc Neplurol 1994; 4: S10-S16.

9. Schulak JA, Hricik DE. Steroid withdrawal after renal transplantation. Clin Transplant $1994 ; 8: 211-216$.

10. Boots IMM, van Duäjnhoven EM, Christiaans MHI, Nieman FHM, van Suylen RJ, van Hooff JP. Single center experience with tacrolimus versus cyclosporin-Neoral in renal transplant recipients. Transplant Int 2001; 14:370-383.

11. Piekoszewski W, Chow FS, Jusko WJ. Phamacokinetic and phamacodynamic efrects of coadministration of methylprednisolone and tacrolimus in rabbits. The Journal of Phamacology and Experimental Therapeutics 1994; 269 (1): 103-109.

12. Moochtala SM, Lee EJD, Earnest L, Wong JYY and Ngoi SS. Inhibition of drug metabolism in rat and human liver microsomes by $\mathrm{FK} 506$ and cyclosporine. Transplant Proc 1991; 23:2786-2788.

13. Omar $G$, Shah $L A$. Thomson AW, Whiting PH and Burke MD. FK 506 inhibition of cyclosporine metabolism by human liver microsomes. Transplant Proc 1993; 23: 690698.

14. Shah $L A$, Whiting PH, Omar $G$, Thomson AW and Burke MD. Effects of FK 506 on human hepatic microsonal cytochrome P-450-dependent drug metabolism in witro. Trunsplant Proc 1991: 23: 2783-2785.

15. Sattler M, Guengerich PF, Yun $\mathrm{CH}$, Christians U and Sewing KF. Cytochrome P-450 $3 \mathrm{~A}$ enzymes are responsible for biotransfromation of FK 506 and rapamycin in man and rat. Drug Metab Dispos 1992; 20:753-761.

16. Sewing $\mathrm{K} \mathrm{Fr}$. Phamacokinetics, dosing principles and blood level monitoring of FK506. Transplant Proc 1994; 26 (6): $3267-3269$. 
17. Lo A, Burckart GJ. P-glycoprotein and drug therapy in organ transplantation. J Clin Pharmacol 1999; 39:995-1005.

18. Christiaans $M$, van Duijnhoven $E$, Beysens $T$, Undre $N$, Schäfer $A$, van Hooff $J$. Effects of breakfast on the oral bioavailibility of tacrolimus and changes in phamacokinetics at different times postmansplant in renal transplant recipients. Transplant Proc 30: 1998; $1271-1273$.

19. Wallemacq PE, Leal T, Besse T, et al. IMx Tacrolimus II vs IMx tacrolimus microparticle enzyme immunoassay evaluated in renal and hepatic transplant patients. Clin Chem 1997; 43 (10): 1989-9 .

20. Tredger JM, Gilkes CD, Gonde CE. Performance of the IMx tacrolimus II assay and practical limits of detection. Clin Chem 1999; $45(10): 1881-2$.

21. Boots JMM, van Duijnhoven EM, Christiaans MHL, Wolffenbuttel BHR, van Hooff JP. Glucose metabolism in renal transplant recipients on tacrolimus: the effect of steroid withdrawal and tacrolimus trough level reduction. JASN 2002; 13:221-227. 
Chapter 8

\section{General discussion and concluding remarks}


Chapers: 


\section{General discussion and concluding remarks}

Renal transplantation evolved from an experimental treatment with a high mortality for a limited number of highly selected patients in the 1960 s to a preferred treatment for most patients with end-stage renal failure by the end of the 1980s. After a successful transplantation, there is an improvement in the quality of life ${ }^{\prime}$ and an increase in life expectancy ${ }^{2}$.

However, by 10 years posttransplantation, only about half of the grafts are still functioning. This is caused by graft loss due to chronic transplant dysfunction or, more frequently, by patient mortality due to cardiovascular disease ${ }^{3}$.

From the 1970s until the 1990s, basic maintenance immunosuppression was almost identical for every patient: cyclosporine with corticosteroids and azathioprine. After 1995, a number of new maintenance immunosuppressive drugs were introduced: tacrolimus as a cornerstone immunosuppressive agent, and mycophenolate mofetil and sirolimus as additional immunosuppressive agents.

When cyclosporine was replaced by tacrolimus, there was a marked reduction in the incidence of acute rejections ${ }^{4-6}$. Both steroid-sensitive and steroid-resistant rejections decreased by about $50 \%$. Because an episode of acute rejection, especially steroid-resistant rejection, is a risk factor for later graft failure, replacing cyclosporine with tacrolimus has led to a better half-life estimate and a lower rate of chronic rejection ${ }^{7-8}$. It has also resulted in an improvement in lipid profile and blood pressure ${ }^{9}$. These factors are associated with chronic transplant dysfunction as well as with posttransplant cardiovascular mortality ${ }^{10}$. However, an increased incidence of posttransplant diabetes mellitus (PTDM) ${ }^{4-5}$ may counteract the potentially beneficial effects of tacrolimus on graft and patient survival ${ }^{11}$.

\section{Posttransplant diabetes mellitus}

In general, (posttransplant) diabetes mellitus developes as a result of low or absent insulin output, increased insulin resistance, or a combination of the two. Given the fasting values of glucose and insulin and an intravenous glucose tolerance test (VGTT), it is possible to discern which mechanisms are responsible for PTDM. From the fasting values, one can calculate insulin resistance, and from the values obtained by the IVGTT, one can calculate insulin output. Moreover, one can visualize the combined impact of both factors on the disappearance rate of a bolus of glucose in the bloodstream (insulin sensitivity index $=\mathrm{k}_{\mathrm{o}}$ ).

The mechanism responsible for the development of PTDM during tacrolimusbased immunosuppression was unclear. Animal studies and in vitro studies reported that tacrolimus caused a decrease in insulin secretion ${ }^{12-14}$, while clinical 
posttransplant studies reported not only a decrease in insulin secretion, but an increase in insulin resistance as well ${ }^{15}$. In the latter studies, patients used not only tacrolimus but also corticosteroids, which may also influence glucose metabolism. Several risk factors for the occurrence of PTDM are known ${ }^{4-5,15-16}$ (Table 8.1). The relative contribution of the various factors, however, is unknown. In the first section of this thesis (Chapter $\mathbf{2}$ - 5), the relative contribution of predisposition, calcineurin inhibitors, and corticosteroids were studied. Basal, fasting levels of glucose, insulin, and C-peptide were used to measure insulin resistance. Stressed increments of insulin and C-peptide area under the curves after intravenous glucose were used to calculate insulin secretion. The impact of both insulin resistance and insulin secretion on glucose metabolism is reflected in the insulin sensitivity index, which was calculated by linear regression from the log-transformed glucose values from 10 to 30 (or 60) minutes after intravenous glucose (Chapter 1).

Table 8.1 Risk factors for the development of PTDM.

\footnotetext{
Genetic factors such as race and family history of diabetes mellitus

Older age

High body mass index

High levels of calcineurin inhibitors

High dosages of corticosteroids
}

Transplant recipients generally take a combination of inmunosuppressive drugs. As mentioned before, not only the calcineurin inhibitors cyclosporine and tacrolimus, but also corticosteroids have been associated with disturbances in glucose metabolic control. In Chapter 2, we investigated the role of tacrolimus in glucose metabolic disorders. By performing the study in nondiabetic dialysis patients, the potential bias due to the concomitant use of corticosteroids could be avoided. After oral administration of tacrolimus, the insulin sensitivity index decreased significantly. This decrease in $\mathrm{k}_{\mathrm{G}}$ occurred in almost every patient and correlated with tacrolimus trough levels. It was caused by a significant reduction in insulin secretion, while insulin resistance was not affected. There was no significant correlation between stressed insulin secretion capacity and age, sex, or body mass index.

Before transplantation, it was also possible to detect which patients would be at risk of developing PTDM. Before transplantation, up to one-third of the patients had an indeterminate or low normal insulin sensitivity index. After transplantation, approximately half of those patients developed PTDM. This is clearly above the $5 \%$ incidence of diabetes mellitus and the $10 \%$ incidence of impaired glucose tolerance found in the general population ${ }^{17}$. None of the patients with higher insulin sensitivity indices, and thus more pancreatic reserve capacity, developed 
PTDM. Thus, by performing an IVGTT while screening for transplantation, it is possible to detect patients who are at risk of developing PTDM.

There are indications that an oral glucose tolerance test can also detect patients at risk for PTDM $^{18}$. Patients awaiting renal transplantation may benefit from pretransplant investigation of their glucose metabolism. Those at risk for PTDM would benefit from immunosuppressive schemes without corticosteroids and with low dosages of calcineurin inhibitors. At the moment, there are, in fact, immunosuppressive regimens that completely avoid the use of corticosteroids ${ }^{192}$; however, there are only limited data available about the efficacy of immunosuppressive regimens that completely avoid the use of calcineurin inhibitors as well ${ }^{21}$.

It has been proven that steroids can safely be withdrawn in stable renal transplant patients on tacrolimus-based immunosuppression ${ }^{10,23-23}$. This made it possible to study renal transplant patients before and after steroid withdrawal. The role of the concomitant use of corticosteroids in glucose metabolic disorders during tacrolimus-based immunosuppression was investigated and described in Chapter 3 . After steroid withdrawal, there was a significant decrease in fasting C-peptide, a decrease in fasting insulin, and a decrease in the insulin/glucose ratio, indicating a reduction in insulin resistance. Insulin secretion did not change after steroid withdrawal. These findings are in accordance with the increased insulin resistance observed in earlier posttransplant studies in patients using tacrolimus as well as corticosteroids. This reduction in insulin resistance after steroid withdrawal may reduce the risk of cardiovascular disease. Another important finding from this study was that levels of all serum lipids decreased after steroid withdrawal. This decrease may reduce the risk of cardiovascular disease even further. However, it is unclear to what extent the obviously beneficial reductions in total cholesterol, LDL cholesterol, and triglycerides are counterbalanced by the concomitant decrease in HDL after steroid withdrawal.

High doses of calcineurin inhibitors had already been mentioned as a risk factor for the development of PTDM ${ }^{24-25}$. In Chapter 3, we addressed the question of whether glucose metabolic disorders induced by tacrolimus are reversible. A tacrolimus trough level reduction of $30 \%$ within the therapeutic window resulted in a significant improvement in pancreatic $\beta$-cell secretion of $25-35 \%$. Thus, the decrease in insulin secretion caused by tacrolimus is not only dose-dependent, but also reversible. This finding is also supported by the observation that PTDM disappears in a later phase after transplantation when tacrolimus blood levels are much lower than levels in the early phase after transplantation.

$\mathrm{HbA} 1 \mathrm{c}$ is a glycosylated form of hemoglobin that is used as a parameter of mean glucose concentration in the last 2 - 3 months. A high $\mathrm{HbAlc}$ level is associated 
with a high (cardiovascular) mortality ${ }^{26}$. In Chapter 3, we found a significant decrease (approximately $10 \%$ ) in $\mathrm{HbAlc}$ in nondiabetic patients, after a $30 \%$ reduction in tacrolimus trough level within the therapeutic range. In our patients, there was a high incidence of subclinical impaiment of glucose metabolism (approxmately $30 \%$ ) before transplantation. This improvement in HbAlc implies that optimalization of tacrolimus blood levels may be important in the prevention and reduction of cardiovascular disease, not only for patients with PTDM, but for many prediabetic patients treated with tacrolimus ${ }^{27-29}$.

After a $30 \%$ reduction in tacrolimus trough level within the therapeutic range, creatinine clearance improved by approximately $15 \%$ (Chapter 3 ). Because renal function is a prognostic parameter for long-term graft survival ${ }^{30-32}$, reducing tacrolimus levels may improve long-term graft survival by improving both renal function and glycemic control. It is still not known what the safe lower range of the tacrolimus target level is for effective maintenance immunosuppression. A reduction in tacrolimus trough levels below $5 \mathrm{ng} / \mathrm{ml}$, not affecting graft survival, has been reported in low-risk patients ${ }^{33}$. With such low tacrolimus levels it is likely that glucose metabolism and renal function will improve even further, almost to levels reported for so-called calcineurin inhibitor-free immunosuppressive regiimens.

The relative role of steroids and tacrolimus is summarized in Table 8.2. Steroids mainly influence insulin resistance, while tacrolimus mainly influences insulin secretion.

Table 8.2 The influence of tacrolimus and steroids on glucose metabolism.

\begin{tabular}{lcc}
\hline & Insulin resistance & Insulin secretion \\
\hline Tacrolimus & - & + \\
Steroids & + & - \\
\hline
\end{tabular}

In Chapter 4, we investigated whether there were differences in glucose metabolism between cyclosporine-based and tacrolimus-based immunosuppression in renal transplant patients, during concomitant use of low-dose steroids. IVGTTs were performed in 12 patients randomized for cyclosporine and 11 patients randomized for tacrolimus at regular intervals for 3 years after transplantation. We also investigated whether chronic $\beta$-cell toxicity occurred after long-term use of either calcineurin inhibitor. Patients were tested at week 3 , month 3 , month 6 , year 1, year 2 , and year 3 posttransplantation.

The only significant difference found in the course of the 3-year follow-up between the tacrolimus and the cyclosporine group was an approximately $50 \%$ lower insulin secretion at week 3 for the tacrolimus group. This is compatible with the clinical 
observation that differences in the incidence of PTDM between cyclosporine and tacrolimus-based immunosuppression occur mainly in the early phase after transplantation and that they become smaller and statistically not significant after one year. In the early phase after transplantation, dosages of steroids are high and target levels of tacrolimus are high compared to in the later phase. Thus, the difference in frequency of PTDM between cyclosporine and tacrolimus-treated patients depends mainly on the levels of the calcineurin inhibitors and on the amount of corticosteroids used.

In both groups, glucose metabolism (insulin sensitivity index) tended to improve in the first 6 months, despite a significant increase in insulin resistance. This higher resistance was probably caused by an increase in body mass index.

After 6 months, there were no significant changes in any of the parameters of glucose metabolism, indicating that long-term use of either tacrolimus or cyclosporine does not lead to chronic, cumulative pancreatic toxicity. This contradicts a study postulating time after transplantation as a risk factor for $\mathrm{PTDM}^{34}$. In all of our studies on glucose metabolism and tacrolimus, major changes in glucose metabolism occurred in the early phase and were largely reversible when immunosuppression was tapered. In our opinion, the later development of diabetes after transplantation is generally caused by mechanisms similar to those that cause type 2 diabetes in the general population, and they may not be directly related to the immunosuppression or transplantation. With increasing age, diabetes mellitus type 2 can devellop due to a decreasing output of insulin and/or to increasing insulin resistance. The observation in Chapter 2 that $30 \%$ of our dialysis patients already had a low insulin output before tacrolimus was administered and the fact that the BMT of most patients increases significantly after succesful transplantation underline this hypothesis.

In Chapter 5, a patient is described who developed PTDM late after transplantation after contracting hepatitis $C$. In the first year after transplantation, it was repeatedly shown that $\beta$-cell function was completely normal in the early phase after transplantation. Thereafter, she contracted hepatitis $C$ and developed PTDM. Insulin resistance was shown to be increased during the acute infection, before the development of PTDM. Infections have, in the past, been associated with a transient increase in insulin resistance ${ }^{35}$. However, when the hepatitis $\mathrm{C}$ infection became less active and the PTDM had disappeared, the patient not only had an increased insulin resistance, but also a marked decrease in insulin secretion. The latter observation suggests a direct effect of hepatitis $\mathrm{C}$ viral infection on insulin production. This marked decrease in insulin secretion persisted for 4 years. In patients with a sudden, unexpected late occurrence of PTDM, an infection, 
especially with hepatitis $C$ or cytomegalovirus, which has also been associated with an increased risk for PTDM ${ }^{1636}$, should be considered (Table 8.3).

Table 8.3 Main causes of PTDM.

\begin{tabular}{ll}
\hline Early PTDM & Late PTDM \\
\hline $\begin{array}{ll}\text { Calcineurin inhibitor toxicity } \\
\text { Corticosteroids }\end{array}$ & Natural history of type 2 diabetes mel litus \\
Infection & Obesity \\
Infection $(\mathrm{HCV})$
\end{tabular}

\section{Management of posttransplant diabetes mellitus}

From our studies in Chapters 2,3,4, and 5, we can conclude that measures taken to improve glucose metabolism in tacrolimus-treated renal transplant recipients who develop PTDM early after transplantation must consist of steroid withdrawal and tacrolimus dose reduction to the lowest possible levels to prevent rejection. During the first 4 weeks after transplantation, tacrolimus levels should be kept between 10 and $20 \mathrm{ng} / \mathrm{ml}$ to avoid acute rejection, because acute rejection will endanger the graft and treatment with steroid boluses will lead to worsening of PTDM. In our opinion, the minor differences in glucose metabolism observed at week 3 after transplantation between patients treated with cyclosporine and tacrolimus, which are completely reversible from month 3 onwards, do not warrant conversion to cyclosporine-based immunosuppression at this time. After the first 4 weeks, steroids should be withdrawn or replaced by mycophenolate mofetil or sirolimus. After steroid withdrawal, tacrolimus trough levels should be gradually reduced to $5-7 \mathrm{ng} / \mathrm{ml}$. This will result in an improvement in glucose metabolism and the disappearance of PTDM in approximately $80 \%$ of the patients ${ }^{19}$. If, at the same time, insulin and/or oral hypoglycemic medication is not tapered, hypoglycemia will occur. Therefore, during cessation of steroids and tapering of tacrolimus dosages, concomitant decreases or even complete discontinuation of oral blood glucose-lowering drugs or insulin is mandatory (Table 8.4). If PTDM does not disappear after all these measures have been taken, determining insulin resistance (fasting glucose and insulin) is indicated. When insulin resistance is increased, this is generally due to infection or high body mass index. When present, infection and obesity should be treated.

Whether the immunosuppressive regimen should be changed in those few remaining patients with persisting impairment of glucose metabolism after implementation of all these measures is, at this moment, unclear. Replacing tacrolimus with cyclosporine would be illogical since there are no differences in glucose metabolism between tacrolimus and cyclosporine-treated patients after the first months posttransplantation (Chapter 4 ). 
Table 8.4 Management of PTDM in renal transplant recipients on tacrolimus-based immunosuppression.

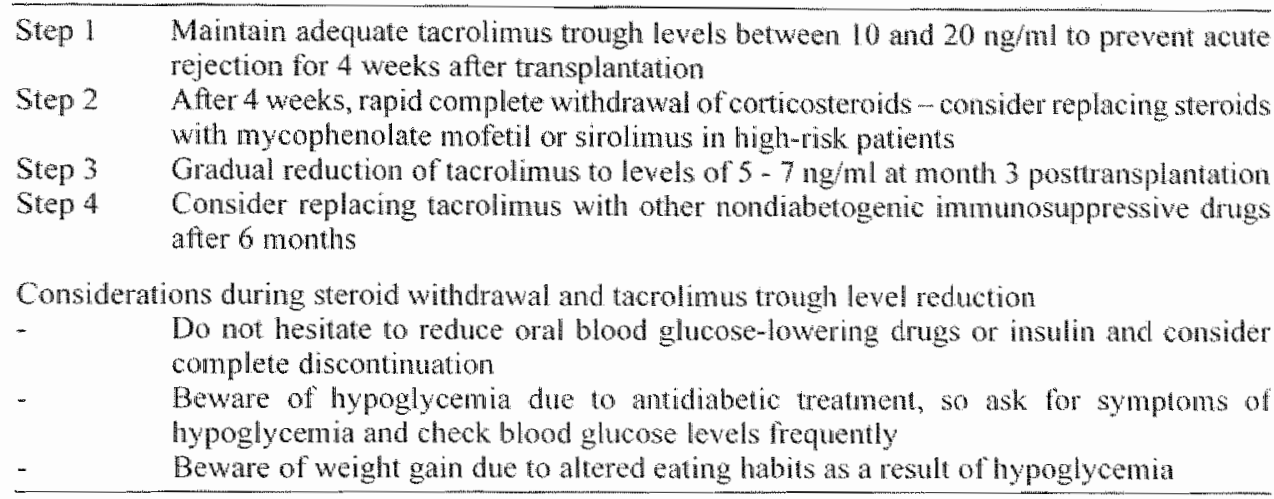

Replacing tacrolimus with mycophenolate mofetil or possibly sirolimus should be considered. Mycophenolate mofetil is not known to affect glucose metabolism. As for sirolimus, this is still unknown. A major side effect of sirolimus is hypercholesterolemia, which increases the risk of cardiovascular morbidity and mortality. Therefore, conversion to mycophenolate mofetil would probably be the most logical approach. At this moment, however, there is only one study available concerning conversion to mycophenolate mofetil. monotherapy ${ }^{21}$. Although the results are promising, more data are needed to clarify this issue, especially with regard to risk and late effects of acute rejection and the effect on PTDM and other cardiovascular risk factors. In Figure 8.11, a decision tree reflects the current views on the treatment of PTDM in renal transplant recipients on a tacrolimus-based immunosuppressive regimen. It is based on the reversibility of the insulin secretion problem during tacrolimus treatment found in our studies.

In Table 8.5, the main conclusions of the studies deseribed in Chapters $2-5$ of this thesis are summarized. 


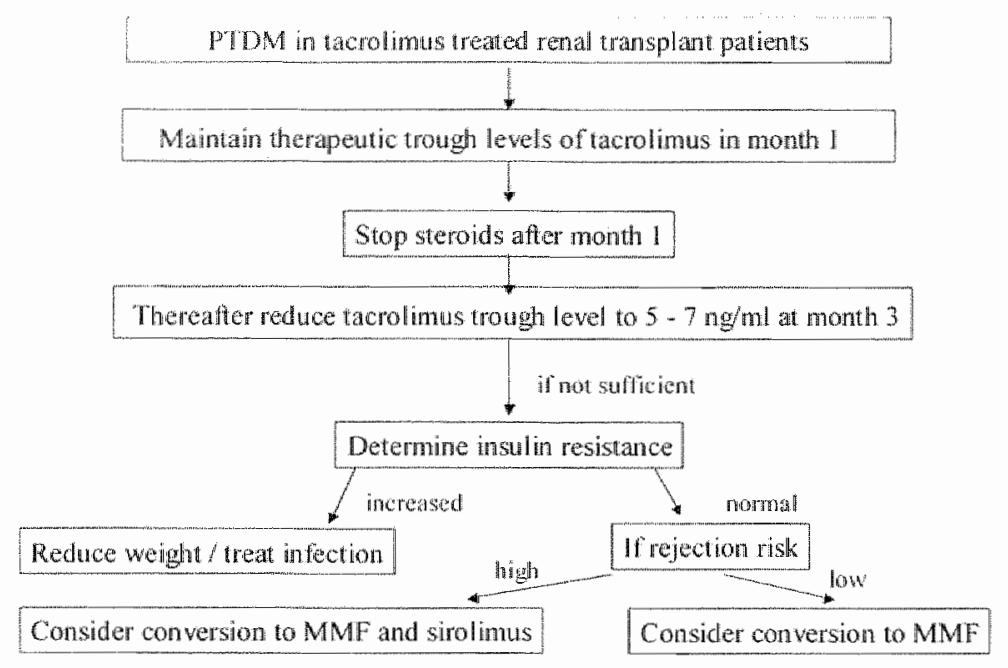

Figure 8.1 Guiclelines for the management of PTDM in renal transplant recipients on tacrolimusbased immunosuppression.

Table 8.5 Metabolic conclusions.

- Many dialysis patients are prediabetic, not due to increased insulin resistance, but mainly due to low insulin secretion.

- Patient with "little $\beta$-cell reserve" are at risk of developing PTDM after transplantation.

- Tacrolimus causes a dose-dependent decrease in insulin secretion.

- Tacrolimus does not influence insulin resistance.

- Steroid withdrawal results in a decrease in insulin resistance as well as in a decrease in serum lipids.

- Tacrolinus trough level reduction results in a decrease in insulin secretion and has no discernable effects on serum lipids.

- Even after prolonged treatment with tacrolimus, the effects on insulin secretion are reversible.

- Tacrolinus trough level reduction improves $\mathrm{HbAl}$, a risk factor for cardiovascular mortality.

- Tacrolimus drough level reduction improves creatinine clearance even ater a prolonged period of therapy.

- At our prevaling levels of calcineurin inhibitors and low doses of concomitant steroids, there appear to be no long-term diferences in glucose metabolism between cyclosporine and bicrolimus-treated renal transplant recipients.

- After renal transplantation with calcineurin-based immunosuppression, glucose metabolism improves in the furst 6 months after transplantation and does not change thereafter. Therefore, there are no indications for chronic $\beta$-cell toxicity as a result of long-term use of calcineurin inhibitors.

- Hepatitis C virus intection may impair insulin secretion.

\section{Pharmacokinetics}

The second part of this thesis addresses questions concerning pharmacokinetic aspects of tacrolimus.

The basic pharmacokinetics of tacrolimus are discussed in Chapter 1. There is a large interindividual variation in absorption, probably due to extensive gut 
metabolism by cytochrome P450 enzyme. After absorption. tacrolimus is distributed extensively throughout the body and binds to hemoglobin and albumin in the blood. The small free tacrolimus fraction in the blood is supposed to be responsible for its immunosuppressive and toxic actions. Elimination occurs by slow metabolism in the liver by the cytochrome P450 enzyme. Total exposure can most accurately be measured by pharmacokinetic profiles (area under the curve = AUC). Because obtaining complete pharmacokinetic profiles tor every patient is not feasible in clinical practice, a parameter strongly correlating with AUC was sought. The fairly strong correlation between AUC and the trough concentration of tacrolimus in whole blood $(r=0.80-0.95)$ led to the use of trough levels as an indicator of systemic exposure and, therefore, to dose adjustments ${ }^{37}$.

In liver transplant recipients, large individual differences in pharmacokinetic profiles have been reported ${ }^{38}$. In Chapter 6 a, we investigated whether such large interindividual differences in pharmacokinetic profules also occurred in potential renal transplant recipients and, if so, whether there were differences between diabetics and nondiabetics. As in liver transplant recipients, tacrolimus exposure showed large interindividual differences in patients with renal insufficiency, with maximum AUCs four to seven times those of minimal AUCs. Differences were slightly more pronounced in diabetics. Therefore, although time-consuming, pretransplant pharmacokinetic profiles may be valuable to detect patients with low and high systemic exposure.

Our group demonstrated that the predictive value of a pretransplant AUC was limited with respect to posttransplant dosing requirements ${ }^{39}$. However, one blood level measured at 2 hours after administration of the first dose could be used to detect patients at risk for high or low levels. In our opinion, the costs involved in this kind of pretransplant pharmacokinetic examination are marginal compared to the costs incurred by the occurrence of low tacrolimus levels (acute rejection) and high tacrolimus levels (toxicity, PTDM).

In healthy volunteers and liver transplant recipients, the presence of food containing a high fat or carbohydrate content affected the oral bioavailability of tacrolimus ${ }^{40}$. Therefore, all patients were advised not to eat or drink anything from 2 hours prior until 1 hour after ingestion of tacrolimus. With twice daily dosing, this meant that no food or beverage could be consumed for 6 hours of each day! Whether such inconvenient measurements were, indeed, necessary for our kidney transplant recipients, who consumed a generally low-fat European breakfast, was unclear.

In Chapter $6 \mathrm{~b}$, the question of whether nonfasting ingestion of tacrolimus influenced its oral bioavailibility was studied in dialysis patients. This was studied separately for nondiabetics and diabetics. A standard high fat breakfast was given 
to the patients. The median $\mathrm{C}_{\text {max }}$ decreased by $22 \%$ in nondiabetics and by $42 \%$ in diabetics, and the median $t_{\text {max }}$ increased by $50 \%$ and $100 \%$, respectively, but the median $A \cup C$ remained unchanged. This indicated that although the rate of absorption was slowed, the total exposure was not affected by concomitant ingestion of food and tacrolimus.

In Chapter 6c, differences between fasting and nonfasting tacrolimus ingestion were studied in renal transplant recipients. We also studied whether there were differences at different times after transplantation. In addition, changes in oral clearance after transplantation were investigated. Again, a breakfast with a high fat content $(34 \%)$ was given to the patients. When comparing ingestion without fasting to that with fasting, mean $\mathrm{C}_{\max }$ and mean $\mathrm{t}_{\mathrm{max}}$ increased up to approximately $40 \%$, but decreases in AUC were much smaller: only $2 \%$ (at week 3) to 12\%. As in the study described in Chapter 6b, this indicates later absorption of the drug at a more distal part of the gut. Decreases in trough level were generally more pronounced in diabetics than in nondiabetics.

In Chapter 6d, we investigated whether tacrolimus trough levels remained in the therapeutic range after outpatient conversion to nonfasting ingestion of tacrolimus. Patients were free to choose their own food. They started ingestion of tacrolimus, together with food, one week before a routine check-up. After one week, when tacrolimus trough levels were in a new steady state, they were checked. Tacrolimus trough levels did not change significantly. Moreover, all trough levels remained in the therapeutic range after conversion, and no rejections occurred.

\section{Management of nonfasting tacrolimus ingestion}

From the studies in Chapter 6, we could conclude that absorption of tacrollimus was somewhat less after simultaneous ingestion of tacrolimus and food, especially in diabetics, but that the differences were clinically irrelevant because all levels remained in the therapeutic window, and, therefore, did not warrant the life-long rules of fasting ingestion of tacrolimus. Therefore, our current policy is to convert every patient to nonfasting tacrolimus ingestion (Figure 8.2). Because the smallest difference in AUC between fasting and nonfasting ingestion of tacrolimus occurred at 3 weeks after transplantation and was only $2 \%$, we recommend conversion to nonfasting ingestion of tacrolimus without changes in tacrolimus dose at 3 weeks after transplantation, provided tacrolimus levels are within the therapeutic range. Additional reasons for choosing this point in time are the facts that, at 3 weeks posttransplantation, tacrolimus trough levels are relatively high, resulting in higher accuracy of tacrolimus trough level measurements, and that no additional checkups are necessary, since at 3 weeks posttransplantation, patients are generally seen at least once or twice a week. For patients still ingesting tacrolimus according to the fasting instructions who underwent transplantation before we made this 
recommendation, we recommend conversion to nonfasting ingestion of tacrolimus at therapeutic trough levels one week before a new check-up.

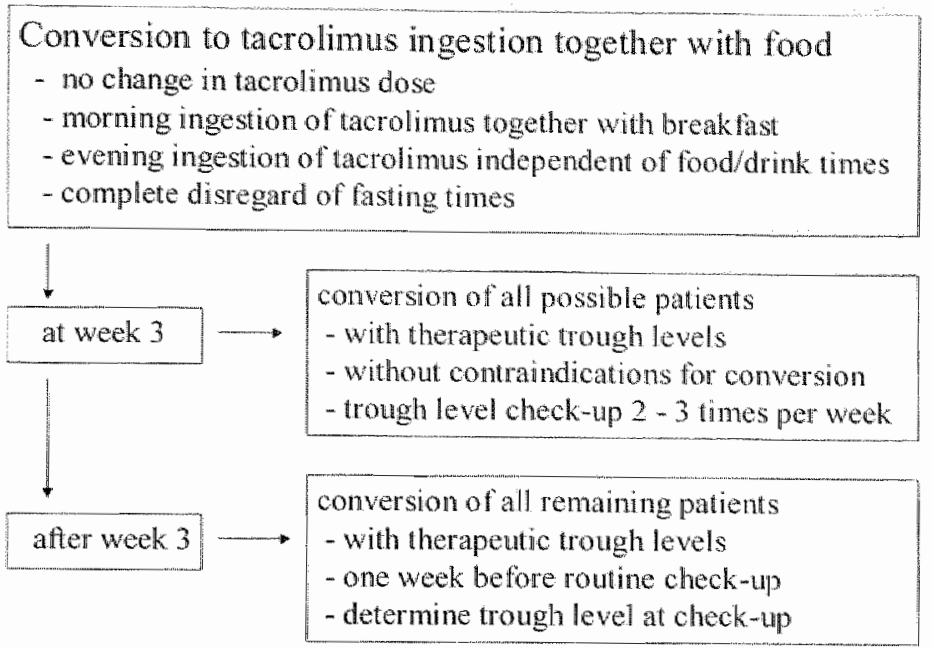

Figure 8.2 Guidelines for conversion to nonfasting tacrolimus ingestion.

\section{Interaction between tacrolimus and corticosteroids}

Tacrolimus is extensively bound to albumin and hemoglobin. The elimination halflife of tacrolimus is long, approximately 40 hours. The free fraction is responsible for its action and is also the fraction metabolized ${ }^{41}$. When hemotocrit and albumin levels are low, the elimination of tacrolimus increases. Metabolization occurs via the cytochrome P450 3A4 iso-enzyme in the gut, and especially in the liver". Corticosteroids are inducers of cytochrome P450 $3 \mathrm{A4}$ iso-enzyme ${ }^{43}$. In animal and in vitro studies, an interaction between tacrolimus and corticosteroids was described $^{4448}$. Human data were not available. In Chapter 7 , we investigated tacrolimus trough levels after steroid withdrawal. After withdrawall of $5-10 \mathrm{mg}$ prednisolone, tacrolimus exposure increased up to $40 \%$, and in individual patients by as much as $200 \%$. This effect of steroids on tacrolimus levels appears to be dose-dependent because the increase in tacrolimus trough level was higher after withdrawal of $10 \mathrm{mg}$ prednisolone than after withdrawal of $5 \mathrm{mg}$. Clinically relevant increases of more than $20 \%$ occurred in approximately half of the patients, which may be explained by genetic polymorphism of cytochrome P450 3 A4 expression $^{49}$. Based on clinical parameters, we could not differentiate between patients responding with an increase in tacrolimus trough level after steroid withdrawal and those not responding. Therefore, tacrolimus levels should be monitored regularly during steroid withdrawal. Immediately after transplantation. the effects of reducing high corticosteroid dosages on tacrolimus exposure may 
have been much higher and may partly explain the decreasing dose requirements of tacrolimus over time.

Like cyclosporine, tacrolimus is nephrotoxic. It causes dose-dependent vasoconstriction in the kidney ${ }^{41}$. In Chapter 7 , we observed that increasing tacrolimus trough levels caused an increase in serum creatinine, which could be misinterpreted as rejection. Therefore, understanding this issue has practical implications for clinical practice.

In Figure 8.3, some of the complex interactions that occur between tacrolimus and corticosteroids early after transplantation are summarized.

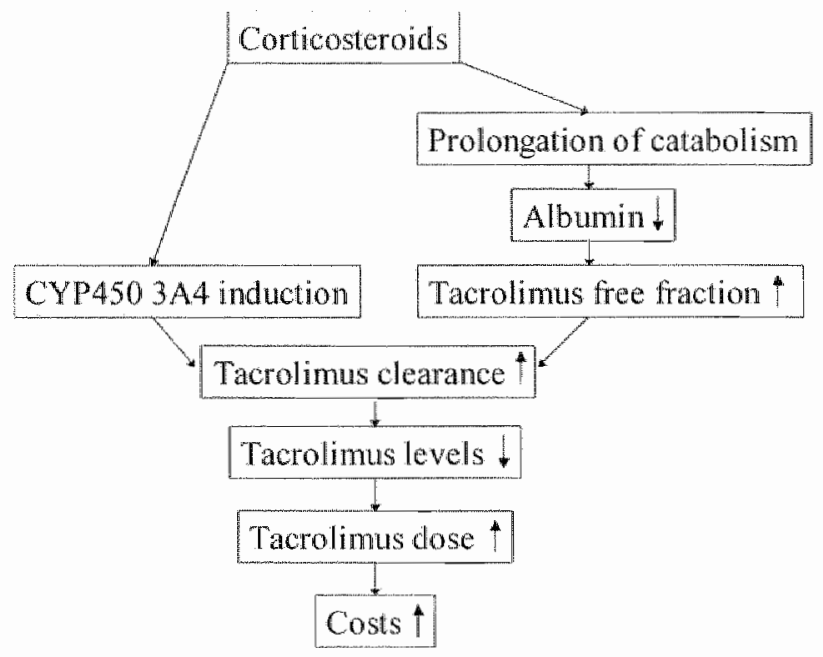

Figure 8.3 Interactions between tacrolimus and corticosteroids early after transplantation.

In Table 8.6 the main conclusions of the studies described in Chapters 6 and 7 of this thesis are summarized.

Table 8. 6: Parmacokinetic conclusions.

- In renal transplant recipients, there are large interindividual differences in tacrolimus oral bioavalability.

- Testing before transplantation is indicated.

- Ingestion of tacrolimus together with food results in a slower absorption, but does not significantly influence total exposure.

- Interindividual differences in oral bioavailibility of tacrolimus and changes after nonfasting ingestion of tacrolimus are somewhat more pronounced in diabetics than in nondiabetics, but total exposure is not significantly different for either group.

- Atter conversion to nonfasting ingestion of food, tacrolimus trough levels do not change significantly and remain within the therapeutic window for all patients.

- Steroid withdrawal results in an increase in tacrolimus trough levell, probably as a result of reversal of induction of cytochrome $\mathrm{P} 4503 \mathrm{~A} 4$ by corticosteroids.

- By increasing tacrolimus trough levels, steroid withdrawal results in increased serum creatinine levels. 


\section{Concluding remarks}

In the first section of this thesis, the roles of tacrolimus and of corticosteroids in the impairment of glucose metabolism were described. Tacrolimus caused a reversible decrease in pancreatic $\beta$-cell secretion, whereas corticosteroids were associated with increased insulin resistance. Corticosteroids were also associated with hyperlipidemia. Therefore, steroid withdrawal and keeping tacrolimus trough levels as low as possible will improve the lipid profile and minimize the impairment of glycemic control posttransplantation. During steroid withdrawal, tacrolimus levels should be closely monitored. An increase in tacrolimus levels, due to interaction between tacrolimus and steroids, will occur in up to half of the patients.

Compared to cyclosporine, tacrolimus is associated with less acute rejection, less hypertension, and less hyperlipidemia. Moreover, unlike cyclospotine, tacrolimus is not associated with hirsutism or gingival hyperplasia. We showed that long-term glucose metabolism was not significantly different for patients treated with cyclosporine and those treated with tacrolimus. Therefore, the risk profiles for long-term graft failure and for cardiovascular disease and mortality are better for tacrolimus-treated patients than for cyclosporine-treated patients. Based on the available studies concerning the efficacy of different immunosuppressive regimens, and on the studies in this thesis, tacrolimus is currently the preferred immunosuppressive agent for cornerstone immunosuppression in renal transplant recipients. 


\section{References}

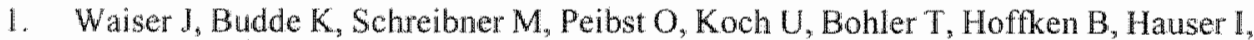
Neumayer HH. The quality of life in end stage renal disease care. Transpl Int 1998; 11 Supp! 1: \$42-\$45.

2. Schnuelle $P$, Lorenz D, Trede $M$, wan der Woude FJ. Impact of renal cadaveric transplantation on survival in end-stage renal failure: evidence for reduced mortality risk compared with hemodialysis during long-term follow-up. I Am Soc Nephrol $1998 ; 9: 2135-2141$.

3. Sikensen JR. Long-term complications in renal transplantation. J Am Soc Nephrol $2000 ; 11(3): 582-588$.

4. Mayer AD, Dimitrewski J, Squifflet JP, Bessen T, Grabensee B, Klein B, Eigler FW, Heemann U, Pichlmayr R, Behrend M, Vanenterghem $Y$, Donck J, van Hooff J, Christiaans M, Morales JM, Andres A, Johnson RWG, Short C, Buchholz B, Rehmert N, Land W, Schleibner S, Forsythe JLR, Talbot D, Neumayer HH, Hauser I, Ericzon BG, Brattström C, Claesson K, Mühlbacher F, Pohanka E. Multicenter randonized trial comparing tacrolimus (FK506) and cyclosporine in the prevention of renal allograft rejection. Transplantation 1997; 64: 436-443.

5. Pirsch JD, Miller J, Deierhoi MH, Vincenti F, Filo RS. A comparison of tacrolimuls (FK506) and cyclosporine for immunosuppression after cadaveric renal transplantation. FK506 Kidney transplant group. Transplantation 1997; 63: 977-983.

6. Johnson C, Ahsan N, Gonwa T, Halloran P, Stegall M, Hardy M, Metzger R, Shield C. Rocher L, Scandling J, Sorensen J, Mulloy L, Light J, Corwin C, Danovitch G, Wachs M, van Veldhuisen P, Salm K, Tolzman D, Fitzsimmons WE. Randomized trial of tacrolimus (Prograf) in combination with azathioprine or mycophenolate mofetil versus cyclosporine (Neoral) with mycophenolate mofetil after cadaveric kidney transplantation. Transplantation 2000;69 (5): 834-841.

7. Saase van JLCM, van der Woude FJ, Thorogood J, Hollander AA, van Es LA, Weening JJ, van Bockel JH, Bruijn JA. The relation between acute vascular and interstitial renal allograft rejection and subsequent chronic rejection. Transplantation $1995 ; 59: 1280-1285$.

8. Mayer AD, and the European Tacrolimus Multicenter Renal Study Group. Better halllife estimate and lower rate of chronic rejection with tacrolimus compared to cyclosporin: 5-year follow-up results of the European Tacrolimus Mullicentre Study. ICI, San Diego, 6-8 Dec 2001, abstract 66.

9. Ligtenberg $\mathrm{G}_{\|}$Hene RJ, Blankestin PJ, Koomans HA. Cardiovascular tisk factors in renal transplant patients: cyclosporin A versus tacrolimus. I Am Soc Nephrol 2001; 12 (2): $368-373$

10. Revanur VK, Jardine AG, Kingsmore DB, Jaques BC, Hamilton DH, Jindal RM. Influence of diabetes mellitus on patient and gratt survival in recipients of kidney transplantation. Clin Transplant 2001; 15(2): 89-94.

I1. Hjelmesath J, Hartmann A, Midtvedt K, Aakhus S, Stenstrom, Mørkrid L, Egeland T, Tordarson H, Fauchald P. Metabolic cardiovascular syndrome after renal transplantation. Nephrol Dial Transpl. 2001; $16(5)$ : 1047-1052.

12. Tamura K. Fujimura T, Tsutsumi T, Nakamura $K$, Ogawa $T$, Atumaru C, Hirano $Y$, Ohara K, Ohtsuka K, Shimomura K, Kobayashi M. Transcriptional inhibition of insulin by FK 506 and possible involvement of FK 506 binding protein-12 in pancreatic beta-cell. Transplantation 1995; 59:1606-1613. 
13. Ricordi $C$, Zeng $Y$, Alezandro R, Tzakis A, Venkatamaman R, Fung I, Bereiter $D$, Mintz D, Starzl T. In vivo effect of FK 506 on human pancreatic islers. Transplantation $1991 ; 52: 519-522$.

14. Rilo $H$, Zeng $Y$, Alejandro R, Carroll PB, Bereiter D, Venkataramanan $R$, Tzakis A. Starzl T, Ricordi C. Effect of FK 506 on function of human islets of Langerhans. Transplant Proc 1991:23: 3164-3165.

15. Weir MR, Fink JC. Risk for posttransplant diabetes mellitus with current immunosuppressive medications. Am J Kidney Dis 1999; 34: 1-13.

16. Hjelmesaeth J, Hartmann A, Kofstad J, Stenstrom J, Leivestad T, Egeland T, Fauchald P. Glucose intolerance after renal transplantation depends upon prednisolone dose and recipient age. Transplantation 1997; 64 (7): 979-983.

17. Vegt de F, Dekker JM, Jager A, Hienkens E, Kostense PJ, Stehouwer CD, Nijpels G, Bouter LM, Heine RJ. Rellationship of impaired fasting and postload glucose with incident type 2 diabetes in a Dutch population: the Hoorn Study. JAMA 2001; 285 (16): $2109-2113$.

18. Nam JH, Mun JI, Kim SI, Kang SW, Choi KH, Park K, Ahn CW, Cha BS, Song YD, Lim SK, Kim KR, Lee HC, Huh KB. $\beta$-cell dysfunction rather than insulin resistance is the main contributing factor for development of postrenal transplantation diabetes mellitus. Transplantation 2001; 71 (10): 1417-1423.

19. Boots JMM, wan Duijnhoven EM, Christiaans MHL, Nieman FHM, van Suylen R-J, van Hooff JP. Single center experience with tacrolimus versus cyclosporin-Neoral in renal transplant recipients. Transplant Int $2001 ; 14: 370-383$.

20. Squifflet JP, Vanrenterghem $\mathrm{Y}$, Abramowicz D, Mourad M, Kuypers D, Meurisse M, Daems $J$. The clinical outcone of a single-arm pilot trial in renal transplant patients investigating the safety of a low FK506/low-stop corticosteroid regimen in combination with mycophenolate mofetil and daclizumab induction therapy. ICI, San Diego, 6-8 Dec 2001, abstract 104.

21. Land W, Schneeberger H, Weiss M, Ege T, Stümpfig L. Mycophenolate mofetil monotherapy: an optimal, safe, and efficacious immunosuppressive maintenance regimen in kidney transplant patients. Transpl Proc 2001; 33 (Suppl 4A): 29S-35S.

22. Shapiro R, Jordan ML, Scantlebury VP, Vivas C, Gritsch HA, Corry RJ, Egidi F, Mc Cauley J, Ellis D, Gilboa $N$. The superiority of tacrolimus in renal transplant recipients - the Pittsburgh experience. Clin Transpl 1995: 199-205.

23. Chakrabarti $P$, Wong $H Y$, Scantlebury VP, Jordan ML, Vivas C, Ellis D, Lombardozzi-Lane S, Hakala TR, Fung JJ, Simmons RL, Strazl TE, Shapiro R. Outcome after steroid withdrawal in pediatric renal transplant patients receiving tacrolimus based immunosuppression. Transplantation 2000; 70: 760-764.

24. Golling M, Lehmann T, Senninger N, Herfarth $C$, Otto G. Tacrolimus reduction improves glucose metabolism and insulin secretion after liver transplantation. Transpl Proc 1996; 28: 3180-3182.

25. Fernandez L, Lehmann R, Luzi L, Battezzati A, Angelico M, Ricordi C, Tzakis A, Alejandro R. The effects of maintenance doses of FK506 versus Cyclosporin A on glucose and lipid metabolism after orthotopic liver transplantation. Transplantation $1999 ; 68: 1532-1541$.

26. Khaw $K$, Wareham $N$, Luben $R$, Bingham $S$, Oakes $S$, Welch $A$, Day N. Glycated haemoglobin, diabetes, and mortality in men in Norfolk cohort of European Prospective Investigation of Cancer and Nutrition (EPIC, Norfolk). BMJ 200 I; 322 : 15-18. 
27. The DECODE study group. European diabetes epidemiology group. Glucose tolerance and mortality: comparison of WHO and American Diabetes Association diagnostic criteria. Diabetes Epidemiology: Collaborative analysis of diagnostic criteria in Europe. Lancet 1999; 354 (9179): 617-621.

28. Balkau B, Pyörälä M, Shipley MJ, Forhan A, Jarrett RJ, Eschwege E, Pyörälä K. High blood glucose concentration is a risk factor for mortality in middle-aged nondiabetic men - 20-year follow-up in the Whitehall Study, the Paris Prospective Study, and the Helsinki Policemen study. Diabetes Care 1998; 21:360-367.

29. Barrett Connor E, Wingard DL. "Normal" blood glucose and coronary risk. Dose response effects seems consistent throughout the glycaemic continum. BMJ 2001: $322: 5-6$.

30. Vanrethergem Y, Peeters J. In Touraine $J$, et al (eds): Late graft loss. Great Brittain: Kluwer Academic Publishers; 1997: 85.

31. Kasiske BL. Clinical correlates to chronic renal allograft rejection. Kidney Int 1997; 52 (Suppl 63): S71-S74

32. Kuo PC, Johnson LB, Schweitzer EJ, Alfrey EJ, Waskerwitz J, Bartlett ST. Utilization of the older donor for renal transplantation. Am J Surg 1996; 172: $551-557$.

33. Heemann $U$, Kohnle $M$, Zimmermann U, Philipp $T$. Tacrolimus in maintenance therapy, which trough level is right? ICl, San Diego, 6-8 Dec 2001, abstract P-95.

34. Cosio FG, Pesavento TE, Osei K, Henry ML, Ferguson RM. Post-transplant diabetes mellitus: Increasing incidence in renal allograft recipients transplanted in recent years. Kidney Int 2001; 59: 732-737.

35. Sammalkorpi K. Glucose intolerance in acute infections. II Intern Med 1989;225 (1): $15-19$.

36. Knobler H, Stagnaro-Green A, Wallenstein S, Schwartz M, Roman SH. Higher incidence of diabetes in liver transplant recipients with hepatitis $\mathrm{C}$. J Clin Gastroenterol 1998; 26:30-33.

37. Mekki Q, Lee C, Aweeka F, Laskow D, Neylan J, Mendez R, Steinmuller D, Schechter P. Pharmacokinetics of tacrolimus (FK506) in kidney transplant patients. Clin Pharmacol Ther 1993; 53 (2): 238, abstract PIII-130.

38. Venkataramanan R, Jain A, Warty VS, Abu-EImagd K, Alessiani M, Lever J, Krajak A. Flowers J, Mehta S, Zuckerman S, Fung J, Todo S, Starzl TE. Pharmacokinetics of FK506 in transplant patients. Transp Proc 1991: 23 (6): 2736-2740.

39. Boots JMM, Christiaans MHL, Undre NA, van Hoof JP. Pre-transplant pharmacokinetics: does it predict the dose of tacrolimus after renal transplantation? ICl, San Diego, 6-8 Dec 2001, abstract P-89.

40. Mekki Q, Lee C, Carrier S, Klintmalm G, Shaefer M, Burke P, Schechter P. The effect of food on oral bioavailability of tacrolimus (FK506) in liver transplant patients. Clin Pharmacol Ther 1993; 53 (2): 229, abstract PIII-92.

41. Plosker GL, Foster RH. Tacrolimus: a further update of its pharmacology and therapeutic use in the management of organ transplantation. Drugs 2000;59 (2): $323-389$.

42. Vincent $\mathrm{SH}$, Karanam BV, Painter SK, Chiu SH. In vitro metabolism of FK-506 in rat, rabbit and human liver microsomes: identification of a major metabolite and of cytochrome P450 $3 \mathrm{~A} 4$ as the major enzymes responsible for its metabolism. Arch Biochem Biophys 1992; 294 (2): 454-460.

43. Sewing $\mathrm{K}$ Fr. Pharmacokinetics, dosing principles and blood level monitoring of FK 506. Transplant Proc 1994; 26 (6): 3267-3269.

44. Piekoszewski W, Chow FS, Jusko WJ. Phamacokinetic and pharmacodynamic effects of coadministration of methylprednisolone and tacrolimus in rabbits. The Journal of Pharmacology and Experimental Therapeutics 1994;269 (1): 103-109. 
45. Moochhala SM, Lee EJD, Earnest L, Wong JYY, Ngoi SS. Inhibition of drug metabolism in rat and human liver miorosomes by FK 506 and cyclosporine. Transplant Proc 1991; 23:2786-2788.

46. Omar G, Shah LA, Thomson AW, Whiting PH, Burke MD. FK 506 inhibition of cyclosporine metabolism by human liver microsomes. Transplant Proc $1993 ; 23: 690$ 698.

47. Shah LA, Whiting PH, Omar G, Thomson AW, Burke MD. Effects of FK 506 on human hepatic microsomal cytochrome P-450-dependent drug metabolism in vitro. Transplant Proc 1991; 23: 2783-2785.

48. Sattler M, Guengerich PF, Yun CH, Christians U, Sewing KF. Cytochrome p-450 $3 \mathrm{~A}$ enzymes are responsible for biotransfromation of FK 506 and rapamycin in man and rat. Drug Metab Dispos 1992; 20:753-761.

49. Westlind $A$, Löfberg L, Tindberg N, Andersson TB, Ingelman-Sundberg MI. Interindividual differences in hepatic expression of CY P3A4: relationship to genetic polymorphism. Biochemical and biophysical research communications 1999; 259 (1): 201-205. 

Chapter 9

\section{Samenvatting}


Chomes 


\section{Samenvatting}

Niertransplantatie heeft zich in de twintigste eeuw ontwikkeld van een experimentele behandeling in de jaren zestig met een hoge mortaliteit toegankelijk voor een beperkt aantal sterk geselecteerde patiënten, tot een voorkeursbehandeling voor patiënten met kunstnierbehandeling in verband met zogenaamde terminale nierinsufficiëntie aan het eind van de tachtiger jaren. Na een succesvolle transplantatie verbetert de kwaliteit van leven en neemt tevens de levensverwachting toe.

Echter tien jaar na transplantatie functioneert nog slechts ongeveer de helft van alle donornieren. Dit verlies aan getransplanteerde nieren wordt veroorzaakt door niet goed meer functioneren van de getransplanteerde nier (chronische transplantaatdisfunctie) en nog frequenter door overlijden van de patiënt met een goed functionerende transplantaatnier. Dit overlijden wordt meestal veroorzaakt door hart- en vaatziekten.

Van \pm 1980 tot \pm 1995 bestond de onderhouds-immunosuppressieve therapie (medicijnen die de afweer onderdrukken en daarmee moeten voorkomen dat de transplantaatnier wordt afgestoten) vrijwel voor alle patiënten uit cyclosporine met corticosteroïdlen en azathioprine. Vanaf 1995 kwamen er een aantal nieuwe immunosuppressiva ter beschikking: tacrolimus, een middel te gebruiken als hoeksteen van de behandeling en mycophenolate mofetil, en sirolimus, te gebruiken als toegevoegde medicijnen.

Wanneer tacrolimus werd gegeven in plaats van cyclosporine, bleken acute afstotingen belangrijk minder vaak voor te komen. Dit gold zowel voor corticosteroid-gevoelige als voor corticosteroid-ongevoelige afstotingen. Vanwege het feit dat acute afstotingen en met name corticosteroid-ongevoelige acute afstotingen in verband gebracht werden met een hoger risico op chronische transplantaat-disfunctie, werd verwacht dat het gebruik van tacrolimus zou leiden tot een betere transplantaatoverleving dan bij gebruik van cyclosporine het geval was. Inmiddels zijn er sterke aanwijzingen gevonden dat deze verwachtingen gerechtvaardigd waren. Daarnaast leidde het gebruik van tacrolimus in plaats van cyclosporine tot een verbetering van de vetten in het bloed en tot een lagere bloeddruk. Ook deze factoren worden in verband gebracht met chronische transplantaatdisfunctie en tevens met sterfte ten gevolge van hart- en vaatziekten na transplantatie. Bij gebruik van tacrolimus werd echter vastgesteld dat diabeies mellitus (suikerziekte) na transplantatie (posttransplantatie diabetes mellitus = PTDM) vaker voorkwam dan bij gebruik van cyclosporine het geval was. Dit zou de eerder genoemde mogelijke voordelen ten aaanzien van overleving van de 
transplantaatmier en ten aanzien van de patientenoverleving weer teniet kunnen doen.

\section{Posttransplantatie diabetes mellitus}

In het algemeen zijn er drie verschillende manieren waarop PTDM kan ontstaan: verminderde of afwezige insulineproductie door de alvleesklier, toegenomen ongevoeligheid voor insuline (insulineresistentie), of een combinatie van deze. Met behulp van nuchtere bloedwaarden van glucose en insuline gecombineerd met een intraveneuze glucose-tolerantie-test (IVGTT) is het mogelijk om de manier waarop PTDM ontstaat nauwkeuriger vast te stellen. Met bebulp van de nuchtere bloedwaarden kan de insulineresistentie berekend worden, en met bebulp van de waarden verkregen door middel van de IVGTT, kan de insulineproductie worden berekend. Bovendien is het mogelijk om het gezamenlijke effect van deze beide factoren op de verdwijnsnelheid van een bolus glucose uit de bloedbaan te bepalen (insuline-sensitiviteitsindex $=k_{\sigma_{j}}$ ).

Het mechanisme verantwoordelijk voor het ontstaan van PTDM tijdens op tacrolimus gebaseerde immunosuppressie was onduidelijk. Bij dierstudies en experimentele studies werd een afname van de insulineproductie vastgesteld, terwijl klinische onderzoeken bij mensen na transplantatie tevens een toename in de insulineresistentie vaststelden. Bij deze onderzoeken na transplantatie gebruikten de patiënten niet alleen tacrolimus maar eveneens corticosterö̈den. Deze laatste kunnen ook de suikerstofwisseling (het glucosemetabolisme) beïnvloeden.

Er waren reeds verscheidene risicofactoren voor PTDM beschreven, o.a. genetische factoren, hogere leeftijd, overgewicht, en hogere doseringen van calcineurine-inhibitoren (tacrolimus en cyclosporine) en van corticosteroïden. De relatieve bijdrage van al deze factoren was echter niet bekend. In het eerste deel van dit proefschrift (Hoofdstuk 2 - 5) zijn de relatieve bijdragen van aanleg, calcineurine-inhibitoren en corticosteroïden bestudeerd. De insulineresistentie werd berekend met behulp van de basale (nuchtere) waarden van glucose, insuline en $\mathrm{C}$-peptide. Berekeningen van de toename van het oppervlak van het gebied onder de curve van C-peptide en insuline werden gebruikt om de insulineproductie vast te stellen. Het belang van zowel insulineresistentie als insulineproductie op het glucosemetabolisme wordt weergegeven in de insuline-sensitiviteitsindex $\left(k_{\mathrm{G}}\right)$. Deze werd berekend door lineaire regressie van de natuurlijke logaritme van de glucosewaarden tussen 10 en 30 (of 60) minuten na toediening van een intraveneuze bolus glucose (Hoofdstuk 1). 
Transplantatiepatiënten gebruiken gewoonlik een combinatic van meerdere immunosuppressieve medicijnen. Zoals reeds eerder vermeld, worden niet alleen de calcineurine-inhibitoren tacrolimus en cyclosporine geassocieerd mer stoomissen in het glucosemetabolisme, maar geldt dit ook voor corticosteroiden. In Hoofdstuk 2 werd de rol van tacrolimus in stoomissen van het ghcosemetabolisme onderzocht. Omdat dialysepatiënten werden onderzocht konden foutieve conclusies veroorzaakt door gelijktijdig gebruik van corticosteroïden worden voorkomen. Na orale toediening (inname via de mond) van tacrolimus, daalde de insuline-sensitiviteitsindex $\left(\mathrm{k}_{\mathrm{G}}\right)$ significant. Deze daling van de $\mathrm{k}_{\mathrm{G}}$ trad bij vrijwel iedere patiënt op en veranderde met de hoogte van de tacrolimusdalspiegels. Deze daling werd veroorzaakt door een significante afname van de insulineproductie. De insulineresistentie veranderde niet. Een significant verband tussen insulineproductie en leeftijd, geslacht, of body mass index (gewicht gedeeld door lengte in het kwadraat) werd niet gevonden.

Voorts bleek het mogelijk om al voor transplantatie vast te stellen welke patiënten risico lopen op het ontwikkelen van PTDM na transplantatie. Vóór transplantatie had bijna een derde van de dialysepatiënten een $\mathrm{k}_{\mathrm{G}}$-waarde in het laagnormale gebied of hier nog onder. Ongeveer de helft van deze patiënten ontwikkelde na de transplantatie PTDM. Geen van de patiënten met hogere $\mathrm{k}_{\mathrm{G}^{-}}$-waarden, en dus een betere hormonale alvleesklierfunctie, ontwikkelde PTDM. Daarom kan gesteld worden dat het door middel van IVGTTs uitgevoerd voor transplantatie mogelijk is om vast te stellen welke patiënten het risico lopen om PTDM te ontwikkelen na transplantatie. Bij dergelijke patiënten is het zinvol om medicamenten die de kans op diabetes mellitus kunnen vergroten (de calcineurine-inhibitoren tacrolimus en cyclosporine en corticosteroïden) te vermijden. De werkzaamheid en bijwerkingen van dergelijke schema's, bestaande uit onlangs ontwikkelde immunosuppressiva, zijn echter op dit moment nog onvoldoende duidelijk.

Toen het aangetoond was dat het veilig was om corticosteroïden te stoppen bij stabiele niertransplantatiepatiënten, werd het mogelijk de rol van corticosteroïden tijdens gelijktijdig gebruik van tacrolimus bij stoornissen in het glucosemetabolisme te onderzoeken. Dit is beschreven in Hoofdstuk 3. Na staken van de corticosteroïden daalde de nuchtere C-peptidewaarden, de insulinewaarden, en de insuline/glucose ratio, wijzend op een afname van de insulineresistentie. De insul ineproductie veranderde niet na het staken van de corticosteroïden. De afname in insulineresistentie na het staken van de corticosterö̈den zou een afname van de kans op hart- en vaatziekten kunnen betekenen. Een andere belangrijke bevinding van dit onderzoek was de daling van alle vetten in het bloed na het staken van de corticosteroïden. Ook dit zou een afname van hart- en vaatziekten kunnen betekenen. Echter, het is niet duidelijk in hoeverre de vanzelfsprekend gunstige 
dalingen van het rotaal-cholesterol, LDL-cholesterol en de triglyceriden, teniet kunnen worden gedaan door een gelijktijdige ongunstige daling van het HDLcholesterol.

Een hoge dosering tacrolimus of cyclosporine was reeds gemeld als risicofactor voor het ontwikkelen van PTDM. In Hoofdstuk 3 hebben we onderzocht of stoornissen in het glucosemetabolisme veroorzaakt door tacrolimus omkeerbaar zijn. Een $30 \%$ verlaging van de tacrolimus dalspiegel, binnen de streefwaarden, bij patiënten die al meer dan een jaar tacrolimus gebruikten, bleek een significante toename van de insulineproductie met $25 \%$ tot $35 \%$ te veroorzaken. Hieruit konden we concluderen dat de afname van de insulineproductie veroorzaakt door tacrolimus niet alleen dosisafhankelijk was, maar ook omkeerbaar, zelfs na langdurig gebruik van tacrolimus. De waarneming dat PTDM vaak weer verdwijnt in een latere fase na transplantatie als tacrolimusbloedspiegels veel lager zijn dan in de eerste maanden na transplantatie, ondersteunt deze conclusie.

$\mathrm{HbAlc}$ is een geglycosileerde (versuikerde) vorm van hemoglobine, die gebruikt wordt als maat voor de gemiddelde glucoseconcentratie tijdens de afgelopen 2 à 3 maanden. Een hoge $\mathrm{HbAlc}$ spiegel wordt in verband gebracht met een grote kans op overlijden ten gevolge van hart- en vaatziekten. In Hoofdstuk 3 vonden we een significante afname van het $\mathrm{HbAlc}$ van ongeveer $10 \%$ bij niet-diabetespatiënten na een verlaging van de tacrolimusdalspiegel met $30 \%$. Deze verbetering van het HbAlc betekent dat zover als mogelijke verlaging van tacrolimusbloedspiegels zou kunnen bijdragen aan het voorkomen van en verminderen van hart- en vaatziekten. Dit is niet alleen het geval bij patiënten met PTDM, maar ook bij patiënten met afwijkingen in het glucosemetabolisme die nog niet hebben geleid tot waanneembare diabetes mellitus. Zoals al eerder vermeld waren dergelijke afwijkingen voorafgaand aan de transplantatie in onze onderzoeksgroep reeds bij $30 \%$ alanwezig.

Na een $30 \%$ verlaging van de tacrolimus dalspiegel binnen de streefwaarden nam de nierfunctie met ongeveer 15\% toe (Hoofdstuk 3). De nierfunctie heeft een voorspellende waarde voor de lange termijn transplantaatoverleving. Verlaging van tacrolimusspiegels zou daarom bij kunnen dragen aan een verbetering van de lange termijn transplantaatoverleving door enerzijds de nierfunctie te verbeteren en anderzijds het glucosemetabolisme.

In Hoofdstuk 4 hebben we onderzocht of er verschillen waren in glucosemetabolisme tussen patiënten die tacrolimus en patiënten die cyclosporine als belangrijkste immunosuppressivum kregen. Beide groepen gebruikten een gelijke lage dosering corticosteroïden. Met behulp van IVGTTs werden 12 patiënten, die geloot hadden voor cyclosporine, en 11 patiënten, die geloot hadden voor tacrolimus, onderzocht gedurende de eerste drie jaar na transplantatie. Tevens werd 
onderzocht of er blijvende schade aan de hormonale functie van de alvleesklier optrad na langdurig gebruik van één van deze medicijnen. De patiënten werden onderzocht 3 weken, 3 en 6 maanden, en 1, 2 en 3 jaar na transplantatie.

Het enige significante verschil tussen de tacrolimus- en cyclosporinegroep tijdens dit drie jaar durende vervolgonderzoek, was een ongeveer $50 \%$ lagere insulineproductie drie weken na transplantatie in de tacrolimusgroep. Dit komt overeen met de klinische waarneming dat verschillen in het ontstaan van PTDM tussen op cyclosporine en tacrolimus gebaseerde immunosuppressie met name optreden in de eerste maanden na transplantatie en steeds geringer worden en na een jaar niet meer significant zijn. In de eerste maanden na transplantatie zijn de tacrolimusdoseringen en de streefspiegels veell hoger dan in de latere periode. Deze hogere spiegels vormen de meest waarschijnlijke verklaring voor de significant لagere insulineproductie en het vaker voorkomen van PTDM in de eerste maanden na transplantatie. Ook de veel hogere doseringen corticosteroïden in de eerste maanden na transplantatie in vergelijking met doseringen in de latere periode kunnen bijdragen aan het frequenter voorkomen van PTDM in de eerste maanden na transplantatie.

Bij beide groepen was er een tendens tot verbetering van het glucosemetabolisme (insuline-sensitiviteitsindex) in de eerste zes maanden na transplantatie. Dit ondanks een gelijktijdige toename van de insulineresistentie, vermoedelijk veroorzaakt door een toename van het lichaamsgewicht in de eerste maanden na transplantatie.

$\mathrm{Na}$ de eerste zes maanden na transplantatie waren er in het geheel geen veranderingen meer in enige van de parameters (maatstaven) voor glucosemetabolisme. Dit wijst erop dat langdurig gebruik van geen van deze beide middelen leidt tot blijvende schade aan de $\beta$-cellen (de cellen die insuline maken) in de alvleesklier. Dit is in tegenspraak met een onderzoek waarbij gevonden werd dat de kans op PTDM toeneemt met de tijd verstreken sinds de transplantatie. Naar onze mening zijn de late gevallen van diabetes mellitus na transplantatie doorgaans veroorzaakt door mechanismen die ook verantwoordelijk zijn voor type 2 diabetes mellitus ("ouderdomssuikerziekte") in de algemene populatie (zoals ouderdom en overgewicht) en stonden deze waarschijnlijk niet direct in verband met de immunosuppressie of met de transplantatic. De waarneming dat $30 \%$ van onze dialysepatiënten al een lage insulineproductie had voordat tacrolimus werd gestarl, en dat het lichaamsgewicht bij de meeste patiënten toeneemt na een succesvolle transplantatie, onderstrepen deze veronderstelling.

In Hoofdstuk 5 wordt een patiënte beschreven die twee jaar na transplantatie PTDM ontwikkelde, in aansluiting aan een hepatitis $\mathrm{C}$ infectie. In het eerste jaar na transplantatie werd herhaaldelijk een volledig normale hormonale alvleesklier- 
functie vastgesteld. Daana kreeg ze een hepatitis $\mathrm{C}$ infectie en ontstond PTDM. Tijdens de acute infectie bleek de insulineresistentie toe te nemen. Echter toen de hepatitis $\mathrm{C}$ infectie wat minder actief werd, en de PTDM al weer verdwenen was, bleek er niet alleen sprake van een toegenomen insulineresistentie, maar bleek er tevens sprake te zijn van een sterk gedaalde insulineproductie. Deze laatste waarneming suggereert een direct effect van het hepatitis C virus op de insulineproductie. Deze verminderde productie bleef alle vier de jaren, waarin patiënte na het verdwijnen van de PTDM gevolgd werd, bestaan.

Bij patiënten bij wie zich onverwacht laat na transplantatie PTDM voordoet moet een infectie, vooral hepatitis $C$ en op grond van literatuurgegevens ook cytomegalovirus, overwogen worden.

\section{Beleid bij posttransplantatie diabetes mellitus}

Op grond van de onderzoeken beschreven in Hoofdstuk 2, 3, 4 en 5 hebben we een aantal beleidsrichtlijnen opgesteld gericht op verbetering van het glucosemetabolisme bij niertransplantatiepatiënten die behandeld worden met tacrolimus als basis-immunosuppressivum. Pijlers van dit beleid zijn afbouwen en staken van de corticosteroilden en vervolgens verminderen van de tacrolimusdosering. De exacte uitwoering van deze maatregelen is beschreven in Hoofdstuk 8.

\section{Farmacokinetische onderzoeken}

Het tweede deel van het proefschrift richt zich op vragen betreffende farmacokinetische aspecten van tacrolimus. Bij farmacokinetiek wordt bekeken hoe een geneesmiddel zich gedraagt in het lichaam. Voorbeelden hiervan zijn: hoe snel en hoeveel wordt er opgenomen uit de darm? Waar komt het dan in het lichaam terecht? Welk deel van de totale hoeveelheid van het medicament in het lichaam is verantwoordelijk voor de werking? Hoe wordt het middel afgebroken en hoe wordt het verwijderd uit het lichaam?

De basale farmacokinetische aspecten van tacrolimus worden besproken in Hoofdstuk 1. Er is een grote variatie tussen personen in opname (absorptie), mogelijk ten gevolge van een belangrijke omzetting (metabolisatie) in de darm door cytochroom P450. Na opname bindt tacrolimus aan hemoglobine en albumine in het bloed en verdeelt het zich verder in het lichaam. Er is slechts een zeer klein ongebonden gedeelte in het bloed aanwezig wat verantwoordelijk is voor de immunosuppressieve werking en ook voor de bijwerkingen.

De uitscheiding vindt plaats via omzetting in de lever door het cytochroom P450enzym. De totale blootstelling kan het nauwkeurigst worden gemeten door middel van farmacokinetische profielen. Hierbij worden op meerdere tijdstippen tacrolimusspiegels bepaald vanaf een tijdstip onmiddellijk voorafgaand aan de 
inname van een ochtenddosis tot aan het tijdstip voorafgaand aan de inname van de daarop volgende avonddosis. De totale blootstelling kan dan worden berekend door de spiegels tegen de tijd uit te zetten in een grafiek en vervolgens de oppervlakte onder de concentratie-tijd-curve (AUC) te berekenen. Omdat het klinisch onmogelijk is om bij iedere patiënt dergelijke farmacokinetische profielen uit te voeren werd er een maat gezocht die goed overeenkwam met de AUC. Het vrij sterke verband tussen AUC en dalspiegelconcentraties van tacrolimus in volbloed leidden tot het gebruik van dalspiegels als maat voor de totale blootstelling en daardoor tevens als maat voor doseringsaanpassingen.

Bij levertransplantatiepatiënten werden grote verschillen tussen personen in farmacokinetische profielen beschreven. In Hoofdstuk 6a hebben we onderzocht of dergelijke grote verschillen tussen farmacokinetische profielen zich ook voordoen bij niertransplantatiekandidaten, en indien dit het geval is of er dan nog verschillen bestaan tussen diabetes mellitus patiënten en patiënten zonder diabetes mellitus. Dit laatste omdat bij patiënten met diabetes mellitus stoornissen in de maagontlediging kunnen voorkomen die de opname van tacrolimus zou kunnen beïnvloeden. Zoals bij levertransplantatiepatiënten waren er ook hier grote verschillen tussen de transplantatiekandidaten, met maximale AUCs vier tot zeven maal zo hoog als minimale AUCs. Deze verschillen waren iets uitgesprokener voor diabetes mellitus patiënten. Hoewel het maken van farmacokinetische profielen tijdrovend en kostbaar is, lijkt het uiterst waardevol om patiënten met een te hoge blootstelling aan tacrolimus (hetgeen de nierfunctie negatief zal beïnvloeden) en met een te lage blootstelling aan tacrolimus (een risicofactor voor afstoting) op te sporen.

Bij gezonde vrijwilligers en bij levertransplantatiepatiënten beïnvloedde de aanwezigheid van vetrijk of koolhydraatrijk voedsel de orale biologische beschikbaarheid (het werkzame gedeelte van de ingenomen dosis) van tacrolimus. Daarom werd alle patiënten geadviseerd om niets te eten of drinken van twee uur voor tot één uur na de tweemaal daagse inname van tacrolimus. Dit betekende dat er gedurende zes uur per dag geen voedsel of drinken genuttigd kon worden! of deze onplezierige maatregelen ook noodzakelijk waren voor niertransplantatiepatiënten, die bovendien een in het algemeen minder vetrijk Europees ontbijt gebruikten was onbekend.

In Hoofdstuk $\mathbf{6 b}$ werd bij transplantatiekandidaten onderzocht of niet-nuchtere inname van tacrolimus de orale biologische beschikbaarheid zou beïnvloeden. Dit werd zowel voor diabetes mellitus als niet-diabetes mellitus patiënten onderzocht. De patiënten kregen een standaardontbijt met een hoog vetgehalte. Bij gelijktijdige inname met voedsel, daalde de maximaal bereikte concentratie $\left(\mathrm{C}_{\max }\right)$ met $22 \%$ bij niet-diabetes patiënten en met $42 \%$ bij diabetes patiënten. De tijd tot het bereiken van de maximale concentratie $\left(\mathrm{t}_{\max }\right)$ nam toe met respectievelijk $50 \%$ en $100 \%$, 
terwijl de AUC onveranderd bleef. Dit wijst erop dat, ondanks tragere opname, de totale blootstelling aan tacrolimus niet beinvloed wordt door gelijktijdige inname van tacrolimus en voedsel.

In Hoofdstuk $6 \mathrm{c}$ werden de verschillen tussen niet-nuchtere en nuchtere inname van tacrolimus bestudeerd in niertransplantatiepatiënten. Bovendien werd er bekeken of deze anders waren op verschillende tijdstippen na transplantatie. Opnieuw werd een standaardontbijt met een hoog vetgehalte verstrekt. Wanneer we de nuchtere inname en de niet-nuchtere inname van tacrolimus vergeleken zagen we dat de gemiddelde $\mathrm{C}_{\max }$ ongeveer $40 \%$ afnam en de gemiddelde $\mathrm{t}_{\max }$ ongeveer $40 \%$ toenam, maar dat er slechts geringe afnamen in de AUCs werden gevonden: slechts $2 \%$ tot $12 \%$. Dit wijst evenals het onderzoek beschreven in Hoofdstuk $6 \mathrm{~b}$ op vertraagde opname van het medicament verderop in het maagdarmkanaal. Dalingen van de tacrolimusdalspiegels waren in het algemeen meer uitgesproken bij diabetes mellitus patiënten.

In Hoofdstuk 6d hebben we onderzocht of tacrolimusdalspiegels binnen de streefwaarden bleven na poliklinische omzetting van nuchtere naar niet-nuchtere inname van tacrolimus. De patiënten mochten hun eigen voedsel kiezen. Zij startten een week voor een routinecontrole. Na deze week werden de dalspiegels bepaald die na een dergelijke periode een nieuwe stabiele waarde bereikt hebben. De tacrolimusdalspiegel veranderde niet significant. Alle dalspiegels bleven bovendien binnen de streefwaarden en er traden geen afstotingen op.

\section{Beleid met betrekking tot niet-nuchtere inname van tacrolimus}

Op grond van de onderzoeken beschreven in Hoofdstuk 6 concluderen we dat er weliswaar verschillen tussen niet-nuchtere en nuchtere inname van tacrolimus bestaan, met name bij diabetes mellitus patiënten, maar dat deze verschillen klinisch niet belangrijk zijn omdat alle dalspiegels binnen de streefwaarden bleven en dat daarom levenslange regels met betrekking tot nuchtere inname van tacrolimus niet nodig zijn. Daarom is ons huidige beleid gericht op omzetting naar niet-nuchtere inname van tacrolimus bij alle patiënten. Omdat het geringste verschil tussen de nuchtere en niet-nuchtere AUCs gevonden werd drie weken na transplantatie en slechts $2 \%$ bedroeg adviseren we omzetting naar niet-nuchtere inname van tacrolimus zonder aanpassing van de dosis op dit tijdstip, op voorwaarde dat de tacrolimus dalspiegels voor omzetting binnen de streefwaarden liggen. Bij patiënten die na deze periode tacrolimus nog op nuchtere maag innemen, kan de methode beschreven in Hoofdstuk $6 \mathrm{~d}$ gevolgd worden, dat wil zeggen omzetting één week voor een routinepolibezoek. 


\section{Interactie tussen tacrolimus and corticosteroiden}

De eliminatiehalfwaardetijd (de tijd waarin de helft van het geneesmiddel verwijderd is) van tacrolimus is lang, ongeveer 40 uur. Tacrolimus is in bloed grotendeels gebonden aan albumine en hemoglobine. Het ongebonden gedeelte is verantwoordelijk voor de immunosuppressieve werking en is ook het gedeelte dat omgezet wordt. Omzetting vindt plaats via het cytochroom P450 3 A4 iso-enzym in de darm en vooral in de lever. Corticosteroiden verhogen de activiteit van het cytochroom P450 3A4 iso-enzym. Vanuit dierproeven en experimentele onderzoeken was een interactie (onderlinge beïnvloeding) tussen tacrolimus en corticosteroïden beschreven. Er waren geen gegevens bekend bij mensen. In Hoofdstuk 7 hebben we het effect van stoppen van corticosteroiden op de tacrolimusdalspiegels onderzocht. Na het staken van 5 of 10 milligram prednisolon steeg de mediane tacrolimusblootstelling met $40 \%$, en bij individuele patiënten wel tot $200 \%$. Dit effect lijkt dosisafhankelijk, aangezien de toename van de tacrolimusdalspiegel hoger was na het staken van $10 \mathrm{mg}$ dan na het staken van $5 \mathrm{mg}$ prednisolon. Klinisch belangrijke toenamen van meer dan $20 \%$ werden gevonden bij ongeveer de helft van de patiënten. Het feit dat er bij de overigen geen verhoging van de tacrolimusdalspiegel optrad, kan mogelijk te maken hebben met verschillen in de activiteit van het cytochroom P450 3A4. Op grond van klinische parameters konden we geen onderscheid maken tussen patiënten bij wie de tacrolimusdalspiegel steeg en bij wie dit niet gebeurde. Daarom is het belangrijk om tacrolimusdalspiegels regelmatig te controleren tijdens vermindering van de dosering corticosteroïden. Het is mogelijk dat kort na transplantatie de effecten van verlaging van de in aanvang hogere doseringen corticosteroïden nog veel uitgesprokener zijn. Dit zou een bijkomende verklaring kunnen zijn voor de afnemende behoefte aan tacrolimus in de loop van de tijd.

Evenals cyclosporine, is ook tacrolimus schadelijk voor de nierfunctie. Het veroorzaakt een dosisafhankelijke vaatvernauwing in de nier. In Hoofdstuk 7 zagen we dat een toename van de tacrolimusdalspiegel na staken van corticosteroïden een toename van het serumkreatinine (een maat voor de nierfunctie; hoe hoger het kreatinine in het bloed, hoe slechter de nierfunctie) veroorzaakte. Dit zou foutief beoordeeld kunnen worden als afstoting! Daarom is kennis van de interactie tussen tacrolimus en corticosteroïden van praktisch belang voor de directe patiëntenzorg.

\section{Tot slot}

In het eerste gedeelte van dit proefschrift werd de rol van tacrolimus en corticosteroïden in stoornissen van het glucosemetabolisme beschreven. 
Tacrolimus veroorzakte een omkeerbare afname van de insulineproductie door de alvleesklier, terwijl corticosteroïden in verband werden gebracht met een toename van de insulineresistentie. Corticosteroïden werden tevens in verband gebracht met stbornissen in de vetstofwisseling. Daarom zal staken van corticasteroïden en handhaving van een zo laag mogelijke tacrolimusdalspiegel de vetstofwisseling verbeteren en zal het verstoring van thet glucosemetabolisme minimaliseren. Tijdens de afbouwfase van de corticosteroïden moeten de tacrolimusspiegels nauwkeurig bewaakt worden. Een toename van de tacrolimusdalspiegel als gevolg van een interactie tussen tacrolimus en corticosteroïden zal optreden bij ongeveer de helft van de patiënten.

In vergelijking met gebruik van cyclosporine, gaat gebruik van tacrolimus gepaard met minder acute afstotingen, minder hypertensie (hoge bloeddruk) en minder hyperlipidemie (verhoging van de vetten in het bloed). Bovendien wordt tacrolimus, in tegenstelling tot cyclosporine, niet in verband gebracht met hirsutisme (overmatige haargroei) en gingiva-hyperplasie (tandvleeswoekering). Wij toonden aan dat op lange termijn het glucosemetabolisme niet significant verschillend was voor patiënten die behandeld werden met cyclosporine in vergelijking met patiënten behandeld met tacrolimus. Daarom is de kans op lange termijn transplantaatdisfunctie en op overlijden ten gevolge van hart- en vaatziekten lager voor patiënten behandeld met tacrolimus dan voor patiënten behandeld met cyclosporine. Gebaseerd op de beschikbare onderzoeken met betrekking tot werkzaamheid van de verschillende immunosuppressieve schema's, en op de onderzoeken in dit proefschrift, heeft tacrolimus de voorkeur als belangrijkste immunosuppressivum bij de onderhoudsbehandeling van niertransplantatiepatiënten. 


\section{Dankwoord}




\section{Dankwoord}

Voor het verrichten van onderzoek is hulp van anderen altijd onontbeerlijk. Zonder die hulp had ik dit proefschrift dan ook niet kunnen voltooien. Vandaar dat ik allen die me geholpen hebben hier wil bedanken.

Op de eerste plaats wil ik alle dialyse- en transplantatiepatiènten bedanken die enthousiast en bereidwillig hun vertrouwen hebben geschonken aan de onderzoeken beschreven in clit proefschrift. Hoewel de prognose voor patienten met nierziekten belangrijk verbeterd is in de afgelopen decennia, is de levensverwachting en kwaliteit van leven nog altijd beduidend minder goed dan de levensverwachting en kwaliteit van leven van de gemiddelde West-Europese populatie. Ik hoop met dit proefschrift een bescheiden bijdrage in de inzichten en mogelijkheden ten aanzien van verbetering van die prognose te hebben kunnen leveren. Tevens hoop ik met mijn inzet voor de in dit proefschrift beschreven onderzoeken ook de Nierstichting enigszins te kunnen bedanken voor de financiering van mijn opleidingsplaats tot nefroloog enkele jaren geleden.

De onderzoeken beschreven in dit proefschrift werden grotendeels verricht op afdeling D5 van het academisch ziekenhuis Maastricht. Bij de uitvoering van de onderzoeken, werd geregeld assistentie verleend door het personeel van deze afdeling, zowel door het subhoofd, de heer Dakkus, die op korte termijn samen met mij de transplantaties van levende donoren gaat coördineren, als door vele anderen werkzaam op deze afdeling. Graag wil ik hen allen hiervoor bedanken.

Sinds enige jaren is Monique Mullens aangesteld als onderzoeksassistente nefrologie. Zij heeft een belangrijk gedeelte van de praktische uitvoering van de laatste onderzoeken gecoördineerd en uitgevoerd. Met behulp van haar organisatorische talent en de zorgvuldige uitvoering van de onderzoeken was het mogelijk de laatste onderzoeken in een versneld tempo uit te voeren. Dankjewel Monique, ik hoop dat we nog lange tijd zo plezierig kunnen blijven samenwerken.

Voorts wil ik een aantal andere collegae van het azM bedanken die actief betrokken zijn geweest bij de onderzoeken beschreven in dit proefschrift. Fred Nieman wil ik bedanken voor de hulp bij de statistische bewerking van de onderzoeksgegevens. Valère Goossens voor zijn hulp bij de virologische aspecten van hepatitis C. De apothekers en overige personeelsleden van de afdeling klinische farmacologie wil ik bedanken voor de vele tacrolimusspiegels die ze hebben bepaald. Hans Boots wil ik bedanken voor de uitvoering van een groot 
gedeelte van het onderzoek beschreven in hoofdstuk 3 van dit proefschrift. Daarnaast vooral ook voor de overname van een onderzoek met een gigantische hoeveelheid gegevens waarop ik was vastgelopen toen ik net begonnen was met promotieonderzoek. Gelukkig zijn de resultaten van dit onderzoek inmiddels door jou gepubliceerd.

De leden van de beoordelingscommissie, Prof. dr. Donckerwolcke (voorzitter), Prof. dr. Cohen-Tervaert, Prof. dr. Squifflet, Dr. Wolffenbuttel en Dr. Undre bedank ik voor hun bereidheid om het manuscript te beoordelen. Prof. dr. Squifflet thank you for reviewing my manuscript.

Een speciaal woord van dank wil ik richten tot Dr. Wollfenbuttel. Bruce, mijn dank voor je kritische beoordeling en welkome aanbevelingen t.a.v. de manuscripten betrekking hebbend op het glucosemetabolisme. Mede dankzij jou hulp heb ik mijn voorliefde voor de nefrologie en endocrinologie binnen de interne geneeskunde kunnen combineren.

Dr. Undre, dear Nas, thank you very much for all your help and advise regarding the pharmacokinetic studies in this thesis. Your contribution has increased my insight in pharmacology. Already, I'm looking forward to future collaboration.

Het maken van dit proefschrift heeft mijn kijk op onderzoek en patiëntenzorg belangrijk veranderd. In belangrijke mate heeft mijn promotor, Prof. dr. van Hooff hieraan bijgedragen. Beste Hans, na een moeizame start met onderzoek tijdens mijn opleiding tot nefroloog en tijdelijk zelfs het stopzetten ervan, heb jij me, toen Esther in oktober 2000 naar de basisschool ging, overgehaald toch weer verder te gaan met mijn onderzoek. Ik ben blij dat ik naar je geluisterd heb. Gaandeweg het onderzoek ben ik meer en meer het grote belang van onderzoek voor de klinische praktijk gaan inzien. Daarnaast ben ik het doen van onderzoek ook leuk gaan vinden! Bewondering heb ik voor de wijze waarop je me hebt aangezet tot puzzelen op een juiste interpretatie van de gegevens, het verkrijgen van meer diepgang en een zeer precieze formulering, waarbij er steeds praktische conclusies ten aanzien van patiëntenbeleid geformuleerd werden.

Een andere belangrijke rol in mijn groeiend plezier in het maken van dit proefschrift speelde mijn co-promotor, Dr. Christiaans. Beste Maarten, grote gedeelten van het praktisch werk van de eerste onderzoeken heb je zelf verricht. Je hebt, ondanks al je diverse taken, steeds minutieus mijn manuscripten gecorrigeerd. Deze correcties moest je omdat ze onleesbaar waren dan ook nog eens mondeling toelichten! Daarnaast heb je me geholpen met de noodzakelijke statistiek en met het vervaardigen van figuren. Zoals jij en Hans weten, en ook Esther al. weet, ben ik dol op letters en woorden, maar houd ik niet zo van plaatjes! Voor al je hulp, en voor je morele steun als het onderzoek eens wat minder wilde vlotten, will ik je 
bedanken. Ik hoop dat we nog lang zo plezierig en goed kunnen blijven samenwerken.

De vroegere en huidige leden van de werkgroep nefrologie, Karel Leunissen, Frank van der Sande, Jeroen Kooman, Stijn Konings, Charles Beerenhout, Willy van Kuijk, Mariëlle Krekels en Mariëlle Gelens, will ik bedanken voor hun hulp en voor de plezierige samenwerking in de afgelopen jaren. Daarnaast wil ik Etienne, Anke en Marleen, de werkgroepsecretaresses bedanken. Tiny Wouters wil ik bedanken voor de wijze waarop ze de layout en het drukklaar maken van het proefschrift heeft verzorgd.

Zonder een vertrouwde en goede oppas voor Esther was het niet gelukt om me voldoende te kunnen concentreren op mijn onderzoek. Mevr. Vrencken, beste Truus, hartelijk dank hiervoor. Daarnaast will ik mijn schoonouders bedanken voor al die keren dat zij, al dan niet samen met Tonek, voor Esther gezorgd hebben als ik naar een congres of cursus was of als Tonek en ik er samen even tussenuit wilden.

Mijn ouders wil ik bedanken voor de mogelijkheid om geneeskunde te studeren en de ondersteuning, zowel financieel als met name ook moreel die ik hierbij kreeg. Zowel mij ouders als mijn schoonouders wil ik voorts bedanken voor hun support en geloof in mijn capaciteiten.

Lieve Esther, zoveel mogelijk heb ik gewerkt als jij op school was of als je naar bed was, maar soms kon ik het onderzoek niet helemaal. loslaten en heb je er toch wel wat van gemerkt. Gelukkig is het boek dat jij daarom op jou pe bent gaan maken nog maar in de beginfase! Laat het maar wat rusten. Vanaf nu hoop ik nog meer tijd te hebben om van je te genieten en samen te spelen. Tot slot, Tonek, wil ik jou bedanken voor je adviezen en voor je actieve bijdrage aan mijn proefschrift. Vaak heb je mee nagedacht over de juiste Engelstalige formulering van mijn bevindingen. Daarnaast ben ik heel blij dat je de omslag voor me hebt ontworpen. Voorts heb je me steeds ook moreel gesteund door je geloof in mij. Esther heb ik zoveel mogelijk kunnen ontzien bij het maken van mijn proefschrift, maar jou kon ik niet ontzien. Vele avonden heb ik als Esther op bed lag achter in de kamer aan mijn laptop zitten werken. Ik hoop de komende tijd weer meer tijd voor ons gezin, maar in het bijzonder voor jou te hebben. 



\section{Curriculum Vitae}




\section{Curriculum Vitae}

13-01-1964 Born in Veghel

1976-1982 Gymnasium- $\beta$, cum laude, Jeroen Bosch College in 's-Hertogenbosch

1982-1989 Study Medicine at the Medical Faculty of the Catholic University of Nijmegen; 1986 Doctoral degree; 1989 Medical degree

1989-1990 Senior house officer department of Intemal Medicine at the Wever Hospital in Heerlen

1990-1994 Training in Internal medicine at the Wever Hospital in Heetlen (Dr. F.A.Th. Lustermans)

19-03-1994 Marriage to Dr. A.P.J. Jansen

1994-1996 Continuation of training in Internal Medicine at the University Hospital Maastricht (Prof. dr. J.A. Flendrig); 1996 Registration as internist

24-09-1996 Birth of daughter Esther

1997-1999 Training in Nephrology at the section Nephrology and Transplantation (Prof. dr. J.P. van Hooff) of the University Hospital Maastricht; 1999 Registration as nephrologist

Since 1997 Staff member of the department of Internal Medicine of the section Nephrology and Transplantation, University Hospital Maastricht. 



\section{List of publications}


Wetzels JF, van Duijnhoven EM, Hoitsma AJ, Koene RA. Increased tubular secretion of creatinine after a meat meal. Nephrol Dial Transplant 1988; 3(6): 846 .

Wetzels JF, Wiltink PG, van Duijnhoven EM, Hoitsma AJ, Koene RA. Short-tem protein restriction in healthy volunteers: effects on renal hemodynamics and renal response to a meat meal. Clin Nephrol 1989; $31(6): 311-315$.

Duijnhoven van EM, Rijken J, Theunissen PHMH. Postinfectieuze tropische malabsorptie en de verschillen met niet-tropische spruw (coeliakie). Ned Tijdsch Geneeskd 1993; 137; 2552-2554.

Duijnhoven van $\mathbb{E M}$, Lustermans FAT, van Wersch JWJ. Evaluation of the coagulation/ fibrinolysis balance in patients with colorectal cancer. Haemostasis 1993;23:168-172.

Duijnhoven van EM, Lustemans FAT, van Wersch JWJ. Het gebruik van hemostase.. parameters voor vaststelling van metastasering bij patiënten met colorectale kanker vergeleken met CEA, alkalische fosfatase en LDH. Trombose, atherosclerose en ontsteking. Verslag van het 9e Amstol symposium, pg 166-167.

Gezici A, van Duijnhoven EM, Bakker SJL, Heidendal GAK, van Kroonenburgh MJPG. Lung and gastric uptake in bone scintigraphy of sarcoidosis. I Nucl Med 1996; 37(9): 15301532 .

Dug̈nhoven van E, Christiaans $M$, Schäfer A, Undre $N$, van Hooff J. Tacrolimus dosing requirements in diabetic and non-diabetic patients calculated from pretransplantation data. Transplantation Proceedings 1998; 30: 1266-1267.

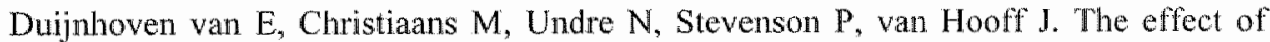
breakfast on the onal bioavailability of tacrolimus in diabetic and non-diabetic patients before transplantation. Transplantation Proceedings 1998; 30: 1268-1270.

Christiaans $M$, van Duijmhoven $\mathrm{E}$, Beysens T, Undre $\mathrm{N}$, Schäfer A, van Hooff J. The effect of breakfast on the oral bioavailability of tacrolimus and changes in pharmacokinetics at different times post-transplant in renal transplant recipients. Transplantation Proceedings $1998 ; 30: 1271-1273$.

Hooff van J, Christiaans M, van Duijnhoven E. Glucose metabolism, insulin and C-peptide secretion in the first two years after renal transplantation: comparison between tacrolimus and ciclosporin. In Tacrolimus in organ transplantation: prevention and treatment of allograft rejection. ISBN 3-933151-42-2.

Hooff van IP, van Duijnhoven EM. Christiaans MHL. Tacrolimus and glucose metabolism. Transplantation Proceedings 1999; 31 (7A) Suppl. S: 49S-50S. 
Hooff van JP, Boots JMM, van Dujnhoven EM, Christiaans MHL. Dosing and management guidelines for tacrolimus in renal transplant patients. Transplantation Proceedings 1999; 31 (7A) Suppl. S: 54S-57S.

Duijnhoven van EM, Cheriex EC, Tordoir JHM, Kooman JP, wan Hooff JP. Effect of closure of the arteriovenous fistula on left ventricular dimensions in renal transplant patients. Nephrol Dial Transplant $2001 ; 16: 368-372$.

Duijnhoven van EM, Boots JMM, Christiaans MHL, Wolffenbuttel BHR, van Hooff JP. Influence of tacrolimus on glucose metabolism before and after renal transplantation: a prospective study. I Am Soc Nephrology 2001; 12:583-588.

Duijnhoven van EM, Christiaans MHL, Boots JMM, Nieman FHM, Wolffenbuttel BHR, van Hooff JP. Glucose metabolism in the first 3 years after renal transplantation in patients on tacrolimus versus cyclosporine-based immunosuppression. I Am Soc Nephrology 2002; $13: 213-220$.

Boots JMM, van Duijnhoven EM, Christiaans MHL, Wolffenbuttel BHR, van Hooff JP. Glucose metabolism in renal transplant recipients on tacrolimus: the effect of steroid withdrawal and tacrolimus trough level reduction. J Am Soc Nephrology 2002; 13:221227.

Boots IMM, van Duijnhoven EM, Christiaans MHL, Nieman FHM, van Suylen R-J, van Hooff JP. Single center experience with tacrolimus versus cyclosporin-Neoral in renal transplant recipients. Transplant Int 2001; 14:370-383.

Duijnhoven van EM, Christiaans MHL, Boots JMM, van Hooff JP. Evidence that fasting does not significantly affect trough levels of tacrolimus in stable renal transplant recipients. Transpl Proc in press.

Duijhhoven van EM, Christiaans MHL, Boots JMM, Goossens VJ, Undre NA, van Hooff $J P$. A late episode of postransplant diabetes mellitus during active hepatitis $C$ infection in a renal allograft recipient using tacrolimus. Am J Kidney Dis in press.

Duijnhowen van EM, Boots JMM, Christiaans MHL, Stolk LML, Undre NA, van Hooff JP. Increase in tacrolimus trough levels after steroid withdrawal. Submitted. 